International Collaboration Among Social Science Scholars

International Collaboration Among Social Science Scholars: Opportunities to Bridge Institutional Goals of Internationalization With Faculty Research Agendas

\author{
A Dissertation \\ Presented to \\ The Faculty of the Curry School of Education \\ University of Virginia
}

In Partial Fulfillment

Of the Requirement for the Degree

Doctor of Philosophy

by

Karen Marsh King

August 2016 


\title{
Center for the Study of Higher Education
}

\author{
Curry School of Education \\ University of Virginia \\ Charlottesville, Virginia
}

\begin{abstract}
Approval of the Dissertation
This dissertation, International Collaboration among Social Science Scholars:

Opportunities to Bridge Institutional Goals of Internationalization with Faculty Research Agendas, has been approved by the Graduate Faculty of the Curry School of Education in partial fulfillment of the requirements for the degree of Doctor of Philosophy.
\end{abstract}

Brian Pusser, Chair

Patrick Meyer

Christian Steinmetz

Justin Thompson 
International Collaboration Among Social Science Scholars

\section{Abstract}

Faculty of universities throughout the world form scholarly networks to exchange ideas, research, and build a knowledge infrastructure that supports the scholarly activities for their subject discipline. Merton describes this phenomenon in his theory of the Sociology of Knowledge as a social organization of scientific research in which "groups organize around distinct subject orientation (Merton, 1968).” Many higher education scholars have written about the ongoing challenges that universities face in their efforts to internationalize. Although internationalization is a common institutional priority, many universities are unable to accomplish the unilateral involvement of their faculty in international initiatives. One strategy aimed at increasing faculty participation in international initiatives involves bridging individual research agendas with the institutional mission to internationalize (Childress, 2010). The ultimate goal of this research was to inform the development of institutional policies and programs aimed at encouraging faculty to participate in collaborative research projects with their international colleagues. This research was focused on individual social science scholars who were involved in international collaborative research projects that resulted in a co-authored article. One aspect of the research concentrated on understanding the scholar's motivation for participating in the international collaboration. Additionally, the research gathered data related to university research policies including funding for participation in international collaborative projects and the value of participation in international collaborations related to the tenure and promotion review. This research incorporated the cross sectional survey design of quantitative methodology. The unit of analysis was an individual social science scholar involved in a specific international collaborative research project that resulted in a co-authored article published in a scholarly journal. Descriptive statistics along with an explanatory regression model were 
developed. The results of this study may be used to develop institutional research policy aimed at expanding faculty research activities associated with international research collaboration and co-authorship thereby enabling universities to advance towards their institutional missions and goals related to internationalization.

Keywords: international collaboration, co-authorship, social science scholars, research policy, higher education, internationalization, cross sectional survey, regression model, quantitative methodology 
International Collaboration Among Social Science Scholars

\section{Acknowledgements}

Completing the research and writing for this dissertation has been very challenging and rewarding journey. My professors, family, friends, colleagues, and fellow students have been a wonderful encouragement to me along this journey.

Many thanks to Brian Pusser for being “all in”. What more could a PhD student need than a totally supportive chair? As a middle aged PhD student my journey has not been a typical one. Your encouragement, humor, and enthusiasm for my research has been wonderful.

To my committee members Patrick Meyer, Christian Steinmetz, and Justin Thomson. Thank you for your ideas, attention to detail, and support throughout the dissertation. It has been an honor to work with you.

To Libby Eshbach, Sara Hess, Anna Hoebeke, Rhonda Hudson, Patsy Leonard, Susan Norrisey, Frances Smith, Lee Ann Long Tyler, Frances Smith, Cordelia Jaudon, my fellow library team members at the Darden School, you have been a constant source of positive energy for me throughout the process. The hours of listening to my research ideas, reading my work, and giving your thoughts on the best next steps. Your friendship is a precious gift to me. A special thanks to Libby Eshbach who read hundreds of pages of my work and with the red pen in hand and made many helpful recommendations.

To my friends and collegues at the Darden Business School and the University of Virginia; Maureen Wellen, Debbie White, Gerry Yemen, Steve Momper, Chris Lehmbeck, Sarah Elliott, Orn Wawsri, Bruno LaPierre, Bob Bruner, Alec Horniman, Sheilah Sprouse, Barbie Selby, Kay Buchanan, Juliet Trail, and Ellen Ramsey; thanks so much for you encouragement and support. 
International Collaboration Among Social Science Scholars

To Sue Sharon for your steadfast friendship, encouragement, weekly dinners, luscious cupcakes, discussions about research, visions of future travel adventures, counseling sessions in the kitchen, and especially for you and the boys hosting me in the sewing room through the finish line. Thanks for being a great friend to Mike and I both. You are the best!

To Lance Matheson, thanks for your encouragement to the dual $\mathrm{PhD}$ couple and for insisting that we had to dissertate rather than teach in Germany for a second summer.

To Cliff Ragsdale, Alan Abrahams, and the scary brain trust, thanks for your positive perspective and the help with the code.

To my mom and dad, Ben and Kathy Marsh who have always been my steady rock of encouragement. Even in my 50s it means so much to me to have your love and support.

To my supportive family, Joyce, Bruce, Leigh, Andrew, David, Katrina, Scott, Alan, Lillian, Daniel, Joseph, Hannah, Rebekah, Elizabeth, Alex, Nathan, David K, Steve, Pam and Ian. Thanks for the positive encouragement.

To the guys at the Smoky Bar-B-Que truck, the Duck Donuts staff, the program director of the smooth jazz channel on Pandora, and the outstanding $21^{\text {st }}$ floor team at the Fairmont Singapore, thanks for smoothing the way with some great food, soothing music, and amazing hospitality.

Last but not least, to my husband Mike, my best friend, my data guru and fellow mid-aged $\mathrm{PhD}$ student. When I hit my stride and look to see you right there beside me, it is no wonder that my heart is so full of love for you. You are always there when I need Gatorade at 13,800. Thanks for being a wonderful partner in life. We did it! We are now Dr. King ${ }^{2}$ 
International Collaboration Among Social Science Scholars

Table of Contents

Introduction

page 1

Literature Review

page 22

Methodology

page 48

Results

page 66

Discussion

page 125

References

page 147

Appendix A: Research Question Mapped to Survey Question Numbers

page 158

Appendix B: Academic Journals Social Science

page 162

Appendix C: Web of Knowledge Data Example

page 163

Appendix D: Participants Recruiting Message

page 164

Appendix E: Survey Version Computer View

page 166

Appendix F: Survey Version Smart Phone View Selected Pages

page 179

Appendix G: Cross Tabulation Data

page 186 


\section{Chapter One: The Problem and Its Setting}

Many higher education scholars recognize the ongoing challenges that universities face in their efforts to internationalize. The major aspects of internationalization that involve faculty relate to curriculum and research, specifically the development of international curriculum, research on an international topic, and research collaborations with international colleagues. Internationalization is recognized as an indicator for academic quality and research excellence (Rostan, Flavio and Metcalfe, 2014, p.120). Although internationalization is an institutional priority, many universities are unable to accomplish the unilateral involvement of their students and faculty in international initiatives. One strategy aimed at increasing faculty participation in international initiatives involves bridging individual research agendas with the institutional mission to internationalize (Childress, 2010). This strategy can be facilitated by providing support, for example travel funding or sabbaticals, that enable faculty to participate in international collaborative research projects. However, in order to successfully bridge institutional and faculty goals, it is essential that universities develop an understanding of the motivations associated with a faculty member's choice of research agendas and collaborative partners. Faculty decisions are related to their evolving role as a scholar within the network of colleagues in their subject discipline. Scholars within the network undertake a socio-cognitive process whereby they determine their own research stream, path of inquiry and make choices to work independently or to collaborate with colleagues on research projects (Melin, 2000).

In her work The New Invisible College, Wagner states that "scholars self-organize into collaborative teams based on relatively simple rules (that are) set and followed at the individual 
International Collaboration Among Social Science Scholars

level (Wagner, 2008, p. 62).” The rules are based on the concept of preferential attachment in that scholars desire to enhance their own reputation through collaborative projects. Furthermore Wagner explains "those seeking new research opportunities reason: If this connection gives me access to data, funding, or ideas that will advance this research, then I should seek to make the connections (p.61).” Scholars that are approached to join a research initiative will follow a similar formula: "If this collaboration will help me advance my research or its diffusion, then I should participate in it. (p. 61)" Scholars make pragmatic decisions related to their research agendas. It is likely that universities will have more success engaging faculty in international research initiatives if they develop a deep understanding of the factors that influence a scholar's decision to undertake research initiatives.

\section{Attracting Faculty to Become Involved in International Initiatives}

It has been documented in higher education scholarly literature that one of the primary challenges universities face in accomplishing their goals of internationalization is attracting faculty involvement in international initiatives. Knight (2008) reported on the results of the IAU $3^{\text {rd }}$ Global Survey that was conducted by the International Association of Universities (IAU) in 2005. Data was collected from higher education institutions representing 95 countries and 526 individual institutions. The goal of the IAU survey was to identify issues, trends, and new developments in internationalization as perceived by the higher education institutions (Knight, 2008). The survey defined faculty involvement in international initiatives as: 1 ) leading student groups on international trips, 2) developing curriculum that expands international learning for students, 3) collaborating on international research projects, 4) hosting conferences that focus on international issues or themes, and 5) hosting international scholars. Survey results showed that institutions worldwide identified the lack of faculty interest and involvement in international 
International Collaboration Among Social Science Scholars

activities as the main barrier to accomplishing institutional goals of internationalization (Knight, 2008, p.209). Furthermore, institutions participating in the IAU survey reported that the top three benefits to internationalization were more internationally oriented students and staff; improved academic quality; and strengthened research and knowledge production of faculty members (Knight, 2008, p.219).

Conducted in 2013, The IAU $4^{\text {th }}$ Global Survey was designed to collect more extensive data on the activities and priorities of internationalization initiatives in higher education institutions. The number of respondents to the 2013 IAU survey doubled the previous survey with participation from 1336 institutions of higher education representing 131 countries (EgronPolak and Hudson, 2014, p.5) The IAU $4^{\text {th }}$ Global Survey leadership team stated that "the [survey] findings demonstrate that internationalization remains, or indeed grows in importance for higher education institutions” (p.6) Institutions reported an expansion in programs, funding, policy development, and administrative structures associated with their internationalization initiatives. They ranked mobility opportunities for students and faculty international research collaborations as the top two priorities of internationalization activities within their institutions. One of the primary conclusions of the study was that the problem of attracting faculty to participate in international activities persists as a barrier in accomplishing institutional goals of internationalization. Reflecting the confounding nature of this issue, the $4^{\text {th }}$ IAU Global survey report stated the results of this survey and the previous survey raise a persistent question about what "the exact nature of the role of faculty in internationalization" should be (p.8). 
International Collaboration Among Social Science Scholars

\section{Institutional Strategies Related to Internationalization}

In the book Higher Education in Turmoil: The Changing World of Internationalization Knight (2008) creates a contrasting framework of national, institutional and organizational strategies for internationalization. National strategies focus on policy, funding programs, and regulatory guidelines which facilitate the development of international initiatives. Institutional strategies include a diverse group of organizational strategies and program strategies.

Organizational strategies focus on institutional governance and operations. Governance aspects include "expressed commitment by senior leaders, active involvement of faculty and staff, articulated rationale and goals for internationalization, and recognition of international dimension in institutional mission statements, planning and policy documents” (Knight, 2008, p.25). Examples of organizational strategies are "integrated institution-wide and departmentlevel planning, budgeting, and quality review systems; appropriate organization structure systems (formal and informal) for communication and coordination of activities; balance between centralized and decentralized promotion and management of internationalization; adequate financial support and resource allocation systems” (Knight, 2008, p.25).

In contrast to organizational strategies, Knight delineates program strategies as specific activities, resources, and initiatives that support the expansion of institutional internationalization. Knight divides program strategies into two categories. The first, academic programs, includes “student exchange programs, foreign language study, internationalized curricula, area or thematic studies, work/study abroad, in-bound international students, teaching/learning process, joint/double degree programs, cross-cultural training, faculty and staff mobility programs, visiting lectures and scholars” (Knight, 2008, p.34). The second category relates to international research and scholarly collaboration programs. This category includes 
International Collaboration Among Social Science Scholars

"area and theme centres [SIC], joint research projects, international conferences and seminars, publishing articles and papers that are co-authored with international colleagues, international research agreements, and research exchange programs” (Knight, 2008, p. 28). This proposed research had the goal of informing the development of institutional policy related to this second category of program strategies, specifically those that support faculty whose scholarly agendas include cross-national research and collaboration with scholars in their subject discipline. This research concentrated on aspects of the personal experience of the individual faculty member related to a particular cross-national collaborative project that resulted in a published article. The phenomenon of collaboration differs from subject discipline to subject discipline therefore this study was limited to scholars from the disciplines of sociology, economics, and management.

\section{Expansion of Scholarly Collaboration}

“Academic work increasingly is teamwork” (Posner, 2001, p.540)

The second half of the $20^{\text {th }}$ century was dominated by the growth of collaborative research among scholars (Beaver \& Rosen, 1979; Fox \& Faver, 1982; Leband \& Tollison, 2000; Persson et al., 2004; Glanzel \& Schubert, 2004; Adams et.al., 2005; Wutchy et.al., 2007; Wagner, 2008). Derek J De Solla Price coined the term "big science” to describe the post WWII changes in how scientific academic research was accomplish (Price, 1963) There was a shift from the small university based research labs to large scale international research facilities. The literature reports that the expansion of collaboration was a direct result of the "big science" .movement and was predominantly associated with the sciences, technology, engineering, and mathematics, also known as the STEM fields, as well as medicine (Luukkonen, Persson \& Sivertsen, 1992; Bordons \& Gomez, 2000; Newman, 2004; Lee \& Bozeman, 2005; Wagner, 
International Collaboration Among Social Science Scholars

2008; Rostan, Ceravolo \& Metcalfe, 2014). The "big science” projects were characterized by massive funding for large international research teams (Glanzel \& Schubert, 2004; Wagner, 2008; Mali et al., 2012). The projects were funded by a combination of organizations including universities, government agencies, and corporations. Research shows an increase in collaboration across the board in all disciplines, however comparative studies indicated that there was a compounded increase in collaborative activities the STEM fields as opposed to the fields of social science, humanities, and the arts. (Cronin, 2001, pp560-561; Wray, 2002, p.159; Rostan, Ceravolo \& Metcalfe, 2014, p. 135). In contrast to the STEM fields, there has been a slower growth in collaborative activities in the social sciences and humanities (Lariviere et al, 2006). The expansive growth of collaboration in the STEM fields has been reflected in the literature. The significant portion of the articles report on the collaborative activities in the STEM fields as compared to the social sciences. This research extends the literature on social science collaboration and specifically on international collaboration.

\section{The Self-Organization of Scholars within Disciplines}

Faculty at universities throughout the world form scholarly networks to exchange ideas and build a knowledge infrastructure that supports scholarly activities for their subject discipline. The scholarly network is an embodiment of Merton's theory of the "Sociology of Knowledge”. Merton describes this phenomenon as the social organization of scientific research in which “groups organize around distinct subject orientations to coordinate, complement, and sometimes overlap their inquiry”. In these activities members agree on the characteristics of subject matter, definition of problems, concepts of data, utilization of research techniques, and social organization of research activities. (Merton, 1968, p 63) 
International Collaboration Among Social Science Scholars

Clark Kerr states that, "faculty members are less members of the particular university and more colleagues within their national academic discipline groups (Kerr, 1963, p 23).” Kerr’s statement foreshadows the work of sociologist Diane Crane and her introduction of the concept of the invisible college. Crane used the methodology of bibliometric analysis to conduct her research published in Invisible Colleges: Diffusion of Knowledge in Scientific Communities (Crane, 1972). The bibliometric analysis technique consists of tracking the patterns of scholars citing another scholar in their invisible college group; analyzing the influence of publications coauthorship, as opposed to single authored publications, based on the variations of subsequent patterns of citations; and tracking the expansion of research initiatives based on the diffusion of ideas between scholars. Her research illuminated how research communities form, how scholars exchange ideas through patterns of scholarly communication, and to what extent members of an invisible college influence each other's work.

In contrast, the research of Leah Lievrouw (1990) accentuated the fact that aspects of communication and social interaction between scholars are not represented in the earlier models of the invisible college. Earlier models relied on bibliographic evidence of citations to represent the networked connections between scholars. However, this only told a portion of the story. The model does not represent the socio-metric links between scholars. Lievrouw stated that given this omission an updated model was required to account for the social structures and social processes that are evident in an invisible college.

Lievrouw's research provides an updated model which contains four constructs that define a more holistic model of an invisible college (1990, p 63). The first element of Lievrouw's model is the formal and informal patterns of communication that form the infrastructure for an exchange of ideas among scholars within an invisible college. The second element is the 
International Collaboration Among Social Science Scholars

presence of a collaborative exchange of ideas between scholars. Third is the periodic co-creation of research and scholarly articles. Finally, the fourth element is the mutual goal to move knowledge of the subject discipline forward through invisible college activities (Lievrouw, 1990). While each of the aspects of the invisible college are inter-related, they differ in the level of faculty interaction required and in the specific type of work faculty perform with other academics within the subject discipline. Lievrouw illuminates the fluid nature of choices that an individual scholar will make as he or she participates in one or more elements of the invisible college.

\section{National Academic Groups Expand and Become International Academic Groups}

Based on her work Revisiting The Invisible College, Alesia Zuccula redefines the invisible college as "a set of interacting scholars or scientists who share similar research interests concerning a subject specialty, who often produce publications relevant to this subject and who communicate both formally and informally with one another to work towards important goals in the subject, even though they may belong to geographically distant research affiliates (Zuccula, 2004, p. 66).”. The Zuccula model is distinguished for its representation of the multiple dimensions of invisible college activities, the prominence of social processes between faculty in a subject discipline, and the adaptation of the model to represent the collaborative activities of scholars in geographically disparate areas. (Zuccula, 2006, p. 156).

Wagner (2008) highlights the emergence of a new model that is characterized by a global network of scholars that are leveraging the opportunity to be linked through virtual ties. Wagner states "these networks constitute an invisible college of researchers who collaborate not because they are told to but because they want to work together not because they share a laboratory or 
International Collaboration Among Social Science Scholars

even a discipline but because they can offer each other complementary insight, knowledge, or skills. (Wagner, 2008, p 2).” Wagner identifies “five forces” that are driving the shift of the scholarly networks from national structures to global structures and thereby changing the nature of invisible colleges. The first force is the expansion of networks across geographic distances that supports both informal and formal initiatives among members of the scholarly groups. Next is the concept of the emergence of new ideas that are generated based on the "combination and recombination of people and knowledge as researchers have the freedom to identify the people and tools that can advance their work (p. 4).” The third concept is that knowledge, information, and scholars circulate which allows for the serendipitous discovery of new connections, ideas, and initiatives. Next is the concept of stickiness that encompasses the need to cluster resources, people, and ideas in order to be efficient in the production of new knowledge. Distribution is the fifth concept and final concept and highlights the value of forming teams to collaborate and distribute tasks. Teams can be made up of scholars from around the globe and provides an opportunity for diverse groups to form and take advantage of knowledge and expertise not available locally (p 5).

\section{Two Dimensions of Faculty Activities in the Internationalization of Research}

The Internationalization of the Academy: Changes, Realities and Prospects is a compilation of works analyzing the results of the Changing Academic Profession survey (Education Policy Institute, 2009) conducted in 2008-2009 (Huang, Finkelstein, and Rostan, 2015). There were 25,938 respondents representing 19 countries that participated in the Changing Academic Profession survey (CAP survey). The CAP survey questionnaire included questions that were mapped to 37 independent variables related to the internationalization of faculty. Cluster analysis of the independent variables was clustered into five broad categories 
International Collaboration Among Social Science Scholars

relating to academic activities, consequently one cluster, a specific interest for this research, was categorized as research activities. The instrument design organized the question related to research activities into four categories of questions: whether their primary research was international in orientation or scope; if scholars participated in research collaboration and projects with their international colleagues; the administrative processes related to collaborative projects, for example, the language of choice for project related activities, how tasks are assigned, or what technology was used to accomplish their work; and finally sources of funding that sustain their participation in research collaborations (Rostan et al., 2014, p. 24-25).

Rostan, Ceravolo, and Metcalfe participated in The Internationalization of the Academy project by co-authoring a paper titled “The Internationalization of Research” (2014). Their work produced a framework of activities associated with faculty international research activities in the context of research and scholarship. Their research was based on the analysis of data from the CAP survey. The study quantified two dimensions related to the internationalization of academic research. Their nuanced concepts were, in their words, "the international content of researches and international collaboration in the research process” (p. 121). The first dimension was related to instances when the focus of a scholar's research had an international context. "International" was defined as a choice to conduct research related to a different country other than the scholar's home country. The second dimension was related to international collaboration explicitly when scholars chose to collaborate with colleagues who are working in different nations. The authors analyzed international collaboration based on two types of activities. Their first type are informal activities related to relationships and communication that flow between individuals that collaborate with their international colleagues. Their second type is a more formal activity when scholars participate international collaborative projects that result 
International Collaboration Among Social Science Scholars

in a co-authored article (Rostan, Ceravolo, and Metcalfe, 2014, p. 121).Rostan, Ceravolo and Metcalfe provide an important distinction related to this research proposal, that is to say, the contrast of the choice of international sites in which to pursue research topics as compared to international collaborative activities related to research collaborations that incorporate scholars from more than one nation. It is an important distinction, because the former can be accomplished without the latter, in other words scholars can research topics that are related to countries outside of their home country without collaborating with scholars outside of their home country. Those researchers classified solely as international in the content of their research, and not their collaboration with international colleagues to accomplish this research, were excluded from this study.

\section{Importance of Studying Particular Disciplines}

Kraut, Galegher, and Egido developed a “Model of Research Collaboration” based on their examination of research collaborations in the scholarly disciplines of social psychology, management, and computer science (1987). They developed the model by interviewing individual scholars that were selected based on their participation in a long distance collaborative research project that resulted in a published article. The participants were asked to provide a narrative history of their collaboration from the first time they connected with their co-authors up to the time that the resulting article was published. A three stage model of a collaborative research project emerged from their research indicating that collaborators pass through three stage process of initiation, execution, and public presentation. During the initiation stage “potential collaborators establish (or reaffirm) a personal relationship, commit themselves working together, and plan a project. Their primary goal is to establish an interpersonal relationship based on shared interests. The central goal of the execution stage of the 
International Collaboration Among Social Science Scholars

collaboration is to move from the specification of a research objective through the many and varied tasks that must be carried out to complete the project” (Kraut, et.al. 1987, p. 34). During the public presentation stage scholars document their results by writing an article and disseminate their research by publishing the work in a refereed scholarly journal. Kraut, Galegher, and Egido concluded that the goals and expectations within the initiation and public presentation stages are very generalizable across the disciplines within their study. However they concluded that goals and activities within the execution stage were nuanced according to the norms and expectations of individual scholarly disciplines. (Kraut et.al., 1987, p. 34)

\section{Models That Inform This Research Design}

Childress Model of Faculty Engagement in Internationalization

\section{Lisa Childress’s The Twenty-First Century University: Developing Faculty Engagement} in Internationalization highlights the ongoing struggle most institutions face stating, “despite consistent calls for internationalization over the past half century, implementation remains challenging, and therefore lacking, in many higher education institutions” (Childress, 2010, p.4). To address these challenges, Childress created a faculty engagement model that is designed to help university leaders operationalize their plans to expand faculty engagement in internationalization initiatives (Childress, 2010). The model was developed using qualitative methods in order to identify variables that play a part in encouraging faculty participation in institutional internationalization activities. She maintains that each of the variables acts as a catalyst either individually or in combination to encourage faculty participation in institutional initiatives related to internationalization. The concepts that make up the "Childress model five I's of faculty engagement in internationalization” are: intentionality, investments, infrastructure, 
institutional networks, and individual support (Exhibit One: Childress Model of the Five I's of Faculty in Internationalization).

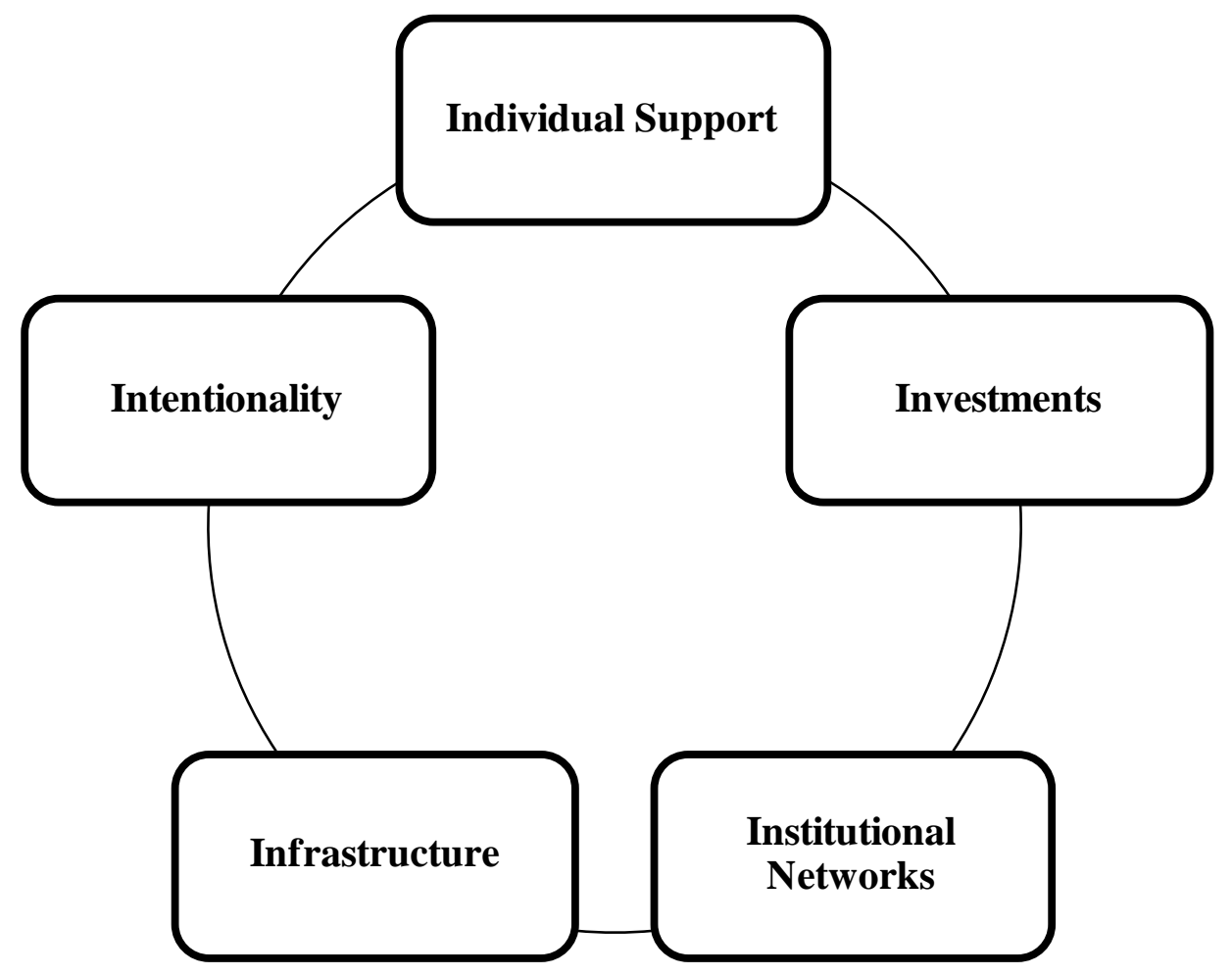

Figure 1. Childress Model of the Five I's of Faculty Engagement in Internationalization (Childress, 2010, p.140)

Aspects of this research are based on Childress's (2010) theoretical model (p.199). Childress (2009) stated that the most difficult aspect of accomplishing institutional goals of internationalization is moving from the planning phase to the operating phase (p.43). Childress explained that allowing faculty to connect with institution-wide goals through their individual scholarly agendas is one of the keys to operationalizing university internationalization. Moreover, Childress maintained that the broad application of her model creates robust model of 
International Collaboration Among Social Science Scholars

support for individual faculty by "connecting faculty with international opportunities based on their personal areas of expertise and regional (international) interests.” (Childress, 2010, p.201)

The central question this research sought to answer was, what motivates a scholar to participate in a collaborative research project with colleagues from institutions that are located in different countries? In the Policy Paradox: The Art of Political Decision, Stone presents her theory of inducements and states, “one can alter people’s self-propelled progress toward their goals by changing obstacles and opportunities they face” (Stone, 2002, p.266). In Stone’s theory, the positive inducement is called a carrot and the negative a stick. Given the challenge that universities face in attracting faculty involvement in international activities, a university may use funding, for example, as a carrot to induce faculty to make international activities a priority.

This research integrated three facets of the Childress model; investments, individual support, and institutional networks into the survey design. Childress's work explored how differential investments serve as a catalyst for faculty engagement in internationalization plans at universities. She defines differential investments as the "strategic allocation of funds from a variety of sources that are distributed at a variety of institutional levels in order to increase involvement in a particular institutional priority, in this case internationalization” (Childress, 2009, p.34). This research intended to determine if the Childress facet of investments, such as travel funding and faculty being given time off to participate in cross national collaborative research projects, first was a part of the experience of the survey participants and second if these aspect of investments are associated with higher participation in international collaborative projects. To that end, the facet of individual support was incorporated into the survey design and data collection. The concept of individual support in the Childress model is twofold. The first aspect relates to an institutional perspective that an individual faculty member's choice to 
International Collaboration Among Social Science Scholars

participate in cross national research project is related to personal research agenda and their individual role in their scholarly network. Secondly, another aspect of individual support that the institution values participation in cross national collaborative research projects by counting it favorably and preferentially during tenure and promotion evaluations.

Finally, institutional networks is a concept in the Childress model that relates to the development of intra-institutional communication channels that a university provides in order for “faculty to learn about international opportunities, resources and their colleagues’ areas of expertise and regional interests (p. 142).” Examples are: faculty seminars on international projects, supporting the development of deeper relationships with faculty in other countries, or formalizing faculty research exchange agreements with institutions in other countries. The Childress model informed the development of research questions in this study that focus on funding and support as well as rewards in the tenure and promotion process that are associated with international collaboration.

Micro vs. Macro Analysis of Collaborative Research

In his article "Pragmatism and Self-Organization: Research Collaboration on the Individual Level”, Goran Melin highlights the individual nature of a scholar's choice to collaborate (Melin, 2010). Research on collaboration can be conducted from a macro or micro perspective. In the past, studies on research collaboration have traditionally focused on the macro aspects, for example, studies on the dimensions of research collaboration, the use of coauthorship to measure collaboration, on the frequency of co-authored articles, studies that investigate the collaborative activities' of one particular country or studies on the phenomenon of higher citations rates for articles that are co-authored. In contrast, the micro level of 
International Collaboration Among Social Science Scholars

investigation relates to research topics such as the decision to collaborate based on shared interest, the process of choosing co-authors, the individual reasons for collaborating, or nature of the relationship between collaborators, for example advisor and advisee (p.32). Melin states "we do not know very much about this micro level and the processes at work since there have been few attempts to leave the macro level of analysis and get closer to the actual collaborators," (p.32). Of the few studies that have been done at the micro level, "none of the studies investigate anything about the motives behind collaboration, the different forms that it can take or what effects it has. Hence, Melin highlights the need to move the level of analysis from macro to micro, and start finding out what the researchers’ opinions are considering collaboration, and which kind of dynamic processes are at work in the teams and networks (p.33).”

The macro vs micro perspective is also highlighted in the work of Katz and Martin which illuminates the misalignment of institutional policies related to research collaboration by asking the question “Who are the research collaborators?” The authors' response is "at the most basic level, it is people who collaborate, not institutions. Direct co-operation between two or more researchers is the fundamental unit of collaboration. However, we often talk about collaboration at other levels - between research groups within a department, between departments within the same institution, between institutions, between sectors, and between geographical regions and countries. Indeed most policies are aimed at fostering collaborations at these higher level rather than inter-individual collaboration (Katz and Martin, 1997, p. 9).” Their work describes how collaborative partnerships "begin informally and are often the result of informal conversation that may then lead to increasing commitment to co-operate. P.4)”. The decision formalize a commitment of between individuals results in a "research collaboration" which Katz and Martin define as "the working together of researchers to achieve the common goal of producing new 
International Collaboration Among Social Science Scholars

scientific knowledge (p.7)” with the ultimate outcome being the co-authorship of a scholarly piece related to their work. Katz and Martin succinctly focus the reader on the need to develop micro level policies and programs aimed at supporting individual faculty in their collaborative research projects. The work of Melin as well as Katz and Martin informed the development of the research model for this study. The unit of measure was be the individual scholar. Therefore the collection of data and subsequent analysis was performed at the micro level.

\section{Co-Authorship: An Indicator of Scholarly Collaboration}

"Collaboration is an intense form of interaction that allows for effective communication as well as the sharing of competence and other resources (Melin and Persson, 1996, p.363)”. In their article "What is Research Collaboration?", Katz and Martin articulate that "for decades the multiple-author publication, frequently referred to as a co-authored publication, has been used as a basic counting unit to measure collaborative activity” (Katz and Martin, 1997, p. 2). However, the literature on the subject reflects an ongoing debate of the strengths and weaknesses of using co-authorship as an indicator of scholarly collaboration. Aspects of weaknesses, for example, are that collaboration between scholars can take on many forms and not all collaboration leads to a co-authored article. Aspects of strengths are that co-authorship as a measurement is verifiable, studies may be replicated, and it is an inexpensive and practical method for quantifying collaboration (Katz and Martin, 1997). Melin states "a direct way of measuring collaboration is through co-authorships, since a published product must exist as an outcome of the cooperative effort (Melin, 2000, p.33).” Given that co-authorship is a standard that is used as a measurement of scholarly collaboration, this research used co-authorship as an indicator of the existence of scholarly collaboration and more specifically participation in a collaborative research project. 
International Collaboration Among Social Science Scholars

\section{Definition of Terms}

As stated earlier, this research was focused on higher education scholars who have been involved in international collaborative research project that has resulted in a published article. The term cross-national indicates that scholars on the collaboration team are working in different nations. For the purposes of this research the terms international collaboration and cross-national collaboration were used interchangeably. The focal point of this inquiry was on the personal experience of an individual scholar and was based on a specific collaborative research project that resulted in a published article. This decision to use the term project, as in collaborative research project, was informed by the work of Kraut, Galegher, and Egido and the subsequent development of their "Model of Research Collaboration” (1987). A group of scholars that are involved in a particular project were called a team. In the context of higher education, the term colleague typically refers to individual that is a member of a network of scholars within a university or a broader network of scholars within a particular subject discipline. For the purposes of this study the term was defined as the latter. The use of the term colleague was used in the broader context and as such refers to the group of scholars that are members of the network of scholars within a subject discipline.

\section{Overview of Research}

This research was focused on studying collaboration between social science scholars who are working in different nations therefore the unit of analysis for this research was an individual scholar who has participated in an international collaborative research project. There were four dimensions of this inquiry. The first analyzed the scholar's motivations based on a specific international collaborative project that resulted in a published co-authored article. This 
International Collaboration Among Social Science Scholars

dimension of inquiry was informed by the literature on motivations for international collaboration among scholars. Rostan, Ceravolo, and Metcalfe (2014) describe participation in an international collaboration as "a very demanding type of contact that requires a significant commitment (p. 124)”. Gibson and Gibbs (2006) conclude that geographically dispersed teams are often not able to realize the full benefit of collaborative nature of their work due to reduced communication. The reduced efficiency of a collaborative team due to inefficient communication across distances is an example of the concept of cost that is associated with collaboration. There are benefits and costs associated with participation in any type of collaborative project however international collaborative projects typically incur higher costs than that of internal or domestic collaborative projects (Ou, et al., 2012). Given the higher costs, this study sought to understand what motivates scholars to collaborate with their international colleagues?

The second dimension of inquiry was focused on the scholar's experience within the context of their university. This dimension of inquiry was informed by the model that Childress developed on faculty engagement in internationalization. This aspect of inquiry was designed to determine if the scholar's university offers funding, time off from their teaching responsibilities, or networking opportunities, in association with their participation in international collaborative research projects. Moreover, this research documented the institutional expectations and rewards related to participation in international collaborative projects, specifically those that were associated with the tenure and promotion process.

While the first two dimensions of this study were descriptive in nature the third dimension of inquiry was relational in nature. The questions were designed to enable analysis that considered the relationship between two or more variables. This researcher examined 
International Collaboration Among Social Science Scholars

patterns that emerged by analyzing, for example, the relationship between reported motivations for participation in international collaborative projects and tenure level; the association between participation in international collaborative projects and gender; or the association between the number of international co-authored articles over the past ten years and a scholar's native language.

The research questions related to the first four dimensions of this study were as follows:

- What motivates social science scholars to collaborate on research projects with their international colleagues?

- What university resources are available to support social science scholars who participate in international collaborative research projects?

- What expectations and rewards do universities have in the tenure and promotion process for social science scholars that participate in international collaborative research projects?

- What patterns of participation in international collaborative projects emerge when analyzing across dimensions related to motivations, university support and expectations, demographics, career level, and experiential factors?

The fifth dimension of this study incorporated linear regression as a modeling technique with the goal of generating an explanatory model. A baseline model was developed followed by the development of a parsimonious model. The two models were compared to determine if there were improvements associated second iteration of the model.

A survey instrument was used to gather data for this research. The target population for the study was social science faculty at post-secondary institutions throughout the world within the 
International Collaboration Among Social Science Scholars

disciplines of Management, Sociology, and Economics, that had co-authored papers with colleagues outside of their country. To be precise, the term cross-national collaboration was used to indicate collaboration between scholars who are working in different nations. (Abramo, d'Angelo \& Murgia, 2014). For the purpose of this research, the term cross-national collaboration was used interchangeably with the term international collaboration. The sample was selected using a bibliometric technique in the Web of Science database. The researcher searched the database for collaborative research projects that resulted in peer review papers that were published in fifteen social science academic journals over the past five years. The results were analyzed to identify co-author teams that consisted of scholars that were at universities located in different countries. Each scholar on the team was be asked to participate in the survey.

The list of potential survey participants was developed using the Web of Knowledge database. The database was queried to identify social science scholars that had co-authored a peer reviewed article with at least one colleague that is working in a different nation. The coauthored articles were selected from fifteen unique peer reviewed journals that were published from 2011 until 2015. The list of journals consisted of five English language journals from three social science disciplines, management, sociology, and economics. Each journal was selected based on five year impact factor and the availability of contact information for each co-author. Journals that were ranked in the top ten percent of five year impact factors, covering the research time frame, for the subject discipline were considered for inclusion in this study. (Appendix B: Academic Journals List Social Science Scholars International Collaboration Research) 


\section{Chapter Two: Literature Review}

This review provides an overview of the primary literature related to this research. Initially the theories related to the certainty of scholars self-organizing based on their mutual interest in a subject discipline are discussed. The opening sections provide an overview of the progression of literature starting with the initial theory of the sociology of knowledge, continuing with the invisible college theories, and concluding with the theories of the scholarly network. Current models of the scholarly networks feature four social processes that include: 1) information and formal scholarly communication, 2) collaborative exchanges of ideas, 3) collaborative research projects and co-authorship and 4) the mutual goal to support knowledge creation in the subject discipline forward by participating in scholarly network activities. (Zuccala, 2004, p.45) A primary goal of this research was to understand motivations related to participation in the third aspect of the scholarly network model, that of collaborative research and co-authorship.

The remaining sections of the review provide a summary of the principle literature on scholarly collaboration and co-authorship. The second part two of the review begins with a summary of the literature related to the benefits and costs associated with scholarly collaboration. Furthermore, it explains how the choice of collaboration mode, for example internal, domestic, or international collaboration, may affect the costs related to participation in collaboration. The fourth section provides an overview of the literature that discusses two dimensions of the internationalization of research. The first dimension is indicated when research has an international context and the second when research is the result of international 
International Collaboration Among Social Science Scholars

collaboration. The fifth section is a discussion of research methods that are represented in the collaborative research and co-authorship literature. Specifically, it summarizes studies that used quantitative methods, social science network analysis, and qualitative methods. Literature that is relevant to the development of this research are highlighted throughout this literature review. The conclusion discusses major insights from the literature that support and justify this research.

\section{Part One:}

\section{Foundational Theory of the Sociology of Knowledge}

“Influenced by belonging to groups”- Mannheim

The theory of the sociology of knowledge developed as a sociological movement in the late 1920s and was based on the work of Karl Mannheim. As such, Mannheim is considered the founder of the sociology of knowledge movement. The purpose of his renowned work, Ideology and Utopia, was to illuminate his theory related to "the social roots of our knowledge" (Mannheim, 1929). Scholars of the early discipline of the Sociology of Knowledge, such as Karl Mannheim, focused their research on "how the social location of individuals and groups shapes their knowledge" (Stehr and Meja, 1984). Mannheim considered knowledge to be "the product of social structures and social interaction” (Glover \& Strawbridge, 1985). Mannheim made it his life’s work to create a model of sociology of knowledge that would become "the scientific guidance of political life” (Mannheim, 1960, p.4). Driven by his true concern that civilization was breaking down, he attempted to create a logical model of sociological theory.

Many of the concepts from Mannheim's theory relate to the later evolution of the invisible college. “Our ideas are not conditioned by social class alone, even though this tends to be the major factor; we are also influenced by belonging to groups” (Mannheim, 1960, p.17). To 
International Collaboration Among Social Science Scholars

prove his theory, Mannheim describes two types of groups, ideology and utopia. The ideology group is characterized by being resistant to change and out of touch with the needs of society. This group maintains control of its membership by limiting group members’ access to knowledge and perpetuating its ingrained patterns through intolerance of new ideas. In contrast, the utopia group embraces an alternative view of open discovery of new ideas that may be contrary to past ideas. Mannheim believed that this second type of group could be cultivated to understand and contribute to the political and religious problems that his society was facing. The utopia group was established "as a special social group, of the modern intelligentsia, whose members were recruited on the bases of merit and who had no firm ties to any particular section of society” (Mannheim, 1960, p.19). These members were brought together with the purpose to synthesize all aspects of a problem and work on creating a solution. Their goal was to ultimately change society for the better.

Present day participants in scholarly networks go beyond their local and individual affiliations to band with a diverse group of scholars. Together they have the collective aim to create new knowledge in a given academic field. Faculty that are members of scholarly networks and participate by developing research agendas for a given subject discipline, sharing products of their research, and collaborating on research projects. Reflecting Mannheim's utopian concept, faculty members organize into subject discipline networks and transcend their institutional affiliations to participate in a broader group of like-minded intellectuals. 
International Collaboration Among Social Science Scholars

\section{Normalization of the Sociology of Knowledge}

“Groups organize around distinct subject orientations” - Merton

Using the English adaptation of Karl Mannheim’s Idealogie and Utopie, Robert Merton (1968) conducted a thorough review of the scholar's work. Although Mannheim's research was limited to the academic disciplines of politics and religion, Merton shifted the focus of his study of the sociology of knowledge to exclusively include the academic disciplines of the natural sciences. Subsequently, Merton justified the creation of the sociology of science as a specialty area within the sociology of knowledge. In his original work, "Mannheim felt that the natural sciences produced knowledge which was free from social influences.” Furthermore, “Merton drew attention to science as a social institution with its own form of organization and ethos” (Glover \& Strawbridge, 1985, p.30). He justified this specialty area of study by describing the social context of scientific research. Merton's work precipitated a transition in the theory from the sociology of knowledge to the new theory of the sociology of science.

Merton's research became a springboard transforming the conceptual structure of the theory of the sociology of knowledge. Scholars shifted from thinking about "differing social locations and interests of individuals or groups to a focus of how kinds of social organizations make whole orderings of knowledge possible” (Stehr and Meja, 1984, p.52). In other words, there was a conceptual shift away from conflict between groups with differing stances to the coordination of groups formed with the purpose to organize and expand knowledge. Merton highlighted this shift from competition to collaboration in his depiction of the social organization of scientific research. Groups organized around "distinct subject orientations to coordinate, complement, and sometimes overlap their inquiry” (Merton, 1968, p.494). Members agree on 
International Collaboration Among Social Science Scholars

the “characteristics of subject matter, definition of problems, concepts of data, utilization of research techniques, and social organization of research activities” (Merton, 1968, p.494). Merton's research defined the social roles of individuals within the context of the sociology of science. By shifting the research focus from disparate groups to organized collaborative groups, he launched the development of new constructs within the sociology of knowledge. The structure of these new constructs became the conceptual foundation of the following theory of invisible colleges and subsequent models of academic scholarly networks.

The significance of Mannheim's research to this study is the introduction of the concept that people organize to gain knowledge and share knowledge. It is the foundation of the concept of the scholarly network. Merton developed Mannheim's theory to indicate that people organize in smaller groups in order to focus on particular subjects. Merton's work was the foundation of the concept of the subject discipline. This research studied scholars who are a part of the subject disciplines of economics, sociology, and management. These groups are the manifestation of Merton’s research.

\section{The Invisible College}

“Practical communication system and citation network “- Price

The term "invisible college" was first used by the founding members of the Royal Society of London in the seventeenth century. The society members gathered regularly to share thoughts on their mutual scientific interests. The word invisible was incorporated into the description of their group because many of the members did not belong to a scholarly, scientific, or research institution. The primary feature that sustained the group was their passionate 
International Collaboration Among Social Science Scholars

devotion to the process of acquiring knowledge through experimental investigation (Lievrouw, 1990; Price, 1963).

The term invisible college appeared again three hundred years later in the article “Collaboration in an Invisible College” (Price \& Beaver, 1965). Price and Beaver stated that the invisible college had become the predominant form of organization in science and as such created new opportunities to study the sociology of modern science. The major element of the new model emphasized communication patterns between scientists. The authors observed that within the "highly competitive specialties in the sciences there seemed to be an in-group" (p 28). Members of the in-group remained in touch with each other by communicating at conferences and by circulating preprints and reprints of work to other members. Price and Beaver described that the power to grant prestige within the subject field lay in the hands of the invisible college group members. Members of the invisible college had the ability to affect personal prestige as well as to direct the fate of scientific ideas.

Price and Beaver grappled with the challenge of how to study, analyze, and collect information about the invisible college (Price and Beaver, 1965). They remarked that it is truly difficult to map out an informal group and determine its member boundaries. They conducted qualitative research in order to develop an appropriate metric with which to define an invisible college. Specifically, they did an in-depth analysis of the communication activities of an existing scientific specialty group. Communication activities among the group members consisted of the circulation of preprints of papers by mail to members who were located in countries across the world. The group called themselves “a continuing international congress by mail” (Price, 1965). Price observed that groups with specific research interests split off from the main group and organized. Furthermore, small work teams began to form in order to collaborate on research 
International Collaboration Among Social Science Scholars

projects and co-author papers. It was through the notation and tabulation of these collaborative activities that Price developed the descriptive phrase of a "practical communication system” (p. 64). Through his research, Price developed the concept of a network of people that share similar research interests. This by-product led to the development of the model for understanding the citation network.

The citation network is a mechanism by which researchers in a very small subject field can monitor the progress of research by peers and colleagues. A second aspect of the citation network system is the development of the value system by which the cited research becomes a form of currency. Price (1965) describes "the relationship which is given by the citation of one paper by another in the footnotes or bibliography” (p. 101). The more an author's research is cited, the higher the measurable impact of the research within a closely related peer network. When an author cites a work of another colleague, that author is judging the research of a peer to be of high quality based on their inclusion of the concepts within their own research. (Price, 1965) Price’s research recognized the material contribution of individual invisible college members as such Price’s model is classified as a structural model. The data used to build the model was publications and the subsequent number of times that a publication is cited by other scholars. Price's initial work in the analysis of citations is represented in bibliometric tools of today. Citation counts and the resulting metrics of impact factor are currently used as one of the evaluative elements for some university tenure and promotion reviews. Price's work served as the foundation for present day bibliographic resources such as the online database Web of Science and Web of Knowledge. 
International Collaboration Among Social Science Scholars

\section{"Scientific communities affect the growth of knowledge" - Crane}

In her book Invisible Colleges: Diffusion of Knowledge in Scientific Communities Crane, (1972) explores the research question, "how do scientific communities affect the growth of knowledge?” Crane’s study was an extension of Price’s research on citation networks.

Specifically, her work focused on how research communities form, how scholars exchange ideas through patterns of scholarly research, and how members of scientific groups collaborate and influence each other's work. She selected the methodology of bibliometric analysis to determine whether "variations in communication patterns among scientists actually affect the development of knowledge" (p. 78). The bibliometric analysis consisted of tracking the patterns of one scholar citing another scholar in their invisible college group as well as discovering patterns of coauthorship activity.

The results of the research indicated that differences in citation patterns did affect the development of knowledge and thus Crane's research became the foundation for the emerging theory of the invisible college. Her research included a comprehensive description of the informal organization and activities of the invisible college within the sciences. Her work expanded the concept of the invisible college beyond the mere exchange of papers and the analysis of citation patterns. She developed a socio-metric methodology that can be used for studying how an invisible college group forms, how they collaborate, as well as a process for measuring the effect that scholars have on the development of knowledge within their subject discipline. Merton's sociology of science theory categorizes scholars into the individual organizations by subject disciplines based on their mutual interest, however Merton's theory does not consider the "relationships within the internal structure of the organization and the cultural products developed and accepted within the group” (Crane, 1972). In summary, Crane’s 
International Collaboration Among Social Science Scholars

model is taking into account the cultural norms and values of a group and reporting the effect that these norms and values have on the work accomplished by the group of scholars

\section{Social Process Models of the Scholarly Network}

Following Crane, Leah Lievrouw’s (1990) model of the scholarly network is primarily focused on relationships between members and their activities within the subject discipline. Lievrouw calls these activities scholarly communication and defines this term as any activity that takes place between members of scholarly network to share ideas and information. Scholarly communication falls into two categories: formal and informal modes.

In the article "Reconciling Structure and Process in the Study of Scholarly Communication” Lievrouw (1990) proposed that Crane's concept of the invisible college is limited and that the model should be expanded to the multi-dimensional concepts of a scholarly network. Lievrouw presented a contrasting viewpoint related to bibliometric evaluation that is in direct opposition to Price’s structural model. Price’s model was built on the philosophy that the invisible colleges are structures of scholarship that are defined by the evidence of published documents and subsequent citing of published articles by other colleagues in the invisible college. Leivrouw's model was built on the philosophy that the invisible college is defined as a social process. The proposed social process model of invisible colleges focuses on the interaction of scholars through formal/informal communication and collaborative activities. Formal modes of communication consist of published articles in subject discipline journals, the co-citation of another scholar's work, the formalized release of research in a working paper series, or a presentation delivered at a subject-based conference. Examples of informal modes of 
International Collaboration Among Social Science Scholars

communication are the sharing of ideas through face-to-face conversations, interaction at conferences, written correspondence, or e-mail.

In Lievrouw’s model each scholar was a social actor within the invisible college and participated in a range of activities. The combination of activities that a scholar does is dynamic from year to year. Leivrouw's model included a range of activities that were the framework of a subject discipline’s scholarly network. The Leivrouw model included four major conceptual components: 1) information and formal scholarly communication, 2) collaborative exchanges of ideas, 3) periodic co-creation of research and writing, and 4) the mutual goal to move the knowledge of the subject discipline forward through the scholarly network activities (Leivrouw, 1990).

\section{Social Process and Structural Model of the Scholarly Network}

Alesia Zuccala’s $(2004,2006)$ research is a direct response to Leivrouw’s (1990) research that ponders whether the structure of scholarship is measurable from outside elements or whether it is instead a social process rooted in informal communication behaviors that can only be identified by members of the scholarly network. Zuccula proposes new concepts for defining and observing an international invisible college - the subject specialty, the scientist/scholars as social actors, and the information use environment. Her study focused on the international invisible college activities of faculty conducting research on the singularity theory in mathematics. Subsequently Zuccula developed an invisible college model that blends the elements of previous structural models and social process models in an international context.

Zuccala analyzed the invisible college by applying the research techniques of author cocitation analysis, co-authorship, social network analysis, and ethnography of communication. 
International Collaboration Among Social Science Scholars

Bibliographic analyses typically focus on cognitive forms of interaction (e.g., scholars citing each other or co-authoring work), while socio-metric analysis can help to clarify social forms of interaction (e.g., scholars meeting with each other at worldwide conferences). Qualitative forms ethnographic methodology were applied to allow the researcher to focus on specific ways that scholars communicate and behave with colleagues within their scholarly network (e.g., competitive behavior; collaborative behavior) (Zuccala, 2004, p.122). Earlier invisible college researchers had used some of these methodologies, however; Zuccala was the first to apply all three methodologies, bibliographic analysis, socio-metric analysis, and ethnographic methods. The resulting data and detail allowed Zuccala to "graphically superimpose socio-metric data on bibliometric data” as the means for creating a unique description of an international invisible college related to a specific subject discipline. (Zuccala, 2006)

Based on the new description, Zuccula developed an updated multi-dimensional definition of an invisible college.

An invisible college is a set of interacting scholars or scientists who share similar research interests concerning a subject specialty, who often produce publications relevant to this subject and who communicate both formally and informally with one another to work towards important goals in the subject, even though they may belong to geographically distant research affiliates (Zuccula, 2004, p. 66).

Zuccula's new definition describes a diverse set of activities that members of the international invisible college undertake to facilitate the advancement of knowledge within a subject discipline. This definition is the most recent from the literature related to the study of the invisible college and scholarly networks, furthermore it is now the accepted norm for the study of the social organization of scholars within their subject discipline. Moreover, Zuccula’s work created a new 
International Collaboration Among Social Science Scholars

research model that can graphically represent levels of international involvement in the invisible college as well as relationships with other members.

\section{Part Two:}

\section{Expansion in Collaborative Research Initiatives}

“Academic work increasingly is teamwork” (Posner, 2001, p.540)

The second half of the $20^{\text {th }}$ century was dominated by the growth of collaborative research among scholars (Clark Kerr, 1963, Beaver \& Rosen, 1979; Fox \& Faver, 1982; Leband \& Tollison, 2000; Persson et al., 2004; Glanzel \& Schubert, 2004; Adams et.al., 2005; Wutchy et.al., 2007; Wagner, 2008). The expansion was most noticeable in the disciplines related to science (Price, 1963) which was characterized by a shift in scientific research from small regional projects that were funded by universities to predominantly large scale global projects that were jointly funded by universities, government agencies, and corporations (Glanzel \& Schubert, 2004; Wagner, 2008; Mali et al., 2012). Derek J de Solla Price introduced the phase “big science” in his book Little Science Big Science (1963). Price’s work reported on the changes in the way that scientific research was being accomplished. There was a trend post WWII to pool resources and talent to create large research teams. The literature reports that the expansion of collaboration is a direct result of the "big science" movement that is predominantly reflected in the scholarly activities associated with the sciences, technology, engineering, and mathematics, also known as the STEM fields, as well as medicine (Luukkonen, Persson \& Sivertsen, 1992; Bordons \& Gomez, 2000; Newman, 2004; Lee \& Bozeman, 2005; Wagner, 2008; Rostan, Ceravolo \& Metcalfe, 2014). However, research showed an increase in collaboration across the board in all disciplines, however comparative studies indicated a compounded increase in collaborative activities the STEM fields and medicine as opposed to the 
International Collaboration Among Social Science Scholars

fields of social science, humanities, and the arts. (Cronin, 2001, pp560-561; Wray, 2002, p.159;

Rostan, Ceravolo \& Metcalfe, 2014, p. 135).

\section{The Benefits and Costs of Collaboration}

The literature suggests there are a number of benefits associated with collaborative research initiatives. The benefit of increased academic productivity is recognized in the literature as one of the most compelling benefits of collaboration among scholars (Lee \& Bozeman, 2005; McFadyen \& Cannella, 2004; Wuchty et al., 2007; Jeong et al., 2011; Ou et al., 2012). Empirical evidence suggests that co-authored papers are more often published in journals with higher impact factors when compared with those of single authors (Katz \& Martin, 1997; Bozeman \& Corley, 2004; Lee \& Bozeman, 2005; Jeong et al., 2011, Rostan et al., 2014). Collaboration stimulates intellectual creation and provides the opportunity for the crossfertilization of ideas across a discipline (Beaver \& Rosen, 1978; Katz \& Martin, 1997; Melin, 2000; Bozeman \& Corley, 2004; Ou et al., 2012). There are additional personal benefits that are closely related to a scholar's motivations for participating in collaborative research projects.

Benefits such as intellectual companionship and personal pleasure through interaction with likeminded scholars (Katz \& Martin, 1997; Melin, 2000; Thorsteinsdottir, 2000; Beaver, 2001; Bozeman \& Corley, 2004; Ou et al., 2012); the effective division of labor reflecting the unique talents of team members that have an array of knowledge, skills, and abilities (Senker, 1993; Katz \& Martin, 1997, Melin, 2000; Beaver, 2001; Bozeman \& Corley, 2004; Ou et al., 2012); and the transfer of knowledge or skills to other teams members through the experience gained during the collaborative project (Katz \& Martin, 1997; Melin, 2000; Beaver, 2001; Jeong et al.,2011) to name a few. 
International Collaboration Among Social Science Scholars

However, research collaboration also involves costs as well as benefits (Katz \& Martin, 1997; Leydesdorff \&Wagner, 2008; Jeong et al, 2011; Ou et al., 2012; Rostan et al., 2014). Costs can take a variety of forms and are compounded by geographically dispersed teams (Gibson \& Gibbs, 2006). In terms of time, collaboration brings costs related to sharing ideas for a potential project, coordinating details for an upcoming work, following up on the progress of work, and keeping all team members apprised of the ongoing activities (Katz \& Martin, 1997; Vafeas, 2010; Ou et al., 2012). Administrative costs are incurred when, for example, the team is revising and editing documentation related to the results of their research. Coordinating these activities when co-authors are geographically disparate typically requires a process and explicit schedule for accomplishing tasks. Every step of the collaborative process may involve a structured managerial process due to distances between team members. (Katz \& Martin, 1997; Jeong et al., 2011) In financial terms, there are costs related to identifying proper research partners and periodically meeting face to face to propel the momentum of the research activities. In the case of collaborators that are located at another institution, these costs could be travel costs for attending conferences in order to meet potential collaborators or travel to a co-author's institution to participate in a research work session (Katz \& Martin, 1997; Wagner, 2006; Jeong et al., 2011). A loss of efficiency is a type of cost related to the steps needed to accomplish a project. This type of cost may be incurred in collaborative projects if there is inadequate communication or poor understanding of expectations between collaborators (Melin \& Persson, 1996; Katz \& Martin, 1997; Nathan, 1998; Jeong et al., 2011).

In their article "Determinants of Research Collaboration Modes", the authors Jeong, Choi and Kim classify the modes of collaboration as internal collaboration, domestic collaboration, and international collaboration (2011). Their collaboration-mode classification system is related 
International Collaboration Among Social Science Scholars

to the geographic proximity of team members. Internal collaborations are projects that are undertaken by colleagues that are at the same institution; domestic collaborations that entails colleagues at different institutions that are located in the same country and international collaboration that includes colleagues located at institutions in different countries. Other researchers categorize collaborations as intramural, extramural domestic collaboration and extramural international collaboration (Katz \& Martin, 1997; Laudel, 2002; Abramo et al., 2014) Intramural collaborations are between colleagues within a department or institution while extramural collaborations are sub-classified as domestic and international.

A discussion of collaborative modes is relevant to this research given that costs increase based on the mode of the collaborative project (Katz \& Martin, 1997; Ou et al, 2012; Jeong et al., 2014). The costs associated with research collaboration increase from internal, to domestic, to international projects. Wagner (2006) explains that an international collaboration is typically associated with higher administrative, travel, and cultural costs in contrast to collaboration between shorter distances, such as domestic collaboration. Jeong, Choi, and Kim state “researchers take risks when selecting their collaboration modes, a decision taken through strategic decision making that must take account of the environment and the trade-offs among all the alternatives (2011, p. 968)”.

Ou, Varriale and Tusi (2012) report that international collaborative teams balance transaction costs by leveraging the complementary resources of the team. They categorize the transaction costs as those related to cultural diversity, language barriers, dissimilar mindsets, and communication difficulties. The development of complementary resources is related to: interpersonal competencies; supporting a scholar's personal aspirations; choosing projects that leverage common publication goals, research interests, and working style; a commitment to open 
International Collaboration Among Social Science Scholars

and frequent communication; and fostering the development of friendships and trust. They concluded that international collaboration teams are more successful when they are able to develop strategies that leverage complementary resources and reduce the effect of transaction costs (Ou et al., 2012).

\section{Research Methods Represented in Collaboration and Co-Authorship Literature}

Studies of collaboration and co-authorship reveal several approaches to research methodology in collaborative projects. The first approach is based on the concept that collaboration and the resulting co-authorship is best understood through quantitative dimensions of the research collaboration phenomenon. The second approach to research is through the application of social network analysis. These two methodologies apply a macro lens to the analysis of research collaboration. A third approach that uses qualitative methods, applies a micro lens by analyzing the motivations of an individual scholar for collaborating and coauthoring with their colleagues (Melin, 2000).

\section{Quantitative Methods}

Studies that use quantitative measurements to understand the phenomenon of research collaboration have predominantly used co-authorship as a measure of collaborative activity between scholars. A major theme in the application of quantitative methodological approaches to the study of collaboration is simple descriptive statistics presented in time-series form, for example, growth in scholarly collaborative activities over a period of time (Narin, 1991; Luukkonen et al., 1992, 1993; Miquel and Okubo, 1994; Georghiou, 1998; Glanzel, 2001; Wagner, 2006; Rostan et al., 2014). These studies differentiated their research by limiting the focus of their research to a specific geographic area, for example, to a single institution, a region, 
International Collaboration Among Social Science Scholars

a specific country or with no limitations, thus including the entire world (Narin \& Whitlow, 1990; Okubo et al., 1992, Luukkonen et al., 1993; Lariviere et al., 2006; Rostan et al., 2014). Another approach has been to limit the study of participation in collaborative projects to a group of scholars, such as scholars within a particular university or within a subject discipline (Piette \& Ross, 1992; Melin, 2000; Morrison et al., 2003; Kwiek, 2015). Other quantitative studies have analyzed the impact of co-authored work by studying citation frequencies. These studies report the number of citations of co-authored work or include a comparative analysis by contrasting the number of citations from single authored articles as opposed to co-authored articles (Narin, 1991; Persson et al., 2004).

\section{Social Network Analysis Methods}

The research collaboration and co-authorship literature has numerous examples of the application of social network analysis in quantitative studies. Social network analysis is based on the assumption that "actors participate in social systems connecting them to other actors, whose relations comprise important influences in one another’s behaviors” (Knoke \& Yang, 2008, p.4). There are three components that are typically used to construct a social network model. The first construct is the actors that are represented by nodes in social network model. In a model representing collaboration and co-authorship, the actors are the scholars. The second component is the ties of interconnectivity that represent the relationships between actors within the social network. Ties are represented by lines that connect actors who are in direct relationships. The ties that will be represented in this research are the relationships between scholars who collaborate and co-author. The last component is the quantitative nature of the graphical structure that emerges based on the patterns of relationships that exist in the network (Knoke \& Yang, 2008). The result of a social network analysis is a direct or indirect network gap 
representation of the relationships that exist based on collaborative activities within a subject discipline. Quantitative descriptive metrics, such as, degree, density, and centrality are typically analyzed for patterns. Technically the social network analysis models are structural models however the organization of the data has the potential to reflect levels of social involvement and relationships between scholars in a subject discipline.

An illustrative example of a social network analysis is the research conducted by Morlacchi, Wilkinson and Young (2005) in order to describe the social network between scholars and the dynamic nature of co-authorship patterns within the American Marketing Association. The study was done by analyzing the patterns of co-authorship that emerged from an association's annual conference proceedings over a ten-year period. The authors defined coauthorship as the activity when two or more authors collaborate to conduct research, write a paper/book, and have the work published. The authors found that there was a core of 57 researchers that were central to the publication of materials in their discipline. The results of the study were represented by a network graph that portrayed researchers as nodes and co-author relationships as ties between authors. They concluded that based on the patterns of co-authorship during the study, collaborative teams evolved and changed over time, rather than remaining fixed. (Morlacchi, Wilkinson \& Young, 2005)

A different model of social network analysis is represented in "The Invisible College of The Economics of Innovation and Technological Change” by Verspagen \& Werker (2003). Their study expanded the traditional graphical research network model to include two separate ties defined as weak and strong linkages between researchers in the network. Their model is one of the first to create a representation of varying levels of involvement between scholarly network members. A weak link reflects activities, such as, reading articles that are published by other 
researchers in the network, and subsequently citing them in their work, or co-citation of work. A strong link indicates, for example, co-authorship relationships. The development of a model that allows for the representation of various levels of relationships more closely parallels the actual activities and levels of interaction between members of an invisible college. The development of graphical social networking models is a significant breakthrough in the description of relationship patterns in an invisible college. This graphic representation shows the enhanced patterns of activities and relationships between scholars.

The co-authorship social network analysis is conducted in order to: 1) quantify patterns of collaboration; 2) report productivity of collaborative projects; 3) compare collaborative activities between subject disciplines; and 4) represent activity of one subject discipline or geographic area through mapping, (Biancani \& McFarland, 2013, p.158). Each of the following studies represent one of the four outcomes described above. The purpose of this list is to be illustrative as opposed to comprehensive in nature. Leydesdorff and Wagner apply social network analysis methods in order to quantify the growth in patterns of collaboration over a fifteen-year period in the fourteen science disciplines (2008). The results of their research are a graphic indication that the network between scholars expanded and participation in co-authorship increased threefold over fifteen years. In the article "Co-Authorship in Management and Organizational Studies: A Empirical and Network Analysis” the authors, using social network analysis to graphically represent the productivity of collaborative projects and the resulting core of most prominent scholars within their discipline (Adedo et al., 2006). Lariviere, Gingras, and Archambault compare collaborative activities between scholars in the natural sciences, social sciences and the humanities by using social network analysis techniques. The result of their research is a graphical model of collaborative networks present in each discipline (Lariviere et 
International Collaboration Among Social Science Scholars

al., 2006). The work of Glanzel and Schubert is reported in their article "Analyzing Scientific Networks through Co-Authorship” (2004). Their research using social network analysis techniques resulted in a global map indicating the collaborative activities between scholars in the sciences in different countries.

\section{Qualitative Methods}

The literature on collaborative research and co-authorship based on qualitative methods is discussed in this section. One area of considerable qualitative study has been research designed to understand the perception of the value of participation in co-authored projects in regards to the tenure and promotion process (Tompkins et al., 1997; Davies et al., 1996; Siva et al., 1998; Biggs, 2008; Osborne \& Holland, 2009; Bebeau \& Monson, 2011; Lemke et al., 2015). Another example of qualitative research is the group of studies related to the decision process for determining the primary author on a co-authored paper (Lindsey, 1980; Gelman \& Gibelman, 1999; Moore \& Griffin, 2006; Strange, 2008; Seeman \& House, 2010; House \& Seeman, 2010; Welfare \& Sackett, 2010). However, a larger number of qualitative studies consider the motivating factors related to a scholar's decision to participate in collaborative research projects. A considerable array of scholarly articles addresses the motivations and factors that scholars reported were a part of their decision to participate in collaborative research projects. This review is important to this research project, given that the concepts are used in the development of the independent variables for this study’s research model.

Several aspects of motivation have been addressed by scholars of collaborative research. One portion of the literature identifies cultural and experiential proximity as a motivation for participating in a collaborative research project. This category of motivation relates to shared 
International Collaboration Among Social Science Scholars

personal traits and experiences that generate an ease and familiarity between collaborators. For example, when a scholar with a Ph.D. works with a colleague(s) that earned a doctorate from the same institution (Landry et al. 1996; Luukkonen et al. 1992; Katz and Martin, 1997), collaboration among colleagues that are fluent in the same languages (Traore \& Landry, 1997; Bozeman \& Corley, 2004; Ou, et al., 2012), and similar formal training in research paradigms and academic experiences yields a similar mindset of how to organize and accomplish research (Bozeman \& Corley, 2004; Ou et al., 2012). Additional factors presented in the scholarly literature are shared experiences, and success in past collaborative projects (Simonin, 1997; Melin, 2000; Bozeman \& Corley, 2004, Ou et al., 2012). Factors related to educating a student or helping a junior colleague have also been found to be a motivation to collaborate (Crane, 1972; Beaver \& Rosen, 1978; Melin, 2000; Beaver, 2001; Bozeman \& Corley, 2004). Scholars are also motivated to work with certain colleagues because they are pleasant to work with (Katz \& Martin, 1997; Melin, 2000; Thorsteinsdottir, 2000; Beaver, 2001; Bozeman \& Corley, 2004, Ou et al., 2012). Based on experiences in collaborative projects, even if a scholar does not share the exact mix of contextual or cultural elements as the co-authors, the scholar has an understanding of how the mix of elements comes into play in a collaborative project. In this way the more experience gained through participation in collaborative projects, the better equipped a scholar is to be an effective partner in a collaborative research project (Easterby-Smith and Malina, 1999; Nyden and Wiewel, 1992; Ou et al., 2012).

The literature on scholarly collaboration also highlights the strong role that informal communication plays in affecting a scholar's choice to collaborate in a research project. Scholars report that most collaborative projects have their origins in an informal conversation (Solla Price \& Beaver, 1966; Katz and Martin, 1997; Wagner, 2008; Ou et.al., 2012). Informal 
International Collaboration Among Social Science Scholars

communication during the initial stage of a collaborative project is essential in order to establish a strong interpersonal relationship based on shared research interests (Kraut, et al., 1987).

The need for academic excellence as a determinant of collaborative participation is manifested in many ways in the literature. Findings include that scholars need to keep pace with the expanding requirement to develop expertise in, for example, research methods and data analysis techniques. This need compels scholars to seek out colleagues as collaborative partners based on their superior prophecies prior research, knowledge, or capabilities (Katz \& Martin, 1997; Melin, 2000; Thorsteinsdottir, 2000; Beaver, 2001; Bozeman \& Corley, 2004; Wagner, 2006, Ou et al., 20012). Rijnsoever and Hessels report that there is an association between academic excellence and the propensity to collaborate (2010). In their article Multi-university research teams, Jones, Wuchty, and Uzzi state "Not only the formation of a collaboration but its impact is proportional to the academic excellence of its participants (2008, p. 1260).

A scholar's position in their career progression is another factor that can influence motives for research collaboration. Status and salary of scholars is typically linked to output and the impact of their research (Cronin, 1996; Hamermesh et al., 1982; Sauer, 1988; Glanzel \& Schubert, 2004; Wagner, 2008). Participating in research collaboration is considered to be a way to produce greater quality and quantity of work in comparison with research that is done individually (Hudson, 1996; Bozeman \& Corley, 2004; Wagner, 2008). Positional attributes such as reputation for academic achievement, tenure and promotion status, level of past productivity, and attained level of peer recognition within the subject discipline all effect the decision to participate in collaborative research projects (Bozeman \& Corley, 2004; Wagner, 2008; Ou et al., 2012). The literature also indicates developing scholars are motivated to collaborate with senior 
International Collaboration Among Social Science Scholars

colleagues in order to obtain prestige or visibility (Crane, 1972; Beaver \& Rosen, 1978; Katz \& Martin, 1997; Beaver, 2001; Bozeman \& Corley, 2004; Wagner, 2006; Ou et al., 2012).

Other factors related to the process and operational aspects of research projects influenced motivations for participating in research collaboration. Gaining access to data, resources or equipment that one does not have was a motivator (Meadows, 1974; Melin, 2000; Thorsteinsdottir, 2000; Beaver, 2001; Wagner, 2006; Ou et al., 2012). There is also impetus to collaborate given the opportunity to pool knowledge for addressing large and complex problems (Melin, 2000; Thorsteinsdottir, 2000; Beaver, 2001; Bozeman \& Corley, 2004; Ou et al., 2012). In a number of studies collaboration facilitated the development of new research ideas and encourages cross-fertilization across the disciplines (Beaver \& Rosen, 1978; Katz \& Martin, 1997; Melin, 2000; Bozeman \& Corley, 2004). Scholars were also motivated to collaborate to improve access to funds (Heffner, 1981; Beaver, 2001; Laudel, 2001; Lundberg et al., 2006; Wagner, 2008; Ou et al., 2012). The decision to collaborate on a research project was influenced by the availability of funds as well as the goals of organizations that provided the funds (Beaver et al., 2005). Research teams set goals and organized the flow of their research activities, in order to fulfill the intention of the research funding or grant (Lundberg, 2006, Wagner, 2008).

\section{Summary}

The purpose of this review is to present a synthesis of existing literature on international scholarly collaboration and co-authorship thus providing an understanding and context for this research. In order to review the concepts related to the first research question "What motivates social science scholars to collaborate on research projects with their international colleagues?" the researcher conducted extensive review of the literature related to the motivations for 
International Collaboration Among Social Science Scholars

participation in collaborative research projects. A list of independent variable and subsequent survey question were developed from the literature review. The articles primarily discussed collaboration in general with only five being specifically about international collaboration.

The Childress model informed the development of the research questions related to university funding and support that is available for social science scholars that collaborate with their international colleagues. Additionally, her work informs the inquiry of the expectations as well as rewards in the tenure and promotion process that are associated with international collaboration. The facets of the Childress model provide a strong foundation for encouraging faculty participation in internationalization activities. This research considered data related to the strategic choices that scholars make when they participate in internationalization activities. Specifically the socio-cognitive choices and factors of motivation related to the decision to collaborate with their international colleagues. This inquiry was designed to generate data that when analyzed would reflect the experience of individual scholar that has participated in a specific international collaborative project. The ultimate goal of this research was to inform the development of institutional policies and programs aimed at encouraging faculty to participate in collaborative research projects with their international colleagues.

The work of Kraut, Galegher, and Egido influenced the design of this study by highlighting the importance of focusing on the differences between subject disciplines and more specifically within the social sciences. Green and Shoenberg concluded that success in developing effective support systems for faculty is contingent on understanding that each subject discipline has unique patterns of activities, values, standards, and norms. Green and Shoenberg's research also informed the decision to focus on three subgroups within the social sciences. Lastly, the decision to choose the social sciences subject disciplines as the focus of this research 
International Collaboration Among Social Science Scholars

was informed by the research of Wagner (2008) and Melin (2007). Wagner found that the motivation to collaborate for scholars in the natural sciences is reported as the opportunity to build reputation, to gain access to data, labs, or technology that is not available at their home institution, to develop access to funding resources, and to gain the opportunity to join an extended team working on research initiatives. In contrast Melin found that the top four motivations for social scientists to collaborate with their cross national colleagues is to increase knowledge, increase the likelihood that the resulting work will be of higher academic quality, the generation of new ideas, and to make connections with colleagues for future projects. The literature highlights the differences between academic subject disciplines which further supported this researcher's decision to focus this study on three disciplines within the broader field of social sciences, specifically the disciplines of sociology, economics, and organizational behavior.

There is extensive coverage in the literature related to motivations for collaboration among scholars. Although general in nature, the literature establishes a foundation of concepts related to the phenomenon of collaboration. There has been extensive coverage in the literature related to collaboration among scholars in the sciences, technology, engineering, mathematics, and medicine (Mali et al., 2012) as well as studies on the international teams of scholars that collaborate on global research projects within these disciplines (Leydesdorff \& Wagner, 2008). In contrast there have been fewer studies done on scholars that collaborate in the social sciences (Endersby, 1996). Lariviere, Gingras, and Archambault report that although the level of collaboration in the social sciences is lower than that of the fields of the sciences, engineering, mathematics, and medicine; "more research is required to gain insight into the different forms of research collaboration in the social sciences (Lariviere et al, 2006, p. 531)”. Furthermore, the 
literature lacks coverage of social science scholars that participate in international collaborative projects (Ou et al., 2012). The lack of coverage in the literature could be explained by the fact that in the science, technology, engineering, mathematics and medicine disciplines, international collaboration is status quo, whereas in other disciplines it is not the norm. In their article "The Internationalization of Research," Rostan, Ceravolo and Metcalfe state "in the natural sciences, collaboration has been both necessary and desirable, while in social science fields and the humanities, collaboration is often less important than demonstrating individual expertise (Rostan et al., 2014, p. 120).” The differences in patterns of collaboration are dictated by the subject disciplines (Franceschet \& Costantini, 2010; Abramo et al., 2014). Nevertheless, there is a lack of literature related to international scholarly collaboration in the social sciences. This study was conducted to bridge the gap and extend the literature related to the topic of international collaboration among social science scholars. 


\section{Chapter Three: Methodology}

\section{Overview}

This research incorporated the cross sectional survey design of quantitative methodology. This is an observational study, as it was based on surveying subjects without any intervention. The unit of analysis was the individual social science scholars involved in a specific international collaborative research projects. Creswell stated that a survey researcher's focus is on learning about a population and describing its attitudes, opinions, experiences, perceptions, behaviors, and characteristics (2008, p.388). This research design was selected because it is well suited to collecting the perceptions, practices, and experiences of social science scholars involved in international research collaboration and co-authorship activities. The cross sectional survey design provided the opportunity to gather demographic information about the participants' as well as their experiences and perceptions related to a specific international collaborative research project.

The target population for this study was social science scholars from faculty at universities throughout the world. The sampling frame was a group of social science scholars who have co-authored papers with colleagues from universities in other countries. The sample design was developed to identify social science scholars that have co-authored an article in one of fifteen social science academic journals. The criterion for inclusion in the data set was participation in research and collaborative work projects with cross national colleagues that resulted in at least one co-authored article in the past five years. A survey instrument was used to gather quantitative data for this research. 
International Collaboration Among Social Science Scholars

\section{Design of Research Methodology}

Green and Shoenberg stated that support of international activities of faculty should be customized based on the needs of faculty involved in the invisible college activities of their particular subject discipline (2006, p.4). A strength of this research design was the narrow focus of three particular disciplines in the social sciences. The research model was able determine specific patterns of international collaborative activities found in particular group of social science scholars in three subject disciplines.

The following discussion highlights tradeoffs that the researcher considered as well as the subsequent choices that were made in developing this research methodology. The first example of a tradeoff was related to the choice to develop a survey instrument for the research. This survey format used of a web-based survey platform to collect data for this research. Using a survey was considered to be manageable process for accomplishing the research given the scope and timing of the research project. However, this could be considered a weaknesses in this methodology, specifically, the choice to collect data using a survey limits the level of detail that can be gathered from the scholars that have been involved in international co-authorship projects. The opportunity to interview each respondent face to face would yield more granular data however, given the global nature of the sample design, conducting interviews with every participant was improbable. Conducting a survey created a reasonable balance between the timing and cost to conduct this research.

An additional strength of this research design was related to this sampling design which was limited to co-authored articles that were published in the past five years. Limiting the scope to the past five years could be considered a weakness in the design given the design most 
International Collaboration Among Social Science Scholars

certainly eliminated number of international projects that social science scholars had participated in over a longer timeframe, however given the specific nature of questions that a respondent was asked, recall was a factor in this decision to limit the design to the past five years. Scholars were asked to reflect on a particular collaborative project, their perceptions and recall may have been limited as time had passed, therefore this researcher selected a short term horizon of five years for this research.

Another example of a strength of this design was that this research questions were predominantly focused on one specific collaborative research project. The respondent was asked to answer questions about one particular international collaborative project that resulted a coauthored article in a scholarly journal. This allowed the respondent to reflect on a particular project with a team of co-authors. Organizing the research questions in this way had the potential to collect explicit data related to the scholar's motivations and experience associated with a specific collaborative project. The focus on one unique project was in contrast to collecting data related to their overall experiences in a number of projects. The contrasting research design option, to focus on multiple collaborations, was rejected due to its potential to confuse respondents when asking questions about multiple projects as well as accelerate the development of survey fatigue. Given that this the survey questions were specific in nature, for example, asking about a scholar's motivations for participating and the availability of support from their university; the choice to focus on one specific project improved the potential to produce conclusive results. This was considered preferable given that specific results have the potential to inform universities about how to implement funding, services, and programs to attract more faculty participation in research related internationalization initiatives. 
International Collaboration Among Social Science Scholars

\section{Research Questions and Development of Explanatory Model}

\section{Research Questions}

The research questions for this dissertation were as follows:

- What motivates social science scholars to collaborate on research projects with their international colleagues?

- What university resources are available to support social science scholars who participate in international collaborative research projects?

- What expectations and rewards do universities have in the tenure and promotion process for social science scholars that participate in international collaborative research projects?

- What patterns of participation in international collaborative projects emerge when analyzing across dimensions related to motivations, university support and expectations, demographics, career level, and experiential factors?

The Appendix A of this work includes information about the mapping of research questions to survey questions as well as the independent variables and wording of the survey questions.

\section{Explanatory Models}

This aspect of the research incorporated multiple linear regression as a modeling technique with the focus of generating an explanatory model. The magnitude, valence, and statistical significance of the independent variables were analyzed to determine support for the proposed hypotheses. Initially a baseline model was developed. Given the extensive set of independent variables that was used in a baseline explanatory model, feature selection was 
International Collaboration Among Social Science Scholars

subsequently applied to develop a parsimonious model. A backward elimination procedure was applied. This process started with independent variables in the model and in a sequential fashion removed independent variables one at a time. The order of removal was determined by those variables that had the largest p value. Finally, a comparative analysis of the two models was used to determine if there were improvements associated with the second model.

\section{Dependent Variable}

This research is focused on international collaboration and the dependent variable explicitly measures this type of scholarly activity. The ratio associated with the dependent variable represents the proportions of participation in international collaborative co-authored articles with respect to all published articles over a specific time frame.

The dependent variable in this research project was calculated using the following process. The respondent was asked to provide the number of international collaborative projects that they have participated in for the past ten years that resulted in a co-authored article that was published in a refereed scholarly journal. They were also be asked to provide the number of total number of articles that they had written over the same timeframe that have resulted in an article that was published in a refereed scholarly journal. The first number was divided by the second to create a ratio that was used as the dependent variable for this study. For example, if a scholar indicates that she had participated in five international research projects that had resulted in five co-authored articles published in refereed scholarly journal and she reports that she had published twenty total articles in scholarly journals over the past ten years, then her dependent variable was $5 \div 20$ to yield .25 as the dependent variable. 


\section{Independent Variables}

The independent variables for this study were derived from the literature on international collaboration. The results of the literature review for this study were outlined in chapter two of this dissertation. An extensive list of possible independent variables was explored. The literature review facilitated the identification of twelve factors that motivate scholars to collaborate with their international colleagues. The twelve concepts were the foundation for the development of this study’s survey questions. The context of the variables were grouped and mapped to particular research questions. Survey questions were developed from the independent variable concepts. The four categories of independent variables were: 1) motivations for collaborating with international colleagues ; 2) university resources that are available to support scholars who collaborate with international colleagues 3) university expectations and rewards that related to the tenure and promotion process and; 4) demographic and individual information such as gender, first language, worked together in previous projects with one or more of the co-authors, and number of years since graduation from $\mathrm{PhD}$ program. The initial set of independent variables are outlined in Table 1.

The Appendix A of this work includes information about the mapping of research questions to survey questions as well as the independent variables and wording of the survey questions. 
Table 1 :

Initial Independent Variable Set

\begin{tabular}{ll}
\hline Independent Variable & Variable Context \\
\hline & Motivation Dimensions \\
\hline Collaborate to improve access to university funds & \\
Collaborate to improve access to external funds & \\
Collaborator has expertise other than my own & \\
Collaborator has special data or equipment & \\
Collaborate to pool expertise and take on complex & \\
research problems \\
Collaborate to gain peer recognition and visibility \\
Collaborate again based on previous project \\
success \\
Collaborator is fun and pleasant to work with \\
Opportunity to publish with international \\
colleagues \\
Collaborator is fluent in the same language \\
Collaborate to mentor and help a junior colleague \\
or graduate student
\end{tabular}

University offers funding for travel

University offers funding/grants for international

collaboration (other than funding for travel)

University offers sabbatical or release time to

support participation in international

collaborations

University offers seminars or networking sessions

about international collaboration

University stipulates participation in international

collaborative projects for tenure and promotion

University encourages international collaboration

but does not require

Internationally co-authored articles count more

towards tenure and promotion

Personal and Demographic Dimensions

\footnotetext{
Year earned $\mathrm{PhD}$

Tenure level - Assistant, Associate, Full, Other

Gender

Native language

Country earned first degree/undergraduate

$\mathrm{PhD}$ from the same institution as co-author

Co-authored multiple times with collaborators
} 


\section{Format of Questions in the Survey}

The survey design incorporated three types of survey questions. The first type was questions that used a nominal or interval scale to collect information such as demographic details, career level of scholars, length of relationship with co-author, and number of their internationally co-authored papers. The second type was a quasi-interval scale of question that incorporated the Likert four point scale of strongly agree to strongly disagree. This type was used to collect data related to, for example, the forms of university support that were available to faculty based on their participation in international collaborative projects or their motivations for working with their colleagues. Another example, participants were asked to indicate if travel funding was available to them from their universities. Specifically the question read "my university offers travel funding to support participation in international collaborative projects. Survey participants responded to the question by choosing a level on the Likert scale of strongly agree, agree, disagree, or strongly disagree. The third type of question asked study participants to indicate which aspect of motivation was most important to them when deciding to participate in the project. The data collected from this type of question was used to create descriptive format of results. Data was collected using the Qualtrics online survey format. Respondents were faculty at universities throughout the world that have been involved in international research and co-authorship projects. Research questions were been mapped to the survey questions as well as the independent variables in Table 2. The survey document is attached Appendix E and F.

The Appendix A of this work includes information about the mapping of research questions to survey questions as well as the independent variables and wording of the survey questions. 
International Collaboration Among Social Science Scholars

Table 2

Mapping Research Questions to Survey Questions and Independent Variables

\begin{tabular}{|c|c|c|c|}
\hline $\begin{array}{l}\text { Research } \\
\text { Question }\end{array}$ & $\begin{array}{l}\text { Survey } \\
\text { Question }\end{array}$ & Independent Variable & Variable Context \\
\hline $\mathrm{R} 1$ & Q1 & $\begin{array}{l}\text { Collaborator has a strong } \\
\text { reputation }\end{array}$ & Motivation Dimensions \\
\hline R1 & Q2 & $\begin{array}{l}\text { Collaborate to improve access to } \\
\text { department/university funds }\end{array}$ & \\
\hline R1 & Q3 & $\begin{array}{l}\text { Collaborate to improve access to } \\
\text { external funds }\end{array}$ & \\
\hline R1 & Q4 & $\begin{array}{l}\text { Collaborator has expertise other } \\
\text { than my own }\end{array}$ & \\
\hline R1 & Q5 & $\begin{array}{l}\text { Collaborator has special data or } \\
\text { equipment }\end{array}$ & \\
\hline R1 & Q6 & $\begin{array}{l}\text { Collaborate to pool expertise and } \\
\text { take on complex research problems }\end{array}$ & \\
\hline R1 & Q7 & $\begin{array}{l}\text { Collaborate to gain peer } \\
\text { recognition and visibility }\end{array}$ & \\
\hline R1 & Q8 & $\begin{array}{l}\text { Collaborate again based on } \\
\text { previous project success }\end{array}$ & \\
\hline R1 & Q9 & $\begin{array}{l}\text { Collaborator is fun and pleasant to } \\
\text { work with }\end{array}$ & \\
\hline R1 & Q10 & $\begin{array}{l}\text { Opportunity to publish with } \\
\text { international colleagues }\end{array}$ & \\
\hline R1 & Q11 & $\begin{array}{l}\text { Collaborator is fluent in the same } \\
\text { language }\end{array}$ & \\
\hline R1 & Q12 & $\begin{array}{l}\text { Collaborate to mentor and help a } \\
\text { junior colleague or graduate } \\
\text { student }\end{array}$ & \\
\hline R1 & Q13 & $\begin{array}{l}\text { Motivation most important to } \\
\text { scholar for specified article }\end{array}$ & \\
\hline
\end{tabular}

Table continued on next page 


\begin{tabular}{|c|c|c|c|}
\hline R2 & Q14 & University offers funding for travel & $\begin{array}{l}\text { Institutional } \\
\text { Dimensions - } \\
\text { University or } \\
\text { Department }\end{array}$ \\
\hline R2 & Q15 & $\begin{array}{l}\text { University offers funding/grants } \\
\text { for international collaboration } \\
\text { (other than funding for travel) }\end{array}$ & \\
\hline R2 & Q16 & $\begin{array}{l}\text { University offers sabbatical or } \\
\text { release time to support } \\
\text { participation in international } \\
\text { collaborations }\end{array}$ & \\
\hline R2 & Q17 & $\begin{array}{l}\text { University offers seminars or } \\
\text { networking sessions about } \\
\text { international collaboration }\end{array}$ & \\
\hline R3 & Q18 & $\begin{array}{l}\text { University stipulates participation } \\
\text { in international collaborative } \\
\text { projects for tenure and promotion }\end{array}$ & \\
\hline R3 & Q19 & $\begin{array}{l}\text { University encourages international } \\
\text { collaboration but does not require }\end{array}$ & \\
\hline R3 & Q20 & $\begin{array}{l}\text { Internationally co-authored articles } \\
\text { count more towards tenure and } \\
\text { promotion }\end{array}$ & \\
\hline $\mathrm{R} 4$ & Q21 & Year earned PhD & $\begin{array}{l}\text { Personal and } \\
\text { Demographic } \\
\text { Dimensions }\end{array}$ \\
\hline R4 & Q22 & $\begin{array}{l}\text { Tenure Level - Assistant, } \\
\text { Associate, Full, Other }\end{array}$ & \\
\hline R4 & Q23 & Gender & \\
\hline R4 & Q24 & Native Language & \\
\hline R4 & Q25 & Earned PhD in which country & \\
\hline R4 & Q26 & $\begin{array}{l}\text { Introduced to co-author during } \\
\text { PhD program }\end{array}$ & \\
\hline R4 & Q27 & $\begin{array}{l}\text { Co-authored multiple times with } \\
\text { collaborators }\end{array}$ & \\
\hline
\end{tabular}

Notes. R1 - What motivates social science scholars to collaborate on research projects with their international colleagues? R2 - What university resources are available to support social science scholars who participate in international collaborative research projects? R3 - What expectations and rewards do universities have in the tenure and promotion process for social science scholars that participate in international collaborative research projects? R4 - What patterns of participation in international collaborative projects emerge when analyzing across dimensions related to motivations, university support and expectations, demographics, career level, and experiential factors? 
International Collaboration Among Social Science Scholars

\section{Participants}

Participants in the study were social science scholars that participated in recent international collaborative research projects that resulted in co-authorship of at least one published peer reviewed article. Bibliographic analysis technique was used to identify collaborations between social science scholars who were working in different nations that resulted in a co-authored article. Furthermore, the co-authored articles had been published over the past five years in one of fifteen specific academic social science journals. The list consisted of five English language journals from three social science disciplines, management, sociology, and economics. (Appendix B: Academic Journals Social Science Scholars International Collaboration Research) The sampling frame yielded a list of participants that have multiple first languages, however the survey was administered in English, given that the selected journals were published in the English language.

The review of faculty research activities was accomplished by performing bibliographic analysis using the bibliographic database Web of Science. The analysis was done by sorting on the name of journal, country in which the author's university is located, and the publication date. The second stage of analysis was to sort the resulting list by co-authorship patterns in order to identify collaborations between social science scholars who were working in different nations.

The following is a detailed account of the bibliographic analysis technique that was applied to the Web of Science/Web of Knowledge database in order to generate the list of potential participants for this study. Fifteen titles from the Social Science refereed scholarly journals were selected based on their impact factor over the past five years. (Appendix B: Academic Journals Social Science Scholars International Collaboration Research) The group of 
International Collaboration Among Social Science Scholars

journals represented the five titles from the targeted subject disciplines of economics, sociology, and management.

The first step of the bibliographic process was to access the Web of Science/Web of Knowledge database and select the advanced search option. The process continued by limiting the search to the publication name option. The field tag that was assigned to the publication name in this database was "SO", therefore the search was started by entering, for example, $\mathrm{SO}=$ Academy of Management Review. The database generated a list of articles from the journal Academy of Management Review. The list included all articles from all of the years that were available in Web of Science/Knowledge. Based on the parameters of this study it was necessary to limit the search the past five years. The resulting list was all written pieces, (articles, editorials, book reviews) in the Academy of Management Review for the timeframe specified. As a next step, the researcher refined the search by limiting the "document type” to "articles". The search was completed by choosing the "refine further" option with "countries and territories” and clicking all of the countries except the United States. The resulting list was a group of articles that have authors from countries other than the United States however it did not exclude articles that have cross-national teams that included co-authors from the United States.

The final step was a manual review of each article in order to remove the articles that did not meet the parameters of this study. For example, an article that was written by two German scholars from two separate institutions in Germany. The team was international from the standpoint of the United States however the team of co-authors was not cross-national, given that they were in the same country. The focus of this study was on cross-national collaboration and co-authorship and thus the article with two German scholars was beyond the scope of this study. The average number of co-authors participating in collaborative teams in the social sciences is 
International Collaboration Among Social Science Scholars

two therefore articles that have more than five co-authors were not be considered for this study. The process was repeated for each journal within the study and results were combined into a consolidated spreadsheet in Excel. Each co-author was be invited to participate in the study. If a scholar had more than one journal article in the list, the most recent article was selected for the purposes of this study.

The search analysis of international co-authorship activities in the target journals identified 2510 scholars that met the criterion for inclusion in this study. A customized message that included a salutation with their last name, the title of the article that they co-authored, and the name of the journal was generated based on data from Web of Knowledge (Appendix C: Web of Knowledge Data Example With Conversion For Custom Message in Qualtrics). An invitation to participate in the survey was sent to the selected 2510 scholars by email (Appendix D: Participants Recruiting Message). Each invitation included a link that was embedded in the message for access to a unique survey. Each survey was customized to include a greeting containing the recipient's name. Further customization consisted of an embedded field with the recipient's article title and the journal in which it appeared presented multiple times in the body of the survey. The survey was designed to be taken on a computer or smart phone (Appendix E: Survey Version Computer View; Appendix F: Survey Version Smart Phone View Selected Pages). Two reminder messages were sent at five-day intervals during the survey period. There were 276 completed survey submissions over the two week period. However due to regression modeling restrictions, surveys containing two or more empty data fields were removed from the data set, which resulted in a data set with 252 observations. 
International Collaboration Among Social Science Scholars

\section{Participants Confidentiality and Rights}

The design of the study allowed for the confidentiality of the participants to be maintained. Participants were asked to describe information related to a specific collaborative project however the data was reported in aggregate format making it difficult to associate particular information to a specific person. The nature of the questions and requested responses were general description in order to minimize potential harm to existing relationships between co-authors. Faculty members had the option to withdraw from the study, which included the removal of their data, at any time. Data was and will continue to be kept confidential with only the principle investigator and one research staff member working with the raw data having access to the files. Identification of the faculty members was coded into a participants list that is maintained and only accessible to the principle investigator. All data is kept in a confidential file and then destroyed after the completion of the research project.

\section{Limitations}

A number of limitations are associated with this research project. One of the limitations of this research is the use of a survey instrument for the study. Using a survey instrument for this research provided an efficient process to gather data, however, the researcher realizes that the use of a survey instrument limits the opportunity to develop a more robust description of factors that motivate scholars to participate in international collaborative research projects. A qualitative or mixed methods approach to this research could potentially have yielded more descriptive results, however the researcher did not find the alternative approach feasible given of the size of the population studied. 
International Collaboration Among Social Science Scholars

Another limitation of this study is the short time frame associated with the execution of the survey. Data was scheduled to be collected over three week timeframe. Each of the target survey participants received an invitation to participate and two follow up messages. The use of e-mail to contact and follow up with respondents allows for an efficient use of a shorter time frame, however a longer time frame has the potential to allow for more respondents to participate and more data to be gathered.

The limitations of this study also include potential threats to internal validity. The first threat is related to the small sample size and corresponding characteristics of the sample. Social science faculty have a variety of work environments, unique information technology infrastructure, and diverse subject interests within their subject fields. A combination of these factors has the potential to lead to results that were inconclusive or non-representative. In order to mitigate this limitation the sample size that is proposed for this study is 2500 which corresponds to a margin of error of $2.5 \%$ at a confidence of $95 \%$ however the marginal response rate has the potential to limit the generalizability of the results.

The Hawthorne effect is an external validity threat to the study. Participants have the potential to respond differently to the survey questions because they knew that they were being studied. The survey format will collect self- reported information that may not reflect the reality of their communication patterns in collaborative research activities. The Hawthorne effect has the potential to jeopardize the validity of the research because the results may not be generalizable to other social science faculty experiences with international collaborative research and co-authorship project experiences. 
International Collaboration Among Social Science Scholars

The literature emphasizes the need to gain insight into research collaboration in the social sciences however the choice to focus solely on the social sciences limits the generalizability of the research to one group of subject disciplines. This is considered a limitation given that collaborations take place in many other disciplines.

The choice to use co-authorship as a measurement of collaboration is another issue related to validity. Although co-authorship is currently an accepted standard for measuring scholarly collaboration, it is not considered a pure measurement. Scholarly collaboration does not always lead to co-authored papers. Collaboration can lead to other outcomes such as a deeper relationship with a collaborator, the opportunity for in-depth discussion with other scholars, the development of new teaching techniques, or the development of a conference presentation. In addition there are many ways in addition to co-authorship that scholars collaborate. Scholars may also collaborate to develop new curriculum, co-develop conference presentations, or collaborate by serving on a committee that directs professional association activities such as an editorial board.

Given that the participants are selected from a number of universities, and the principle investigator is a member of a university’s leadership team, the investigator is not a totally neutral party. Nevertheless, to control for this external validity issues the principle investigator handled all communication and attempted to create consistent and non-judgmental survey environment for all participants (Creswell, 2008, p. 396).

This study was designed to gather data about social science scholars from a number of nations. The survey was administered in English. This could be considered a deficiency given that English may not be the first language for many respondents. However, this researcher 
International Collaboration Among Social Science Scholars

justified the use of the English language for the survey given that all respondents were coauthors of articles that were published in English language scholarly journals.

The introduction of bias into the study related to the concept of the researcher as instrument is an additional threat to validity. The principle investigator, who is a university business librarian, developed and conducted the survey. There are inherent biases that are based in the researcher's background and life experiences. "The researcher is the key person in obtaining data from respondents. It is through the researcher's facilitative interaction that a context is created that encourages respondents share rich data regarding their experiences” (Poggenpoel \& Myburgh, 2003, p. 52). The researcher facilitated the flow of communication through the way the survey questions was worded, organized, and developed. The creation and adherence to survey procedure had the potential to mitigate this threat. The procedure included the consistent provision of instructions that were thorough and consistent in each section of the survey (Creswell, 2008, p.396). In order to minimize the internal threat to validity, the principle investigator followed a structured procedure for administering the survey and interacting with research participants.

Some additional limitations are related to the methodology chosen for this research. The sample group for this research consisted of 2500 scholars that had co-authored with their international colleagues in a select group of social science of journals. Bearing in mind the total number of social science scholars in the world, the sample size featured in this research design is comparatively small. A second limitation was that this research focused on three social science disciplines. There are several hundred social science disciplines and therefore the results may not be generalizable to all social sciences disciplines. 
The sampling design included five academic journals in three subject disciplines which limited the sample design to fifteen total journals. This could be considered a limitation given there are hundreds of academic journals in each discipline. Furthermore, the journals were selected based on their five year impact factor ranking in the Web of Science database. Based on the selection using the impact factor metric, the journals are considered to be the elite journals in each subject field. This selection criterion has the potential to result in outcomes that are not generalizable to the subject field. Limiting the survey participants to international co-authors that have published in a small number of academic journals was a weakness in this sample design. 


\section{Chapter Four: Research Results}

There were five dimensions of inquiry associated with this study on international collaboration and co-authorship. The first dimension of inquiry was related to the development of an explanatory model using multiple regression analysis. The remaining four dimensions were related to the research questions associated with this study. Discussion of the findings of this research are organized in relation to the five dimensions of inquiry. The initial section is related to the development of an explanatory model based on multiple regression analysis. A baseline model and feature selection model were developed for this research. This chapter will include a discussion of the findings from the development of the models, a comparative analysis of the models, and a discussion of improvements that are associated with the more parsimonious model. The final research dimensions of inquiry presented in this chapter focus on the research findings related to motivations for participation in an international collaboration, institutional support and rewards that are associated with participation, and the patterns of participation that emerge from demographic characteristics and the personal experience of respondents based on their experience participating in a specific international collaborative project.

Appendix A of this work includes information about the mapping of research questions to survey questions as well as the independent variables and wording of the survey questions. 
International Collaboration Among Social Science Scholars

\section{Results from Multiple Regression Analysis}

The first dimension of this research incorporated multiple linear regression as a statistical modeling technique with the focus of generating an explanatory model. This researcher used Microsoft R Open v3.2.3 for data manipulation and statistical analysis. A goal for this research was to investigate the possible relationships or associations between a dependent variable and a set of independent variables, determine the relative importance of the full set of independent variables, and determine the relative importance of an independent variable set reduced by feature selection. An ordinary least squares regression was performed which produced a standard weighted linear combination of the form:

$$
D V=\text { Intercept }+\beta_{1} X_{1}+\beta_{2} X_{2}+\beta_{3} X_{3}+\beta_{4} X_{4}+\cdots \beta_{n} X_{n}
$$

The 252 completed surveys, thus the experimental observations, supported the creation of a multiple linear regression model that contains 24 independent variables, and one dependent variable. The dependent variable was modeled as a continuous variable to meet regression modeling assumptions. The dependent variable was calculated as a ratio of the reported number of peer review journal articles that have been co-authored with their international colleague(s) in the past ten years divided by the reported total number of peer review journal articles that they had published in the past ten years. The independent variables were measured on an ordinal and categorical scale. 


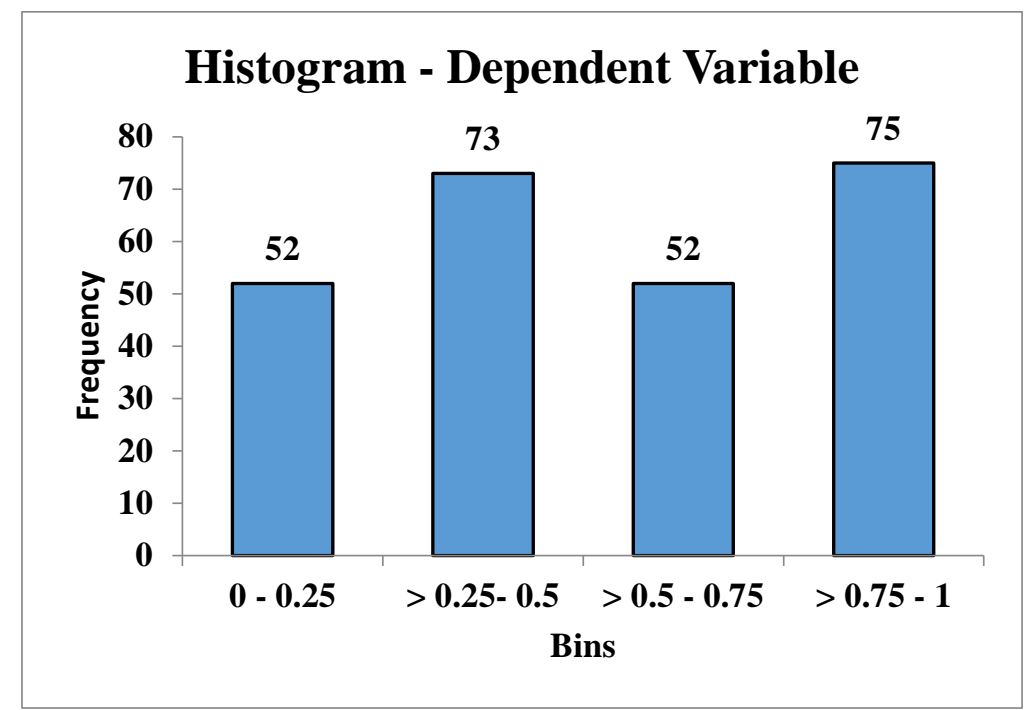

An analysis of the data set confirmed that the standard data set size requirement was achieved. The ratio of observations to independent variables requirement was assessed by two methods. The first method requires the number of observations to be greater than or equal to 50 $+8 *$ (number of independent variables), which equates to at least 250 observations required for a full model ANOVA $F$ test. The second method requires the number of observations to be greater than or equal to 104 + number of individual independent variable, which equates to 128 observations needed to perform individual $t$ test of the independent variables. Thus the current data set size of 252 observations pass both tests (Tabachnick \& Fidell, 2000).

\section{Multiple Regression Modeling Discussion}

\section{Baseline Model}

Initially, a baseline regression model was developed which contained twenty-four of the twenty-seven independent variables. There were three variables that were omitted from the baseline model development due to the lack of a meaningful scale associated with the results of the survey questions. The omitted data were associated with: 1) Survey question 13 which asked 
International Collaboration Among Social Science Scholars

respondents to indicate which of the motivations from survey question one through twelve was the most important motivation for their co-authoring on an article; 2) Survey question 21 that asked the year they earned their PhD; 3) Survey question 25 asked the country that the institution is located in that awarded their $\mathrm{PhD}$. Subsequently five standard regression assessment tests were performed on the data associated with the remaining twenty-four variables. These tests were used for the following purposes: 1 ) calculate and assess the adjusted $\mathrm{R}^{2}$ metric; 2) calculate and assess the analysis of variance $F$ test; 3 ) calculate and assess individual $t$ test for each independent variable; 4) calculate the variance inflation factor for each independent variable to assess multicollinearity; and 5) calculate, access, rank the relative explanatory importance of each independent variable. Each test is discussed in detail in the following section.

Step one of the baseline regression model assessment was to calculate the adjusted $\mathrm{R}^{2}$ metric, which measures the amount of variability in the dependent variable that can be explained by changes in a set of independent variables. The metric measures what is also commonly known as goodness of fit. The baseline model was found to have an adjusted $\mathrm{R}^{2}$ of .2325. This measure was interpreted as a medium goodness of fit.

Step two of the baseline regression model assessment was to calculate an $F$ test statistic. The $F$ test statistic is a hypothesis test to determine whether the slope coefficients of independent variables are all equal to zero.

The null hypothesis is stated as: $H_{0}: \beta_{1}=\beta_{2}=\beta_{3} \ldots \beta_{k}=0$ The alternative hypothesis which indicates that at least one slope coefficient is not equal to zero is stated as: $H_{1}:$ Not all $\beta_{k}=0$

The $F$ test, also known as the overall model test, determines whether there is a linear relationship between the model coefficients and the dependent variable. The $F$ test for the 
baseline model is 4.169 , with a $p$ value of 0.000000004948 which indicates that the full model, when all independent variables are simultaneously modeled, is highly statistically significant. A $p$ value below the given significance level of .05 allows the researcher to reject the null hypotheses and concluded that at least one of the independent variables has a non-zero slope. Step three of the baseline regression model assessment is to calculate the $t$ test and $p$ value for each independent variable.

The $t$ test is a hypothesis test to determine whether the slope of the specific independent variable is equal to zero and is stated by the null hypothesis: $H_{0}: \beta_{k}=0$ The alternative hypothesis indicates that the variable coefficient is not equal to zero: $H_{1}: \beta_{k} \neq 0$ The test determines whether a specific independent variable is related to the dependent variable above and beyond other independent variables regression in the model. Table 3 lists the independent variable name, estimated coefficient, $t$ test value, and $p$ value for each $t$. 
International Collaboration Among Social Science Scholars

Table 3

Coefficients and $t$ Tests

\begin{tabular}{|c|c|c|c|c|c|}
\hline & Estimate & Std. Error $t$ & $t$ value & $\operatorname{Pr}(>|t|)$ & \\
\hline (Intercept) & ๑. 0939192 & 0.1851654 & 0.507 & 0.61249 & \\
\hline Q1 & $-\odot .0317705$ & 0.0224892 & -1.413 & ๑. 15911 & \\
\hline Q2 & ๑. . ๑๑९)171 & $\odot .0315720$ & $\odot .026$ & $\odot .97937$ & \\
\hline Q3 & 0.0612128 & $\odot .0269751$ & 2.269 & $\odot .02419$ & * \\
\hline Q4 & 0.0334960 & 0.0258761 & 1.294 & $\odot .19682$ & \\
\hline Q5 & $-\odot .04 \odot \odot 245$ & $\odot .0176071$ & -2.273 & $\odot .02395$ & * \\
\hline Q6 & ๑. . 0529274 & $\odot .0309798$ & 1.708 & ๑. . 08892 & \\
\hline Q7 & $-\odot .0 \odot 95348$ & $\odot .0226568$ & -0.421 & 0.67427 & \\
\hline Q8 & ๑. . 0590284 & 0.0201393 & 2.931 & $\odot .00372$ & $* *$ \\
\hline Q9 & -0.0036883 & 0.0337463 & -0.109 & 0.91307 & \\
\hline Q10 & -0.0053703 & $\odot .0204449$ & -0.263 & 0.79304 & \\
\hline Q11 & -0.0052413 & ๑. 0182817 & -0.287 & 0.77461 & \\
\hline Q12 & ๑. . 0196141 & 0.0167751 & 1.169 & ๑. 24353 & \\
\hline Q14 & 0.0280136 & 0.0262657 & 1.067 & ๑. 28731 & \\
\hline Q15 & ๑. 0169885 & $\odot .0270408$ & 0.628 & $\odot .53047$ & \\
\hline Q16 & -0.0445804 & $\odot .0254292$ & -1.753 & ๑. . 8093 & . \\
\hline Q17 & ๑. . 4455122 & $\odot .0229647$ & 1.982 & $\odot .0487 \odot$ & * \\
\hline Q18 & 0.1722308 & $\odot .0759009$ & 2.269 & $\odot .02420$ & * \\
\hline Q19 & 0.0291510 & ๑. 0384298 & $\odot .759$ & ๑. 44891 & \\
\hline Q20 & ๑. 0559539 & $\odot .0717976$ & 0.779 & 0.43660 & \\
\hline Q22 & $-\odot .0121089$ & 0.0238051 & -0.509 & 0.61148 & \\
\hline Q23 & ๑. 0182924 & 0.0341276 & 0.536 & 0.59248 & \\
\hline Q24 & -0.1554799 & 0.0369556 & -4.207 & $\odot .0 \odot \odot \odot \odot$ & $* *$ \\
\hline Q26 & ๑. 0233313 & 0.0374436 & $\odot .623$ & $\odot .53384$ & \\
\hline Q27 & $-\odot .0 \odot 51740$ & 0.0524665 & $-\odot .099$ & ๑. 92153 & \\
\hline \multicolumn{6}{|l|}{--} \\
\hline Significa & . & ** 0.01 & $* 0 . c$ & .0 .1 & \\
\hline
\end{tabular}

Based on a significance level of 0.05 , the model contains six statistically significant independent variables as presented in Table 4: Statistical Results from Baseline Regression Model Development. The statistically significant independent variables of the baseline model make intuitive sense and support previous research and literature related to co-authorship. The variables that were found to be statistically significant by this baseline model are discussed in detail in the later comparative section. 
During the exploratory modeling phase, it is common to find non-statistically significant independent variables. With this baseline model, only six variables out of twenty-four were found to be statistically significant and therefore eighteen of the independent variables were not statistically significant. According to the results of these tests of the baseline model it was determined that a majority of the independent variables offer limited explanatory value. This finding provides the justification to develop an additional model using feature selection with the goal of developing a more parsimonious model.

Table 4

Statistical Results from Baseline Regression Model Development

\begin{tabular}{|c|c|c|c|c|}
\hline & $\begin{array}{l}\text { Independent Variable } \\
\text { Full Name }\end{array}$ & $\begin{array}{l}\text { Estimated } \\
\text { Coefficient }\end{array}$ & $\mathrm{t}$ test & P Value \\
\hline $\mathrm{B}_{0}$ & & 0.09392 & 0.50700 & 0.61249 \\
\hline Q1 & $\begin{array}{l}\text { Collaborator has a } \\
\text { strong reputation }\end{array}$ & -0.03177 & -1.41300 & 0.15911 \\
\hline Q2 & $\begin{array}{l}\text { Collaborate to improve } \\
\text { access to department } \\
\text { /university funds }\end{array}$ & 0.00082 & 0.02600 & 0.97937 \\
\hline Q3 & $\begin{array}{l}\text { Collaborate to improve } \\
\text { access to external funds }\end{array}$ & 0.06121 & 2.26900 & 0.02419 \\
\hline Q4 & $\begin{array}{l}\text { Collaborator has } \\
\text { expertise other than my } \\
\text { own }\end{array}$ & 0.03350 & 1.29400 & 0.19682 \\
\hline Q5 & $\begin{array}{l}\text { Collaborator has special } \\
\text { data or equipment }\end{array}$ & -0.04002 & -2.27300 & 0.02395 \\
\hline Q6 & $\begin{array}{l}\text { Collaborate to pool } \\
\text { expertise and take on } \\
\text { complex research } \\
\text { problems }\end{array}$ & 0.05293 & 1.70800 & 0.08892 \\
\hline Q7 & $\begin{array}{l}\text { Collaborate to gain peer } \\
\text { recognition and } \\
\text { visibility }\end{array}$ & -0.00953 & -0.42100 & 0.67427 \\
\hline
\end{tabular}


International Collaboration Among Social Science Scholars

\begin{tabular}{|c|c|c|c|c|}
\hline Q8 & $\begin{array}{l}\text { Collaborate again based } \\
\text { on previous project } \\
\text { success }\end{array}$ & 0.05903 & 2.93100 & 0.00372 \\
\hline Q9 & $\begin{array}{l}\text { Collaborator is fun and } \\
\text { pleasant to work with }\end{array}$ & -0.00369 & -0.10900 & 0.91307 \\
\hline Q10 & $\begin{array}{l}\text { Opportunity to publish } \\
\text { with international } \\
\text { colleagues }\end{array}$ & -0.00537 & -0.26300 & 0.79304 \\
\hline Q11 & $\begin{array}{l}\text { Collaborator is fluent in } \\
\text { the same language }\end{array}$ & -0.00524 & -0.28700 & 0.77461 \\
\hline Q12 & $\begin{array}{l}\text { Collaborate to mentor } \\
\text { and help a junior } \\
\text { colleague or graduate } \\
\text { student }\end{array}$ & 0.01961 & 1.16900 & 0.24353 \\
\hline Q14 & $\begin{array}{l}\text { University offers } \\
\text { funding for travel } \\
\text { related to international } \\
\text { collaboration }\end{array}$ & 0.02801 & 1.06700 & 0.28731 \\
\hline Q15 & $\begin{array}{l}\text { University offers } \\
\text { funding or grants for } \\
\text { international } \\
\text { collaboration (other } \\
\text { than funding for travel) }\end{array}$ & 0.01699 & 0.62800 & 0.53047 \\
\hline Q16 & $\begin{array}{l}\text { University offers } \\
\text { sabbatical or release } \\
\text { time to support } \\
\text { participation in } \\
\text { international } \\
\text { collaborations }\end{array}$ & -0.04458 & -1.75300 & 0.08093 \\
\hline Q17 & $\begin{array}{l}\text { University offers } \\
\text { seminars or networking } \\
\text { sessions about } \\
\text { international } \\
\text { collaboration }\end{array}$ & 0.04551 & 1.98200 & 0.04870 \\
\hline Q18 & $\begin{array}{l}\text { University stipulates } \\
\text { participation in } \\
\text { international } \\
\text { collaborative projects }\end{array}$ & 0.17223 & 2.26900 & 0.02420 \\
\hline
\end{tabular}


International Collaboration Among Social Science Scholars

\begin{tabular}{|c|c|c|c|c|c|}
\hline & $\begin{array}{l}\text { for tenure and } \\
\text { promotion }\end{array}$ & & & & \\
\hline Q19 & $\begin{array}{l}\text { University encourages } \\
\text { international } \\
\text { collaboration but does } \\
\text { not require }\end{array}$ & 0.02915 & 0.75900 & 0.44891 & \\
\hline Q20 & $\begin{array}{l}\text { Internationally co- } \\
\text { authored articles count } \\
\text { more towards tenure } \\
\text { and promotion }\end{array}$ & 0.05595 & 0.77900 & 0.43660 & \\
\hline Q22 & $\begin{array}{l}\text { Tenure Level - } \\
\text { Assistant, Associate, } \\
\text { Full, Other }\end{array}$ & -0.01211 & -0.50900 & 0.61148 & \\
\hline Q23 & Gender & 0.01829 & 0.53600 & 0.59248 & \\
\hline Q24 & $\begin{array}{l}\text { Native Language - } \\
\text { English and other than } \\
\text { English }\end{array}$ & -0.15548 & -4.20700 & $<0.0000005$ & $* * *$ \\
\hline Q26 & $\begin{array}{l}\text { Introduced to co-author } \\
\text { during PhD program }\end{array}$ & 0.02333 & 0.62300 & 0.53384 & \\
\hline Q27 & $\begin{array}{l}\text { Co-authored multiple } \\
\text { times with } \\
\text { collaborator(s) }\end{array}$ & -0.00517 & -0.09900 & 0.92153 & \\
\hline Signi & се: $* * * 0.001 \quad * * 0.01$ & $0.05 \quad .0 .1$ & & & \\
\hline Resic & tandard Error: 0.2554 & & & & \\
\hline Mult & $0.3059 \mathrm{Adj}$ & sted R-squa & d: 0.2325 & & \\
\hline F-sta & 4.169 p-value: $c$ & 00000004 & & & \\
\hline
\end{tabular}

Step four of the baseline regression model assessment is to calculate the variance inflation factor (VIF) for each independent variable to assess multicollinearity. High correlation between independent variables has the potential to cause numerous and problematic issues such as unintuitive coefficients. The VIF calculations for all independent variable the baseline model are within guidelines based on the scale below: 
International Collaboration Among Social Science Scholars

$$
\begin{array}{ll}
\text { VIF } & \text { Status of predictors } \\
\text { VIF }=1 & \text { Not correlated } \\
1<\text { VIF }<5 & \text { Moderately correlated } \\
5<\text { VIF }<10 & \text { Highly correlated } \\
\text { VIF }>10 & \text { Remove variable }
\end{array}
$$

Table 5

Variance Inflation Factors

\begin{tabular}{|c|c|c|c|c|c|c|c|}
\hline $\mathbf{Q 1}$ & $\mathbf{Q 2}$ & $\mathbf{Q 3}$ & $\mathbf{Q 4}$ & $\mathbf{Q 5}$ & $\mathbf{Q 6}$ & $\mathbf{Q 7}$ & $\mathbf{Q 8}$ \\
\hline 1.578773 & 2.334392 & 2.418618 & 1.40342 & 1.420999 & 1.433948 & 1.960099 & 1.678443 \\
\hline & & & & & & & \\
\hline $\mathbf{Q 9}$ & $\mathbf{Q 1 0}$ & $\mathbf{Q 1 1}$ & $\mathbf{Q 1 2}$ & $\mathbf{Q 1 4}$ & $\mathbf{Q 1 5}$ & $\mathbf{Q 1 6}$ & $\mathbf{Q 1 7}$ \\
\hline 1.387138 & 1.692933 & 1.246415 & 1.443583 & 1.828201 & 1.701549 & 1.374445 & 1.586 \\
\hline & & & & & & & \\
\hline $\mathbf{Q 1 8}$ & $\mathbf{Q 1 9}$ & $\mathbf{Q 2 0}$ & $\mathbf{Q 2 2}$ & $\mathbf{Q 2 3}$ & $\mathbf{Q 2 4}$ & $\mathbf{Q I D 2 6}$ & $\mathbf{Q 2 7}$ \\
\hline 1.2463 & 1.268274 & 1.184514 & 1.380051 & 1.143091 & 1.318115 & $\mathbf{1 . 3 2 3 7 1 6}$ & 1.420523 \\
\hline
\end{tabular}

Standard practice supports the use of this scale to assess the VIF metric. In this study there are a large number of independent variables in the regression model, therefore there is a higher probability of multicollinearity issues.

The last step of the baseline regression model assessment is to rank the relative explanatory importance of each independent variable. There are several methods available for ranking independent relative importance for linear regression models. This research used the LMP metric, available in the R RELAIMPO package. This metric decomposes the variance measured by adjusted $\mathrm{R}^{2}$ and assigns relative percentages to each independent variable. The ranking method, while similar to ranking $p$ values it is represented as a percentage and makes comparison easier. 
Table 6

\section{Relative Variable Importance}

\begin{tabular}{|l|l|}
\hline \multicolumn{1}{|c|}{ IV } & LMG \\
\hline Q24 & 0.27000 \\
\hline Q8 & 0.10665 \\
\hline Q18 & 0.10198 \\
\hline Q17 & 0.09365 \\
\hline Q3 & 0.06715 \\
\hline Q14 & 0.05379 \\
\hline Q2 & 0.04292 \\
\hline Q5 & 0.03889 \\
\hline Q6 & 0.03568 \\
\hline Q15 & 0.02854 \\
\hline Q20 & 0.02822 \\
\hline Q19 & 0.01871 \\
\hline Q1 & 0.01765 \\
\hline Q26 & 0.01647 \\
\hline Q9 & 0.01553 \\
\hline Q16 & 0.01514 \\
\hline Q27 & 0.01386 \\
\hline Q4 & 0.01031 \\
\hline Q12 & 0.00687 \\
\hline Q22 & 0.00555 \\
\hline Q10 & 0.00424 \\
\hline Q7 & 0.00421 \\
\hline Q23 & 0.00201 \\
\hline Q11 & 0.00199 \\
\hline & \\
\hline
\end{tabular}

The ranking in effect is very similar to $p$ value ranking, but adds the insight that the first eight independent variables explain $80 \%$ of the adjusted $\mathrm{R}^{2}$ assessment as illustrated in Table 6 Relative Variable Importance and in the following graphic representation of Relative Variable Importance. This observation supports the need to build a more explanatory model by using variable selection. 


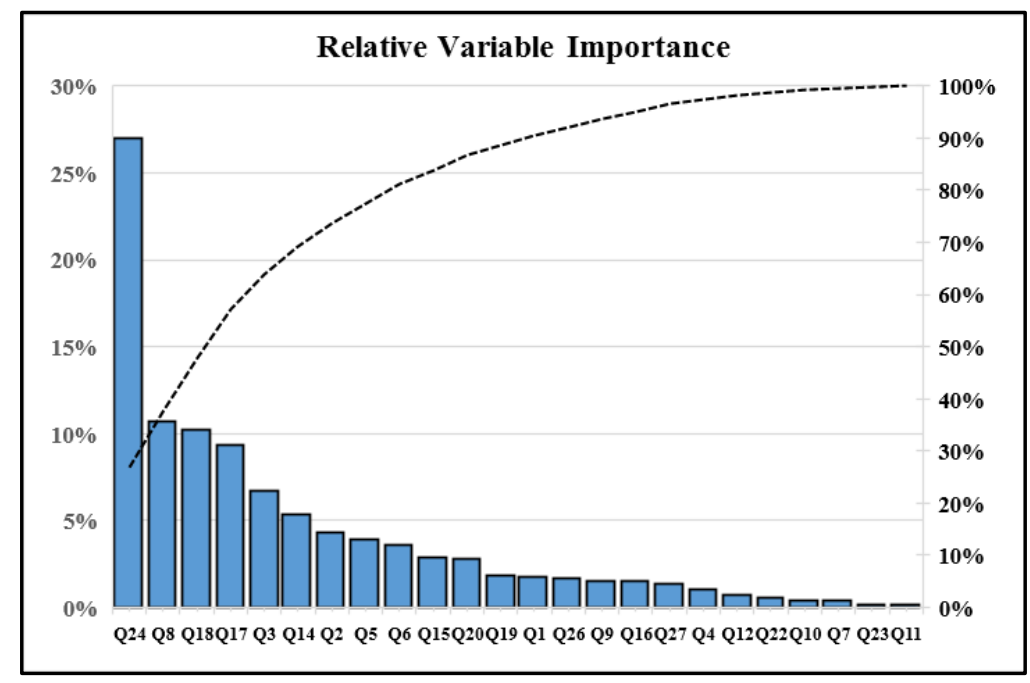

\section{Feature Selection Model}

The baseline model had a substantial number of independent variables that were found to not be statistically significant. The general goal of multiple regression is to make the most parsimonious model with the highest adjusted $\mathrm{R}^{2}$. Given the extensive set of independent variables that were contained in the baseline explanatory model, feature selection was subsequently applied to develop a more parsimonious model. The process started with the initial set of independent variables, less the three variables discussed earlier. The first step involved identifying the variable that is least statistically significant, that is, the one with the largest p value. It was subsequently removed and the model was refitted. This process continued a sequential fashion as independent variables with the largest $p$ value were removed one at a time until the regression model with the highest adjust $\mathrm{R}^{2}$ was achieved. Next, the same five model assessments, as discussed previously, were performed on the feature selection.

For purposes of clarity in the description of the research model, the details of the process are reiterated. This process consisted of completing the five regression model tests as follows: 1 ) calculate and assess the adjusted $\mathrm{R}^{2}$ metric; 2) calculate and assess the analysis of variance $F$ test; 3 ) calculate and assess individual $t$ test for each independent variable; 4) calculate the 
variance inflation factor for each independent variable to assess multicollinearity; and 5) calculate and assess and rank the relative explanatory importance of each remaining independent variable. The result was a model with fewer independent variables than the original baseline model.

After a backward elimination process was completed and fourteen independent variables were removed, the first model test consisted of the calculation and assessment of the adjusted $\mathrm{R}^{2}$ metric. The test determined that the resulting adjusted $\mathrm{R}^{2}$ had increased to 0.2584 as compared to the adjusted $\mathrm{R}^{2}$ from the baseline model. The second test was the calculation and assessment of the analysis of variance $\mathrm{F}$ test. The $F$ test of 9.744 with a $p$ value of essentially zero showed some full model improvement when compared to the baseline model. The third test consisted of the calculation and assessment of individual $t$ tests and $p$ values for each independent variable. This test determines whether an independent variable is related to the dependent variable above and beyond other independent variables in the model. The results from the parsimonious feature selection model, including the individual $t$ tests and $p$ values, are shown in Table 7. 
International Collaboration Among Social Science Scholars

Table 7 : Results from the Parsimonious Feature Selection Regression Model

\begin{tabular}{|c|c|c|c|c|}
\hline & $\begin{array}{l}\text { Estimated } \\
\text { Coefficient }\end{array}$ & $\mathrm{t}$ Test & P Value & \\
\hline (Intercept) & 0.21031 & 1.731 & 0.084793 & . \\
\hline $\begin{array}{l}\text { Q1 Collaborator has a strong } \\
\text { reputation }\end{array}$ & -0.03536 & -1.863 & 0.063697 & . \\
\hline $\begin{array}{l}\text { Q3 Collaborate to improve } \\
\text { access to external funds }\end{array}$ & 0.06053 & 3.196 & 0.001581 & $* *$ \\
\hline $\begin{array}{l}\text { Q5 Collaborator has special } \\
\text { data/equipment }\end{array}$ & -0.03579 & -2.185 & 0.029887 & $*$ \\
\hline $\begin{array}{l}\text { Q6 Collaborate to pool } \\
\text { expertise to take on complex } \\
\text { research problems }\end{array}$ & 0.06278 & 2.257 & 0.024911 & * \\
\hline $\begin{array}{l}\text { Q8 Collaborate again based on } \\
\text { previous project success }\end{array}$ & 0.05411 & 3.395 & 0.000803 & $* * *$ \\
\hline $\begin{array}{l}\text { Q14 University offers funding } \\
\text { for travel related to } \\
\text { international collaboration }\end{array}$ & 0.03483 & 1.552 & 0.121967 & \\
\hline $\begin{array}{l}\text { Q16 University offers } \\
\text { sabbatical or release time to } \\
\text { support participation in } \\
\text { international collaborations }\end{array}$ & -0.04367 & -1.808 & 0.071775 & . \\
\hline $\begin{array}{l}\text { Q17 University offers seminars } \\
\text { or networking sessions about } \\
\text { international collaboration }\end{array}$ & 0.04997 & 2.383 & 0.017959 & $*$ \\
\hline $\begin{array}{l}\text { Q18 University stipulates } \\
\text { participation in international } \\
\text { collaborative projects for tenure } \\
\text { and promotion }\end{array}$ & 0.16892 & 2.433 & 0.015699 & $*$ \\
\hline $\begin{array}{l}\text { Q24 Native language : English } \\
\text { and other than English }\end{array}$ & -0.15615 & -4.611 & 0.000007 & $* * *$ \\
\hline \multicolumn{5}{|c|}{$\begin{array}{l}\text { Significance: } * * * 0.001 * * 0.01 * 0.05 .0 .1 \text { Residual standard error: } 0.251 \\
\text { Multiple R-squared: } \quad 0.2879 \text { Adjusted R-squared: } 0.2584\end{array}$} \\
\hline F-statistic: $\quad 9.744$ p-value & 0.00 & 000 & & \\
\hline
\end{tabular}

The final feature selection model produced seven statistically significant independent variables below the 0.05 level, two independent variables below the 0.10 level as well as one independent variable that ranked high in the relative importance calculation. Table 7. Based on this outcome the feature selection model is considered to be a more explanatory model. An examination of the two models used in this research found that the variable associated with 
International Collaboration Among Social Science Scholars

survey question 6, representing the pooling of expertise to take on complex research problems, was added to the feature selection model. Variables found to be statistically significant by the model developed using feature selection are discussed in more detail later. The concluding segment of this section includes a comparative analysis of the baseline model and the final feature selection model as well as a discussion of the associated improvements with the final model.

\section{Variance Inflation Factor}

The next step was to calculate the variance inflation factor, VIF, for each independent variable in order to assess multicollinearity. Guidelines for assessing VIF are that a value between one and five are considered to be moderately correlated and values between five and ten are considered to the highly correlated. The VIF calculations were all between one and five which is considered to be moderately correlated and therefore within the accepted range. VIF values for the final feature selection model are shown in Table 8.

Table 8

Variance Inflation Factor Analysis

\begin{tabular}{ccccc}
\hline Q1 & Q3 & Q5 & Q6 & Q8 \\
1.163805 & 1.234012 & 1.273154 & 1.196344 & 1.088138 \\
Q14 & Q16 & Q17 & Q18 & Q24 \\
1.381017 & 1.28271 & 1.36891 & 1.079117 & 1.145574 \\
\hline
\end{tabular}

\section{Relative Variable Importance}

The last step of the feature selection regression model assessment is to rank the relative explanatory importance of each independent variable. The feature selection produced a more 
International Collaboration Among Social Science Scholars

concise model while increasing goodness of fit. Table 9 illustrates the relative variable importance rankings.

Table 9

Relative Variable Importance

\begin{tabular}{lc}
\hline \multicolumn{1}{c}{ Independent Variable } & LMG \\
\hline Q24 Native language: English and other than English & 0.319075 \\
Q8 Collaborate again based on previous project success & 0.13514468 \\
$\begin{array}{l}\text { Q17 University offers seminars or networking sessions } \\
\text { about international collaboration }\end{array}$ & 0.12335841 \\
$\begin{array}{l}\text { Q18 University stipulates participation in international } \\
\text { collaborative projects for tenure and promotion }\end{array}$ & 0.11489071 \\
$\begin{array}{l}\text { Q3 Collaborate to improve access to external funds } \\
\text { Q14 University offers funding for travel related to }\end{array}$ & 0.11161832 \\
international collaboration & 0.07744209 \\
$\begin{array}{l}\text { Q6 Collaborate to pool expertise and take on complex } \\
\text { research problems }\end{array}$ & 0.04936119 \\
$\begin{array}{l}\text { Q5 Collaborator has special data or equipment } \\
\text { Q1 Collaborator has a strong reputation }\end{array}$ & 0.03515733 \\
\hline
\end{tabular}

The feature selection model showed relative importance was spread out more evenly among the remaining independent variables. This conclusion is represented in the following graphic representation of the Relative Variable Importance. 


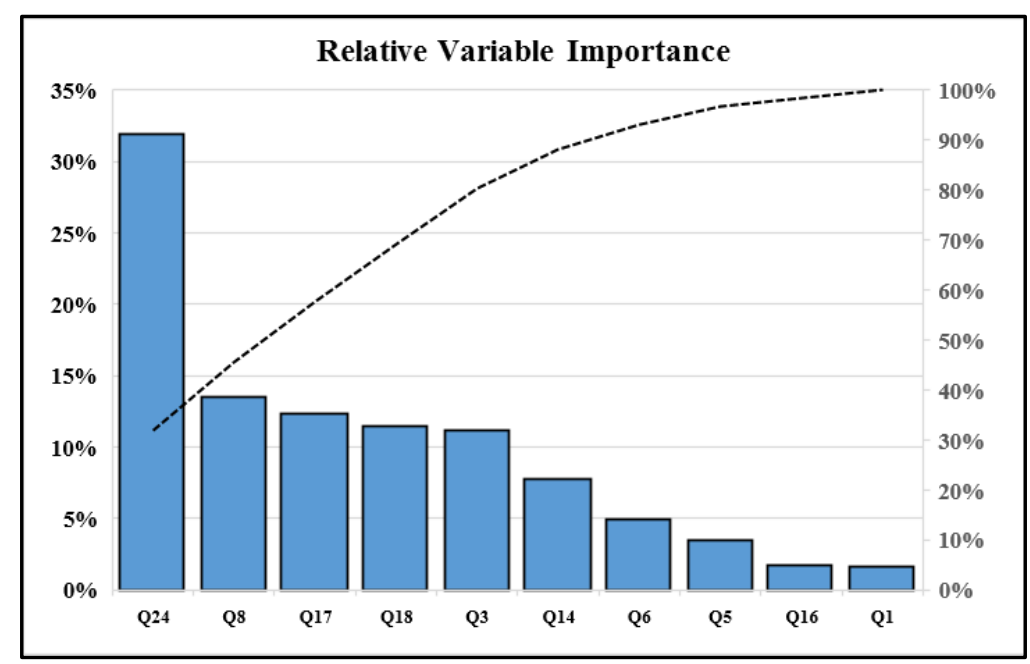

\section{Comparative Analysis of the Baseline Model and Final Feature Selection Model}

The comparative analysis of the two models and discussion of the associated improvements with the final feature selection model are presented this section. Variables that were found to be statistically significant by the baseline model as well as the final model using feature selection are presented in Table 10: Comparative Results from the Baseline Regression Model and the Final Parsimonious Feature Selection Regression Model. 
Table 10

Baseline Regression Model vs. Final Feature Selection Regression Model

\begin{tabular}{|c|c|c|c|c|}
\hline & $\begin{array}{l}\text { P Value } \\
\text { Baseline } \\
\text { Model }\end{array}$ & & $\begin{array}{l}\text { P Value } \\
\text { Feature } \\
\text { Selection } \\
\text { Model }\end{array}$ & \\
\hline $\begin{array}{l}\text { Q3 Collaborate to } \\
\text { improve access to } \\
\text { external funds }\end{array}$ & 0.02419 & $*$ & 0.001581 & $* *$ \\
\hline $\begin{array}{l}\text { Q5 Collaborator has } \\
\text { special data or } \\
\text { equipment }\end{array}$ & 0.02395 & * & 0.029887 & $*$ \\
\hline $\begin{array}{l}\text { Q6 Collaborate to pool } \\
\text { expertise and take on } \\
\text { complex research } \\
\text { problems }\end{array}$ & $\begin{array}{r}\mathrm{P} \text { value not } \\
\text { statistically } \\
\text { significant } \\
0.08892\end{array}$ & & 0.024911 & $*$ \\
\hline $\begin{array}{l}\text { Q8 Collaborate again } \\
\text { based on previous } \\
\text { project success }\end{array}$ & 0.00372 & $* *$ & 0.000803 & $* * *$ \\
\hline $\begin{array}{l}\text { Q17 University offers } \\
\text { seminars or networking } \\
\text { sessions about } \\
\text { international } \\
\text { collaboration }\end{array}$ & 0.04870 & $*$ & 0.017959 & $*$ \\
\hline $\begin{array}{l}\text { Q18 University } \\
\text { stipulates participation } \\
\text { in international } \\
\text { collaborative projects } \\
\text { for tenure and } \\
\text { promotion }\end{array}$ & 0.02420 & $*$ & 0.015699 & $*$ \\
\hline $\begin{array}{l}\text { Q24 Native language : } \\
\text { English and other than } \\
\text { English }\end{array}$ & $<0.0000005$ & $* * *$ & 0.000007 & $* * *$ \\
\hline
\end{tabular}

The changes from the baseline model to the final feature selection model improved the explanatory ability of the regression model. The overall result is that the final feature selection model yields an increase in the adjusted $\mathrm{R}^{2}$ metric. The increase in the adjusted $\mathrm{R}$ squared for the feature selection model reduces the error of standard deviation by approximately $11 \%$ in relative terms. Furthermore, the feature selection model yields seven statistically significant 
International Collaboration Among Social Science Scholars

independent variables that manifest LMP relative variable importance that is more evenly distributed than those associated with the base line model. The final model with seven variables represents an improvement over the original baseline model that featured 24 variables.

Practically, the results of the final selection model development indicate that one could use fewer questions on a survey to develop a predictive model related to involvement in international coauthorship initiatives, however further research would be required to confirm the validity of the final model that was developed using feature selection.

\section{Model Comparison}

The following is a comparative discussion related to differences in $p$ values of the variables that were found to be statistically significant in the baseline and final feature selection model. One would expect that the development of the feature selection model would result in $p$ values that are smaller than $p$ values in the baseline model. This expectation is based on the concept that researchers routinely observe smaller $p$ values when developing feature selection models with the final results of this process typically validating the concept of parsimony.

The results of the $p$ value calculations from the two models are categorized in three levels of statistical significance. The higher $p$ value level consists of $p$ values that are lower than 0.05 . The next lower level of $p$ values is comprised of variables that have $p$ values that are lower than 0.01 . The lowest level of $p$ values consists of variables that have $p$ values less than 0.001 . Variables with the lowest $p$ values are considered to be more statistically significant than those with higher $p$ values.

The independent variable associated with survey question 3 is related to the motivation to collaborate in order to improve access to external funds. The baseline model generated a $p$ value of 0.02419 which is statistically significant given that it below the value of 0.05 while the final 
International Collaboration Among Social Science Scholars

feature selection model generated a lower $p$ value of 0.001581 which is considered to be more statistically significant given that it is below the $p$ value of 0.01 . Survey question 5 is associated with motivations to collaborate based on access to special data or equipment. The $p$ values from both models are statistically significant at the 0.05 level however the results are considered to be an anomaly given that the $p$ value in the feature selection model is higher at 0.029887 than the $p$ value for the baseline model at 0.02395 . Survey question 6 asked respondents to indicate if they were motivated to collaborate in order to pool expertise and take on complex research problems. The $p$ value from the baseline model was 0.08892 and therefore was not found to be statistically significant. In contrast the $p$ value of survey question 6 from the feature selection model was found to be statistically significant at the 0.05 level with a $p$ value of 0.02491 . The $p$ values associated with survey question 8 , motivated to collaborate again based on previous project success, dropped from statistically significance level of 0.01 to 0.001 with the values of 0.00372 to 0.000803 in the baseline model and feature selection model respectively. Survey question 17 asked if their university offers seminars or networking sessions about international collaboration. The $p$ values from each model were in the 0.01 range and therefore considered to be statistically significant. However the $p$ value from the baseline model was much higher at a 0.04870 value as opposed to the lower 0.017959 value for the feature selection model. Survey question 18 asked respondents if their university stipulates participation in international collaborative projects for tenure and promotion. Again, the $p$ values from each model were in the 0.01 range and therefore considered to be statistically significant. However the $p$ value from the baseline model was much higher at a 0.02420 value as opposed to the lower 0.01569 value for the feature selection model. The survey question 24 was related to a respondent's native language. The $p$ values from both models were found to be the lowest $p$ values in the entire study, significant at the 0.001 level. 
International Collaboration Among Social Science Scholars

Specifically the $p$ value from the baseline model was found to be lower, at a level of significance that was less than 0.0000005 , than the $p$ value from the feature selection model of 0.000007 . When the variables that were found to be statistically significant in the baseline model and feature selection model were compared, all but two of the $p$ values for the independent variables were lower in the final feature selection model. It can therefore be interpreted that the feature selection model is a more explanatory model than the baseline model. Moreover, the $F$ test for the baseline model is 4.169 , with a $p$ value of 0.000000004948 which indicates that the full baseline model, when all independent variables are simultaneously modeled, is highly statistically significant. However, The $F$ test for the final feature selection model is 9.744 with a $p$ value of essentially zero and therefore indicates some full model improvement when compared to the baseline model.

\section{Results from Research Question One}

The first research question was: What motivates social science scholars to collaborate on research projects with their international colleagues? Survey questions one through thirteen were relied upon to generate the results to answer the first research question. Details of the questions and associated independent variables are listed in Table 11. The results from this array of questions suggest that there are a number of motivations for participating in international collaborations for this group of respondents. The results of survey questions one through thirteen follow, accompanied by a discussion of the results. 
Table 11

Research Question One - What motivates social science scholars to collaborate on research projects with their international colleagues? and Associated Survey Questions

\begin{tabular}{|c|c|c|c|}
\hline $\begin{array}{l}\text { Research } \\
\text { Question }\end{array}$ & $\begin{array}{l}\text { Survey } \\
\text { Question }\end{array}$ & Independent Variable & $\begin{array}{l}\text { Questions: I was motivated to } \\
\text { collaborate on this article because... }\end{array}$ \\
\hline R1 & Q1 & $\begin{array}{l}\text { Collaborator has a strong } \\
\text { reputation }\end{array}$ & $\begin{array}{l}\text { My co-authors have strong reputations as } \\
\text { researchers }\end{array}$ \\
\hline R1 & Q2 & $\begin{array}{l}\text { Collaborate to improve access } \\
\text { to department/university } \\
\text { funds }\end{array}$ & $\begin{array}{l}\text { Working on this collaborative project } \\
\text { improved my access to university funds. }\end{array}$ \\
\hline R1 & Q3 & $\begin{array}{l}\text { Collaborate to improve access } \\
\text { to external funds }\end{array}$ & $\begin{array}{l}\text { Working on this collaborative project } \\
\text { improved my access to external funds. }\end{array}$ \\
\hline R1 & Q4 & $\begin{array}{l}\text { Collaborator has expertise } \\
\text { other than my own }\end{array}$ & $\begin{array}{l}\text { My co-authors have expertise different } \\
\text { than my own. }\end{array}$ \\
\hline R1 & Q5 & $\begin{array}{l}\text { Collaborator has special data } \\
\text { or equipment }\end{array}$ & $\begin{array}{l}\text { Participating improved my access to } \\
\text { special data or research equipment. }\end{array}$ \\
\hline R1 & Q6 & $\begin{array}{l}\text { Collaborate to pool expertise } \\
\text { and take on complex research } \\
\text { problems }\end{array}$ & $\begin{array}{l}\text { Working together allowed us to pool } \\
\text { knowledge to accomplish complex } \\
\text { research. }\end{array}$ \\
\hline R1 & Q7 & $\begin{array}{l}\text { Collaborate to gain peer } \\
\text { recognition and visibility }\end{array}$ & $\begin{array}{l}\text { Working with my co-authors allowed me } \\
\text { to gain more peer recognition and } \\
\text { visibility. }\end{array}$ \\
\hline R1 & Q8 & $\begin{array}{l}\text { Collaborate again based on } \\
\text { previous project success }\end{array}$ & $\begin{array}{l}\text { I had worked effectively with one of my } \\
\text { co-authors before on a successful project. }\end{array}$ \\
\hline R1 & Q9 & $\begin{array}{l}\text { Collaborator is fun and } \\
\text { pleasant to work with }\end{array}$ & $\begin{array}{l}\text { My co-authors are pleasant and fun to } \\
\text { work with. }\end{array}$ \\
\hline R1 & Q10 & $\begin{array}{l}\text { Opportunity to publish with } \\
\text { international colleagues }\end{array}$ & $\begin{array}{l}\text { Because of the opportunity to publish } \\
\text { with my international colleagues. }\end{array}$ \\
\hline R1 & Q11 & $\begin{array}{l}\text { Collaborator is fluent in the } \\
\text { same language }\end{array}$ & $\begin{array}{l}\text { My co-authors and I are fluent in the same } \\
\text { language. }\end{array}$ \\
\hline R1 & Q12 & $\begin{array}{l}\text { Collaborate to mentor and } \\
\text { help a junior colleague or } \\
\text { graduate student }\end{array}$ & $\begin{array}{l}\text { I wanted to mentor and help a junior } \\
\text { colleague or graduate student. }\end{array}$ \\
\hline R1 & Q13 & $\begin{array}{l}\text { Motivation most important to } \\
\text { scholar for specified article }\end{array}$ & $\begin{array}{l}\text { The most important motivation for } \\
\text { participating in this international } \\
\text { collaboration was... }\end{array}$ \\
\hline
\end{tabular}

The results of each survey question are presented in a data table format. 
International Collaboration Among Social Science Scholars

Table 12

Results from Survey Questions 1 to 7 - I was motivated to collaborate on this article because

\begin{tabular}{|c|c|c|c|c|c|c|c|c|c|}
\hline Questions & $\begin{array}{r}\text { Strongly } \\
\text { Agree }\end{array}$ & & Agree & & Disagree & & $\begin{array}{l}\text { Strongly } \\
\text { Disagree }\end{array}$ & & Total \\
\hline $\begin{array}{l}\text { Q1 - My co-authors } \\
\text { have strong } \\
\text { reputations as } \\
\text { researchers. }\end{array}$ & $48.41 \%$ & 122 & $30.95 \%$ & 78 & $15.08 \%$ & 38 & $5.56 \%$ & 14 & 252 \\
\hline $\begin{array}{l}\text { Q2 - Working on this } \\
\text { collaborative project } \\
\text { improved my access } \\
\text { to university funds. }\end{array}$ & $4.03 \%$ & 10 & $6.45 \%$ & 16 & $35.08 \%$ & 87 & $54.44 \%$ & 135 & 248 \\
\hline $\begin{array}{l}\text { Q3 - Working on this } \\
\text { collaborative project } \\
\text { improved my access } \\
\text { to external funds. }\end{array}$ & $6.80 \%$ & 17 & $13.60 \%$ & 34 & $28.40 \%$ & 71 & $51.20 \%$ & 128 & 250 \\
\hline $\begin{array}{l}\text { Q4 - My co-authors } \\
\text { have expertise } \\
\text { different than my } \\
\text { own. }\end{array}$ & $44.22 \%$ & 111 & $44.22 \%$ & 111 & $9.56 \%$ & 24 & $1.99 \%$ & 5 & 251 \\
\hline $\begin{array}{l}\text { Q5 - Participating } \\
\text { improved my access } \\
\text { to special data or } \\
\text { research equipment. }\end{array}$ & $15.87 \%$ & 40 & $16.67 \%$ & 42 & $28.17 \%$ & 71 & $39.29 \%$ & 99 & 252 \\
\hline $\begin{array}{l}\text { Q6 - Working } \\
\text { together allowed us to } \\
\text { pool knowledge to } \\
\text { accomplish complex } \\
\text { research. }\end{array}$ & $67.46 \%$ & 170 & $28.97 \%$ & 73 & $1.59 \%$ & 4 & $1.98 \%$ & 5 & 252 \\
\hline $\begin{array}{l}\text { Q7 - Working with } \\
\text { my co-authors } \\
\text { allowed me to gain } \\
\text { more peer recognition } \\
\text { and visibility. }\end{array}$ & $28.97 \%$ & 73 & $32.14 \%$ & 81 & $26.98 \%$ & 68 & $11.90 \%$ & 30 & 252 \\
\hline
\end{tabular}


International Collaboration Among Social Science Scholars

Table 13

Results from Survey Questions 8 to 12 - I was motivated to collaborate on this article

\begin{tabular}{|c|c|c|c|c|c|c|c|c|c|}
\hline Questions & $\begin{array}{r}\text { Strongly } \\
\text { Agree }\end{array}$ & & Agree & & Disagree & & $\begin{array}{l}\text { Strongly } \\
\text { Disagree }\end{array}$ & & Total \\
\hline $\begin{array}{l}\text { Q8 - I had worked } \\
\text { effectively with one of } \\
\text { my co-authors before } \\
\text { on a successful } \\
\text { project. }\end{array}$ & $56.40 \%$ & 141 & $17.20 \%$ & 43 & $16.80 \%$ & 42 & $9.60 \%$ & 24 & 250 \\
\hline $\begin{array}{l}\text { Q9 - My co-authors } \\
\text { are pleasant and fun to } \\
\text { work with. }\end{array}$ & $65.48 \%$ & 165 & $31.35 \%$ & 79 & $2.78 \%$ & 7 & $0.40 \%$ & 1 & 252 \\
\hline $\begin{array}{l}\text { Q10 - Because of the } \\
\text { opportunity to publish } \\
\text { with my international } \\
\text { colleagues. }\end{array}$ & $36.51 \%$ & 92 & $34.13 \%$ & 86 & $16.27 \%$ & 41 & $13.10 \%$ & 33 & 252 \\
\hline $\begin{array}{l}\text { Q11 - My co-authors } \\
\text { and I are fluent in the } \\
\text { same language. }\end{array}$ & $30.68 \%$ & 77 & $39.04 \%$ & 98 & $18.33 \%$ & 46 & $11.95 \%$ & 30 & 251 \\
\hline $\begin{array}{l}\text { Q12 - I wanted to } \\
\text { mentor and help a } \\
\text { junior colleague or } \\
\text { graduate student. }\end{array}$ & $19.92 \%$ & 50 & $12.35 \%$ & 31 & $25.90 \%$ & 65 & $41.83 \%$ & 105 & 251 \\
\hline
\end{tabular}

The survey results indicate that social scientists involved in this study are motivated to participate based on a number of factors. The results are presented in a graphic form with standardized scale from zero to eighty percent in order to provide a comparative context. The results of each survey question are presented in graphical representation below. Note: Survey question one $=Q 1$ 


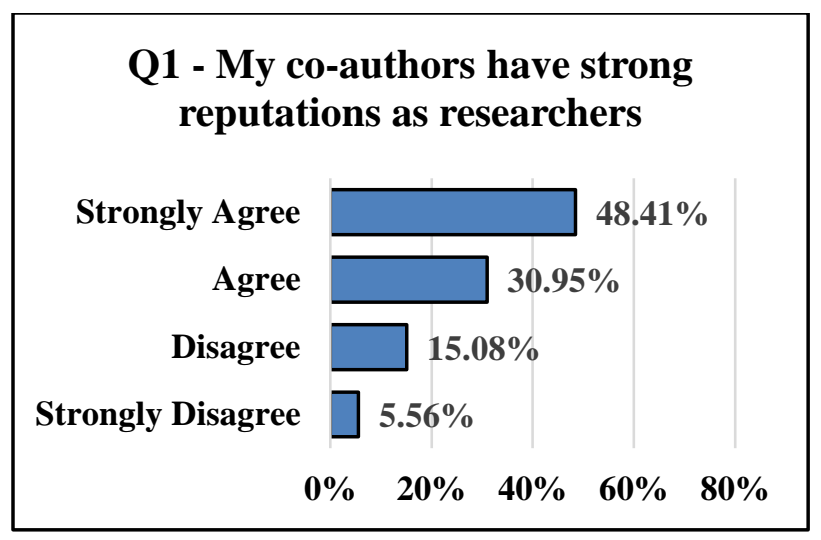

Q2 - Working on this collaborative project improved my access to university funds.

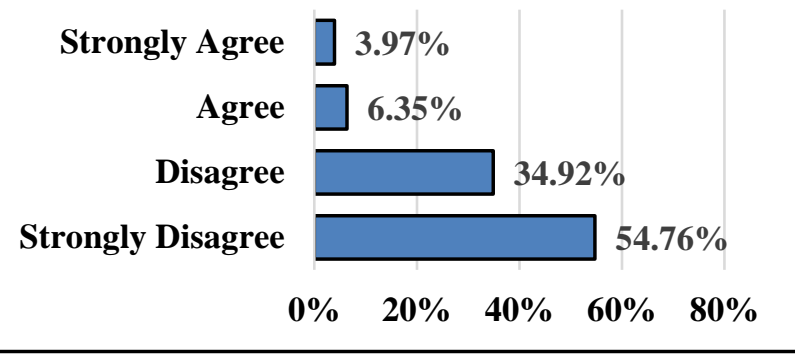

Q3 - Working on this collaborative project improved my access to external funds.

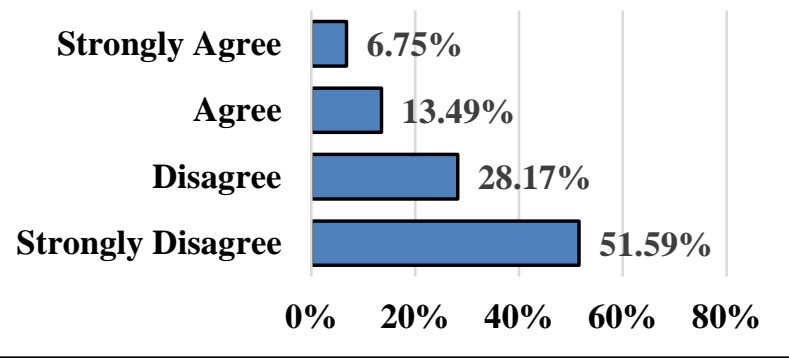

Q4 - My co-authors have expertise different than my own.

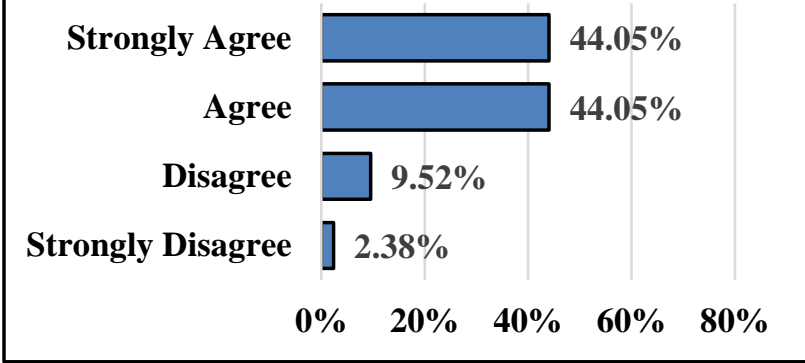

\section{Q5 - Participating improved my access to special data or research equipment.}

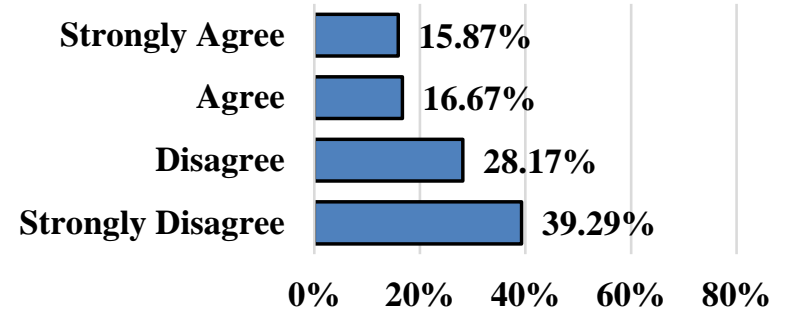

Q6 - Working together allowed us to pool knowledge to accomplish complex research.

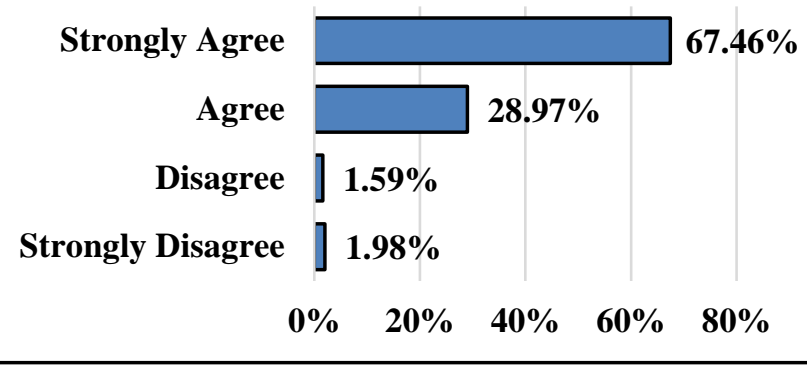



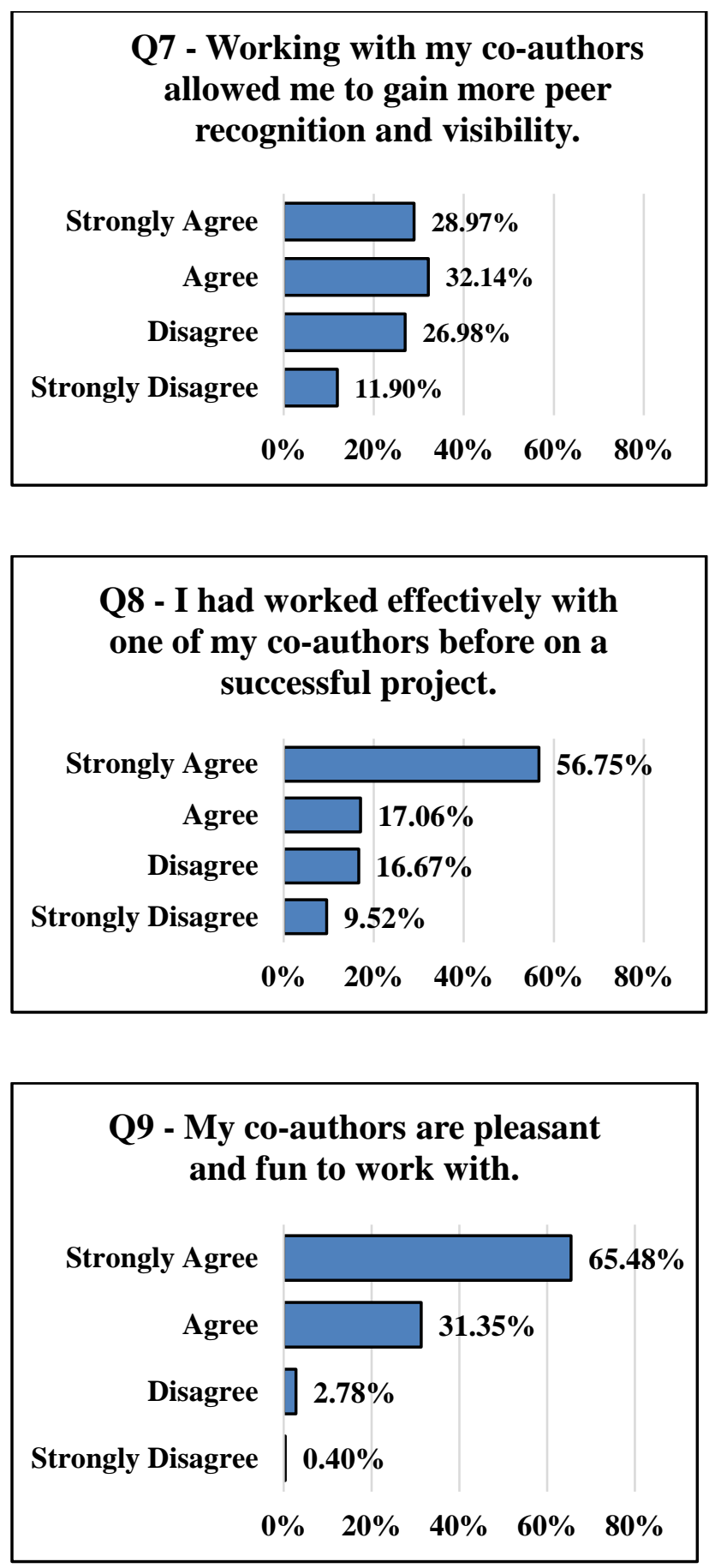
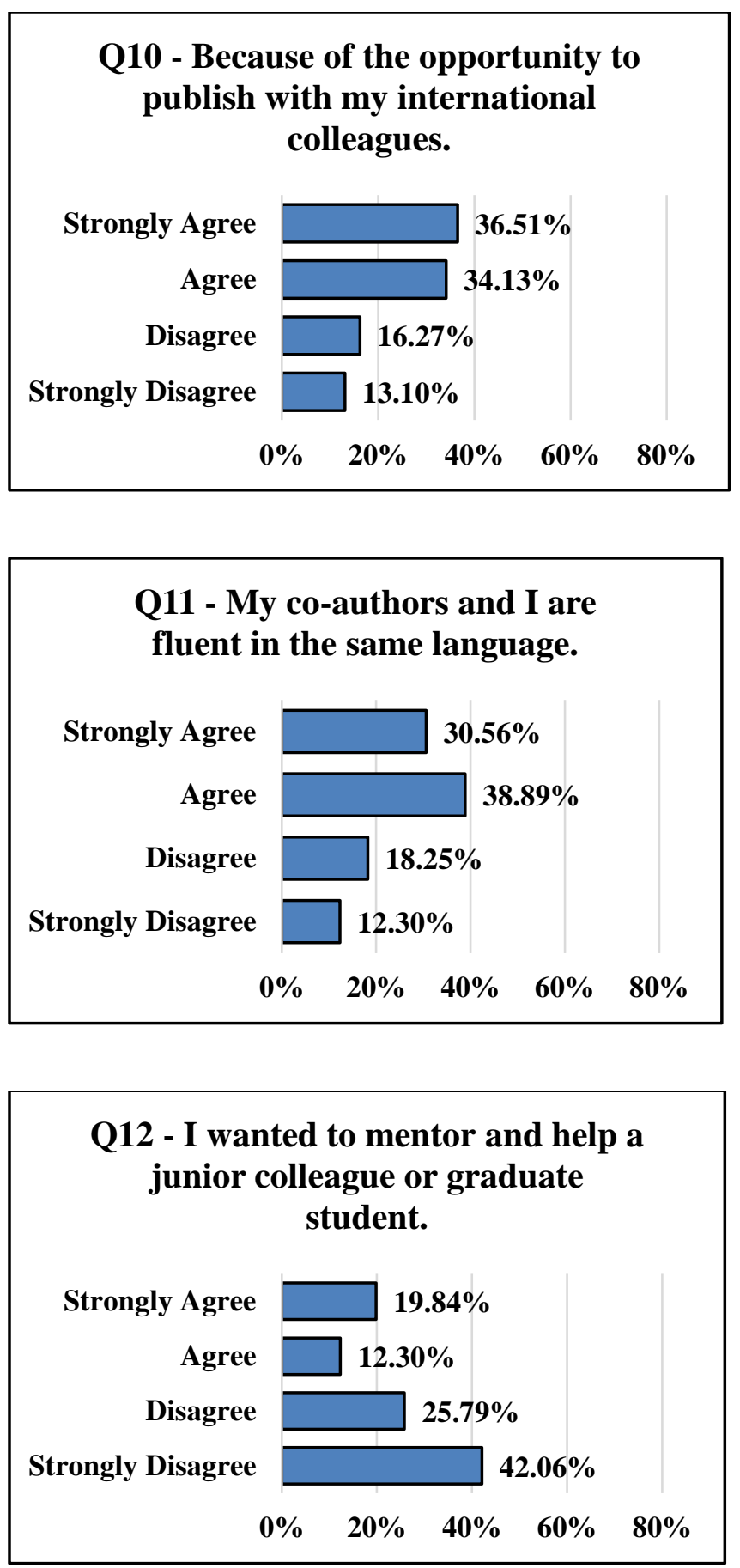


\section{Discussion Research Question One: Motivations for Participation in International Collaborative Projects}

The following section includes a discussion of the results from the survey questions related to why this particular set of scholars were motivated to collaborate on a particular research project with their international colleagues. Aspects of the survey results are discussed in light of the literature review that was initially undertaken to develop the research questions and survey questions for this study. The section includes a discussion of the results from survey question 1 through survey question 12 and from survey question 13, which asked respondents to indicate the most important motivation for participating in this particular research collaboration.

\section{Co-authors Have Strong Reputations as Researchers}

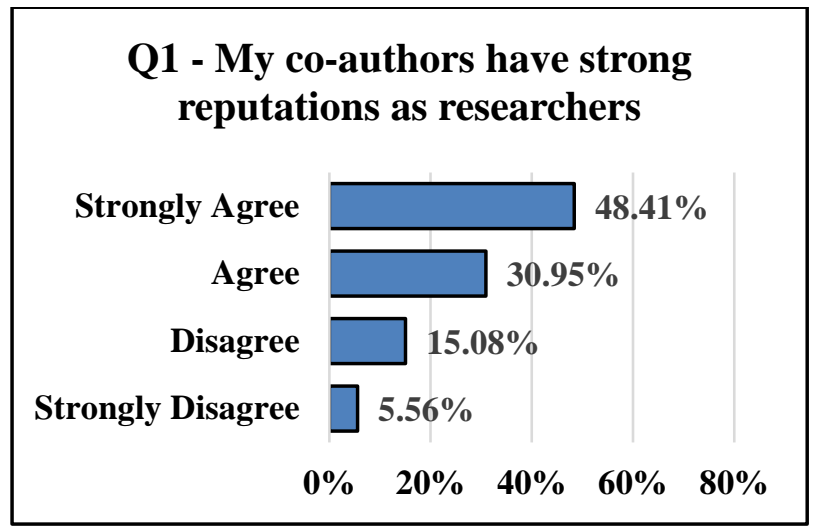

The independent variable associated with survey question 1 is related to a scholar being motivated to participate in a collaborative project based on their co-authors having strong reputations are researchers. The results of this question intuitively make sense given that scholars make pragmatic decisions related to their research agendas and collaborative partnerships. Based on the research of Jones, Wuchty, and Uzzi, a collaborative team's impact is 
proportional to the academic excellence of its participants (2008, p. 1260). In her work The New Invisible College, Wagner states that "scholars self-organize into collaborative teams based on relatively simple rules (that are) set and followed at the individual level” (Wagner, 2008, p. 62). The rules are based on the concept of preferential attachment in that scholars desire to enhance their own reputation through collaborative projects. The descriptive results from survey question 1 support Wagner's findings given that $80 \%$ of the respondents indicated that they agreed or strongly agreed with the statement that they were motivated because their co-authors have strong reputations as researchers. A surprising outcome was that the results of the regression analysis for the independent variable associated with survey question 1 was found to not be statistically significant with $p$ value for the baseline model at 0.15911 and the $p$ value for the feature selection model at 0.063697 . The results were unexpected however looking into more detail it became apparent that the linear association between the variable associated with survey question 1 and the dependent variable, as measured by the correlation coefficient, was extremely low. Furthermore, given that regression models were used in order to take into account the effects of all variables in the model simultaneously and to control for interrelationships among the variables, this outcome is possible. 


\section{Access to Funding}
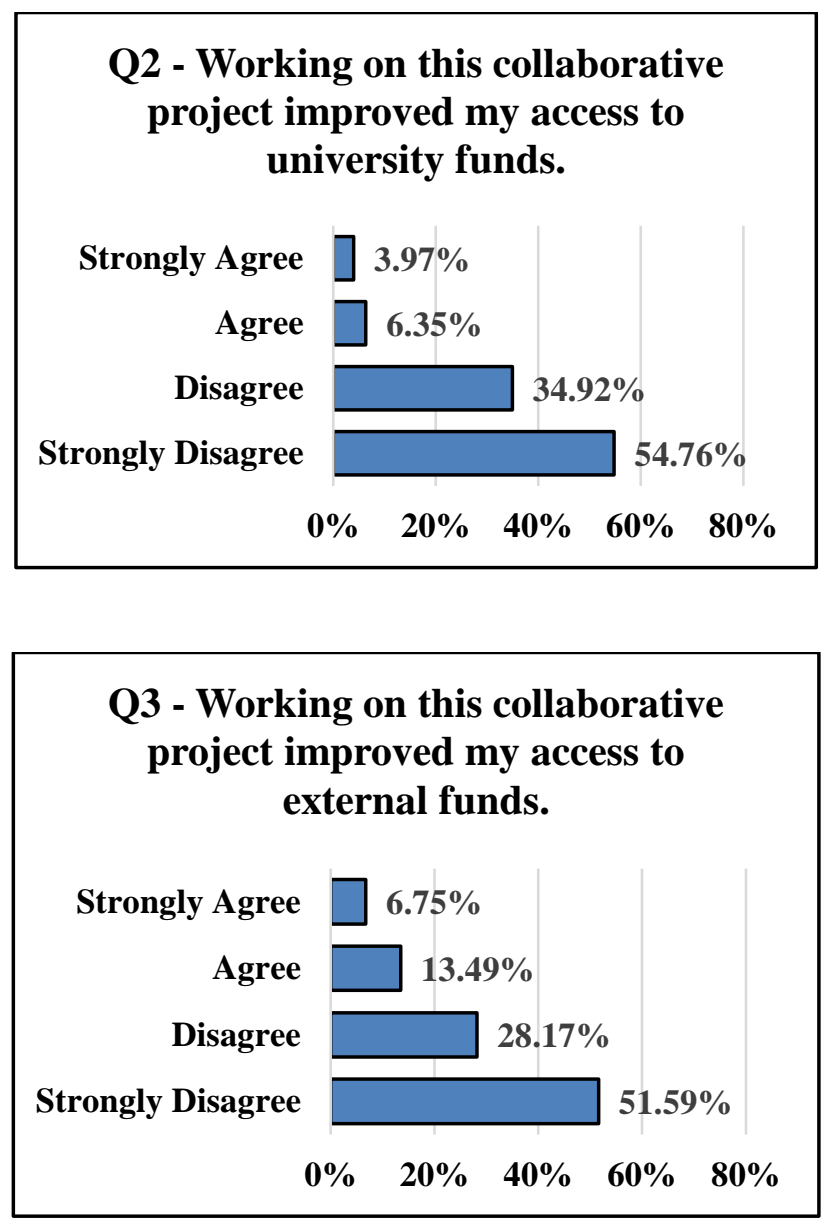

Survey questions 2 and 3 were associated with the independent variables that are focused on motivations based on access to university funding and external funding. Specifically, survey question 2 asked respondents if they are motivated to collaborate in order to improve access to university funds while survey question 3 asked respondents if they are motivated to collaborate in order to improve access to external funds. The results of this survey indicate that a majority of the respondents disagree or strongly disagree with the both statements. The results from this study are contrary to earlier research on scholarly collaboration. There is extensive coverage in the literature about the high levels of motivation to participate in collaborative projects based on the improved access to funds, data, or equipment. The results of this survey’s questions that are 
International Collaboration Among Social Science Scholars

related to motivations related to resources represents one of the major findings of this study. This study found that the results from survey questions 2 and 3 are congruent with the findings of later survey questions that related to university support. The congruence was documented by the fact that a large portion of respondents also indicated that funds were available from their university for international collaboration nonetheless they did not take advantage of them.

The results of the regression analysis for the survey question 2 independent variable, related to the motivation to improve access to university funds, was found to be not statistically significant with $p$ value for the baseline model at 0.97937 . The $p$ value for the feature selection model was not calculated due to the fact that this independent variable was one of the fourteen variables that were removed in the backward elimination process of the feature selection model development process.

The results of the development of regression models related to survey question 3 were unexpected given the low rate of positive responses. Although only $20.24 \%$ of the survey respondents agreed or strongly agreed with the statement, the independent variable related to survey question 3 was found to be statistically significant. The regression results of the baseline model as well as the feature selection model indicate that the independent variable associated with survey question 3 was statistically significant at the 0.05 level with a $p$ value of .024 and at the 0.01 level with a $p$ value of .00158 respectively. The finding of statistical significance may seem counter intuitive given that a low number of respondents strongly agreed or agreed in response to this question. With further analysis it became apparent that the linear association between the variable associated with survey question 3 and the dependent variable, as measured by the correlation coefficient, was high. Furthermore, given that regression models were used in 
International Collaboration Among Social Science Scholars

order to take into account the effects of all variables in the model simultaneously and to control for interrelationships among the variables, this outcome is conceivable.

\section{Different Expertise}

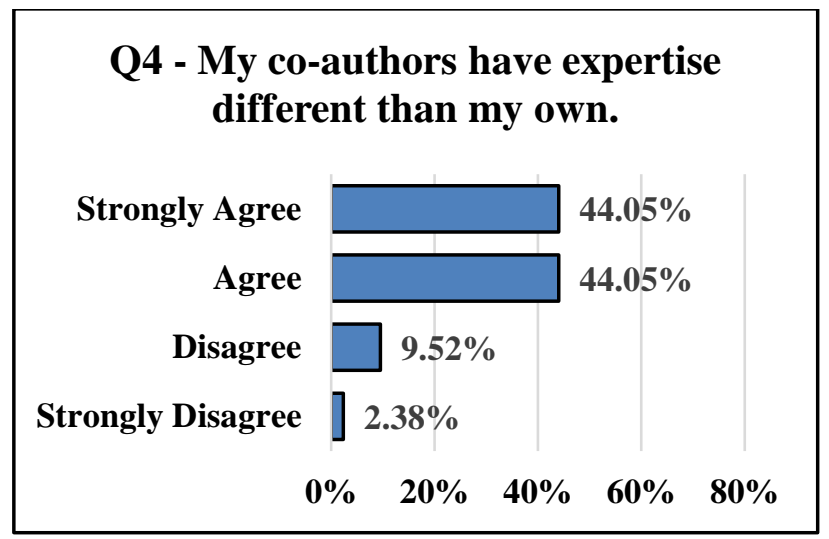

Survey question 4 addresses the independent variable that is related to co-authors having expertise different than my own. The results of this survey indicated that a majority of the respondents agree with this statement. This concept is supported in the literature on scholarly collaboration. Findings in prior literature include that scholars need to keep pace with the expanding requirement to develop expertise in, for example, research methods and data analysis techniques. This need compels scholars to seek out colleagues as collaborative partners based on their superior prophecies prior research, knowledge, or capabilities (Katz \& Martin, 1997; Melin, 2000; Thorsteinsdottir, 2000; Beaver, 2001; Bozeman \& Corley, 2004; Wagner, 2006, Ou et al., 20012). This concept is also documented in the literature by Wagner's work on the The New Invisible College (2008). Wagner highlighted the value of forming research teams to collaborate, share expertise, and distribute tasks. Furthermore, she found that the creation of global teams provided an opportunity for diverse groups of scholars to form and take advantage of the collective knowledge and expertise among team members. 
The descriptive results from survey question 4 support the literature on collaboration as well as Wagner's findings given that over $88 \%$ of the respondents indicated that they agreed or strongly agreed with the statement that they were motivated because their co-authors have expertise different than my own. A surprising outcome was that the results of the regression analysis for the independent variable associated with survey question 4 was found to not be statistically significant with $p$ value for the baseline model at 0.19682 . The $p$ value for the feature selection model was not calculated due to the fact that this independent variable was one of the fourteen variables that were removed in the backward elimination process of the feature selection model development process. These results were surprising however the linear association between the variable associated with survey question 4 and the dependent variable, as measured by the correlation coefficient, was extremely low. Models were developed using multiple linear regression in order to take into account the effects of all variables in the model simultaneously and to control for interrelationships among the variables therefore this outcome is plausible.

\section{Access to Data and Resources}

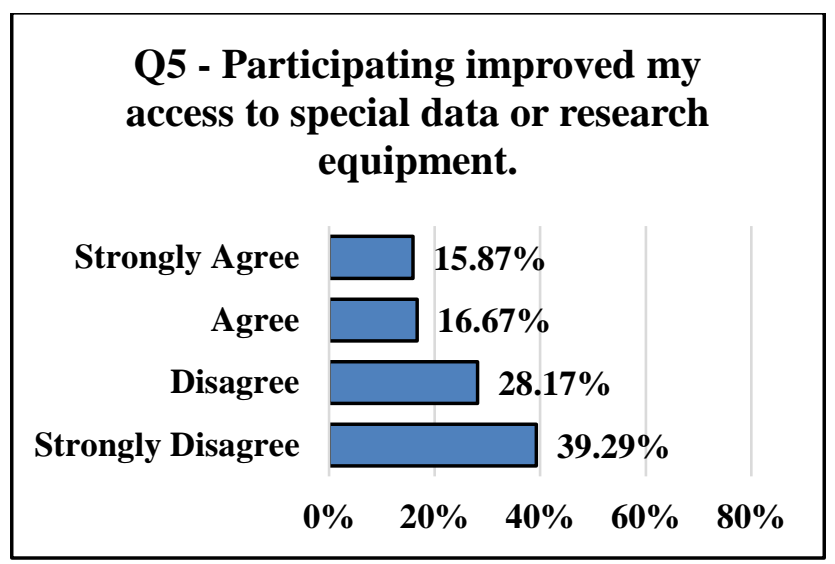


International Collaboration Among Social Science Scholars

Survey question 5 is associated with the independent variable related to motivation based on the opportunity to have access to special data or research equipment. The results for this question indicate that a majority of the respondents disagree or strongly disagree with the question. Only 32.54\% of respondents responded positively while $67.46 \%$ replied negatively. There is extensive coverage in the literature about the high levels of motivation to participate in collaborative projects based on the improved access to data or equipment. Therefore, the results from this study are contrary to earlier research on scholarly collaboration.

The results of the development of regression models related to question 5 were unanticipated given the low rate of positive responses. Although only $32.54 \%$ of the survey respondents agreed or strongly agreed with the statement, "I was motived to participate in the international collaboration because it improved my access to special data or research equipment," the independent variable related to survey question 5 was found to be statistically significant. The results were surprising given that $67.46 \%$ of respondents replied negatively. The regression results of the baseline model as well as the feature selection model indicate that the independent variable associated with survey question 5 was statistically significant at the 0.05 level with a $p$ value of .024 and at the 0.05 level with a $p$ value of .029 respectively. The finding of statistical significance may seem counter intuitive given that a low number of respondents that replied in the positive range for this question. However, with further analysis it became apparent that the linear association between the variable associated with survey question 5 and the dependent variable, as measured by the correlation coefficient, was high. The regression models were developed to test individual variables while holding the influence of the other variables constant therefore this outcome, having descriptive statistics from a survey that 
International Collaboration Among Social Science Scholars

indicate higher levels of disagreement and then the regression model results indicating that the variable is not significant, is not out of the ordinary.

\section{Pool Knowledge to Accomplish Complex Research}

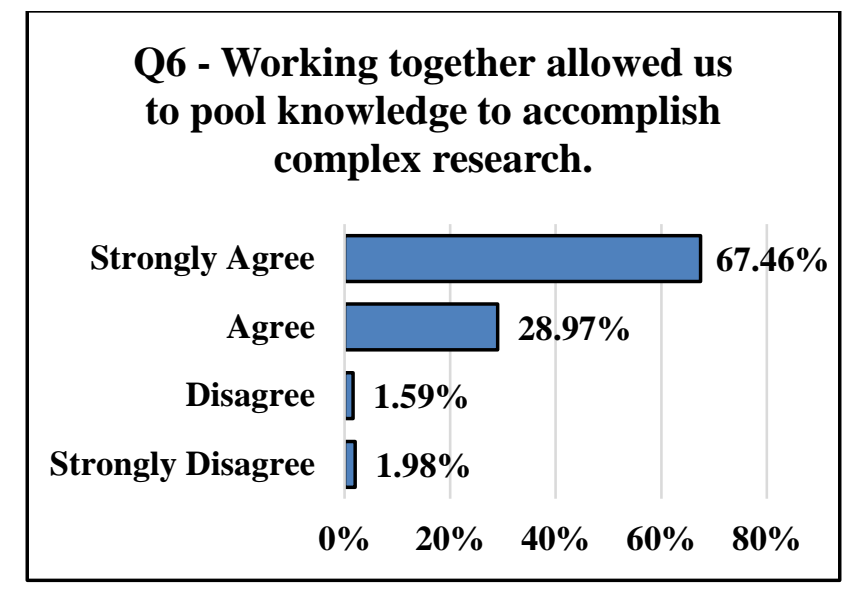

The independent variable associated with survey question 6 related to the motivation to pool knowledge of a team of researchers in order to accomplish complex research. The results of this survey indicated that a majority of the respondents agreed or strongly agreed with the question. Only 3.57\% of respondents responded negatively while $96.43 \%$ replied positively. This survey question 6 is one of two survey questions that shares the highest mean of 3.62 among the group of questions that are related to motivations for participation in international collaborative projects. There is extensive coverage in the literature about the high levels of motivation to participate in collaborative projects based on the opportunity to pool knowledge and accomplish complex research. Therefore, the responses to this question are compatible with earlier research on scholarly collaboration.

The results of the regression found that the independent variable associated with survey question 6 was not statistically significant in with the baseline model however the variable was found to be statistically significant in the final model that was developed using feature selection. 
The feature selection model indicated statistical significance at the 0.05 level with a $p$ value of 0.0249. Intuitively it makes sense that a scholar would be motivated to participate in a collaboration if the team would be able to pool their knowledge in order to accomplish more complex research that they could not accomplish on their own. Participation in collaborative research team allows for the effective division of labor reflecting the unique talents of team members that have an array of knowledge, skills, and abilities (Senker, 1993; Katz \& Martin, 1997, Melin, 2000; Beaver, 2001; Bozeman \& Corley, 2004; Ou et al., 2012)

\section{Gain More Peer Recognition and Visibility}

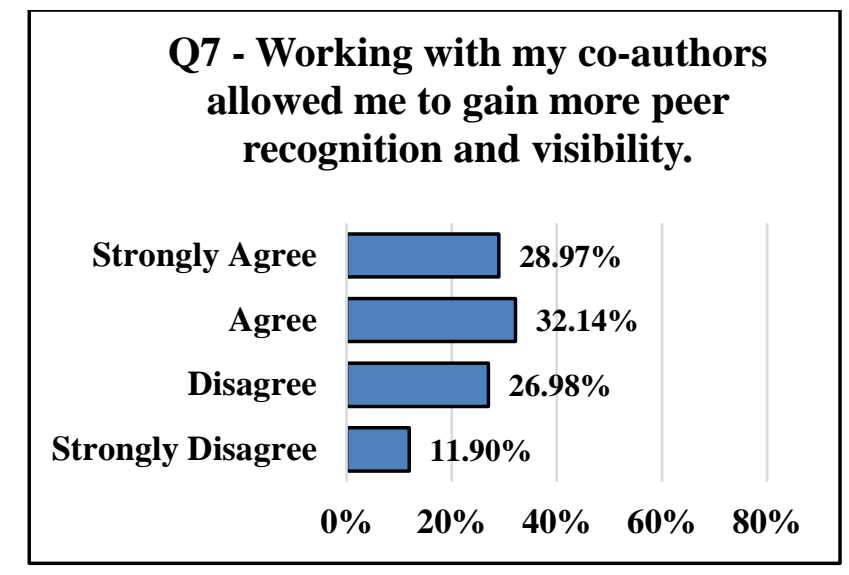

Survey question 7 determined the respondents' motivation to participate in the collaboration because working with co-authors allowed the respondent to gain more peer recognition and visibility. The benefit of increased academic productivity is recognized in the literature as one of the most compelling benefits of collaboration among scholars (Lee \& Bozeman, 2005; McFadyen \& Cannella, 2004; Wuchty et al., 2007; Jeong et al., 2011; Ou et al., 2012). The results from this study found mixed responses in that not every respondent ranked gaining more peer recognition and visibility as a motivation for their participation in a specific international collaborative project. Based on the literature the mixed results were unexpected 
however the nature of the motivation reflected in this question could be considered more nuanced. The concepts of peer recognition and visibility could be perceived in a number of ways and may explain the diverse set of answers collected for this question. The results of the regression analysis for this independent variable were found to not be statistically significant with $p$ value for the baseline model at 0.67427 . The $p$ value for the feature selection model was not calculated due to the fact that this independent variable was one of the fourteen variables that were removed in the backward elimination process of the feature selection model development process.

\section{Prior Collaboration}

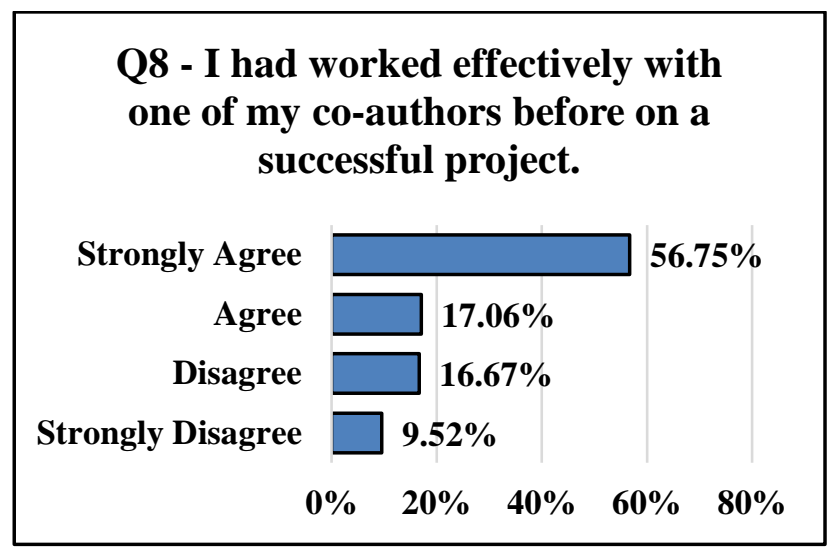

Question 8 is related to the independent variable of having worked effectively with one of the co-authors before on a successful project. The results of this survey question represent one of the major conclusions of this study. This research found that $73.81 \%$ of survey respondents indicated they agreed or strongly agreed with the statement that they were motivated to co-author with their international colleague because they had worked effectively with one of their coauthors before on a successful project. Alternatively only 26.19\% disagreed or strongly disagreed with the statement. 
Furthermore, the regression results of the baseline model as well as the feature selection model indicate that the independent variable associated with Question 8 is statistically significant at the 0.01 level and at the 0.001 level respectively. The results of this question support the conclusion in the literature that teams of researchers collaborate because they want to work together as they have in the past as an efficient team. The literature reports that faculty work with their co-author on multiple projects. An example of the coverage in the scholarly literature on research collaboration is the work of Wagner (2008) who describes the concept of stickiness among scholars. The concept of stickiness encompasses the repeating pattern of the clustering of scholars, ideas, and research in order to be efficient in the production of new research.

The results of survey question 27 in this survey are also related to the concept of a scholar repeatedly working with co-authors. The results of survey question 27 indicate that over $84 \%$ of the respondents have co-authored multiple times with at least one of their co-authors. The combination of the results from Question 8 and Question 27 indicate that creation of international collaborative teams that work together on successive projects is a noteworthy part of the international collaboration phenomenon. Participating in research collaboration is considered to be a way to produce greater quality and quantity of work in comparison with research that is done individually (Hudson, 1996; Bozeman \& Corley, 2004; Wagner, 2008). 


\section{Working Relationships}

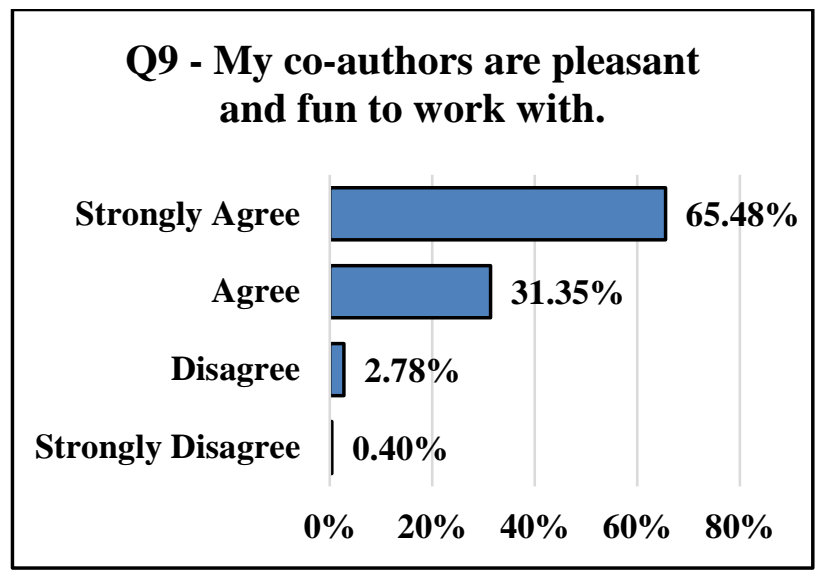

The independent variable for survey question 9 is associated with co-authors that are pleasant and fun to work with. These survey results for this question are congruent with the literature on scholarly collaboration. Benefits such as intellectual companionship and personal pleasure through interaction and work with like-minded scholars is covered extensively in the literature and is recognized as a personal benefit that is closely related to a scholar's motivations for participating in collaborative research projects (Katz \& Martin, 1997; Melin, 2000; Thorsteinsdottir, 2000; Beaver, 2001; Bozeman \& Corley, 2004; Ou et al., 2012). The descriptive results from survey question 9 support the literature given that over $96 \%$ of the respondent indicate that they agreed or strongly agreed with the statement that they were motivated because their co-authors are pleasant and fun to work with.

The results of the regression analysis for this independent variable related to the motivation that the co-authors are pleasant and fun to work with was found to not be statistically significant with $p$ value for the baseline model at 0.91307 . The $p$ value for the feature selection model was not calculated due to the fact that this independent variable was one of the fourteen variables that were removed in the backward elimination process of the feature selection model 
development process. Based on the literature and the overall positive response from the survey respondents the outcome from the regression analysis was surprising. The results were unexpected however through further analysis it became apparent that the linear association between the variable associated with survey question 9 and the dependent variable, as measured by the correlation coefficient, was extremely low. Furthermore, given that regression models were developed in order to take into account the effects of all variables in the model simultaneously and to control for interrelationships among the variables, this outcome is possible.

\section{Opportunity to Co-author with International Colleagues and Fluent in Same Language}
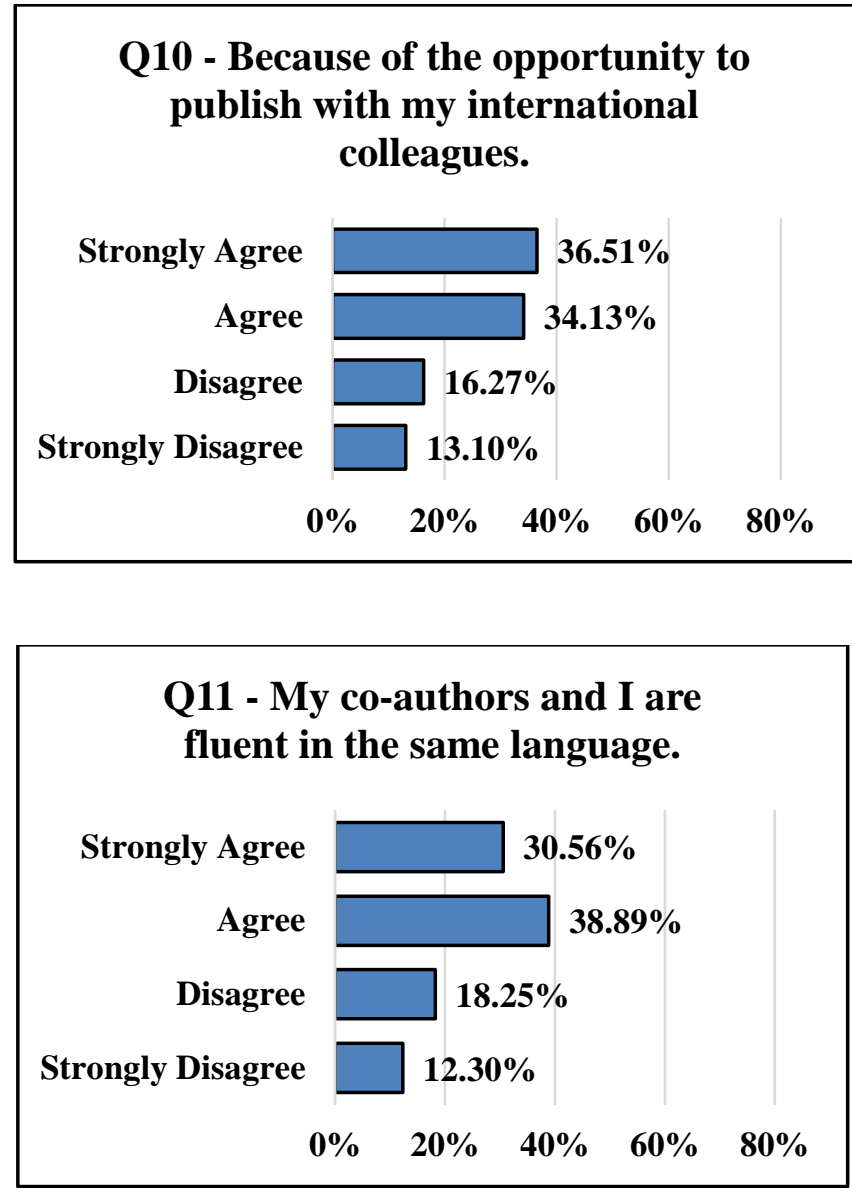
Analyzing the data from Questions 10 and 11 reveals that respondents were divided on the questions, which lowers the means. However, the nature of the motivation reflected in each of these questions could be considered more nuanced and therefore more inclined to reflect a diverse set of answers that has a moderating effect on the mean. For example, Question 11 is related to the independent variable that my co-authors and I are fluent in the same language. The benefit of increased academic productivity is recognized in the literature as one of the most compelling benefits of collaboration among scholars (Lee \& Bozeman, 2005; McFadyen \& Cannella, 2004; Wuchty et al., 2007; Jeong et al., 2011; Ou et al., 2012). The results from this study found mixed responses in that not every respondent ranked having fluency in the same language as a motivation for their participation in a specific international collaborative project.

The results of the regression analysis for the question 10 independent variable that is related to motivation because of the opportunity to publish with an international colleague was found to not be statistically significant with $\mathrm{p}$ value for the baseline model at 0.79304 . The results of the regression analysis for this independent variable associated with question 11 was also found to not be statistically significant with $\mathrm{p}$ value for the baseline model at 0.77461 . The $\mathrm{p}$ values for the feature selection model for both question 10 and question 11 independent variables was not calculated due to the fact that these independent variables were some of the fourteen variables that were removed in the backward elimination process of the feature selection model development process. 


\section{Mentoring}

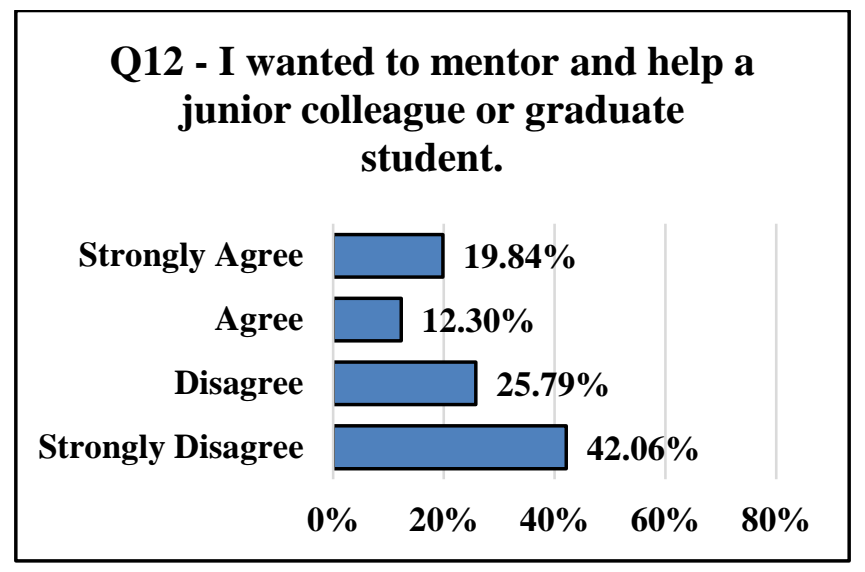

Factors related to educating a student or helping a junior colleague have also been found to be a motivation to collaborate in prior research (Crane, 1972; Beaver \& Rosen, 1978; Melin, 2000; Beaver, 2001; Bozeman \& Corley, 2004). Survey question 12 is related to the independent variable associated with motivation to collaborate in order to mentor a junior colleague or graduate student. A higher motivation to mentor is typically reported by faculty who are more senior in their career and therefore one can project that data will be skewed towards higher tenure levels. This was found to be true with the respondents in this study. Analysis of the cross tabulation results against faculty rank reveals that at the strongly agree level the assistant professor category is $0 \%$, the associate professor is $15 \%$, and the full professor is $29 \%$. The results of the regression analysis for this independent variable associated with the motivation to collaborate in order to mentor and help a junior colleague or graduate student was found to not be statistically significant with $p$ value for the baseline model at 0.24353 . The $p$ value for the feature selection model was not calculated due to the fact that this independent variable was one of the fourteen variables that were removed in the backward elimination process of the feature selection model development process. 
International Collaboration Among Social Science Scholars

\section{Data for Research Question 1 (Survey Questions 1 through 12) Categorized By Mean}

In order to present an illustrative overview of the patterns that emerged from the survey results, in the following section, Question 1 through Question 12 are arranged into three broad groups. Table 14. Respondents were asked to consider the phase I was motivated to collaborate on this article because and reply to a statement, such as, my co-authors have expertise different than my own by indicating if they strongly agree, agree, disagree, or strongly disagree with the statement. The groups below are organized by the calculated mean response of all respondents for each survey question. The calculation is based on the Likert scale categories and values coding of strongly agree $=4$, agree $=3$, disagree $=2$, and strongly disagree $=1$. The data presented in the following table is arranged in three categories. The high group includes survey questions that have a mean between 3 and 4 . The results the study indicate that most respondents indicate that they agree to strongly agree with these survey question. The medium group includes survey questions that have a mean between 2.5 and 3 while the low group includes survey questions that have a mean between 1 and 2.5 . 
Table 14:

Broad Categories - Mean Response Value Questions 1-12 - Organized by High-Medium-Low

\begin{tabular}{|c|c|c|c|}
\hline Group & $\begin{array}{l}\text { Survey } \\
\text { Question }\end{array}$ & $\begin{array}{c}\text { Mean } \\
\text { Range 1-4 }\end{array}$ & $\begin{array}{l}\text { Questions: } \\
\text { I was motivated to collaborate on this article because... }\end{array}$ \\
\hline High & Q6 & 3.62 & $\begin{array}{l}\text { Working together allowed us to pool knowledge to } \\
\text { accomplish complex research. }\end{array}$ \\
\hline High & Q9 & 3.62 & My co-authors are pleasant and fun to work with. \\
\hline High & Q4 & 3.31 & My co-authors have expertise different than my own. \\
\hline High & Q1 & 3.22 & My co-authors have strong reputations as researchers. \\
\hline High & Q8 & 3.20 & $\begin{array}{l}\text { I had worked effectively with one of my co-authors before } \\
\text { on a successful project. }\end{array}$ \\
\hline Medium & Q10 & 2.94 & $\begin{array}{l}\text { Because of the opportunity to publish with my international } \\
\text { colleagues. }\end{array}$ \\
\hline Medium & Q11 & 2.88 & My co-authors and I are fluent in the same language. \\
\hline Medium & Q7 & 2.78 & $\begin{array}{l}\text { Working with my co-authors allowed me to gain more peer } \\
\text { recognition and visibility. }\end{array}$ \\
\hline Low & Q12 & 2.10 & $\begin{array}{l}\text { I wanted to mentor and help a junior colleague or graduate } \\
\text { student. }\end{array}$ \\
\hline Low & Q5 & 2.09 & $\begin{array}{l}\text { Participating improved my access to special data or research } \\
\text { equipment. }\end{array}$ \\
\hline Low & Q3 & 1.76 & $\begin{array}{l}\text { Working on this collaborative project improved my access } \\
\text { to external funds. }\end{array}$ \\
\hline Low & Q2 & 1.6 & $\begin{array}{l}\text { Working on this collaborative project improved my access } \\
\text { to university funds. }\end{array}$ \\
\hline
\end{tabular}

Notes: High group mean values are between 3 and 4. Medium group mean values are between 2.5 and 3. Low group mean values are between 1 and 2.5 . 
International Collaboration Among Social Science Scholars

\section{Most Important Motivation for Collaboration}

Survey question 13 was designed to determine from the list of motivations presented in survey questions 1 through 12 what was the most important motivation. The survey question was: considering all of the motivations that are listed in this survey, what was the most important motivation to you when you made the decision to participate in this collaboration? Table 15 includes results from survey question 13.

Table 15

Results from Survey Question 13 - Most Important Motivation Related to This Collaboration

\begin{tabular}{|c|c|c|}
\hline Answers & $\%$ & Count \\
\hline My co-authors have strong reputations as researchers. & $11.30 \%$ & 26 \\
\hline $\begin{array}{l}\text { Working on this collaborative project improved my access to university } \\
\text { funds. }\end{array}$ & $0.00 \%$ & 0 \\
\hline $\begin{array}{l}\text { Working on this collaborative project improved my access to external } \\
\text { funds. }\end{array}$ & $0.87 \%$ & 2 \\
\hline My co-authors have expertise different than my own. & $13.48 \%$ & 31 \\
\hline Participating improved my access to special data or research equipment. & $5.22 \%$ & 12 \\
\hline $\begin{array}{l}\text { Working together allowed us to pool knowledge to accomplish complex } \\
\text { research. }\end{array}$ & $29.13 \%$ & 67 \\
\hline $\begin{array}{l}\text { Working with my co-authors allowed me to gain more peer recognition } \\
\text { and visibility. }\end{array}$ & $1.74 \%$ & 4 \\
\hline $\begin{array}{l}\text { I had worked effectively with one of my co-authors before on a } \\
\text { successful project. }\end{array}$ & $13.04 \%$ & 30 \\
\hline My co-authors are pleasant and fun to work with. & $10.87 \%$ & 25 \\
\hline Because of the opportunity to publish with my international colleagues. & $5.22 \%$ & 12 \\
\hline My co-authors and I are fluent in the same language. & $0.00 \%$ & 0 \\
\hline I wanted to mentor and help a junior colleague or graduate student. & $9.13 \%$ & 21 \\
\hline Total & $100 \%$ & 230 \\
\hline
\end{tabular}


International Collaboration Among Social Science Scholars

The highest ranked response to survey question 13 was, working together allowed us to pool knowledge to accomplish complex research, with $30 \%$ of respondents indicating that this was their most important motivation. This large response reflects that scholarly collaboration is focused on creating new knowledge through research initiatives within a subject discipline. The next highest response was, my co-authors have expertise different than my own, with $14 \%$ of the respondent indicating that this is the most important motivation. Findings from the prior research literature include that scholars need to keep pace with the expanding requirement to develop expertise in, for example, research methods and data analysis techniques. This need compels scholars to seek out colleagues as collaborative partners based on their prior research, knowledge or expertise. I had worked effectively with one of my co-authors before on a successful project was the third ranked response to the most important motivation, at $13 \%$ of respondents. The fourth ranked response was my co-authors have strong reputations as researchers with 11\% reporting it was the most important motivation. The ranking of this question intuitively make sense given that scholars make pragmatic decisions related to their research agendas and collaborative partnerships. My co-authors are pleasant and fun to work with was the fifth ranked response with $11 \%$ reporting this as their most important motivation. Benefits such as intellectual companionship, personal pleasure through interaction and work with like-minded scholars is covered extensively in the literature and is recognized as a personal benefit that is closely related to a scholar's motivations for participating in collaborative research projects. 
International Collaboration Among Social Science Scholars

\section{Results from Research Question Two}

The second research question was: What university resources are available to support social science scholars who participate in international collaborative research projects? Data from survey questions 14 through 17 were analyzed to generate an answer to the second research question. The responses to this array of questions suggest that there are varying levels of university resources available to support scholars that participate in international collaborations. Furthermore, the group of scholars that participated in this survey indicated that they may or may not take advantage of support that is offered by their universities. The results of the regression analysis in both the baseline model and feature selection model indicate that the variables associated with survey questions 14,15 , and 16 were not statistically significant. In contrast the results for the variable associated with survey question 17 indicated statistical significance in both the baseline regression model and the feature selection model. A discussion of the results from these questions will be presented in the next section.

The results of each survey question are presented in a data table 17. 
International Collaboration Among Social Science Scholars

Table 16:

Survey Questions 14 through 17- What University Resources Are Available to Support

International Collaboration?

\begin{tabular}{|c|c|c|c|}
\hline $\begin{array}{l}\text { Research } \\
\text { Question }\end{array}$ & $\begin{array}{c}\text { Survey } \\
\text { Question }\end{array}$ & Independent Variable & $\begin{array}{l}\text { Questions: } \\
\text { The following questions are related to } \\
\text { your department or university and } \\
\text { what is provided to enable } \\
\text { participation in international } \\
\text { collaborative research projects. }\end{array}$ \\
\hline $\mathrm{R} 2$ & Q14 & $\begin{array}{l}\text { University offers funding for } \\
\text { travel related to international } \\
\text { collaboration }\end{array}$ & $\begin{array}{l}\text { My university offers travel funding to } \\
\text { support participation in international } \\
\text { collaborative projects. }\end{array}$ \\
\hline R2 & Q15 & $\begin{array}{l}\text { University offers } \\
\text { funding/grants for } \\
\text { international collaboration } \\
\text { (other than funding for travel) }\end{array}$ & $\begin{array}{l}\text { My university offers funding or } \\
\text { research grants to support participation } \\
\text { in international collaborative projects } \\
\text { (other than funding for travel) }\end{array}$ \\
\hline $\mathrm{R} 2$ & Q16 & $\begin{array}{l}\text { University offers sabbatical } \\
\text { or release time to support } \\
\text { participation in international } \\
\text { collaborations }\end{array}$ & $\begin{array}{l}\text { My university offers sabbaticals or } \\
\text { release time to specifically support } \\
\text { participation in international } \\
\text { collaborative projects. }\end{array}$ \\
\hline $\mathrm{R} 2$ & Q17 & $\begin{array}{l}\text { University offers seminars or } \\
\text { networking sessions about } \\
\text { international collaboration }\end{array}$ & $\begin{array}{l}\text { My university supports seminars or } \\
\text { networking sessions to facilitate } \\
\text { communication among faculty about } \\
\text { their individual international } \\
\text { collaborations. }\end{array}$ \\
\hline
\end{tabular}

Notes: R2 = Research Question 2 and Q14= Survey Question 14 
International Collaboration Among Social Science Scholars

Table 17

Results from Survey Questions 14 through 17- What University Resources Are Available to

Support International Collaboration?

\begin{tabular}{|c|c|c|c|c|c|c|c|}
\hline Questions & $\begin{array}{l}\text { Yes, this is } \\
\text { offered at my } \\
\text { university. I } \\
\text { took } \\
\text { advantage of } \\
\text { the offer }\end{array}$ & & $\begin{array}{l}\text { Yes, this is } \\
\text { offered at my } \\
\text { university. I } \\
\text { did not take } \\
\text { advantage of } \\
\text { the offer }\end{array}$ & & $\begin{array}{l}\text { No, this is } \\
\text { not offered } \\
\text { at my } \\
\text { university }\end{array}$ & & Total \\
\hline $\begin{array}{l}\text { Q14 - My university } \\
\text { offers travel funding to } \\
\text { support participation in } \\
\text { international } \\
\text { collaborative projects. }\end{array}$ & $36.00 \%$ & 90 & $31.60 \%$ & 79 & $32.40 \%$ & 81 & 250 \\
\hline $\begin{array}{l}\text { Q15 - My university } \\
\text { offers funding or } \\
\text { research grants to support } \\
\text { participation in } \\
\text { international } \\
\text { collaborative projects } \\
\text { (other than travel } \\
\text { funding). }\end{array}$ & $20.88 \%$ & 52 & $33.33 \%$ & 83 & $45.78 \%$ & 114 & 249 \\
\hline $\begin{array}{l}\text { Q16 - My university } \\
\text { offers sabbaticals or } \\
\text { release time to } \\
\text { specifically support } \\
\text { participation in } \\
\text { international } \\
\text { collaborative projects. }\end{array}$ & $16.87 \%$ & 42 & $34.94 \%$ & 87 & $48.19 \%$ & 120 & 249 \\
\hline $\begin{array}{l}\text { Q17 - My university } \\
\text { supports seminars or } \\
\text { networking sessions to } \\
\text { facilitate communication } \\
\text { among faculty about their } \\
\text { individual international } \\
\text { collaborations. }\end{array}$ & $36.55 \%$ & 91 & $21.69 \%$ & 54 & $41.77 \%$ & 104 & 249 \\
\hline
\end{tabular}


International Collaboration Among Social Science Scholars

\section{Discussion of Research Question Two: University Support and Expectations for International Collaboration}

The second research question was focused on the scholars' experiences within the context of their university. This aspect of the survey was designed to determine if the scholar's university offers funding, time off from their teaching responsibilities, or networking opportunities, in association with their participation in international collaborative research projects. Moreover, this research documented the institutional expectations and rewards related to participation in international collaborative projects, specifically those that were associated with the tenure and promotion process.

The Childress model informed the development of research questions in this study that focus on funding and support as well as rewards in the tenure and promotion process that are associated with international collaboration. Childress (2010) stated that the most difficult aspect of accomplishing institutional goals of internationalization was moving from the planning phase to the operating phase (p.43). Childress explained that allowing faculty to connect with institution-wide goals through their individual scholarly agendas is one of the keys to operationalizing university internationalization. Moreover, Childress maintained that implementation of her model would "support individual faculty thereby allowing faculty to connect with international opportunities based on their personal areas of expertise and regional (international) interests” (Childress, 2010, p.201).

The survey questions related to funding and support asked if their university offered travel funding to support participation in international collaborative projects, funding or research grants, or sabbatical and release time. An additional layer of questioning was included to 
determine, in the cases that funding was offered by their university, whether or not respondents did take advantage of the funds. The results of the survey questions are presented in the preceding section. Overall, half of the individual respondents reported that they had access to funding and sabbaticals to support their participation in international collaborations. An interesting finding from the research results was that of the respondents that had the option to take funding and sabbaticals from their university, only half took advantage of the offer.

\section{Funding and Sabbaticals}

It is widely reported in the literature that scholars are motivated to collaborate to improve access to funds (Heffner, 1981; Beaver, 2001; Laudel, 2001; Lundberg et al., 2006; Wagner, 2008; Ou et al., 2012). However, access to funding is not listed as one of the top motivations for the social science scholars that participated in this study. Survey questions 14, 15, and 16 relate to the availability of university funds and sabbaticals to support participation in international collaboration. The results from these questions do not support the themes found in the literature on collaboration. In addition there was a large portion of respondents that indicated that funds were available from their university, however they did not take advantage of them. 


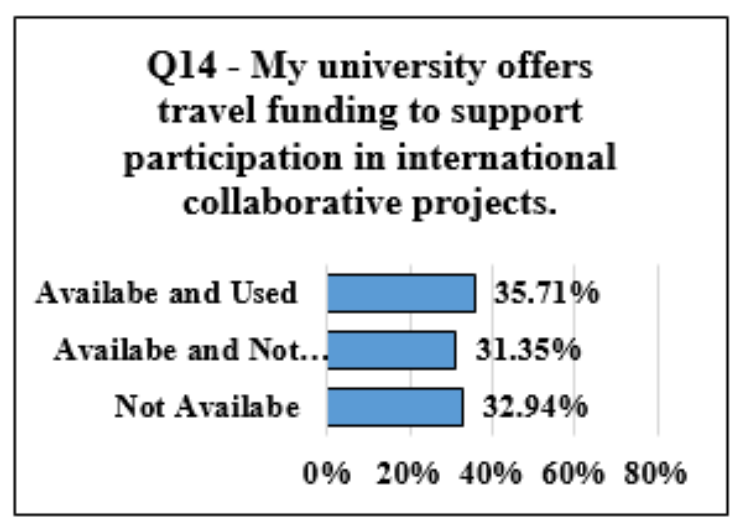

Q14 - My university offers travel funding to support participation in international collaborative projects.
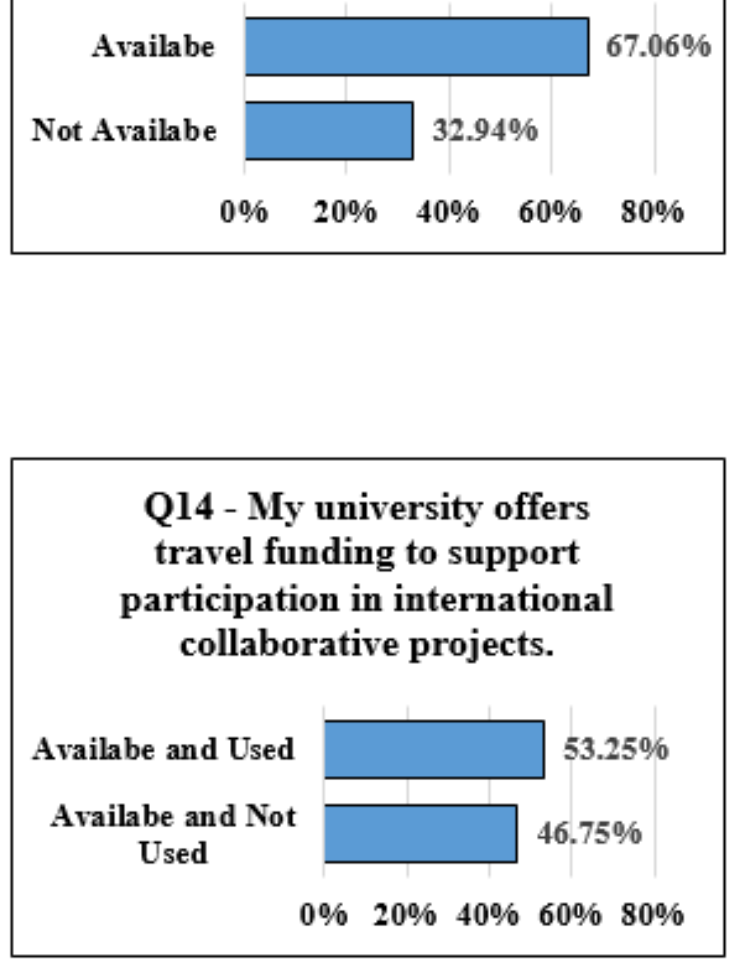

Q15 - My university offers funding or research grants for international collaborative projects (other than travel funding)

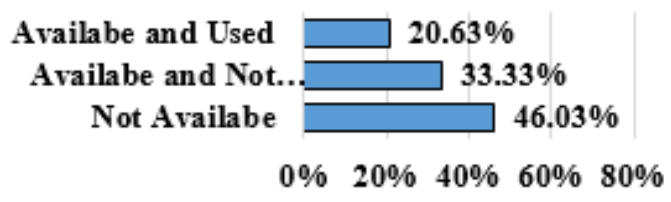

Q15 - My university offers funding or research grants for international collaborative projects (other than travel funding)

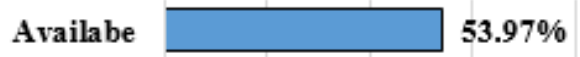

Not Availabe $\longrightarrow 46.03 \%$ $\begin{array}{lllll}0 \% & 20 \% & 40 \% & 60 \% & 80 \%\end{array}$
Q15 - My university offers funding or research grants for international collaborative projects (other than travel funding)

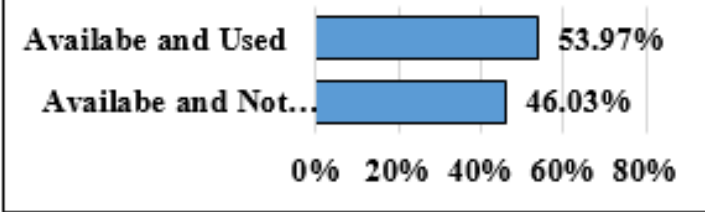



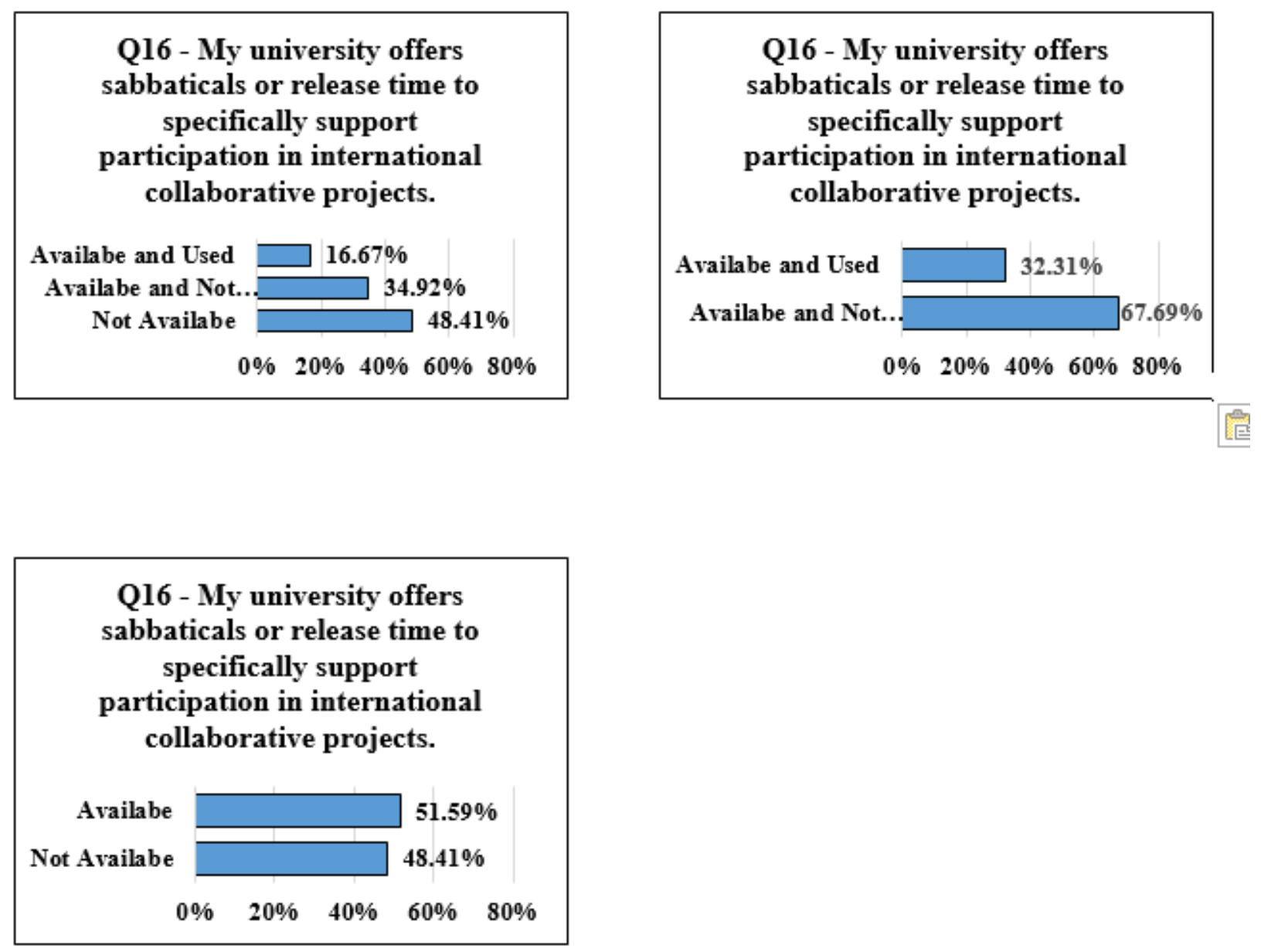

The results of the regression analysis for survey question 14 independent variable related to motivations based on university travel funding to support participation in international collaborative projects was found to not be statistically significant, with a $p$ value for the baseline model at 0.28731 and the $p$ value for the feature selection model at 0.121967 . The results of the regression analysis for survey question 15 independent variable associated with university funding or research grants other than travel funding was also found to not be statistically significant, with a $p$ value for the baseline model at 0.53047 . The $p$ value for the feature selection model was not calculated due to the fact that this independent variable was one of the fourteen 
variables that were removed in the backward elimination process of the feature selection model development process. The result of the regression analysis for the independent variable associated with survey question 16 was found to not be statistically significant, with a $p$ value for the baseline model at 0.08093 and the $p$ value for the feature selection model at 0.071775 .

\section{Seminars and Networking Sessions about International Collaboration}
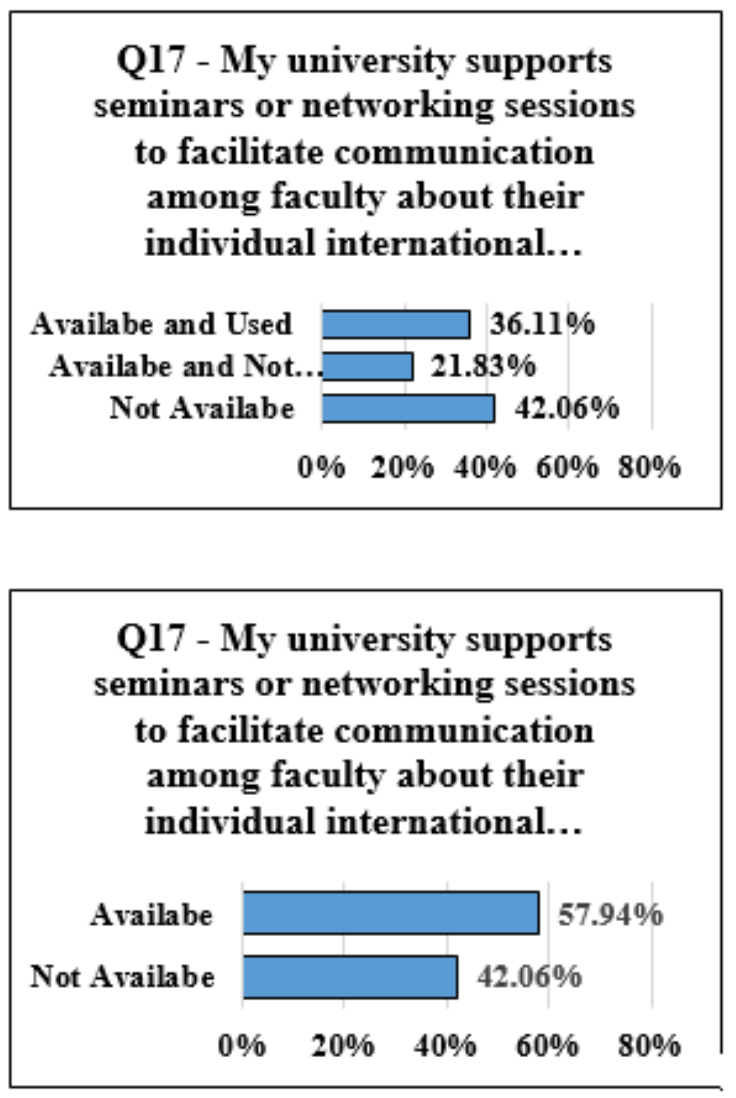

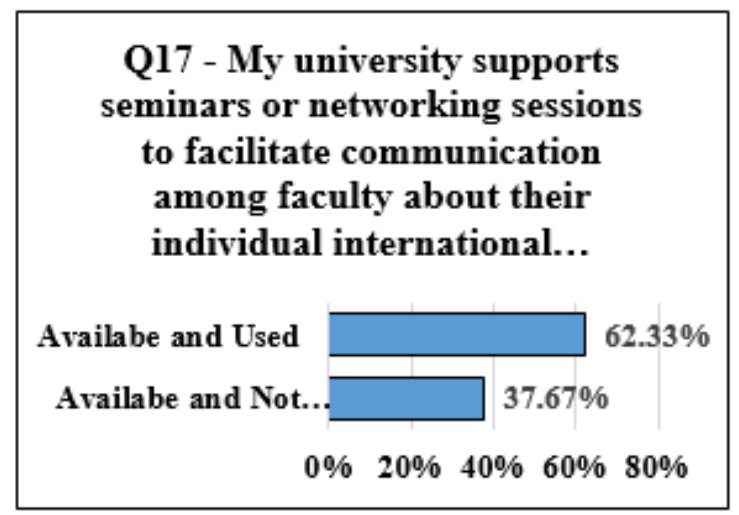

Data Categories:

Available and Used

Available and Not Use

Not Available

Survey question 17 was developed to gather data related to the availability of seminars or networking sessions that facilitate communication among scholars about their individual international collaborations. This question was developed based on an element of the Childress model that is known as "institutional networks." The concept of institutional networks relates to the development of intra-institutional communication channels that a university provides in order 
International Collaboration Among Social Science Scholars

for faculty to learn about resources available to support international collaboration as well as projects in which their university colleagues have participated. The responses to this question indicated that $59 \%$ of respondents had access to this type of programming at their universities. Furthermore of those respondents that have access, 37\% have participated in the programming.

The regression results of the baseline model as well as the feature selection model indicate that the independent variable associated with survey question 17 was statistically significant in both cases at the 0.05 level. This result is interesting in that the provision of seminars and networking sessions aimed at facilitating communication were found to be statistically significant with both regression models and yet the variables related to funding and sabbaticals that are provided by the university were not found to be statistically significant. As discussed earlier, the regression results related to funding and sabbaticals do not support the themes found in the literature on collaboration. Furthermore, there is a lack of literature related to seminars and networking sessions that facilitate communications among faculty about their research initiatives.

\section{Results from Research Question Three}

The third research question was: What expectations and rewards do universities have in the tenure and promotion process for social science scholars that participate in international collaborative research projects? Survey questions 18 through 20 were relied upon to generate the results to answer the third research question. The results of each survey question are presented in a data Table 19. 
Table 18

Research Question Three - What Expectations and Rewards do Universities have in the Tenure and Promotion Process for Social Science Scholars Who Participate in International Collaborative Research? Mapped to Survey Question 18 through 20

\begin{tabular}{|c|c|c|c|}
\hline $\begin{array}{l}\text { Research } \\
\text { Question }\end{array}$ & $\begin{array}{c}\text { Survey } \\
\text { Question }\end{array}$ & Independent Variable & $\begin{array}{l}\text { Questions: } \\
\text { The following questions are related to your } \\
\text { department or university’s expectations } \\
\text { related to participation in international } \\
\text { collaborative projects. }\end{array}$ \\
\hline R3 & Q18 & $\begin{array}{l}\text { University stipulates } \\
\text { participation in international } \\
\text { collaborative projects for } \\
\text { tenure and promotion }\end{array}$ & $\begin{array}{l}\text { My university stipulates that international } \\
\text { collaboration and co-authorship is required } \\
\text { for tenure and promotion. }\end{array}$ \\
\hline R3 & Q19 & $\begin{array}{l}\text { University encourages } \\
\text { international collaboration } \\
\text { but does not require }\end{array}$ & $\begin{array}{l}\text { My university encourages international } \\
\text { collaboration and co-authorship but does not } \\
\text { require it for tenure and promotion. }\end{array}$ \\
\hline $\mathrm{R} 3$ & Q20 & $\begin{array}{l}\text { Internationally co-authored } \\
\text { articles count more towards } \\
\text { tenure and promotion }\end{array}$ & $\begin{array}{l}\text { At my university, when considering articles } \\
\text { published in journals with a similar impact } \\
\text { factor, internationally co-authored articles } \\
\text { count more towards tenure and promotion } \\
\text { than articles co-authored with scholars in } \\
\text { this country. }\end{array}$ \\
\hline
\end{tabular}


International Collaboration Among Social Science Scholars

Table 19

The Results from Survey Questions 18 through 20 - The Following Questions are Related to

Your Department or University's Expectations Related to Participation in International

Collaborative Projects

\begin{tabular}{|c|c|c|c|c|c|}
\hline Questions & Yes & & No & & Total \\
\hline $\begin{array}{l}\text { Q18 - My university stipulates that international } \\
\text { collaboration and co-authorship is required for tenure and } \\
\text { promotion. }\end{array}$ & $5.67 \%$ & 14 & $94.33 \%$ & 233 & 247 \\
\hline $\begin{array}{l}\text { Q19 - My university encourages international } \\
\text { collaboration and co-authorship but does not require it for } \\
\text { tenure and promotion. }\end{array}$ & $67.07 \%$ & 165 & $32.93 \%$ & 81 & 246 \\
\hline $\begin{array}{l}\text { Q20 - At my university, when considering articles } \\
\text { published in journals with a similar impact factor, } \\
\text { internationally co-authored articles count more towards } \\
\text { tenure and promotion than articles co-authored with } \\
\text { scholars in this country. }\end{array}$ & $6.45 \%$ & 16 & $93.55 \%$ & 232 & 248 \\
\hline
\end{tabular}

The results from this array of questions suggest that there is a fairly homogeneous experience for most scholars that participated in this survey in relation to their universities’ tenure and promotion process and expectation or rewards for participating in international collaborative research projects. A comprehensive discussion of the results from these questions will be presented in the next section. 


\section{Discussion Research Question Three: Department or university's expectations related to participation in international collaborative projects.}

\section{University Stipulates International Collaboration}

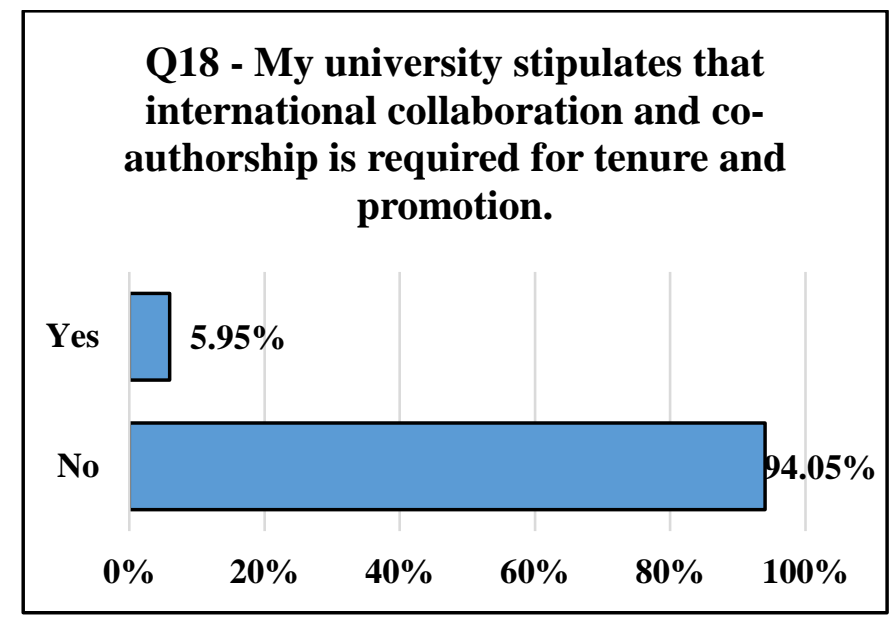

The Childress model informed the development of research Question 18. Specifically the question asks, does your university stipulate that international collaboration and co-authorship is required for tenure and promotion? Childress described this aspect of her model as “university intentionality.” Childress is a proponent of making participation in international initiatives a requirement for the tenure process. Although only $5.67 \%$ of respondents indicated this was true, the independent variable was found to be statistically significant. The results of the baseline model as well as the feature selection model indicated that the independent variable associated with question 18 was statistically significant in both cases at the 0.05 level. The 
results were unexpected given the low number of respondents that reported a positive response however the regression models in this research were used to test individual variables while holding the influence of other variables constant and therefore this outcome was possible.

\section{University Encourages Participation in International Collaboration}

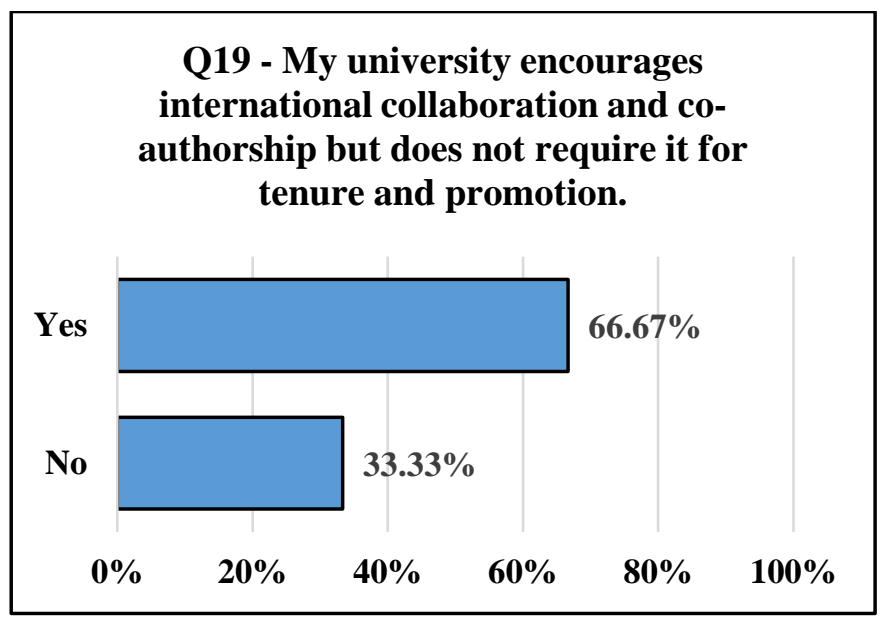

The intent of survey question 19 was to determine if a university encourages international collaboration but does not require it for tenure and promotion. The results indicate that $67 \%$ responded that their university encourages international collaboration and 33\% indicated that their university does not encourage participation. Internationalization is recognized as an indicator for academic quality and research excellence (Rostan, Flavio and Metcalfe, 2014). Considerable research and literature suggests that universities have made internationalization a goal however have been unable to accomplish broad involvement of their faculty (Altbach and Knight, 2011). An unexpected result was the large number of respondents that indicated their university does not encourage participation. The results of the regression 
analysis for this independent variable were found to not be statistically significant with $p$ value for the baseline model at 0.44891 . The $p$ value for the feature selection model was not calculated due to the fact that this independent variable was one of the fourteen variables that were removed in the backward elimination process of the feature selection model development process.

\section{Articles Published Internationally Count for More}

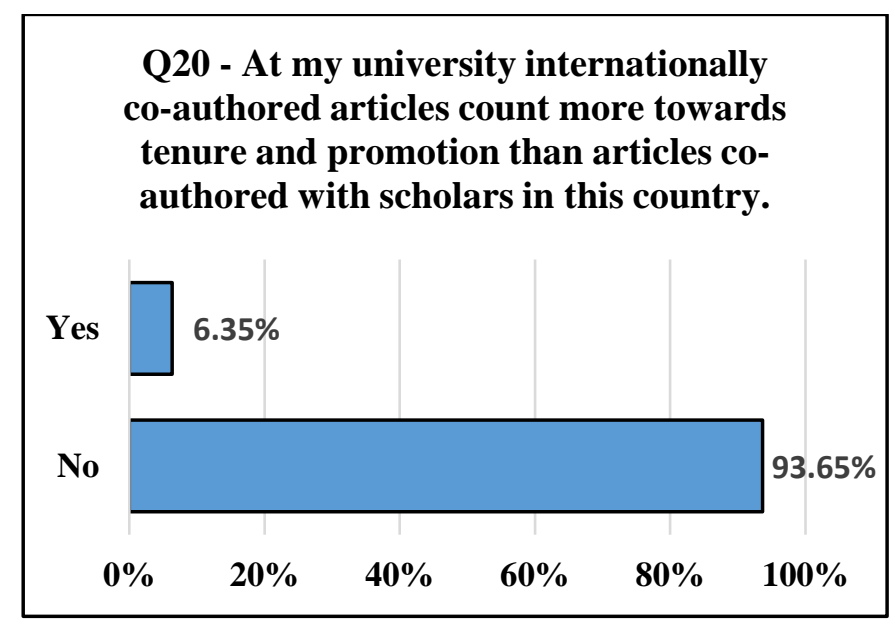

Survey question 20 was the final question about the rewards and expectations for international collaboration related to the tenure and promotion process. The question asked respondents, when considering articles published in journals with a similar impact factor, do internationally co-authored articles count more towards tenure and promotion than articles coauthored with scholar in their own country? Only 6.45\% of survey participants responded yes and $93.55 \%$ indicated no. The researcher conducted a cross tabulation analysis to determine more details about the respondents that indicated yes, all but one of the respondents indicated that English was not their native language. Prior literature suggests that scholars self-organize 
International Collaboration Among Social Science Scholars

into collaborative teams consistent with the concept of preferential attachment, in that scholars desire to enhance their own reputation through collaborative projects (Melin, 2000), because their focus is to enhance their reputation leads to higher levels of tenure and promotion. Given that internationalization and the involvement of faculty in international initiatives is a priority in many universities, it leads one to the question why there are a lack of stipulations or requirements for participation in international collaborative projects as a part of the tenure and promotion requirements.

The results of the regression analysis for this independent variable related to question 20 was found to not be statistically significant with $p$ value for the baseline model at 0.43660 . The $p$ value for the feature selection model was not calculated due to the fact that this independent variable was one of the fourteen variables that were removed in the backward elimination process of the feature selection model development process.

\section{Results and Discussion Research Question Four: Personal, Demographic, and Experiential Factors}

The fourth research question was: What patterns of participation in international collaborative projects emerge when analyzing across dimensions related to motivations, university support and expectations, demographics, career level, and experiential factors? The survey questions 21 through 27 were developed to create context related to a respondent's personal, demographic and experiential factors. The results from most survey questions in this group are reported as descriptive statistics. A selected number of the questions were used to 
cross tabulate data in order to present deeper contexts related to variables. Details of all cross tabulation results are provided in Appendix G: Cross Tabulation Data.

Table 20

Research Question Four and Associated Survey Questions

\begin{tabular}{|c|c|c|c|}
\hline $\begin{array}{l}\text { Research } \\
\text { Question }\end{array}$ & $\begin{array}{l}\text { Survey } \\
\text { Question }\end{array}$ & Independent Variable & $\begin{array}{c}\text { Questions: } \\
\text { The following questions } \\
\text { are related to personal } \\
\text { information }\end{array}$ \\
\hline $\mathrm{R} 4$ & Q21 & Year earned PhD & $\begin{array}{l}\text { I earned my PhD in the } \\
\text { following year. }\end{array}$ \\
\hline $\mathrm{R} 4$ & Q22 & Tenure level & $\begin{array}{c}\text { I am currently an: } \\
\text { Assistant Professor, } \\
\text { Associate Professor, Full } \\
\text { Professor, Other }\end{array}$ \\
\hline R4 & Q23 & Gender & $\begin{array}{c}\text { I identify my gender as: } \\
\text { Male, Female, Trans*, } \\
\text { None of the above, Prefer } \\
\text { not to disclose. }\end{array}$ \\
\hline R4 & Q24 & Native language & $\begin{array}{c}\text { My native Language is: } \\
\text { Choice from list of } \\
\text { languages }\end{array}$ \\
\hline $\mathrm{R} 4$ & Q25 & $\begin{array}{l}\text { Earned PhD in which } \\
\text { country }\end{array}$ & $\begin{array}{c}\text { The country that I earned } \\
\text { my doctorate in is ... } \\
\text { Choice from list of } \\
\text { countries }\end{array}$ \\
\hline R4 & Q26 & $\begin{array}{l}\text { Introduced to co-author } \\
\text { during PhD program }\end{array}$ & $\begin{array}{c}\text { I was introduced to one of } \\
\text { my co-authors during my } \\
\text { PhD program. }\end{array}$ \\
\hline $\mathrm{R} 4$ & Q27 & $\begin{array}{l}\text { Co-authored multiple } \\
\text { times with collaborator(s) }\end{array}$ & $\begin{array}{l}\text { I have co-authored } \\
\text { multiple times with at } \\
\text { least one of my co-authors } \\
\text { (more than one time). }\end{array}$ \\
\hline
\end{tabular}




\section{Year Earned PhD}

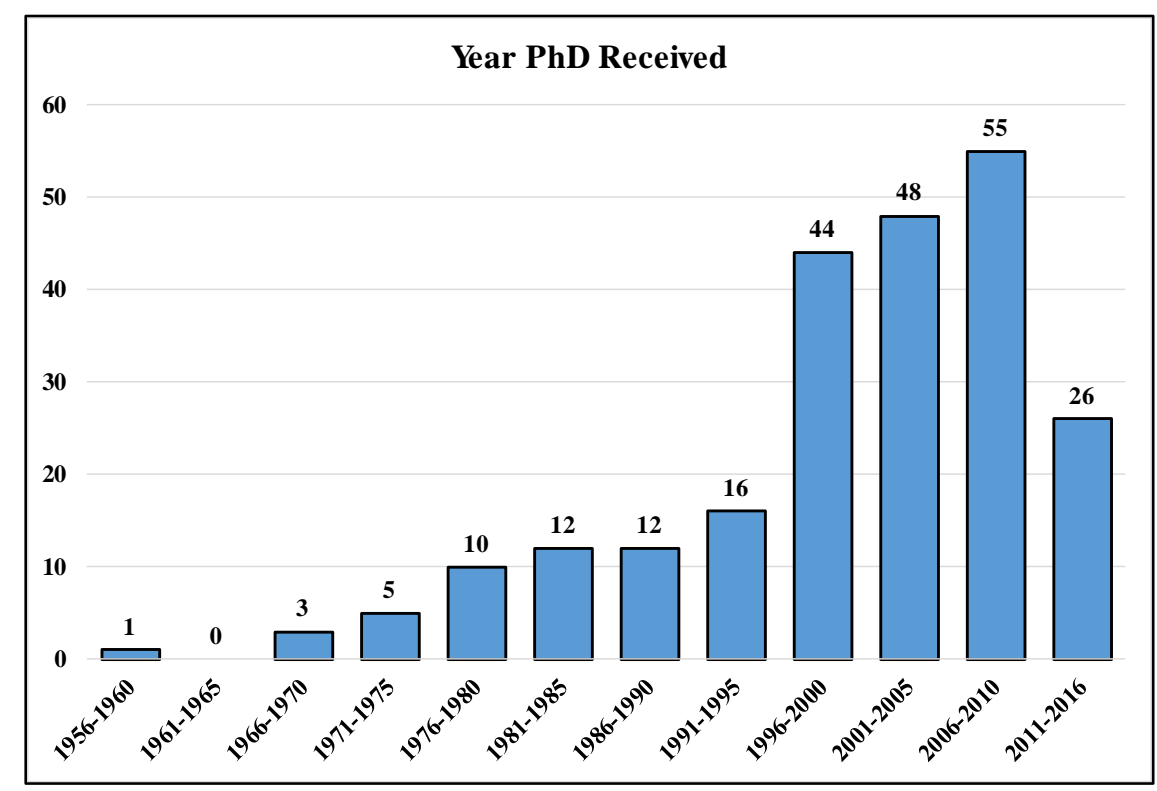

Survey question 21 asks for the respondent to indicate the year that they received their

$P h D$. The results indicate that $66 \%$ of the respondents have graduated in the past 20 years. In contrast, 34\% graduated from 20 to 60 years ago. A predominant number of the survey respondents are no more than 20 years into their career as a scholar. International collaboration is not confined to senior scholars. In the book titled Young Faculty in the Twenty-First Century Yudkevich, Altbach, and Rumbley (2015) discuss the changes to the academic career model for new faculty. Involvement in international projects is an expectation of the individual scholar although the universities have not unilaterally come to reward involvement in the tenure and promotion process. 
International Collaboration Among Social Science Scholars

Table 21

Results of Survey Question 21 - I Earned My PhD in the Following Year

The following questions are related personal information.

Q21 - I earned my PhD in the following year.

\begin{tabular}{l|r|r} 
Answer & $\%$ & Count \\
\hline 2016 & $1.29 \%$ & 3 \\
\hline 2015 & $1.29 \%$ & 3 \\
\hline 2014 & $1.29 \%$ & 3 \\
\hline 2013 & $2.59 \%$ & 6 \\
\hline 2012 & $2.16 \%$ & 5 \\
\hline 2011 & $2.59 \%$ & 6 \\
\hline 2010 & $2.59 \%$ & 6 \\
\hline 2009 & $4.31 \%$ & 10 \\
\hline 2008 & $7.33 \%$ & 17 \\
\hline 2007 & $5.17 \%$ & 12 \\
\hline 2006 & $4.31 \%$ & 10 \\
\hline 2005 & $4.31 \%$ & 10 \\
\hline 2004 & $4.31 \%$ & 10 \\
\hline 2003 & $2.59 \%$ & 6 \\
\hline 2002 & $3.45 \%$ & 8 \\
\hline 2001 & $6.03 \%$ & 14 \\
\hline 2000 & $3.88 \%$ & 9 \\
\hline
\end{tabular}

\begin{tabular}{r|r|r}
\hline 1999 & $3.45 \%$ & 8 \\
\hline 1998 & $5.60 \%$ & 13 \\
\hline 1997 & $2.59 \%$ & 6 \\
\hline 1996 & $3.45 \%$ & 8 \\
\hline 1995 & $3.45 \%$ & 8 \\
\hline 1994 & $1.29 \%$ & 3 \\
\hline 1993 & $0.86 \%$ & 2 \\
\hline 1992 & $0.43 \%$ & 1 \\
\hline 1991 & $0.86 \%$ & 2 \\
\hline 1990 & $0.86 \%$ & 2 \\
\hline 1989 & $1.29 \%$ & 3 \\
\hline 1988 & $0.86 \%$ & 2 \\
\hline 1987 & $1.29 \%$ & 3 \\
\hline 1986 & $0.86 \%$ & 2 \\
\hline 1985 & $1.72 \%$ & 4 \\
\hline 1984 & $0.43 \%$ & 1 \\
\hline 1983 & $1.72 \%$ & 4 \\
\hline 1982 & $0.86 \%$ & 2 \\
\hline 1981 & $0.43 \%$ & 1 \\
\hline 1980 & $0.00 \%$ & 0 \\
\hline 1979 & $1.72 \%$ & 4 \\
\hline 1978 & $0.86 \%$ & 2 \\
\hline 1977 & $0.43 \%$ & 1 \\
\hline 1976 & $1.29 \%$ & 3 \\
\hline
\end{tabular}




\section{Academic Rank}

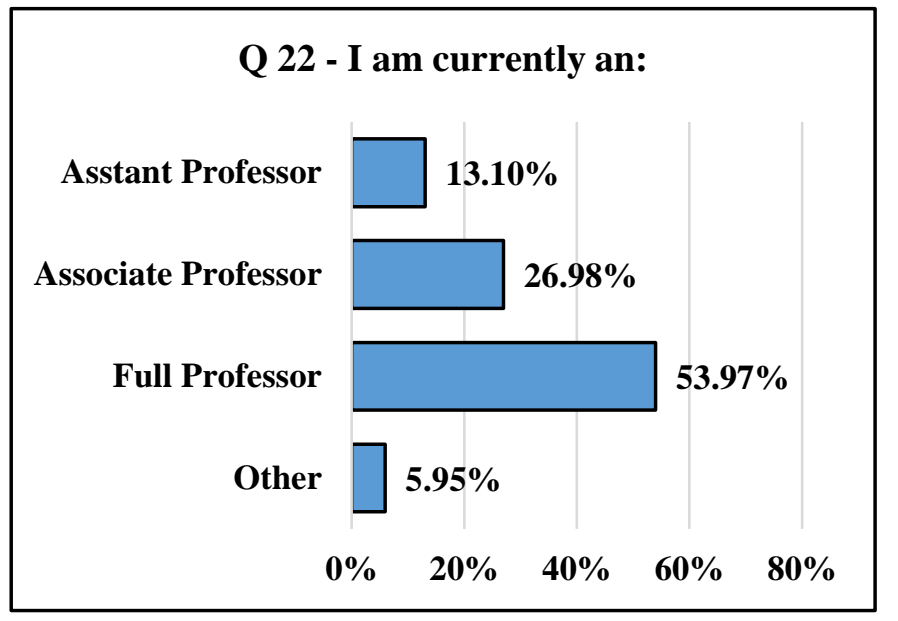

The concept of academic rank was addressed in survey question 22. Respondents in this study were predominately full professors, with 53.97\% indicating that they were at this level. In contrast $26.98 \%$ indicated they were associate professors, $13.10 \%$ indicated they were assistant professors, and 5.95\% reported that they did not hold one of these faculty ranks. Given that the respondents of this study were selected to participate in this research based on their participation in a co-authored article with an international colleague, it was a notable result from this survey question that $80.95 \%$ of the respondents are tenured faculty. Further research would be needed to understand the reasons for this notable difference in the percentage of tenured faculty who coauthor with their international colleagues as opposed to non-tenured faculty.

The results from this question were also used in cross tabulation analysis against other variables in this study. Academic ranks (Assistant, Associate, Full Professor) do have an effect on the distribution of results for particular variables. An example was the comparison of tenure levels of respondents to the question related to the motivation to participate in an international 
collaborative project in order to mentor a junior faculty or PhD student. The results from the cross tabulation analysis indicate there were $0 \%$ of assistant professors that strongly agree with the statement that they were motivated to collaborate because they wanted to mentor and help a junior colleague or graduate student, while there $15 \%$ of the associate professor and $25 \%$ of the full professor strongly agreed with the statement. Cross tabs calculated with this data are included in Appendix G: Cross Tabulation Data.

The results of the regression analysis of responses on academic rank was found to not be statistically significant with $p$ value for the baseline model at 0.61148 . The $p$ value for the feature selection model was not calculated due to the fact that this independent variable was one of the fourteen variables that were removed in the backward elimination process of the feature selection model development process.

Table 22

Results from Survey Question 22 - Tenure Level

Q22 data results - I am currently an:

\begin{tabular}{l|r|r} 
Answers & $\%$ & Count \\
\hline Assistant Professor & $13.15 \%$ & 33 \\
\hline Associate Professor & $26.69 \%$ & 67 \\
\hline Full Professor & $54.18 \%$ & 136 \\
\hline Other & $5.98 \%$ & 15 \\
\hline Total & $100 \%$ & 251 \\
\hline
\end{tabular}




\section{Gender}

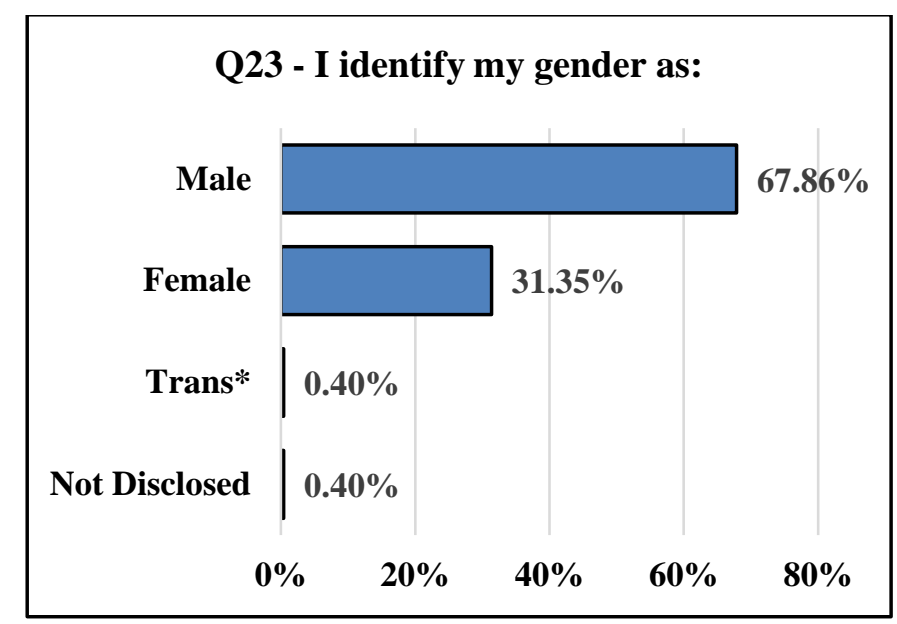

In response to survey question 23, over two thirds of the respondents indicated that they were male. Nearly one third of the respondents indicated that they were female. One respondent indicated that they were trans-gender as well as one respondent reported that neither male, female, nor trans-gender described their gender orientation. Further research would be needed to develop an understanding for this notable difference in the number of males who co-author with their international colleagues as opposed to females. The results of this survey question have been used in cross tabulation analysis, however it was determined that there were nominal changes in the overall results as compared to results with the gender data applied to cross tab calculations.

The results of the regression analysis related to the independent variable associated with gender was found to not be statistically significant with $p$ value for the baseline model at 0.59248. The $p$ value for the feature selection model was not calculated due to the fact that this independent variable was one of the fourteen variables that were removed in the backward elimination process of the feature selection model development process. 
International Collaboration Among Social Science Scholars

Table 23

Results from Survey Question 23 - Gender

Q23 data results- I identify my gender as:

\begin{tabular}{|l|r|r|}
\hline Answers & $\%$ & Count \\
\hline Male & $67.73 \%$ & 170 \\
\hline Female & $31.47 \%$ & 79 \\
\hline Trans* & $0.40 \%$ & 1 \\
\hline None of the above & $0.40 \%$ & 1 \\
\hline Prefer not to disclose & $0.00 \%$ & 0 \\
\hline Total & $100 \%$ & 251 \\
\hline
\end{tabular}

\section{Native Language}

Respondents were asked to indicate their native language in survey question 24 . There were 375 choices of languages provided in a drop down format in the online survey. There were 34 native languages indicated by the survey respondents. 
International Collaboration Among Social Science Scholars

Table 24

Results from Survey Question 24 - Native Language

Q24 - My native language is:

\begin{tabular}{|c|c|c|}
\hline Language & Percent & Count \\
\hline Arabic & $0.81 \%$ & 2 \\
\hline Bengali & $0.81 \%$ & 2 \\
\hline Burmese & $0.41 \%$ & 1 \\
\hline Cantonese & $0.41 \%$ & 1 \\
\hline Danish & $2.44 \%$ & 6 \\
\hline Dutch & $3.66 \%$ & 9 \\
\hline English & $47.97 \%$ & 118 \\
\hline Estonian & $0.41 \%$ & 1 \\
\hline Finnish & $0.41 \%$ & 1 \\
\hline French & $2.44 \%$ & 6 \\
\hline German & $10.57 \%$ & 26 \\
\hline Greek & $1.22 \%$ & 3 \\
\hline Gujarati & $0.41 \%$ & 1 \\
\hline Hebrew & $2.03 \%$ & 5 \\
\hline Hungarian & $0.41 \%$ & 1 \\
\hline Indonesian & $0.81 \%$ & 2 \\
\hline Italian & $5.28 \%$ & 13 \\
\hline Japanese & $0.41 \%$ & 1 \\
\hline Korean & $0.81 \%$ & 2 \\
\hline $\begin{array}{l}\text { Mandarin } \\
\text { (entire } \\
\text { branch) }\end{array}$ & $1.63 \%$ & 4 \\
\hline Marathi & $0.41 \%$ & 1 \\
\hline Norwegian & $0.81 \%$ & 2 \\
\hline Persian & $0.41 \%$ & 1 \\
\hline Polish & $0.81 \%$ & 2 \\
\hline
\end{tabular}

\begin{tabular}{l|r|r} 
Portuguese & $3.66 \%$ & 9 \\
\hline Romanian & $0.41 \%$ & 1 \\
\hline Russian & $2.03 \%$ & 5 \\
\hline $\begin{array}{l}\text { Serbo- } \\
\text { Croatian }\end{array}$ & $0.41 \%$ & 1 \\
\hline Slovene & $0.81 \%$ & 2 \\
\hline Spanish & $4.88 \%$ & 12 \\
\hline Swedish & $0.41 \%$ & 1 \\
\hline Telugu & $0.81 \%$ & 2 \\
\hline Turkish & $0.41 \%$ & 1 \\
\hline Vietnamese & $0.41 \%$ & 1 \\
\hline Total & $100 \%$ & 246 \\
\hline
\end{tabular}


In order to support data analysis based on native language, the researcher recoded the language variable to a binary code of Languages Other Than English coded as a zero and English coded as a 1 . The subsequent results from the recoding and analysis were $48.41 \%$ English and 51.59\% Other Than English.

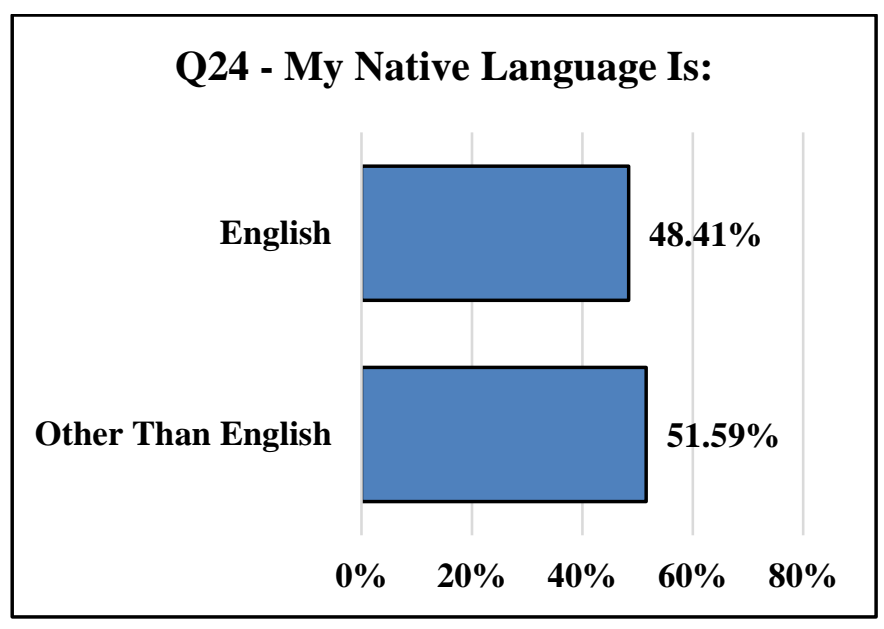

From the regression analysis of this question, the independent variable associated with native language was the most significant variable as related to the dependent variable in this study. The results of the baseline model as well as the feature selection model indicated that the independent variable associated with survey question 24 was statistically significant at the 0.001 level with both models. In both models variable for survey question 24 ranks the highest in statistical significance. The results of this survey question represent one of the important findings of this study. This outcome was not surprising to this researcher, given that the literature on scholarly publications reports journals that are published in the English language tend to hold a higher prestige rating. Therefore it was intuitive that scholars whose native language is a language other than English tend to seek after co-authors whose native language is English.

The results of cross tabulation analysis with native language data against a number of other independent variable generated multiple descriptive contrasts. For example when 
International Collaboration Among Social Science Scholars

comparing the most important motivation for participating in a specific international collaboration with the respondent's selection of my co-authors have strong reputations as researchers of that group of respondents 35\% were English native speakers and 65\% were native speakers of languages other than English. Of the respondents who indicated strongly agree or agree to the statement mentoring a junior colleague or PhD student was a motivation for participating in a specific international collaboration, 40\% were native English speakers and 25\% were native speakers of languages other than English. Cross tabs calculated with this data are included in Appendix G: Cross Tabulation Data.

\section{Country Doctorate Awarded}

Survey question 25 asks respondents to indicate the country that they earned their doctorate in. There were a total of thirty countries that were identified by the respondents. There were 137 scholars that received their doctorate from a university in the United States while 105 indicated that they received their degree in a country outside of the United States. Accordingly over half of the respondents, specifically 56.61\%, received their doctorate in the United States. 
International Collaboration Among Social Science Scholars

Table 25 Results of Survey Question 25 - Country Doctorate Awarded

\begin{tabular}{|c|c|c|}
\hline Q25-Country that I earned my $\mathrm{PhD}$ in is ... & $\%$ & Count \\
\hline Australia & $2.07 \%$ & 5 \\
\hline Austria & $0.83 \%$ & 2 \\
\hline Bangladesh & $0.41 \%$ & 1 \\
\hline Belgium & $1.24 \%$ & 3 \\
\hline Bosnia and Herzegovina & $0.41 \%$ & 1 \\
\hline Canada & $5.37 \%$ & 13 \\
\hline China & $1.24 \%$ & 3 \\
\hline Denmark & $1.65 \%$ & 4 \\
\hline Finland & $0.41 \%$ & 1 \\
\hline France & $1.65 \%$ & 4 \\
\hline Germany & $3.31 \%$ & 8 \\
\hline Hong Kong (S.A.R.) & $0.41 \%$ & 1 \\
\hline Hungary & $0.41 \%$ & 1 \\
\hline Ireland & $0.41 \%$ & 1 \\
\hline Israel & $0.41 \%$ & 1 \\
\hline Italy & $3.72 \%$ & 9 \\
\hline Netherlands & $3.31 \%$ & 8 \\
\hline New Zealand & $0.41 \%$ & 1 \\
\hline Norway & $0.41 \%$ & 1 \\
\hline Poland & $0.41 \%$ & 1 \\
\hline Portugal & $0.83 \%$ & 2 \\
\hline Russian Federation & $0.41 \%$ & 1 \\
\hline Singapore & $0.41 \%$ & 1 \\
\hline Slovenia & $0.41 \%$ & 1 \\
\hline South Africa & $0.41 \%$ & 1 \\
\hline Spain & $1.65 \%$ & 4 \\
\hline Sweden & $0.41 \%$ & 1 \\
\hline Switzerland & $1.24 \%$ & 3 \\
\hline United Kingdom and Northern Ireland & $9.09 \%$ & 22 \\
\hline United States of America & $56.61 \%$ & 137 \\
\hline Total & $100 \%$ & 242 \\
\hline
\end{tabular}




\section{Introduced to One of My Co-Authors During My PhD}

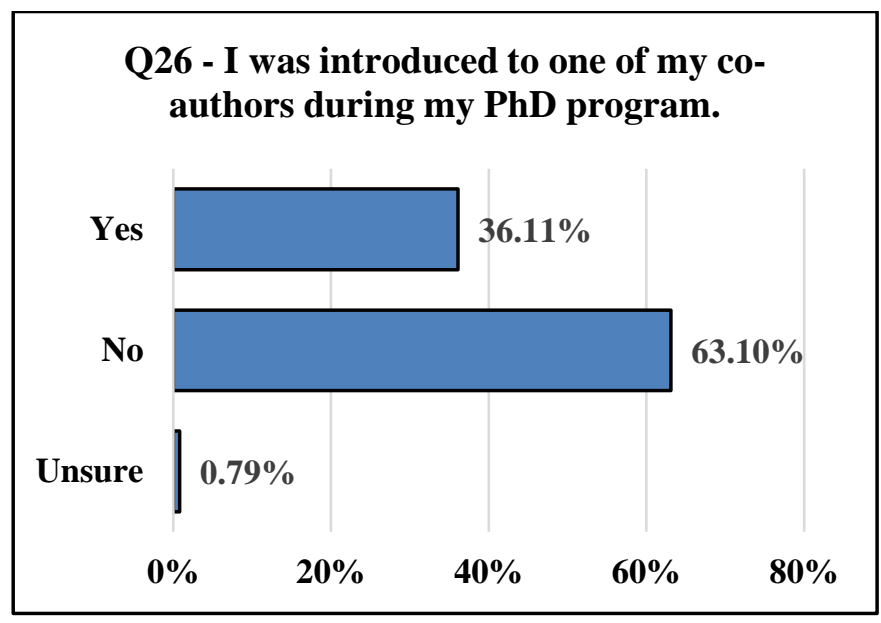

In order to offer some detail about the origins of international collaborative partnerships the prompt for survey question 26 read, I was introduced to one of my co-authors during my PhD program. The results of this question constituted an important findings of this research. Respondents indicated that 36\% were introduced to one of their co-authors during their $\mathrm{PhD}$ program.

The results of the regression analysis for the independent variable related to survey question 26 were found to not be statistically significant, with $p$ value for the baseline model at 0.53384. The $p$ value for the feature selection model was not calculated due to the fact that this independent variable was one of the fourteen variables that were removed in the backward elimination process of the feature selection model development process.

Using cross tabulation analysis against tenure level it was determined that of the respondents who indicated that they met one of their co-authors during their $\mathrm{PhD}, 29.67 \%$ were assistant professors, $29.67 \%$ were associate professors, and $32.97 \%$ were full professors. The 
remaining 7.69\% responded that they were neither assistant, associate, nor full professors. These research results indicate that of the respondents that were in a tenure track position, there was a similar distribution across all tenure levels. Cross tabs calculated with this data are included in Appendix G: Cross Tabulation Data.

In another cross data tabulation is was determine in the categories of native language English 35\% had introduced to one of their co-authors during their PhD program. In the category of native language other than English 65\% were introduced to one of their co-authors during their Ph.D. program. Cross tabs calculated with this data are included in Appendix G: Cross Tabulation Data. Further research would be needed to understand the reasons for this notable difference in the percentage between scholars that have a native language other than English and scholars that have English as their native language. Nevertheless, the outcome is notable, and is worthy of further investigation.

\section{Co-Authored Multiple Times}

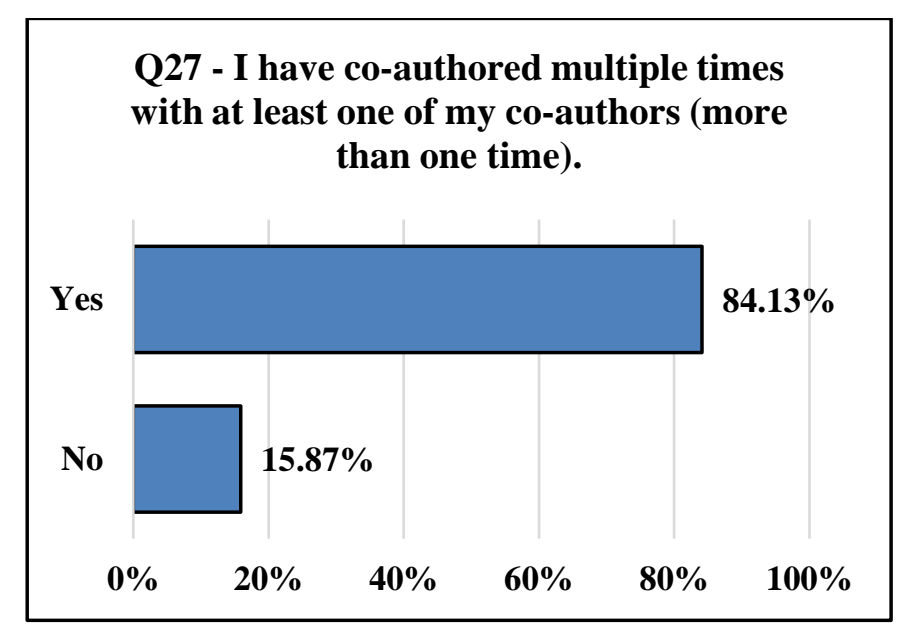


International Collaboration Among Social Science Scholars

Survey question 27 was developed to determine if a scholar had authored multiple times with at least one of their co-authors. The literature on scholarly collaboration indicates shared projects help collaborators align research paradigms and create academic experiences that yield a similar mindset on how to organize and accomplish research (Bozeman \& Corley, 2004; Ou et al., 2012). Additional factors presented in the scholarly literature are that shared experiences and success in past collaborative projects builds cohesive collaborative teams. (Simonin, 1997; Melin, 2000; Bozeman \& Corley, 2004, Ou et al., 2012).

The results of survey question 27 represented one of the outstanding conclusions of this study. The results indicated that $84 \%$ of respondents have co-authored multiple times with at least one of their co-authors. This supports the results of survey question 8 that indicated that $73 \%$ of respondents answered strongly agree or agree to the statement, I was motivated to participate in this international collaboration because I had worked effectively with one of my co-authors before on a successful project. However, the results of the regression analysis for the independent variable associated with survey question 27 was found to not be statistically significant with $p$ value for the baseline model at 0.92153 . The $p$ value for the feature selection model was not calculated due to the fact that this independent variable was one of the fourteen variables that were removed in the backward elimination process of the feature selection model development process. The results are unexpected given the high number of respondents that reported response of agree or strongly agree however the regression models in this research were used to test individual variables while holding the influence of other variables constant and therefore this outcome is possible. 


\section{Conclusion}

The results of this research both confirmed and confounded the results of prior research on international collaboration and co-authorship. This research sought to complement the research on international collaboration and co-authorship in the natural sciences by focusing exclusively on international collaboration between social science scholars. The literature reported that scholars in the natural sciences are motivated to collaborate internationally based on the opportunity to build their research reputation; to gain access to data, labs, or technology that is not available at their home institution; to develop access to funding resources; and to gain the opportunity to join an extended team working on research initiatives (Wagner, 2008; Knight, 2008). In contrast, the literature reported that social scientists are motivated to collaborate and co-author with their international colleagues in order to increase knowledge, increase the likelihood that the resulting work will be of higher academic quality, to generate new research ideas and streams, and to make connections with colleagues for future projects (Melin,2000). The results from this study confirmed the concepts presented in the literature related to the motivation for social scientists to collaborate and co-author with their international colleagues however there were also some confounding results that indicate motivations for social scientists were a mix of all of the above mentioned motivations for both social scientists and natural scientists.

Another example of confounding results was related to Childress's work on the involvement of faculty in university internationalization initiatives. Childress (2010) maintained that there are institutional variables that act as a catalyst either individually or in combination to encourage faculty participation in institutional initiatives related to internationalization.

Specifically Childress identified these catalysts as funding, support and resources available to 
scholars at their university as well as the institutional encouragement or expectations of international collaboration related to the tenure and promotion process. The fact that respondents reported that they had resources available for international collaboration and did not take advantage of them is an example of a confounding result that was been generated by this research. Perhaps international collaborations in the social sciences do not require significant funding. Another explanation could be that the process for securing resources from the university was difficult. The results of this study have been discussed at length in this chapter. The final chapter of this research summarizes the outcomes of this study in relation to past research, discusses the unique contributions that were developed from this study, and outlines future research projects that could be undertaken to expand knowledge related to international collaboration and co-authorship for social science scholars. 
International Collaboration Among Social Science Scholars

\section{Chapter Five: Research Discussion}

In order to keep pace with the global prestige race among their peer academic institutions, universities are striving to find ways to encourage faculty to participate in international research, collaboration, and co-authorship activities. Faculty play a key role in success of institutional goals to internationalize the curriculum, programs, and research activities. The literature has suggested that the alignment of institutional strategies and faculty research goals has the potential to be a win-win opportunity for both faculty and the university. Developing an understanding of the nature of international research, collaborative, and coauthorship activities among social science faculty could be used to develop improvements in university infrastructure for supporting faculty in their international collaborative research and co-authorship activities.

\section{Research Landscape}

There are several types of research methodology that are reported in the higher education literature related to the study of the phenomenon of international research collaboration and coauthorship. Research on collaboration can be conducted from a macro or micro perspective. In the past, studies on research collaboration have traditionally focused on the macro aspects. Macro methodologies typically result in descriptive statistics that take on the form of a time series format for example showing the growth of activity over a period of time with a scope relating to a single institution, a region, or a specific country. Another variation of macro research design limits the study to a group of scholars that is at a particular university or within a subject discipline. Another macro research methodology used to study international research collaboration and co-authorship is social network analysis. Bibliographic analysis, such as citation counts, is a macro methodology used to describe the extent that international co-authorship activity has occurred or to measure the impact of articles that are 
International Collaboration Among Social Science Scholars

co-authored. A third type of research method is characterized by applying a micro lens to the research design.

The micro level of investigation relates to research topics such as the decision to collaborate based on shared interest, the process of choosing co-authors, the individual reasons for collaborating, or nature of the relationship between collaborators (Melin, 2010), In contrast to macro models, micro research models are focused on the individual scholar and have the goal of gathering data related a scholar's experience, motivations, and perceptions that are associated with their participation in international co-authorship initiatives. As discussed earlier in this work, the lack of micro designed research was highlighted by Melin (2012). Melin stated "we do not know very much about this micro level and the processes at work since there have been few attempts to leave the macro level of analysis and get closer to the actual collaborators,” (p.32). Of the few studies that have been done at the micro level, "none of the studies investigate anything about the motives behind collaboration, the different forms that it can take or what effects it has. Hence, Melin highlights the need to move the level of analysis from macro to micro, and "start finding out what the researchers’ opinions are considering collaboration, and which kind of dynamic processes are at work in the teams and networks (p.33).”

In The New Invisible College, Wagner explains that universities will have more success engaging faculty in international research initiatives if they develop a deep understanding of the factors that influence a scholar’s decision to undertake research initiatives (2008). The goal of this research was to support the development of university institutional policies and programs aimed at encouraging faculty to participate in collaborative research projects with their international colleagues. Therefore a micro research model was developed for this research with the goal of generating specific results that would have the potential to inform this endeavor. 
International Collaboration Among Social Science Scholars

The literature reports that the expansion of international collaboration between scholars was a direct result of the "big science” movement and has been predominantly associated with the sciences, technology, engineering, and medicine, also known as the STEM fields (Rostan, Ceravolo \& Metcalfe, 2014). STEM collaborations are characterized by large international teams and funding from a combination of organizations such as universities, government agencies and corporations. In contrast international collaborations in the social sciences, humanities, and the arts are typically small teams that average between two and five members and lack expansive opportunities for funding their research activities. Research shows an increase in collaboration across the board in all disciplines, however comparative studies indicated that there was a compounded increase in collaborative activities the STEM fields as opposed to the fields of social science, humanities, and the arts. (Rostan, Ceravolo \& Metcalfe, 2014, p. 135). In contrast to the STEM fields, there has been a slower growth in collaborative activities in the social sciences and humanities (Lariviere et al, 2006). The expansive growth of collaboration in the STEM fields has been reflected in the literature. The significant portion of the articles report on the collaborative activities in the STEM fields as compared to the social sciences. This research was designed to address the gap and extend the literature on international collaboration among social science scholars.

\section{Research on International Collaboration That Informed The Model For This Study}

The conceptual framework for this research was informed by the work of Wagner, Melin, and Childress. The following sections highlight their theories and discuss how this research on international collaboration is positioned in relation to their work. The discussion will include a comparative analysis related to congruent or incongruent aspects of the results of this research. 
International Collaboration Among Social Science Scholars

Wagner (2008) highlights the emergence of a new model that is characterized by a global network of scholars that are leveraging the opportunity to be linked through virtual ties. Although Wagner's research was predominately focused on scholars in the natural sciences, the model was selected by this researcher to inform the conceptual framework development due to the robust development of the international collaboration model. Wagner states "these networks constitute an invisible college of researchers who collaborate not because they are told to but because they want to work together not because they share a laboratory or even a discipline but because they can offer each other complementary insight, knowledge, or skills, (Wagner, 2008, p 2).” Wagner's statement “they can offer each other complementary insights, knowledge, or skills is supported by the results of this research. Specifically, several of the results from the survey question $I$ was motivated to collaborate on this article because ... support Wagner's statement. Results that apply directly to Wagner's statement are: Question one, I was motivated to collaborate on this article because my co-authors have strong reputations as researchers with $79 \%$ of participants responding in the strongly agree to agree range. Question four, I was motivated to collaborate on this article because my co-authors have expertise different than my own with $88 \%$ of participants responding in the strongly agree to agree range. Question six, I was motivated to collaborate on this article because working with my co-authors allowed us to pool knowledge to accomplish complex research with $96 \%$ of participants responding in the strongly agree to agree range.

As discussed earlier, Wagner identifies "five forces" that are driving the shift of the scholarly networks from national structures to global structures and thereby changing the nature of invisible colleges. This research provides data related to two of the five force, specifically the fourth and fifth forces that related to research teams being made up of scholars from around the globe and the provision of the opportunity for diverse groups to form and take advantage of 
International Collaboration Among Social Science Scholars

knowledge and expertise that is not available locally (p.5). . Specifically, several of the results from the survey question I was motivated to collaborate on this article because ... support the concepts of the fourth and fifth forces. The fourth force relates to the concept of stickiness which encompasses the need to cluster resources, people, and ideas in order to be efficient in the production of new knowledge. The fifth force highlights the value of forming teams to collaborate and distribute tasks. Results that apply directly to Wagner’s forces are as follows: survey question 4 , I was motivated to collaborate on this article because my co-authors have expertise different than my own, with $88 \%$ of participants responding in the strongly agree to agree range; and survey question 6, I was motivated to collaborate on this article because working with my co-authors allowed us to pool knowledge to accomplish complex research with $96 \%$ of participants responding in the strongly agree to agree range.

In her work The New Invisible College, Wagner states, “scholars self-organize into collaborative teams based on relatively simple rules (that are) set and followed at the individual level” (Wagner, 2008, p. 62). The rules are based on the concept of preferential attachment in that scholars desire to enhance their own reputation through collaborative projects. Wagner states that "scholars that are approached to join a research initiative will follow a simple formula: If this collaboration will help me advance my research or its diffusion, then I should participate in it” (p. 61). The results that apply directly to Wagner's concept of preferential attachment are from Question six, I was motivated to collaborate on this article because working with my coauthors allowed us to pool knowledge to accomplish complex research with $96 \%$ of participants responding in the strongly agree to agree range. Also, from Question eight I was motivated to collaborate on this article because I had worked effectively with one of my co-authors before on a successful project with $73 \%$ of participants responding in the strongly agree to agree range. I 
International Collaboration Among Social Science Scholars

had worked effectively with one of my co-authors on a successful project. These two concepts found to be statistically significant in the regression model developed through feature selection in this research. The level of .05 is considered to indicate significance in the social science research, Question 6 at a P value of .025 and Question 8 at a P value of .0008 were found to be significant in the model that was developed by feature selection. Both concepts reflect a conscientious choice made by a scholar based on their assessment of the probability of a successful outcome to the collaborative project.

Wagner reported that the top motivations for scholars in the natural sciences to participate in international research collaborations are: the opportunity to build reputation; to gain access to data, labs, or technology that is not available at their home institution; to develop access to funding resources; and to gain the opportunity to join an extended team working on research initiatives. The results of this research when analyzing the top motivations for participating in international research collaborations are slightly different than reported by Wagner. The top motivations reported by the participants in this research in ranked order for the question I was motivated to collaborate on this article because were: 1) Working together allowed us to pool knowledge to accomplish complex research, 2) My co-authors are pleasant an fun to work with, 3) My co-authors have expertise different than my own, 4) My co-authors have strong reputations as researchers, and 5) I had worked effectively with one of my co-authors before on a successful project. While the nature science scholars highly ranked gaining access to labs, data, or technology and developing access to fund, in contrast the social science scholars ranked these aspects as the lowest concepts on their motivation scale. The questions related to these aspects were: participating improved my access to special data or research equipment; working on this collaborative project improved my access to external funds; working on this 
International Collaboration Among Social Science Scholars

collaborative project improved my access to university funds. The differences in motivations may be accounted for by the differences in the natural sciences and social sciences research environment. Natural science research activities are characterized by the need for extensive labs and access to data.

In his article Pragmatism and self-organization: Research collaboration on the individual level, Goran Melin highlights the individual nature of a scholar's choice to collaborate (Melin, 2010). Melin describes how faculty make decisions about research initiatives and collaborative partnerships based his/her evolving roles as scholars within the network of colleagues in their subject disciplines. Scholars within the network undertake a socio-cognitive process whereby they determine their own research stream, path of inquiry and make choices to work independently or to collaborate with colleagues on research projects. The underlying concept is that scholars self-organize their research agendas and therefore their research activities are typically not dictated by their universities.

Melin found that the top four motivations for social scientists to collaborate with their cross national colleagues was to increase knowledge, increase the likelihood that the resulting work would be of higher academic quality, the generation of new ideas, and to make connections with colleagues for future projects. The results of this research support the concepts in Melin's framework of international collaboration and co-authorship. Specifically, the results from survey question 1 indicated that $79 \%$ of the respondents reported they strongly agree to agree with the statement, I was motivated to collaborate on this article because my co-authors have strong reputations as researchers. The data from survey question 4 indicated that $88 \%$ of respondents reported they strongly agree or agree with the statement, I was motivated to collaborate on this article because my co-authors have expertise different than my own. Furthermore, the results 
International Collaboration Among Social Science Scholars

from survey question 6 indicated that $88 \%$ of respondents stated that the agreed or strongly agreed with the statement, I was motivated to collaborate on this article because working with my co-authors allowed us to pool knowledge to accomplish complex research. The results of this survey creates a representation of the mosaic of motivations that influence social science scholars when they chose to participate in an international collaborative project.

Lisa Childress's The Twenty-First Century University: Developing Faculty Engagement in Internationalization highlights the ongoing struggle most institutions face stating, "despite consistent calls for internationalization over the past half century, implementation remains challenging, and therefore lacking, in many higher education institutions” (Childress, 2010, p.4). Childress's model of faculty engagement in internationalization informed the development of this research, however it differs from the work of Wagner and Melin. The Childress model is a conceptual model in that it describes activities related to institutional initiatives while the Wagner and Melin models focus on specific actions of individual scholars.

Childress (2009) states that the most difficult aspect of accomplishing institutional goals of internationalization is moving from the planning phase to the operating phase (p.43). Childress explains that allowing faculty to connect with institution-wide goals through their individual scholarly agendas is one of the keys to operationalizing university internationalization. To address these challenges, Childress created a faculty engagement model that is designed to help university leaders operationalize their plans to expand faculty engagement in internationalization initiatives (Childress, 2010). The concepts that make up the Childress Model Five I's of Faculty Engagement in Internationalization are : intentionality, investments, infrastructure, institutional networks, and individual support (Exhibit One: Childress Model of the Five I's of Faculty in Internationalization). 
The central question this research sought to answer was, what motivates a scholar to participate in a collaborative research project with colleagues from institutions that are located in different countries? This research integrated three facets of the Childress model; investments, individual support, and institutional networks into the survey design. This research intended to collect data related to the Childress facet of investments, such as travel funding and faculty being given time off to participate in cross national collaborative research projects. To that end, the facet of individual support was incorporated into the survey design and data collection.

The literature reports that scholars are motivated to collaborate in order to improve access to funds. However, access to funding was not found to be one of the top motivations for the social science scholars that participated in this study. Moreover, survey questions 14, 15, and 16 relate to the availability of university funds and sabbaticals to support participation in international collaboration. Results from this research indicated that approximately two thirds of universities provide funding for travel, research grants, and sabbaticals in order to support their faculty’s participation in international collaborative projects. Nevertheless, a large portion of faculty who have access to funds and sabbiticals indicated that they do not take advantage of them. This is a confounding result. Given that the Childress model is focused on facilitating the operationalization of internationalization initiatives, a short-term recommendation is that when funds are available to support participation in international research collaborations, universities should work on streamlining the communication and process for awarding funds and granting sabbaticals. Future research could seek to expand the understanding what factors are related to funding and resources as well as to what extent this type of support motivate faculty to participate in international collaborative research projects. 
“Institutional networks" is an operational concept in the Childress model that relates to the development of intra-institutional communication channels that a university provides in order for “faculty to learn about international opportunities, resources and their colleagues' areas of expertise and regional interests (p. 142).” Examples include faculty seminars on international projects, supporting the development of deeper relationships with faculty in other countries, and formalizing faculty research exchange agreements with institutions in other countries.

This survey included an independent variable and associated question that gathered data related to the availability of seminars and networking sessions that are organized by universities. Programs like this facilitate communication among faculty about their individual international collaborations. In this research the results of the baseline model as well as the feature selection model indicate that this independent variable associated with this question is statistically significant at the 0.05 level. More research is needed understand the relationship between the opportunity to participate in institutional programs on international collaboration and the increased participation in international collaborative projects that result in co-authored articles.

The concept of "individual support" in the Childress model is twofold. The first aspect, discussed above, relates to the individual support, specifically the provision of funding, resources, and time to participate in international collaborations. The second aspect is a nuanced aspect of individual support in which the institution values participation in cross national collaborative research projects. This is evidenced by the institution, for example, counting participation in international collaborative research projects favorably and preferentially during tenure and promotion evaluations. This researcher developed a set of three questions related to this aspect of the Childress model. The questions were preceded by a statement saying: The following questions are related to your department or university's expectations related to 
participation in international collaborative projects. The questions and results were discussed in the preceding chapter however the results of survey question 18 warrant highlighting. Survey question 18 asked respondents to indicate if their university stipulated that international collaboration and co-authorship is required for tenure and promotion. Over $94 \%$ of the respondents indicated that their university does not stipulate that international collaboration and co-authorship is require for tenure and promotion. Less than $6 \%$ of the respondents indicated that it was stipulated for tenure and promotion at their university. Childress has stated that although internationalization is a common institutional priority, many universities are unable to accomplish the unilateral involvement of their faculty in international initiatives. Given that tenure and promotion is a motivating factor for most scholars there could be merit in institutions developing policies and processes for awarding higher value for international collaboration and co-authorship in their tenure and promotion process.

The Childress model informed the development of research questions in this study that focused on funding and support as well as rewards in the tenure and promotion process that are associated with international collaboration. Several of the results from this research were confounding and indicate the need for more research related to the provision of individual support for faculty as well as the lack of institutional polices that assign a higher value to international collaborative research and co-authorship in tenure and promotion considerations.

Childress has a number of specific recommendations in her work that universities can implement to facilitate faculty participation in international initiatives. Two additional ideas for institutional initiatives evolved from this research and focus on ways to strengthen existing international collaborative relationships. The results of this survey found that $84 \%$ of the respondents had co-authored multiple times with at least one of their international co-authors. 
International Collaboration Among Social Science Scholars

The corresponding results from another question specify that $73 \%$ of the respondents indicated that they had worked effectively with one of their co-authors on a successful project. An example of a university initiative that could strengthen existing international collaborative relationships would be to provide funding for a faculty to travel, visit, and work with their coauthors in other countries. The opportunities to work adjacent to co-authors has the potential to strengthen relationships between international co-authors as well as expand prospects for research collaborations in the future. Additionally, a university could undertake an initiative to upgrade technology in order to support a higher level of interaction between international collaborative team members.

\section{Contributions of This Research to the Development of Knowledge About International Collaboration}

The unique contribution of this research was the generation of a broad data set on social science scholars involved in a recent international collaborative projects, the multi-faceted group of concepts represented in the survey questions and the international scope of the respondents. Contributions related to research processes are the development of a survey instrument, the generation of an explanatory model that incorporated multiple linear regression as a statistical modeling technique, and the development of a new bibliographic analysis model for illuminating faculty activities using the Web of Science/Web of Knowledge database.

Many higher education scholars have written about the ongoing challenges and lack of success that that universities have experienced in their efforts to internationalize. Faculty are key factor in the success of institutional initiatives. Although internationalization is an institutional priority for many universities, they have been unable to unilaterally involvement of their faculty in 
International Collaboration Among Social Science Scholars

international initiatives. One strategy aimed at increasing faculty participation in international initiatives involves bridging individual research agendas with the institutional mission to internationalize (Childress, 2010). The ultimate goal of this research was to inform the development of institutional policies and programs aimed at encouraging faculty to participate in collaborative research projects with their international colleagues. Literature on faculty collaboration reports that scholars self-organize into team based on the concept of preferential attachment. Decisions about what and whom to collaborate with on research projects is related to their desire to be involved in successful research initiatives and thereby enhance their own reputation as a scholar. The uniqueness of this research model was that it focused on individual social science scholars who were involved in international collaborative research projects that resulted in a co-authored article. The research design yielded a broad set of data that have the potential to inform the development of effective programs, policies, and procedures related to faculty involvement and institutional goals of internationalization. The research results are multifaceted as data was gleaned from several aspects of a scholar's experience in an international collaboration. One aspect of the research concentrated on understanding the scholar's motivation for participating in the international collaboration. Additionally, the research gathered data related to university research policies including funding for participation in international collaborative projects and the value of participation in international collaborations related to the tenure and promotion review.

The respondents were international in scope encompassing faculty of universities in 47 countries throughout the world. Figure 2. Wagner highlighted the emergence of a new model that was characterized by a global network of scholars. The target population for this study was social science scholars from faculty at universities throughout the world. The sampling frame 
was a group of social science scholars who have co-authored papers with colleagues from universities in other countries. The resulting group respondents was developed with a global scope data related to the phenomenon of international co-authorship.

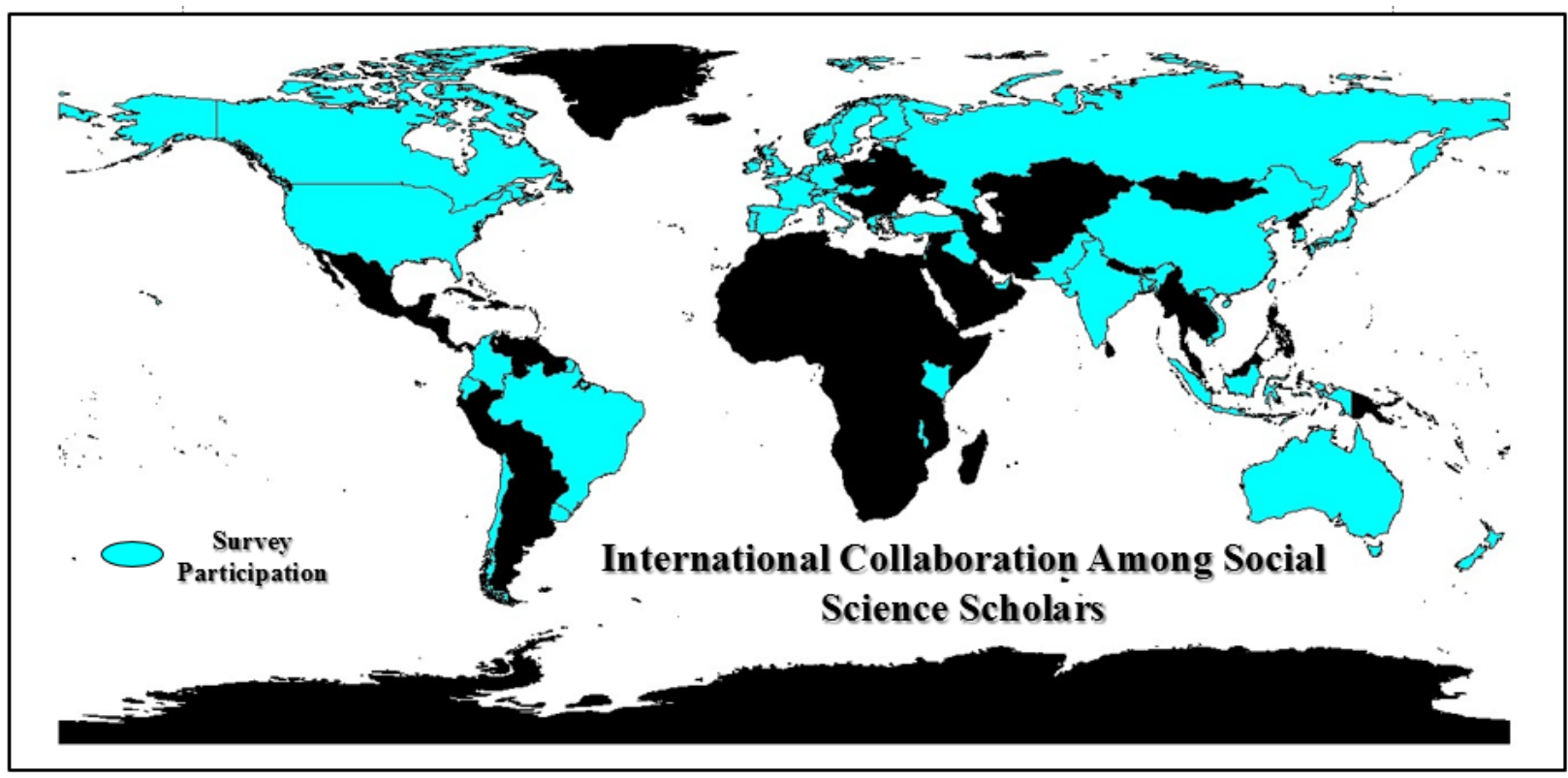

Figure 2. Graphic Representation of Country Location: Institutions of Respondents.

A unique contribution from this study was the development of a survey instrument. The researcher executed an extensive review of literature on international collaboration and coauthorship. The research questions were developed based on purpose of this research and past president indicated in the literature. The survey questions were developed and then review by a subject expert. The instrument underwent a cognitive review process and a pilot test routine. This study was focused on social scientist however the survey instrument is transferable to other subject disciplines. 
International Collaboration Among Social Science Scholars

A distinctive contribution of this research was the application of multiple linear regression as a modeling technique with the focus of generating an explanatory model. The magnitude, valence, and statistical significance of the independent variables was analyzed to determine support for the proposed hypotheses. Initially a baseline model was developed. Given the extensive set of independent variables that was used in a baseline explanatory model, feature selection was subsequently applied to develop a parsimonious model. The backward elimination procedure was applied. This process started with independent variables in the model and in a sequential fashion removed independent variables one at a time. The order of removal was determined by those variables that had the highest p value. Finally, there was a comparative analysis of the two models that determined if there were improvements associated with the development of a second model. The result is a parsimonious model for identifying the independent variables that are associated with participation in international collaborative research and co-authorship.

The final contribution related to research processes is the development of a new bibliographic analysis research design for illuminating faculty activities using the Web of Science/Web of Knowledge database. The process based on the analysis of scholarly publications and is therefore considered to be bibliographic in nature. The objective of this aspect of the research design was to illuminate international co-authorship activities within three specific social science disciplines. The outcome of the bibliographic process using the Web of Science/Web of Knowledge database was the identification of scholars that have published internationally co-authored articles in particular journals. (Appendix C) The resulting data was used to generate a list of scholars that were recruited as survey respondents. The bibliographic analysis model is flexible in nature and may be applied to other scholarly subject disciplines. 


\section{Implications for Future Research}

This research incorporated the cross sectional survey design of quantitative methodology. The unit of analysis was an individual social science scholar involved in a specific international collaborative research project that resulted in a co-authored article published in a scholarly journal. Respondents were selected based on their publication in one of fifteen social science journals within a five year timeframe. Given the narrow focus of this research, the work can be considered a starting point for future research related to the phenomenon of international coauthorship between social science scholars. The following are descriptions of future research that have the potential to expand the knowledge and literature on international collaboration and coauthorship among social science scholars.

Multiple regression is a statistical technique that requires a minimum dataset size. A specific number of observations are needed to meet the modeling assumptions. This number is based on the number of independent variables in the model. The results of this research are based a dataset that is deemed acceptable however it is of minimum size and therefore could be considered a limitation. One advantage of a larger dataset is that it would increase the opportunity to determine if other variables could become statistically significant and explanatory. An additional challenge with this study, is that due to the minimal dataset, the polarity of several of the independent variables are difficult to interpret. A future research initiative with the same research method, only with a larger dataset has the potential to refute, confirm or expand the results of this research.

Participants in this study were social science scholars that has recently co-authored a paper with an international colleague that had been published in a scholarly journal in the past 
International Collaboration Among Social Science Scholars

five years. For the purposes of this research the participants were chosen with a narrow framework. Participants were identified by analyzing five journals from three social science disciplines, management, sociology, and economics. Can the results be generalized to the entire population of social science scholars? Further research would need to be undertaken with an expanded framework that include more social science disciplines as well as an expansion of the number of years beyond five years. The generalizability of the concepts would be determined by ensuring that subsequent research includes respondents in relevant groups from the larger population of social science scholars.

During the data analysis phase of this study a growing list of ideas for future research projects took shape. One such idea evolved during the examination of the results that indicate $84 \%$ of respondents have co-authored multiple times with at least one of their co-authors. These results seem associated with the results of another survey question that indicates $73 \%$ of respondents answered strongly agree or agree to the statement, I was motivated to participate in this international collaboration because I had worked effectively with one of my co-authors before on a successful project. The results of this study have the potential to generate more research questions as one considers how each team came to know one another and work together. The literature on scholarly collaboration indicates shared projects are aligned along mutual research paradigms and parallel academic experiences. Efficiencies of a scholarly research team come from a similar mindset of how to organize and accomplish research (Bozeman \& Corley, 2004; Ou et al., 2012). A future research project would look deeper into relationships of functioning and ongoing international teams of scholars.

Logistic regression was not used in this research, however it is a classic modeling technique that is often used in social science research and could be utilized for future research. 
International Collaboration Among Social Science Scholars

Logistic regression is a type of classification which brings an expanded group of options for modeling and applications. In addition, multiple group regression techniques could be explored. This modeling technique would require a larger data set however it would allow the data to be partitioned based on specific factors or demographic traits. For example, logistic regression would allow the researcher to determine which independent variables are significant for coauthorship teams that are motivated by the opportunity to mentor or to be mentored. Research initiatives that incorporate logistic regression would have the potential to expand our knowledge about the underlying social phenomenon of scholarly collaboration.

In order to collect information about the origins of the respondent's international collaborative partnerships this researcher incorporated the prompt, I was introduced to one of my co-authors during my PhD program. Respondents indicated that 36\% were introduced to one of their co-authors during their $\mathrm{PhD}$ program. Using cross data tabulation it was determined within the group of respondent that indicated English was their native language, 35\% indicated that they had been introduced to one of their co-authors during their $\mathrm{PhD}$ program. In contrast, of the group of respondents that indicted that their native language was not English, 65\% indicated that they were introduced to one of their co-authors during their PhD program. These results captivated this researcher's attention and fueled ideas for future research that would focus solely on this aspect of international scholarly collaboration. Specifically, why is there a $30 \%$ difference in this outcome. Are the differences based on personal preferences or are there explanations that point to cultural differences?

An additional idea for future research would be to study the phenomenon that social science scholars seem not to be motivated by funding or sabbaticals that are available to support their participation in international collaborative projects. Childress maintains that institutional 
International Collaboration Among Social Science Scholars

variables related to funding and sabbaticals acts as a catalyst either individually or in combination to encourage faculty participation in institutional initiatives related to internationalization. This researcher is interested in the confounding result that faculty have resources available to support international collaboration and do not take advantage of them. A future research project could focus on the intertwined nature of university support and the motivations of faculty to participate in international collaborative projects.

The results related to the respondents segment that classified themselves as a native speaker of a language other than English are very interesting to this researcher. The results of the baseline model as well as the feature selection model in this study indicate that the independent variable associated with native language other than English is statistically significant at the 0.001 level and at the 0.001 level respectively. The interpretation of these results is that faculty for whom English is not their native language, have published more coauthored articles with their international colleagues as compared to faculty for whom English is their native language. A future research initiative could gather more data about the factors related to their education, countries were they worked in and mobility patterns of faculty who have native language other than English. Developing a study that uses a mixed methods design would allow the researcher to gather a mix of quantitative and qualitative data that has the potential to create a more robust description of this phenomenon.

A future research initiative could change the research lens to focus on faculty mobility as a factor in the story of international collaboration. The process for identifying the respondents for this research involved analyzing journal articles from the past five years from fifteen social science journals. When an author submits an article for publication, the academic journal requires that they submit information about their institutional affiliation and email address. As a 
step in the data checking this researcher confirmed each scholar's email address through a search with their home institution that was indicated. This researcher found that approximately $25 \%$ of the faculty had moved from one institution to another institution within the five year timeframe that the journal article was published and the administration of this researcher's survey. The Boston College Center for International Higher Education reported in January 2017 that international faculty mobility was a crucial element of internationalization in the higher education landscape and stated that it was understudied. An example of a research question related to faculty mobility and international collaboration is: Do international co-authorship relationships tend to originate when scholars are co-located and then the relationship become international when one scholar moves out of country? Another research question, Do international co-author relationships lead to scholars choosing to co-locate at the same university? Using the research model used in this project, one could identify faculty that have coauthored with international colleagues and moved from one university to another. This type of research design has the potential to enlighten the phenomenon of faculty mobility and the degree to which it is associated with international collaboration and co-authorship.

The third research question in this study was: What expectations and rewards do universities have in the tenure and promotion process for social science scholars that participate in international collaborative research projects? This dimension of inquiry was focused on the scholar's experience within the context of their university. Survey questions in this line of inquiry were designed to document the institutional expectations and rewards related to participation in international collaborative projects and co-authorship, specifically those that were associated with the tenure and promotion process. The survey question specifically related to tenure asked respondents if their university stipulates that international collaboration and co- 
International Collaboration Among Social Science Scholars

authorship is required for tenure and promotion. Less than $6 \%$ of the respondents indicated that it is stipulated for tenure and review. Given that internationalization and the involvement of faculty in international initiatives is a priority in many universities, it leads one to the question why there are a lack of stipulations or requirements for participation in international collaborative projects as a part of the tenure and promotion requirements. There was a similar outcome related to the question when considering articles published in journals with a similar impact factor, do internationally co-authored articles count more towards tenure and promotion than articles co-authored with scholar in their own country with $6.45 \%$ of survey participants responding yes and $93.55 \%$ responding no. Future research is needed to expand knowledge related to why universities do not require participation or place higher value on participation when internationalization is an institutional priority.

\section{Conclusion}

Faculty of universities throughout the world form scholarly networks to exchange ideas, research, and build a knowledge infrastructure that supports the scholarly activities for their subject discipline. Many higher education scholars have written about the ongoing challenges that universities face in their efforts to internationalize. Although internationalization is a common institutional priority, many universities are unable to accomplish the unilateral involvement of their faculty in international initiatives. One strategy aimed at increasing faculty participation in international initiatives involves bridging individual research agendas with the institutional mission to internationalize (Childress, 2010). The ultimate goal of this research was to inform the development of institutional policies and programs aimed at encouraging faculty to participate in collaborative research projects with their international colleagues. This research was focused on individual social science scholars who were involved in international 
collaborative research projects that resulted in a co-authored article. One aspect of this research concentrated on understanding the scholar's motivation for participating in the international collaboration. Additionally, the research gathered data related to university research policies including funding for participation in international collaborative projects and the value of participation in international collaborations related to the tenure and promotion review. Descriptive statistics along with an explanatory regression model were developed. The results of this study may be used to develop institutional research policy aimed at expanding faculty research activities associated with international research collaboration and co-authorship thereby enabling universities to advance towards their institutional missions and goals related to internationalization. 


\section{References}

Abramo, G., D’Angelo, C. A., \& Murgia, G. (2014). Variation in research collaboration patterns across academic ranks. Scientometrics, 98(3), 2275-2294.

Acedo, F. J., Barroso, C., Casanueva, C., \& Galán, J. L. (2006). Co-Authorship in Management and Organizational Studies: An Empirical and Network Analysis. Journal of Management Studies, 43(5), 957-983.

Adair, J. G. (1984). The Hawthorne effect: A reconsideration of the methodological artifact. Journal of applied psychology, 69(2), 334.

Adams, J. D., Black, G. C., Clemmons, J. R., \& Stephan, P. E. (2005). Scientific teams and institutional collaborations: Evidence from US universities, 1981-1999. Research policy, 34(3), 259-285.

Altbach, P., \& Knight, J. (2011). Higher education’s landscape of internationalization Leadership for world-class universities: Challenges for developing countries. New York: Routledge.

Altbach, P. G., \& Knight, J. (2007). The internationalization of higher education: Motivations and realities. Journal of studies in international education, 11(3-4), 290-305.

Beaver, D., \& Rosen, R. (1978). Studies in scientific collaboration: Part I. The professional origins of scientific co-authorship. Scientometrics, 1(1), 65-84.

Beaver, D. D. (2001). Reflections on scientific collaboration (and its study): past, present, and future. Scientometrics, 52(3), 365-377. 
International Collaboration Among Social Science Scholars

Bebeau, M. J., \& Monson, V. (2011). Authorship and publication practices in the social sciences: Historical reflections on current practices. Science and engineering ethics, 17(2), 365388.

Becher, T., \& Trowler, P. (2001). Academic tribes and territories: Intellectual enquiry and the culture of disciplines: McGraw-Hill Education (UK).

Berger, P., \& Luckmann, T. (1966). The Social Construction of Reality: A Treatise in the Sociology of Knowledge.

Biancani, S., \& McFarland, D. A. (2013). Social networks research in higher education Higher education: Handbook of theory and research (pp. 151-215): Springer.

Biggs, J. (2008). Allocating the credit in collaborative research. PS: Political Science \& Politics, 41(01), 246-247.

Bordons, M., \& Gómez, I. (2000). Collaboration networks in science. The web of knowledge: A festschrift in honor of Eugene Garfield, 197-213.

Borgman, C. L. (1990). Scholarly communication and bibliometrics.

Bozeman, B., \& Corley, E. (2004). Scientists’ collaboration strategies: implications for scientific and technical human capital. Research policy, 33(4), 599-616.

Childress, L. K. (2009). Planning for internationalization by investing in faculty. Journal of International and Global Studies, 1(1), 30-50.

Childress, L. K. (2010). The twenty-first century university: Developing faculty engagement in internationalization (Vol. 32): Peter Lang.

Crane, D. (1972). Invisible colleges; diffusion of knowledge in scientific communities.

Creswell, J. W. (2008). Educational research: Planning, conducting, and evaluating quantitative. New Jersey: Upper Saddle River: Pearson Education. 
International Collaboration Among Social Science Scholars

Cronin, B. (1982). Invisible colleges and information transfer a review and commentary with particular reference to the social sciences. Journal of Documentation, 38(3), 212-236.

Davies, H., Langley, J. M., \& Speert, D. P. (1996). Rating authors' contributions to collaborative research: the PICNIC survey of university departments of pediatrics. Pediatric Investigators' Collaborative Network on Infections in Canada. CMAJ: Canadian Medical Association Journal, 155(7), 877.

de Solla Price, D. J. (1965). Networks of scientific papers. Science, 149(3683), 510-515.

de Solla Price, D. J., \& Beaver, D. (1966). Collaboration in an invisible college. American psychologist, 21(11), 1011.

DeLong, J. B. (2006). The invisible college. Chronicle of Higher Education, 52(47), B8.

Easterby-Smith, M., \& Malina, D. (1999). Cross-cultural collaborative research: Toward reflexivity. Academy of Management Journal, 42(1), 76-86.

Educational Policy Institute (2009). Changing Academic Profession. Fairfield, Australia.

Egron-Polak, E., Hudson, R., \& Gacel-Avila, J. (2010). Internationalization of higher education: Global trends, regional perspectives: IAU 3rd global survey report: International Association of Universities Paris.

Fox, M. F., \& Faver, C. A. (1982). The process of collaboration in scholarly research. Scholarly Publishing, 13(4), 327-339.

Galegher, J., Kraut, R. E., \& Egido, C. (2014). Intellectual teamwork: Social and technological foundations of cooperative work: Psychology Press.

Gelman, S. R., \& Gibelman, M. (1999). A quest for citations? An analysis of and commentary on the trend toward multiple authorship. Journal of Social Work Education, 35(2), 203-213.

Georghiou, L. (1998). Global cooperation in research. Research policy, 27(6), 611-626. 
International Collaboration Among Social Science Scholars

Gibson, C. B., \& Gibbs, J. L. (2006). Unpacking the concept of virtuality: The effects of geographic dispersion, electronic dependence, dynamic structure, and national diversity on team innovation. Administrative Science Quarterly, 51(3), 451-495.

Glänzel, W., \& Schubert, A. (2004). Analyzing scientific networks through co-authorship Handbook of quantitative science and technology research (pp. 257-276): Springer.

Glover, D., \& Strawbridge, S. (1985). The sociology of knowledge: Sheridan House Incorporated.

Green, M. F., \& Shoenberg, R. E. (2006). Where faculty live: Internationalizing the disciplines (Vol. 2): American council on education.

Green, M. F., \& Shoenberg, R. E. (2006). Where faculty live: Internationalizing the disciplines (Vol. 2): American council on education.

House, M. C., \& Seeman, J. I. (2010). Credit and authorship practices: educational and environmental influences. Accountability in research, 17(5), 223-256.

Huang, F., Finkelstein, M., \& Rostan, M. (2014). The internationalization of the academy. Changes, Realities and Prospects.

Hudson, R. A. (1996). Sociolinguistics: Cambridge University Press.

Jeong, S., Choi, J. Y., \& Kim, J. (2011). The determinants of research collaboration modes: Exploring the effects of research and researcher characteristics on co-authorship. Scientometrics, 89(3), 967-983.

Katz, J. S., \& Martin, B. R. (1997). What is research collaboration? Research policy, 26(1), 1-18.

Kerr, C. (1963). [The uses of the university. The Godkin lectures at Harvard University].

Kerr, C. (1963). The uses of the university. Cambridge, MA: Harvard University Press. 
International Collaboration Among Social Science Scholars

Kettler, D., Mannheim, K., Meja, V., \& Stehr, N. (1982). Structures of Thinking: London; Boston: Routledge \& Kegan Paul.

Knight, J. (2004). Internationalization remodeled: Definition, approaches, and rationales. Journal of studies in international education, 8(1), 5-31.

Knight, J. (2008). Higher education in turmoil: The changing world of internationalization: Sense Publ.

Knoke, D., \& Yang, S. (2008). Social network analysis (Vol. 154): Sage.

Krambia Kapardis, M., \& Vafeas, N. (2010). Determinants of single authorship. EuroMed journal of business, 5(3), 332-344.

Kwiek, M. (2015). The Internationalization of Research in Europe A Quantitative Study of 11 National Systems From a Micro-Level Perspective. Journal of studies in international education, 1028315315572898.

Laband, D. N., \& Tollison, R. D. (2000). Intellectual collaboration. Journal of Political economy, 108(3), 632-662.

Landry, R., Traore, N., \& Godin, B. (1996). An econometric analysis of the effect of collaboration on academic research productivity. Higher Education, 32(3), 283-301.

Larivière, V., Gingras, Y., \& Archambault, É. (2006). Canadian collaboration networks: A comparative analysis of the natural sciences, social sciences and the humanities. Scientometrics, 68(3), 519-533.

Laudel, G. (2002). What do we measure by co-authorships? Research Evaluation, 11(1), 3-15.

Lee, S., \& Bozeman, B. (2005). The impact of research collaboration on scientific productivity. Social studies of science, 35(5), 673-702. 
International Collaboration Among Social Science Scholars

Lemke, R., Johnson, L. M., \& Jenks, D. (2015). Perceptions of the trend of collaborative publications: Results from a survey of criminal justice and criminology department chairs. Journal of Criminal Justice Education, 26(1), 1-21.

Leydesdorff, L., \& Wagner, C. S. (2008). International collaboration in science and the formation of a core group. Journal of Informetrics, 2(4), 317-325.

Lievrouw, L. A. (1990). Reconciling structure and process in the study of scholarly communication. Scholarly communication and bibliometrics, 59-69.

Lindsey, D. (1980). Production and citation measures in the sociology of science: The problem of multiple authorship. Social studies of science, 10(2), 145-162.

Lundberg, J., Tomson, G., Lundkvist, I., \& Brommels, M. (2006). Collaboration uncovered: Exploring the adequacy of measuring university-industry collaboration through coauthorship and funding. Scientometrics, 69(3), 575-589.

Luukkonen, T., Persson, O., \& Sivertsen, G. (1992). Understanding patterns of international scientific collaboration. Science, Technology \& Human Values, 17(1), 101-126.

Mali, F., Kronegger, L., Doreian, P., \& Ferligoj, A. (2012). Dynamic scientific co-authorship networks Models of science dynamics (pp. 195-232): Springer.

Mannheim, K. (1970). Ideology and utopia: an introduction to the sociology of knowledge. New York: Harcourt Brace Jovanovich.

Mannheim, K., Kettler, D., Meja, V., \& Stehr, N. (1982). Structures of Thinking: Text and Translation Edited and Introduced by David Kettler, Volker Meja and Nico Stehr. Translated by Jeremy J. Shapiro and Shierry Weber Nicholsen: Routledge [and] Kegan Paul. 
International Collaboration Among Social Science Scholars

McFadyen, M. A., \& Cannella, A. A. (2004). Social capital and knowledge creation:

Diminishing returns of the number and strength of exchange relationships. Academy of Management Journal, 47(5), 735-746.

McMillan, G. S. (2008). Mapping the invisible colleges of R\&D Management. $R \& D$ Management, 38(1), 69-83.

Melin, G. (2000). Pragmatism and self-organization: Research collaboration on the individual level. Research policy, 29(1), 31-40.

Melin, G., \& Persson, O. (1996). Studying research collaboration using co-authorships. Scientometrics, 36(3), 363-377.

Merton, R. K. (1968). Social theory and social structure: Simon and Schuster.

Miquel, J., \& Okubo, Y. (1994). Structure of international collaboration in science-Part II: Comparisons of profiles in countries using a link indicator. Scientometrics, 29(2), 271297.

Moody, J. (2004). The structure of a social science collaboration network: Disciplinary cohesion from 1963 to 1999. American sociological review, 69(2), 213-238.

Moore, M. T., \& Griffin, B. W. (2006). Identification of factors that influence authorship name placement and decisions to collaborate in peer-reviewed, education-related publications. Studies in Educational Evaluation, 32(2), 125-135.

Morlacchi, P., Wilkinson, I. F., \& Young, L. (2005). Social networks of researchers in B2B marketing: A case study of the IMP Group 1984-1999. Journal of Business-to-Business Marketing, 12(1), 3-34.

Morrison, P. S., Dobbie, G., \& McDonald, F. J. (2003). Research collaboration among university scientists. Higher Education Research \& Development, 22(3), 275-296. 
International Collaboration Among Social Science Scholars

Mulkay, M. J., Gilbert, G. N., \& Woolgar, S. (1975). Problem areas and research networks in science. Sociology, 9(2), 187-203.

Narin, F. (1991). Globalization of research, scholarly information, and patents-ten year trends. The Serials Librarian, 21(2-3), 33-44.

Narin, F., \& Whitlow, E. (1990). Measurement of Scientific Cooperation and Coauthorship in CEC-related Areas of Science (Report EUR 12900, Office for Official Publications of the European Communities, Luxembourg). INK S IN S C IE N C E.

Newman, M. E. (2004). Coauthorship networks and patterns of scientific collaboration. Proceedings of the national academy of sciences, 101(suppl 1), 5200-5205.

Okubo, Y., \& Miquel, J.-F. (1992). International scientific collaboration of Japan: Co-authorship analysis. Journal of Science Policy and Research Management, 6(4), 1-16.

Osborne, J. W., \& Holland, A. (2009). What is authorship, and what should it be? A survey of prominent guidelines for determining authorship in scientific publications. Practical Assessment, Research \& Evaluation, 14(15), 1-19.

Ou, A. Y., Varriale, L., \& Tsui, A. S. (2012). International collaboration for academic publication: Implications from the resource-based view and transaction cost theory. Group \& Organization Management, 1059601112448422.

Paisley, W. J. (1968). Information needs and uses. Annual review of information science and technology, 3(1), 1-30.

Persson, O., Glänzel, W., \& Danell, R. (2004). Inflationary bibliometric values: The role of scientific collaboration and the need for relative indicators in evaluative studies. Scientometrics, 60(3), 421-432. 
International Collaboration Among Social Science Scholars

Piette, M. J., \& Ross, K. L. (1992). An analysis of the determinants of co-authorship in economics. The Journal of Economic Education, 23(3), 277-283.

Poggenpoel, M., \& Myburgh, C. (2003). The researcher as research instrument in educational research: A possible threat to trustworthiness? (A: research instrument). Education, 124(2), 418.

Rostan, M., Ceravolo, F. A., \& Metcalfe, A. S. (2014). The internationalization of research The Internationalization of the Academy (pp. 119-143): Springer.

Scheler, M. (1980). Problems of a Sociology of Knowledge.

Seeman, J. I., \& House, M. C. (2010). Influences on authorship issues: An evaluation of receiving, not receiving, and rejecting credit. Accountability in research, 17(4), 176-197.

Siaya, L. M., \& Hayward, F. M. (2003). Mapping internationalization on US campuses: Final report, 2003: American Council on Education.

Simonin, B. L. (1997). The importance of collaborative know-how: An empirical test of the learning organization. Academy of Management Journal, 40(5), 1150-1174.

Siva, N., Hermanson, D. R., \& Hermanson, R. H. (1998). Co-authoring in refereed journals: Views of accounting faculty and department chairs. Issues in Accounting Education, 13(1), 79.

Speier, H. (1988). Mannheim as a Sociologist of Knowledge. International Journal of Politics, Culture, and Society, 2(1), 81-94.

Stehr, N., \& Meja, V. (1984). Society and Knowledge: Contemporary Perspectives on the Sociology of Knowledge. New Brunswick: NJ: Transaction Books.

Stone, D. A. (2002). Policy paradox: The art of political decision making: Norton New York. 
International Collaboration Among Social Science Scholars

Strange, K. (2008). Authorship: why not just toss a coin? American Journal of Physiology-Cell Physiology, 295(3), C567-C575.

Tabachnick, B. G., \& Fidell, L. S. (2000). Using Multivariate Statistics. Boston Allyn \& Bacon.

Thorsteinsdottir, O. (2000). External research collaboration in two small science systems. Scientometrics, 49(1), 145-160.

Tompkins, J. G., Nathan, S., Hermanson, R. H., \& Hermanson, D. R. (1997). Coauthoring in Refereed Journals: Perceptions of Finance Faculty and Department Chairs.

Traoré, N., \& Landry, R. (1997). On the determinants of scientists' collaboration. Science Communication, 19(2), 124-140.

Van Rijnsoever, F. J., \& Hessels, L. K. (2011). Factors associated with disciplinary and interdisciplinary research collaboration. Research policy, 40(3), 463-472.

Verspagen, B., \& Werker, C. (2003). The invisible college of the economics of innovation and technological change. Estudios de Economía Aplicada, 21(3), 393-419.

Wagner, C. S. (2009). The new invisible college: Science for development: Brookings Institution Press.

Wagner, C. S., \& Leydesdorff, L. (2005). Network structure, self-organization, and the growth of international collaboration in science. Research policy, 34(10), 1608-1618.

Weber, M., Henderson, A. M., \& Parsons, T. (1947). The theory of social and economic organization.

Welfare, L. E., \& Sackett, C. R. (2010). Authorship in student-faculty collaborative research: Perceptions of current and best practices. Journal of Academic Ethics, 8(3), 199-215.

Wuchty, S., Jones, B. F., \& Uzzi, B. (2007). The increasing dominance of teams in production of knowledge. Science, 316(5827), 1036-1039. 
International Collaboration Among Social Science Scholars

Yudkevich, M., Altbach P. G., \& Rumbley, L.E. (2015). Young Faculty in the Twenty-First Century: International Perspectives. State University of New York Press. Albany, NY.

Zuccala, A. (2006). Modeling the invisible college. Journal of the American Society for information Science and Technology, 57(2), 152-168.

Zuccala, A. A. (2004). Revisiting the invisible college: A case study of the intellectual structure and social process of singularity theory research in mathematics. University of Toronto. 
Appendix A: Research Questions Mapped to Survey Question Number, Independent Variable and Wording of Survey Questions

Research Question One - What motivates social science scholars to collaborate on research projects with their international colleagues?

\begin{tabular}{|c|c|c|c|}
\hline $\begin{array}{l}\text { Research } \\
\text { Question }\end{array}$ & $\begin{array}{l}\text { Survey } \\
\text { Question }\end{array}$ & Independent Variable & $\begin{array}{l}\text { Survey Question Wording: I was } \\
\text { motivated to collaborate on this article } \\
\text { because... }\end{array}$ \\
\hline $\mathrm{R} 1$ & Q1 & $\begin{array}{l}\text { Collaborator has a strong } \\
\text { reputation }\end{array}$ & $\begin{array}{l}\text { My co-authors have strong reputations as } \\
\text { researchers }\end{array}$ \\
\hline R1 & Q2 & $\begin{array}{l}\text { Collaborate to improve access } \\
\text { to department/university } \\
\text { funds }\end{array}$ & $\begin{array}{l}\text { Working on this collaborative project } \\
\text { improved my access to university funds. }\end{array}$ \\
\hline R1 & Q3 & $\begin{array}{l}\text { Collaborate to improve access } \\
\text { to external funds }\end{array}$ & $\begin{array}{l}\text { Working on this collaborative project } \\
\text { improved my access to external funds. }\end{array}$ \\
\hline R1 & Q4 & $\begin{array}{l}\text { Collaborator has expertise } \\
\text { other than my own }\end{array}$ & $\begin{array}{l}\text { My co-authors have expertise different } \\
\text { than my own. }\end{array}$ \\
\hline R1 & Q5 & $\begin{array}{l}\text { Collaborator has special data } \\
\text { or equipment }\end{array}$ & $\begin{array}{l}\text { Participating improved my access to } \\
\text { special data or research equipment. }\end{array}$ \\
\hline R1 & Q6 & $\begin{array}{l}\text { Collaborate to pool expertise } \\
\text { and take on complex research } \\
\text { problems }\end{array}$ & $\begin{array}{l}\text { Working together allowed us to pool } \\
\text { knowledge to accomplish complex } \\
\text { research. }\end{array}$ \\
\hline R1 & Q7 & $\begin{array}{l}\text { Collaborate to gain peer } \\
\text { recognition and visibility }\end{array}$ & $\begin{array}{l}\text { Working with my co-authors allowed me } \\
\text { to gain more peer recognition \& visibility. }\end{array}$ \\
\hline R1 & Q8 & $\begin{array}{l}\text { Collaborate again based on } \\
\text { previous project success }\end{array}$ & $\begin{array}{l}\text { I had worked effectively with one of my } \\
\text { co-authors before on a successful project. }\end{array}$ \\
\hline R1 & Q9 & $\begin{array}{l}\text { Collaborator is fun and } \\
\text { pleasant to work with }\end{array}$ & $\begin{array}{l}\text { My co-authors are pleasant and fun to } \\
\text { work with. }\end{array}$ \\
\hline R1 & Q10 & $\begin{array}{l}\text { Opportunity to publish with } \\
\text { international colleagues }\end{array}$ & $\begin{array}{l}\text { Because of the opportunity to publish } \\
\text { with my international colleagues. }\end{array}$ \\
\hline R1 & Q11 & $\begin{array}{l}\text { Collaborator is fluent in the } \\
\text { same language }\end{array}$ & $\begin{array}{l}\text { My co-authors and I are fluent in the same } \\
\text { language. }\end{array}$ \\
\hline R1 & Q12 & $\begin{array}{l}\text { Collaborate to mentor and } \\
\text { help a junior colleague or } \\
\text { graduate student }\end{array}$ & $\begin{array}{l}\text { I wanted to mentor and help a junior } \\
\text { colleague or graduate student. }\end{array}$ \\
\hline R1 & Q13 & $\begin{array}{l}\text { Motivation most important to } \\
\text { scholar for specified article }\end{array}$ & $\begin{array}{l}\text { The most important motivation for } \\
\text { participating in this international } \\
\text { collaboration was... }\end{array}$ \\
\hline
\end{tabular}


Research Question Two - What University Resources Are Available to Support Social Science Scholars Who Participate in International Collaborative Research?

\begin{tabular}{|c|c|c|c|}
\hline $\begin{array}{l}\text { Research } \\
\text { Question }\end{array}$ & $\begin{array}{c}\text { Survey } \\
\text { Question }\end{array}$ & Independent Variable & $\begin{array}{l}\text { Survey Question Wording: } \\
\text { The following questions are related } \\
\text { to your department or university } \\
\text { and what is provided to enable } \\
\text { participation in international } \\
\text { collaborative research projects. }\end{array}$ \\
\hline R2 & Q14 & $\begin{array}{l}\text { University offers funding } \\
\text { for travel related to } \\
\text { international collaboration }\end{array}$ & $\begin{array}{l}\text { My university offers travel funding } \\
\text { to support participation in } \\
\text { international collaborative projects. }\end{array}$ \\
\hline $\mathrm{R} 2$ & Q15 & $\begin{array}{l}\text { University offers } \\
\text { funding/grants for } \\
\text { international collaboration } \\
\text { (other than funding for } \\
\text { travel) }\end{array}$ & $\begin{array}{l}\text { My university offers funding or } \\
\text { research grants to support } \\
\text { participation in international } \\
\text { collaborative projects (other than } \\
\text { funding for travel) }\end{array}$ \\
\hline R2 & Q16 & $\begin{array}{l}\text { University offers sabbatical } \\
\text { or release time to support } \\
\text { participation in } \\
\text { international collaborations }\end{array}$ & $\begin{array}{l}\text { My university offers sabbaticals or } \\
\text { release time to specifically support } \\
\text { participation in international } \\
\text { collaborative projects. }\end{array}$ \\
\hline R2 & Q17 & $\begin{array}{l}\text { University offers seminars } \\
\text { or networking sessions } \\
\text { about international } \\
\text { collaboration }\end{array}$ & $\begin{array}{l}\text { My university supports seminars or } \\
\text { networking sessions to facilitate } \\
\text { communication among faculty } \\
\text { about their individual international } \\
\text { collaborations. }\end{array}$ \\
\hline
\end{tabular}


International Collaboration Among Social Science Scholars

Research Question Three - What Expectations and Rewards do Universities have in the Tenure and Promotion Process For Social Science Scholars Who Participate in International Collaborative Research?

\begin{tabular}{|c|c|c|c|}
\hline $\begin{array}{l}\text { Research } \\
\text { Question }\end{array}$ & $\begin{array}{c}\text { Survey } \\
\text { Question }\end{array}$ & Independent Variable & $\begin{array}{l}\text { Survey Question Wording: } \\
\text { The following questions are related to } \\
\text { your department or university’s } \\
\text { expectations related to participation in } \\
\text { international collaborative projects. }\end{array}$ \\
\hline R3 & Q18 & $\begin{array}{l}\text { University stipulates } \\
\text { participation in } \\
\text { international collaborative } \\
\text { projects for tenure and } \\
\text { promotion }\end{array}$ & $\begin{array}{l}\text { My university stipulates that } \\
\text { international collaboration and co- } \\
\text { authorship is required for tenure and } \\
\text { promotion. }\end{array}$ \\
\hline R3 & Q19 & $\begin{array}{l}\text { University encourages } \\
\text { international collaboration } \\
\text { but does not require }\end{array}$ & $\begin{array}{l}\text { My university encourages international } \\
\text { collaboration and co-authorship but does } \\
\text { not require it for tenure and promotion. }\end{array}$ \\
\hline R3 & Q20 & $\begin{array}{l}\text { Internationally co- } \\
\text { authored articles count } \\
\text { more towards tenure and } \\
\text { promotion }\end{array}$ & $\begin{array}{l}\text { At my university, when considering } \\
\text { articles published in journals with a } \\
\text { similar impact factor, internationally co- } \\
\text { authored articles count more towards } \\
\text { tenure and promotion than articles co- } \\
\text { authored with scholars in this country. }\end{array}$ \\
\hline
\end{tabular}


Research Question Four - Descriptive Data Related to Education, Career Level, Gender, Native Language, Country Earned PhD, and Relationship With CoAuthor

\begin{tabular}{|c|c|c|c|}
\hline $\begin{array}{l}\text { Research } \\
\text { Question }\end{array}$ & $\begin{array}{l}\text { Survey } \\
\text { Question }\end{array}$ & Independent Variable & $\begin{array}{l}\text { Survey Question Wording: } \\
\text { The following questions are } \\
\text { related to personal information }\end{array}$ \\
\hline $\mathrm{R} 4$ & Q21 & Year earned PhD & $\begin{array}{l}\text { I earned my } \mathrm{PhD} \text { in the } \\
\text { following year. }\end{array}$ \\
\hline $\mathrm{R} 4$ & Q22 & Tenure level & $\begin{array}{l}\text { I am currently an: } \\
\text { Assistant Professor, Associate } \\
\text { Professor, Full Professor, } \\
\text { Other }\end{array}$ \\
\hline R4 & Q23 & Gender & $\begin{array}{l}\text { I identify my gender as: } \\
\text { Male, Female, Trans*, None of } \\
\text { the above, Prefer not to } \\
\text { disclose. }\end{array}$ \\
\hline R4 & Q24 & Native language & $\begin{array}{l}\text { My native Language is: } \\
\text { Choice from list of languages }\end{array}$ \\
\hline $\mathrm{R} 4$ & Q25 & $\begin{array}{l}\text { Earned PhD in which } \\
\text { country }\end{array}$ & $\begin{array}{l}\text { The country that I earned my } \\
\text { doctorate in is ... }\end{array}$ \\
\hline $\mathrm{R} 4$ & Q26 & $\begin{array}{l}\text { Introduced to co-author } \\
\text { during PhD program }\end{array}$ & $\begin{array}{l}\text { Choice from list of countries } \\
\text { I was introduced to one of my } \\
\text { co-authors during my PhD } \\
\text { program. }\end{array}$ \\
\hline $\mathrm{R} 4$ & Q27 & $\begin{array}{l}\text { Co-authored multiple } \\
\text { times with collaborator(s) }\end{array}$ & $\begin{array}{l}\text { I have co-authored multiple } \\
\text { times with at least one of my } \\
\text { co-authors (more than one } \\
\text { time). }\end{array}$ \\
\hline
\end{tabular}


Appendix B: Academic Journals Social Science Scholars International Collaboration Research

\begin{tabular}{|c|c|c|}
\hline Journal Title & $\begin{array}{c}\text { Five Year } \\
\text { Impact Factor }\end{array}$ & $\begin{array}{l}\text { Subject Discipline and Rank } \\
\text { in Web of Science Database }\end{array}$ \\
\hline Academy of Management Review & 12.45 & Management - 1 \\
\hline Academy of Management Journal & 10.59 & Management - 2 \\
\hline MIS Quarterly & 9.51 & Management - 3 \\
\hline Administrative Science Quarterly & 7.52 & Management - 4 \\
\hline Organization Science & 6.14 & Management - 5 \\
\hline American Sociological Review & 8.38 & Sociology - 1 \\
\hline American Sociological Review & 6.92 & Sociology - 2 \\
\hline Annals of Sociology \& Tourism Research & 3.88 & Sociology - 3 \\
\hline Politics \& Society & 2.56 & Sociology - 4 \\
\hline Agriculture and Human Values & 2.53 & Sociology - 5 \\
\hline Journal of Economic Perceptivities & 6.66 & Economics - 1 \\
\hline Journal of Accounting \& Economics & 5.97 & Economics - 2 \\
\hline $\begin{array}{l}\text { American Economic Journal - Applied } \\
\text { Economics }\end{array}$ & 5.43 & Economics - 3 \\
\hline Econometrica & 5.40 & Economics - 4 \\
\hline American Economic Review & 5.14 & Economics - 5 \\
\hline
\end{tabular}

Derived from Web of Science Journal Rankings by Subject Discipline data retrieved 6/4/16 


\begin{tabular}{|c|c|c|c|c|}
\hline $\begin{array}{l}\text { Data From Web } \\
\text { of Knowledge }\end{array}$ & 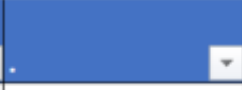 & - & $\ldots$ & $\ldots$. \\
\hline Authors Full Name & Title of Article & Joumal Name & Authors Name and University Affiliation & $\begin{array}{l}\text { Authors E-Mail } \\
\text { Addresses }\end{array}$ \\
\hline $\begin{array}{l}\text { Magill, Michael; } \\
\text { Quinzii, Martine; } \\
\text { Rochet, Jean- } \\
\text { Charles }\end{array}$ & $\begin{array}{l}\text { A Theory of the } \\
\text { Stakeholder } \\
\text { Corporation }\end{array}$ & Econometrica & $\begin{array}{l}\text { [Magill, Michael] Univ So Calif, Dept } \\
\text { Econ, Los Angeles, CA } 90089 \text { USA; } \\
\text { [Quinzii, Martine] Univ Calif Davis, Dept } \\
\text { Econ, Davis, CA 95616 USA; [Rochet, } \\
\text { Jean-Charles] Univ Zurich, Dept Banking } \\
\text { \& Finance, CH-8032 Zurich, Switzerland; } \\
\text { [Rochet, Jean-Charles] SFI, CH-8032 } \\
\text { Zurich, Switzerland; [Rochet, Jean- } \\
\text { Charles] Toulouse Sch Econ IDEI, F- } \\
\text { 31015 Toulouse, France }\end{array}$ & $\begin{array}{l}\text { magill@usc.edu; } \\
\text { mmquinzii@ucd } \\
\text { avis.edu; } \\
\text { jeancharles.roch } \\
\text { et@gmail.com }\end{array}$ \\
\hline $\begin{array}{l}\text { Hoerner, Johannes; } \\
\text { Takahashi, Satoru; } \\
\text { Vieille, Nicolas }\end{array}$ & $\begin{array}{l}\text { Truthful } \\
\text { Equilibria in } \\
\text { Dynamic } \\
\text { Bayesian Games }\end{array}$ & Econometrica & $\begin{array}{l}\text { [Hoerner, Johannes] Yale Univ, Cowles } \\
\text { Fdn, New Haven, CT } 06520 \text { USA; } \\
\text { [Takahashi, Satoru] Natl Univ Singapore, } \\
\text { Fac Arts \& Social Sci, Dept Econ, } \\
\text { Singapore } 117570, \text { Singapore; [Vieille, } \\
\text { Nicolas] HEC Paris, F-78351 Jouy En } \\
\text { Josas, France }\end{array}$ & $\begin{array}{l}\text { johannes.horner } \\
\text { @yale.edu; } \\
\text { ecsst@nus.edu.s } \\
\text { g; vieille@hec.fr }\end{array}$ \\
\hline $\begin{array}{l}\text { Kim, Kyungmin; } \\
\text { Kircher, Philipp }\end{array}$ & $\begin{array}{l}\text { Efficient } \\
\text { Competition } \\
\text { Through Cheap } \\
\text { Talk: The Case of } \\
\text { Competing } \\
\text { Auctions }\end{array}$ & Econometrica & $\begin{array}{l}\text { [Kim, Kyungmin] Univ Iowa, Henry B } \\
\text { Tippie Coll Business, Dept Econ, Iowa } \\
\text { City, IA } 52242 \text { USA; [Kircher, Philipp] } \\
\text { Univ Edinburgh, Sch Econ, Edinburgh } \\
\text { EH8 9JT, Midlothian, Scotland }\end{array}$ & $\begin{array}{l}\text { kyungmin- } \\
\text { kim@uiowa.edu } \\
\text {;philipp.kircher } \\
\text { @ed.ac.uk } \\
\end{array}$ \\
\hline
\end{tabular}

\begin{tabular}{|l|l|l|l|l|}
$\begin{array}{l}\text { Data Organized } \\
\text { For Loading Into } \\
\text { Qualtrics }\end{array}$ & & & & \\
\multicolumn{1}{c|}{ LastName } & \multicolumn{1}{|c|}{ FirstName } & \multicolumn{1}{|c|}{ PrimaryEmail } & \multicolumn{1}{c|}{ ArticleTitle } & Journal \\
\hline Hoerner & Johannes & johannes.horner@yale.edu & $\begin{array}{l}\text { Truthful Equilibria In Dynamic } \\
\text { Bayesian Games }\end{array}$ & Econometrica \\
\hline Kim & Kyungmin & kyungmin-kim@uiowa.edu & $\begin{array}{l}\text { Efficient Competition Through Cheap } \\
\text { Talk: The Case Of Competing Auctions }\end{array}$ & Econometrica \\
\hline Kircher & Philipp & philipp.kircher@ed.ac.uk & $\begin{array}{l}\text { Efficient Firm Dynamics In A Frictional } \\
\text { Labor Market }\end{array}$ & American Economic Review \\
\hline Magill & Michael & magill@usc.edu & $\begin{array}{l}\text { A Theory Of The Stakeholder } \\
\text { Corporation }\end{array}$ & Econometrica \\
\hline Quinzii & Martine & mmquinzii@ucdavis.edu & $\begin{array}{l}\text { A Theory Of The Stakeholder } \\
\text { Corporation }\end{array}$ & Econometrica \\
\hline Rochet & Jean-Charles & jeancharles.rochet@gmail.com & $\begin{array}{l}\text { A Theory Of The Stakeholder } \\
\text { Corporation }\end{array}$ & Econometrica \\
\hline Takahashi & Satoru & ecsst@nus.edu.sg & $\begin{array}{l}\text { Truthful Equilibria In Dynamic } \\
\text { Bayesian Games }\end{array}$ & Econometrica \\
\hline Vieille & Nicolas & vieille@hec.fr & $\begin{array}{l}\text { Truthful Equilibria In Dynamic } \\
\text { Bayesian Games }\end{array}$ & Econometrica \\
\hline & & & & \\
\hline
\end{tabular}


International Collaboration Among Social Science Scholars

Appendix D: Participants Recruiting Message

Subject Line for E-mail Distribution:

International Collaboration- Your Recent Article

Message Text:

International Collaboration - Your recent article (FILL IN ARTICLE NAME) in the (JOURNAL NAME)

Dear Professor LAST NAME OF SCHOLAR,

You are invited to participate in a confidential survey based on the article NAME OF ARTICLE in NAME OF JOURNAL that you recently co-authored with your international colleagues.

The purpose of the study is to inform the development of university programs and policies aimed at encouraging faculty to participate in international collaborative research projects. The responses will be used to develop an understanding of the factors and motivations related to international collaboration. The survey is brief and will take about 15 minutes to complete. Your participation in the survey is completely voluntary. Please click the link below to go to the survey. Thank you very much for your time and cooperation.

Sincerely,

Karen King

(Qualtrics generated customized link to the online survey- Each link was unique and based on personal information)

Purpose of the research study: The purpose of the study is to inform the development of university programs and policies aimed at encouraging faculty to participate in international collaborative research projects. You are invited to participate in a confidential survey on the basis of an article that they recently co-authored with your international colleagues in a peer reviewed journal. The responses will be used to develop an understanding of the factors and motivations related to international collaboration.

What you will do in the study: You will be asked to answer the survey questions in relation to your experience co-authoring the article NAME OF ARTICLE (customized from Qualtrics panel list) in the NAME OF JOURNAL (customized from Qualtrics panel list). The questions will ask about your motivations for participating in the collaboration, factors related to your decision to participate in the project, and university resources that are available to support you in the collaboration with international colleagues. Your participation in the study is completely voluntary. You may omit any questions that you prefer not to answer or stop the survey at any time. 
Time required: The study will require about 15 minutes of your time.

Risks: There are no anticipated risks in this study.

Benefits: There are no direct benefits to you for participating in this research study. The study may help us develop an understanding of the motivations associated with a faculty member's choice of research agendas and international collaborative partners. The information has the potential to help universities develop institutional programs and policies aimed at encouraging faculty to participate in international collaborative research projects.

Confidentiality: Your responses to the survey question are confidential. Although your co-authors will also be invited to participate in the survey, the information that you give during the study will not be shared with your co-authors. Participants will be asked questions related to a specific collaborative project however the data will be reported in aggregate format in order to assure that particular information cannot be associated to a specific person.

\section{If you have questions about the study, contact:}

Karen Marsh King

Darden School of Business, Darden Camp Library 100 Darden Blvd

University of Virginia, Charlottesville, VA 22903.

Telephone: 1- (434) 924-7271

Email address: kmr3m@virginia.edu

o IRB SBS \# (insert)

Principal Investigator: Karen Marsh King 


\section{Survey on International Collaboration and Co-Authorship}

Hello Professor (Last Name Coded From Participant Data),

You have been selected for this study based on a recent article that you coauthored with one or more of your international colleagues. Participants in this study are scholars from 62 countries. The survey is designed for smart phone, Ipad, or computer. Thank you for supporting my research.

Karen Marsh King

The following section is a description of the survey and details related to your participation. Please read this consent agreement carefully before you decide to participate in the study.

Click on the I AGREE button at the bottom to enter the survey.

Purpose of the research study: The purpose of the study is to inform the development of university programs and policies aimed at encouraging faculty to participate in international collaborative research projects. You are invited to participate in a confidential survey on the basis of an article that you recently co-authored with one or more of your international colleagues in a peer reviewed journal. The responses will be used to develop an understanding of the factors and motivations related to international collaboration. 
What you will do in the study: You will be asked to answer the survey questions in relation to your experience co-authoring the article (Article Name Coded From Participant Data) in (Journal Name Coded From Participant Data). The questions will ask about your motivations for participating in the collaboration, factors related to your decision to participate in the project, and university resources that are available to support you in the collaboration with international colleagues. You may omit any questions that you prefer not to answer or stop the survey at any time.

Time required: The study will require about 15 minutes of your time.

Risks: There are no anticipated risks in this study.

Benefits: There are no direct benefits to you for participating in this research study. The study may help to develop an understanding of the motivations associated with a faculty member's choice of research agendas and international collaborative partners. The information has the potential to help universities develop institutional programs and policies aimed at encouraging faculty to participate in international collaborative research projects.

Confidentiality: Your responses to the survey question are confidential. Although your co-authors will also be invited to participate in the survey, the information that you give during the study will not be shared with your co-authors. Participants will be asked questions related to a specific collaborative project however the data will be reported in aggregate format in order to assure that 
particular information cannot be associated to a specific person. Your name will not be used in any report. Your responses will be assigned a code number. Access to data for this research project is password protected and may only be accessed by the principle investigator. When the study is completed the individual identifying information will be removed from the dataset.

Voluntary participation: Your participation in the study is completely voluntary.

Right to withdraw from the study: You have the right to withdraw from the study at any time.

How to withdraw from the study: If you choose to withdraw from the study, the information you have provided will be immediately destroyed. To withdraw from the study, you may simply close your browser window at any point before completing the survey. If you choose to withdraw from the study after completing and submitting the survey, you may contact Karen King at kmr3m@virginia.edu and your survey responses will be removed from the study and destroyed.

Payment: You will receive no payment for participating in the study.

\section{If you have questions about the study, contact:}

Karen Marsh King

Darden School of Business, Darden Camp Library 100 Darden Blvd University of Virginia, Charlottesville, VA 22903.

Telephone: (434) 924-7271

Email address: kmr3m@virginia.edu

Brian Pusser 
Curry School Of Education, Center for the Study of Higher Education,

Ruffner Hall 290

University of Virginia, Charlottesville, VA 22903.

Telephone: (434) 924-7731

Email address: bp6n@virginia.edu

If you have questions about your rights in the study, contact:

Tonya R. Moon, Ph.D.

Chair, Institutional Review Board for the Social and Behavioral

Sciences

One Morton Dr Suite 500

University of Virginia, P.O. Box 800392

Charlottesville, VA 22908-0392

Telephone: (434) 924-5999

Email: irbsbshelp@virginia.edu

Website: www.virginia.edu/vpr/irb/sbs

Your participation is very important to the success of this survey and is greatly appreciated. Thank you.

\section{Agreement: I agree to participate in the research study described above.}

Click on Yes if you agree to participate below and click next begin the survey.

Click on No if you do not agree to participate and click next to exit the survey.

Yes, I agree to participate.

No, I do not agree to participate. 
International Collaboration Among Social Science Scholars

The following questions are related to your scholarly publication activities.

Please refer to your academic CV or academic publications list in order to answer the following two questions.

How many articles have you published in peer reviewed journals during the past ten years?

Of the articles that you have published in peer review journals over the past ten years, how many have been co-authored with your international colleagues? 
The following questions are related to your motivations or reasons for participating in the international collaborative project that led to this co-authored article.

in the

I was motivated to collaborate on this article because...

Strongly Agree

I was motivated to collaborate on this article because ...

My co-authors have strong reputations as researchers.

Working on this collaborative project improved my access to university funds.

Working on this collaborative project improved my access to external funds.

My co-authors have expertise different than my own.

Participating improved my access to special data or research equipment.

Working together allowed us to pool knowledge to accomplish complex research.

Working with my coauthors allowed me to gain more peer recognition and visibility.
Agree

Disagree

Strongly Disagree
$\mathrm{O}$

$\mathrm{O}$

$\mathrm{O}$

$\bigcirc$

$\bigcirc$

O

$\bigcirc$

$\mathrm{O}$

O<smiles>[O]</smiles>

O

O
O<smiles>O</smiles><smiles>O</smiles>

O

$\mathrm{O}$ 
The following are additional questions related to your motivations or reasons for participating in the international collaborative project that led to this co-authored article.

in the

I was motivated to collaborate on this article because ...

Strongly Agree

I was motivated to collaborate on this article because...

I had worked effectively with one of my coauthors before on a successful project.

My co-authors are pleasant and fun to work with.

Because of the opportunity to publish with my international colleagues.

My co-authors and I are fluent in the same language.

I wanted to mentor and help a junior colleague or graduate student.
Agree

Disagree

Strongly Disagree 
(Article Name Coded From Participant Data) in (Journal Name Coded From Participant Data)

Considering all of the motivations that are listed in this survey, what was the most important motivation to you when you made the decision to participate in this collaboration?

in the

The most important motivation for participating in this international collaboration was ...

My co-authors have strong reputations as researchers.

Working on this collaborative project improved my access to university funds.

Working on this collaborative project improved my access to external funds.

\section{My co-authors have expertise different than my own.}

Participating improved my access to special data or research equipment.

Working together allowed us to pool knowledge to accomplish complex research.

Working with my co-authors allowed me to gain more peer recognition and visibility.

I had worked effectively with one of my co-authors before on a successful project.

My co-authors are pleasant and fun to work with.

Because of the opportunity to publish with my international colleagues.

My co-authors and I are fluent in the same language.

I wanted to mentor and help a junior colleague or graduate student. 
The following questions are related to your department or university and what is provided to enable participation in international collaborative research projects.

\author{
Yes, this is offered at my \\ university. I took \\ advantage of the offer
}

\author{
Yes, this is offered at my \\ university. I did not take \\ advantage of the offer
}

No, this is not offered at my university

My university offers

travel funding to support participation in

international collaborative projects.

\section{My university offers}

funding or research grants to support participation in international collaborative projects (other than funding for travel).

\section{My university offers} sabbaticals or release time to specifically support participation in international collaborative projects.

\section{My university supports} seminars or networking sessions to facilitate communication among faculty about their individual international collaborations. 
The following questions are related to your department or university's expectations related to participation in international collaborative projects.

Yes No

My university stipulates that international collaboration and co-authorship is required for<smiles>O</smiles><smiles>O</smiles>
tenure and promotion.

My university encourages international collaboration and co-authorship but does not require it for tenure and promotion.

At my university, when considering articles published in journals with a similar impact factor, internationally co-authored articles count more towards tenure and promotion than articles coauthored with scholars in this country. 
International Collaboration Among Social Science Scholars

The following questions are related personal information.

I earned my $\mathrm{PhD}$ in the following year.

$2005 \checkmark$

I am currently an:

Assistant Professor

Associate Professor

Full Professor

Other

I identify my gender as:

Male

Female

Trans*

None of the above

Prefer not to disclose 
My native language is:

\section{Danish}

If you have a doctorate:

The country that I earned my doctorate in is ....

Denmark

The following questions are related to the article

in the

I was introduced to one of my co-authors during my $\mathrm{PhD}$ program.

Yes

No

Unsure

I have co-authored multiple times with at least one of my co-authors (more than one time).

\section{Yes}

No

The two questions above have customized information for each participant (Article Name Coded from Participant Data) in (Journal Name Coded from Participant Data) 
International Collaboration Among Social Science Scholars

Thank you for participating in the survey on International Collaboration and Co-authorship. Your participation is very important to the success of this research and is greatly appreciated.

Powered by Qualtrics

Powered by Qualtrics 


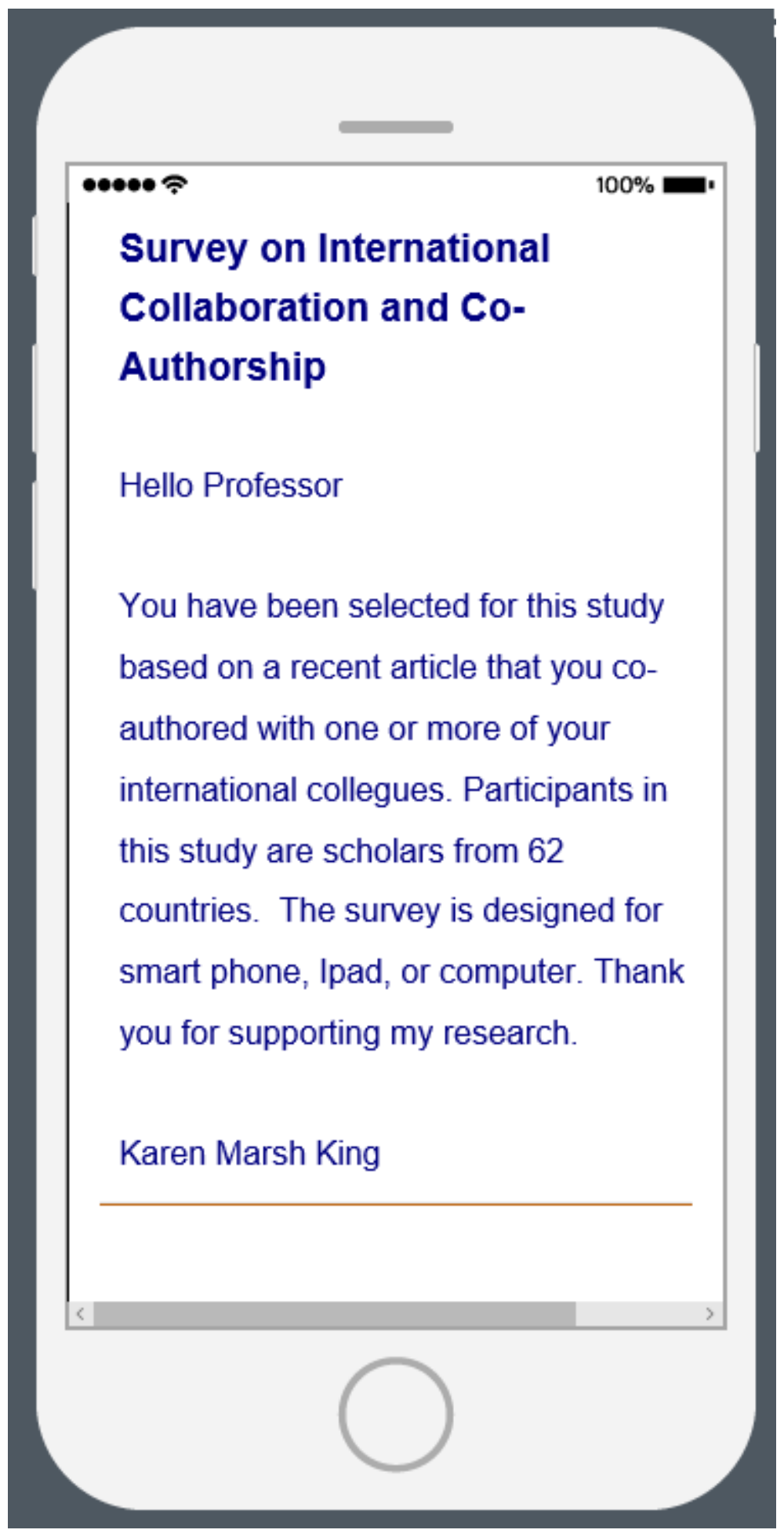




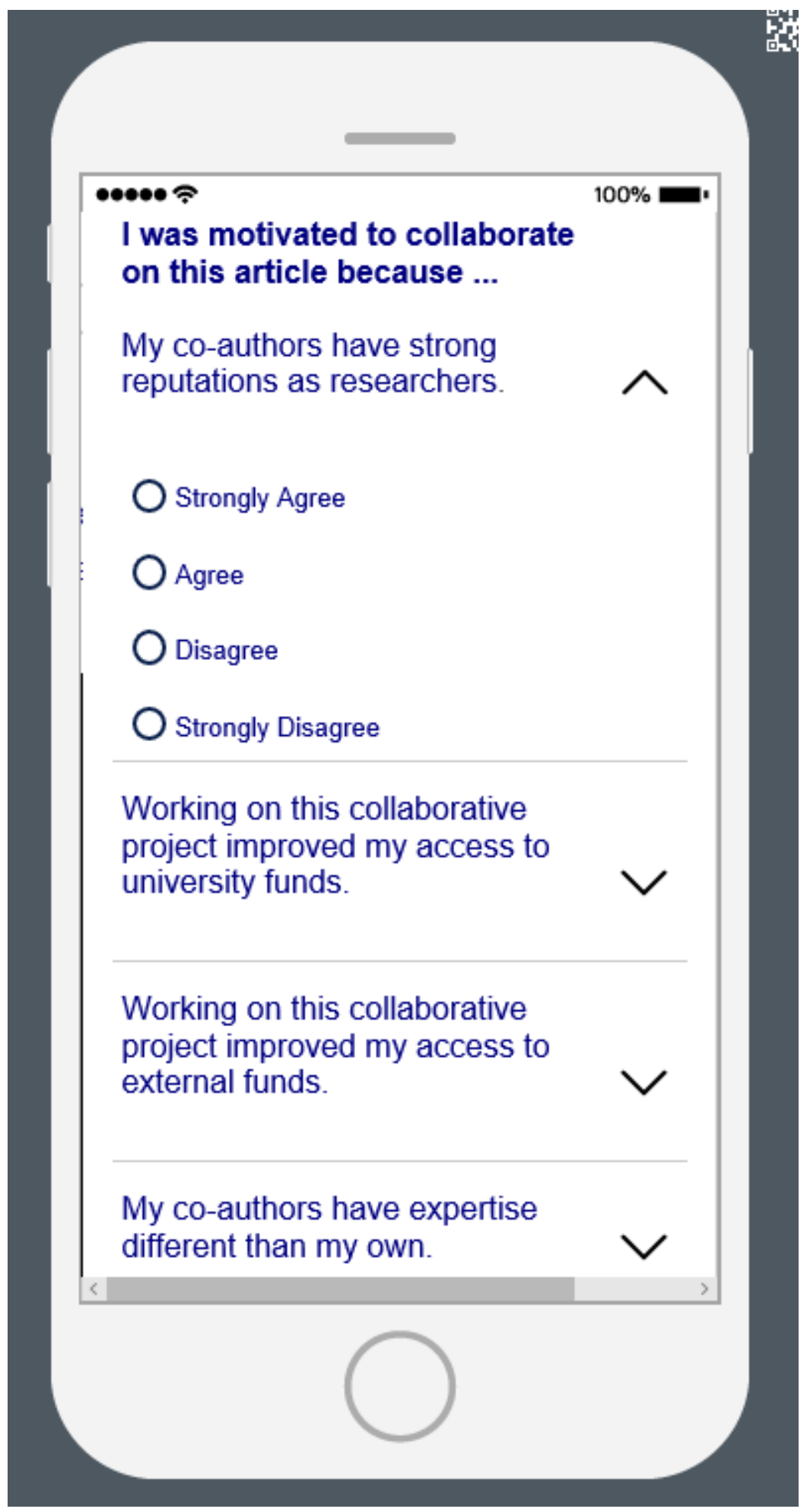




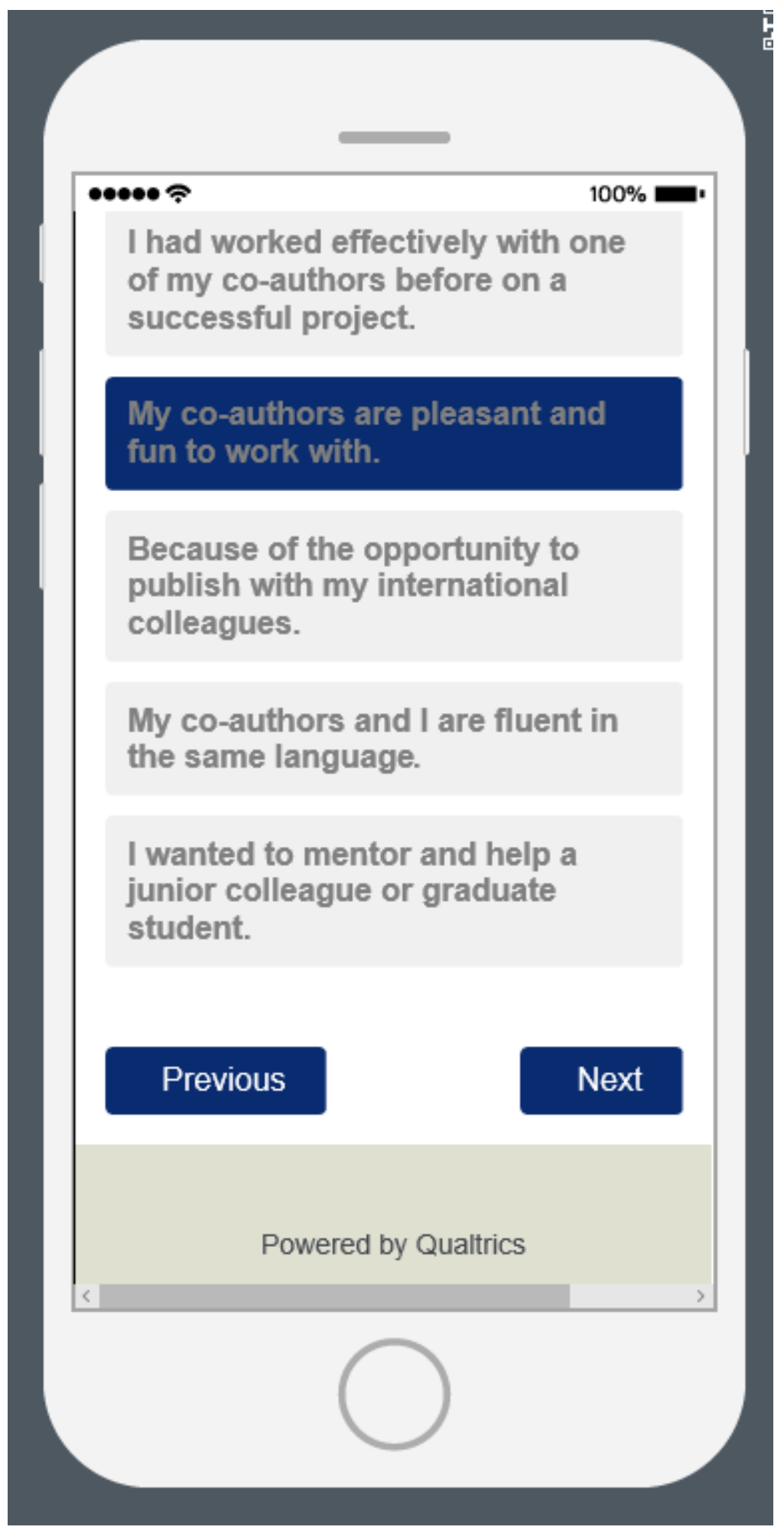




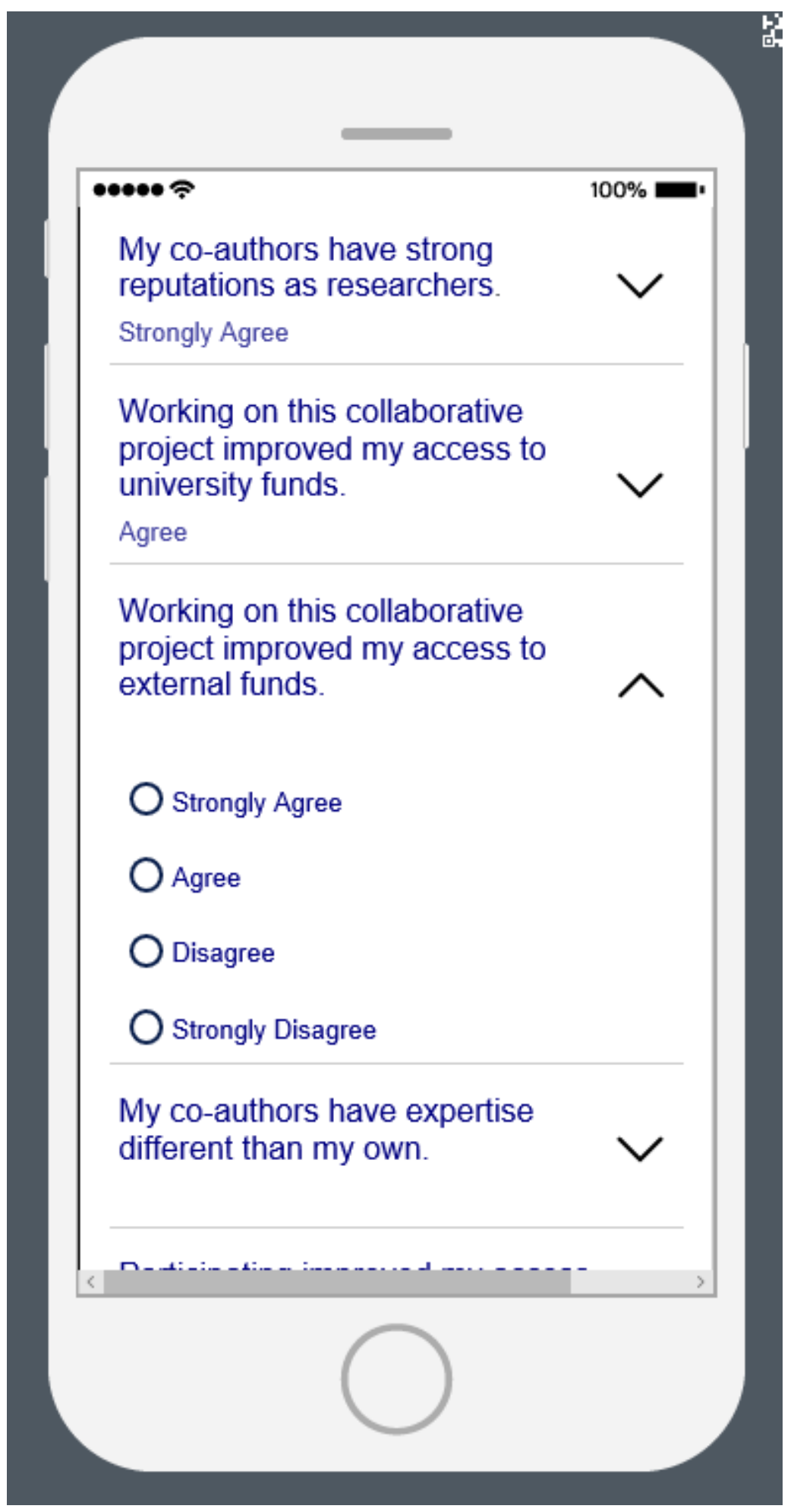




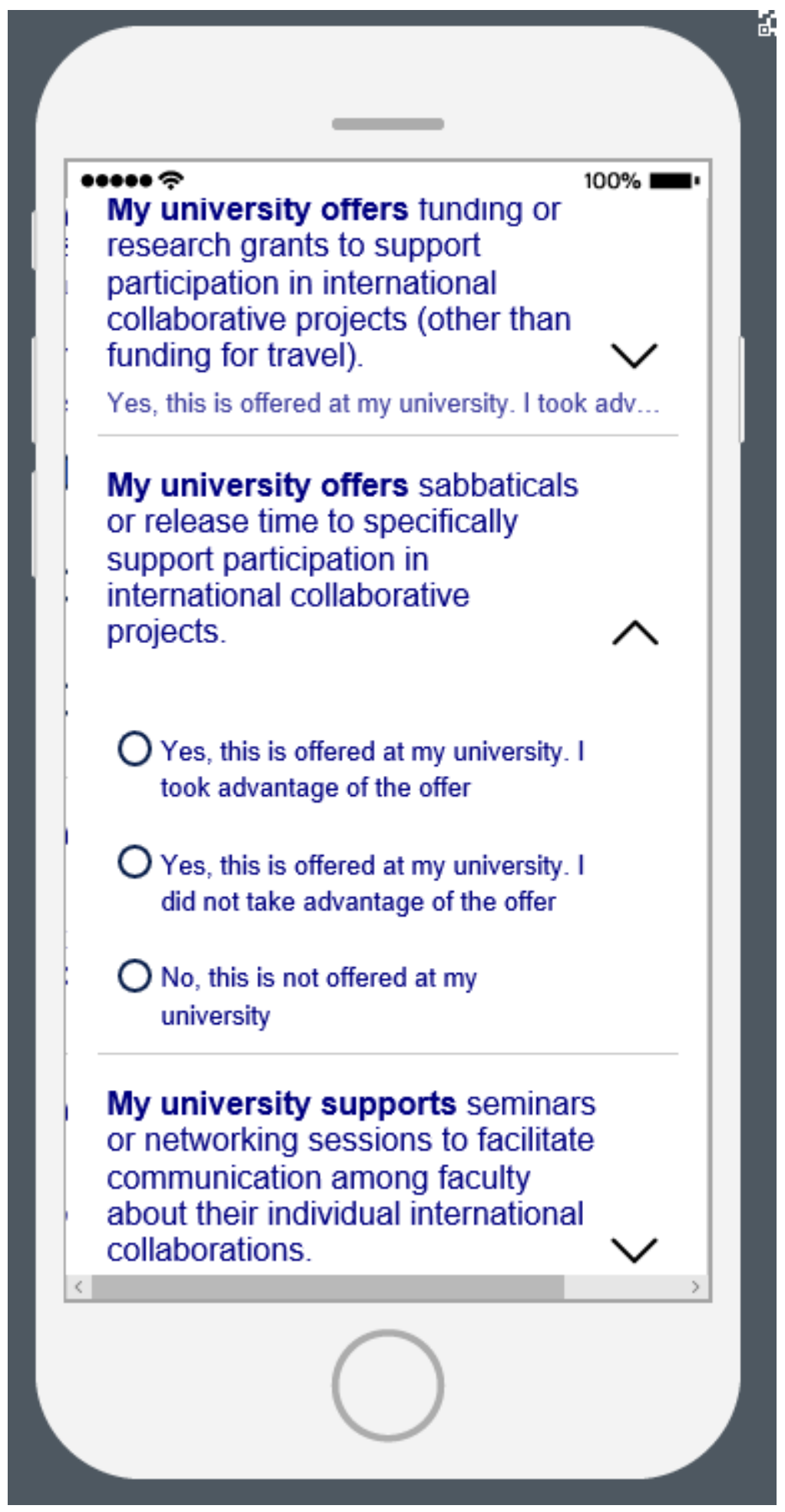




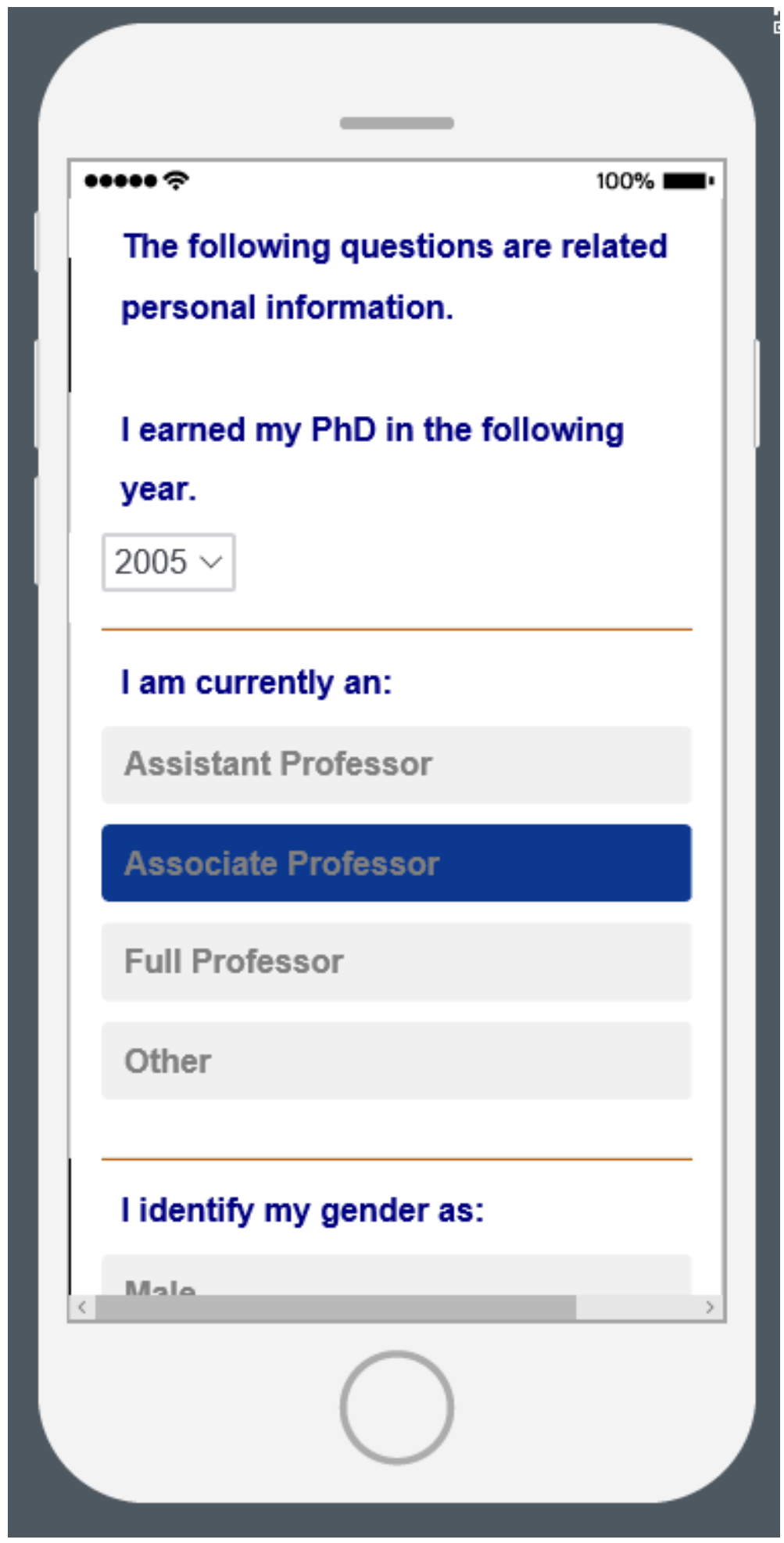


Thank you for participating in the survey on International Collaboration and Co-authorship. Your participation is very important to the success of this research and is greatly appreciated.

Powered by Qualtrics 
International Collaboration Among Social Science Scholars

Appendix G: Cross Tabulation Data

Table 26: Research Question Four - Cross Tabulation Q1-Q12 Motivation

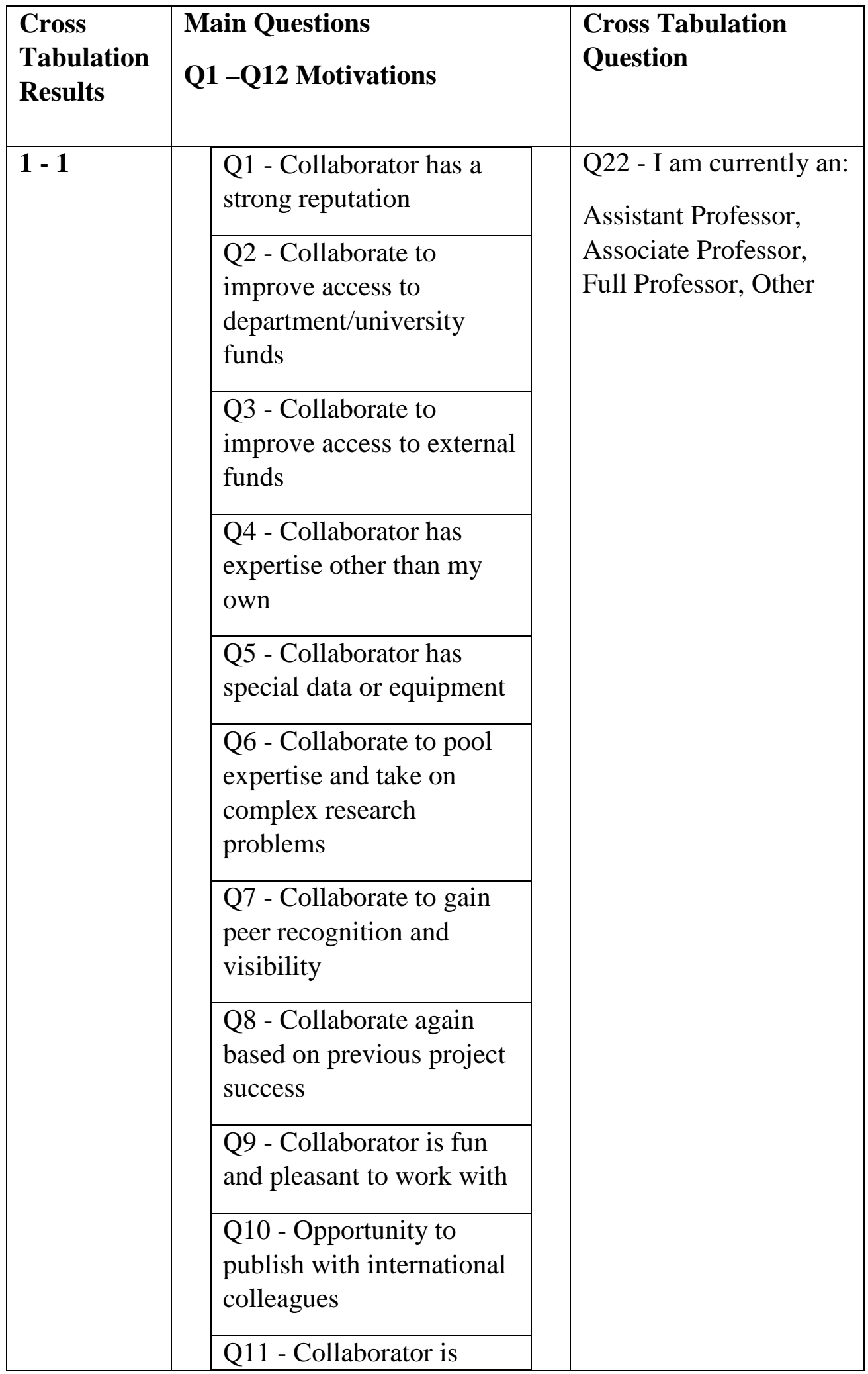




\begin{tabular}{|c|c|c|}
\hline & \begin{tabular}{|l|}
$\begin{array}{l}\text { fluent in the same } \\
\text { language }\end{array}$ \\
$\begin{array}{l}\text { Q12 - Collaborate to } \\
\text { mentor and help a junior } \\
\text { colleague or graduate } \\
\text { student }\end{array}$ \\
\end{tabular} & \\
\hline $1-2$ & As Above & $\begin{array}{l}\text { Q23 - I identify my } \\
\text { gender as: } \\
\text { Male, Female, Trans*, } \\
\text { None of the above, } \\
\text { Prefer not to disclose. }\end{array}$ \\
\hline $1-3$ & As Above & $\begin{array}{l}\text { Q24 -My native } \\
\text { language is: Choice } \\
\text { from list of languages. } \\
\text { Sub-organized: } \\
\text { languages other than } \\
\text { English and English }\end{array}$ \\
\hline $1-4$ & As Above & $\begin{array}{l}\text { Q26 - I was introduced } \\
\text { to one of my co-authors } \\
\text { during my PhD } \\
\text { program. }\end{array}$ \\
\hline $1-5$ & As Above & $\begin{array}{l}\text { Q27 - I have co- } \\
\text { authored multiple times } \\
\text { with at least one of my } \\
\text { co-authors (more than } \\
\text { one time). }\end{array}$ \\
\hline
\end{tabular}




\section{Cross Tabulation Table: 1-1}

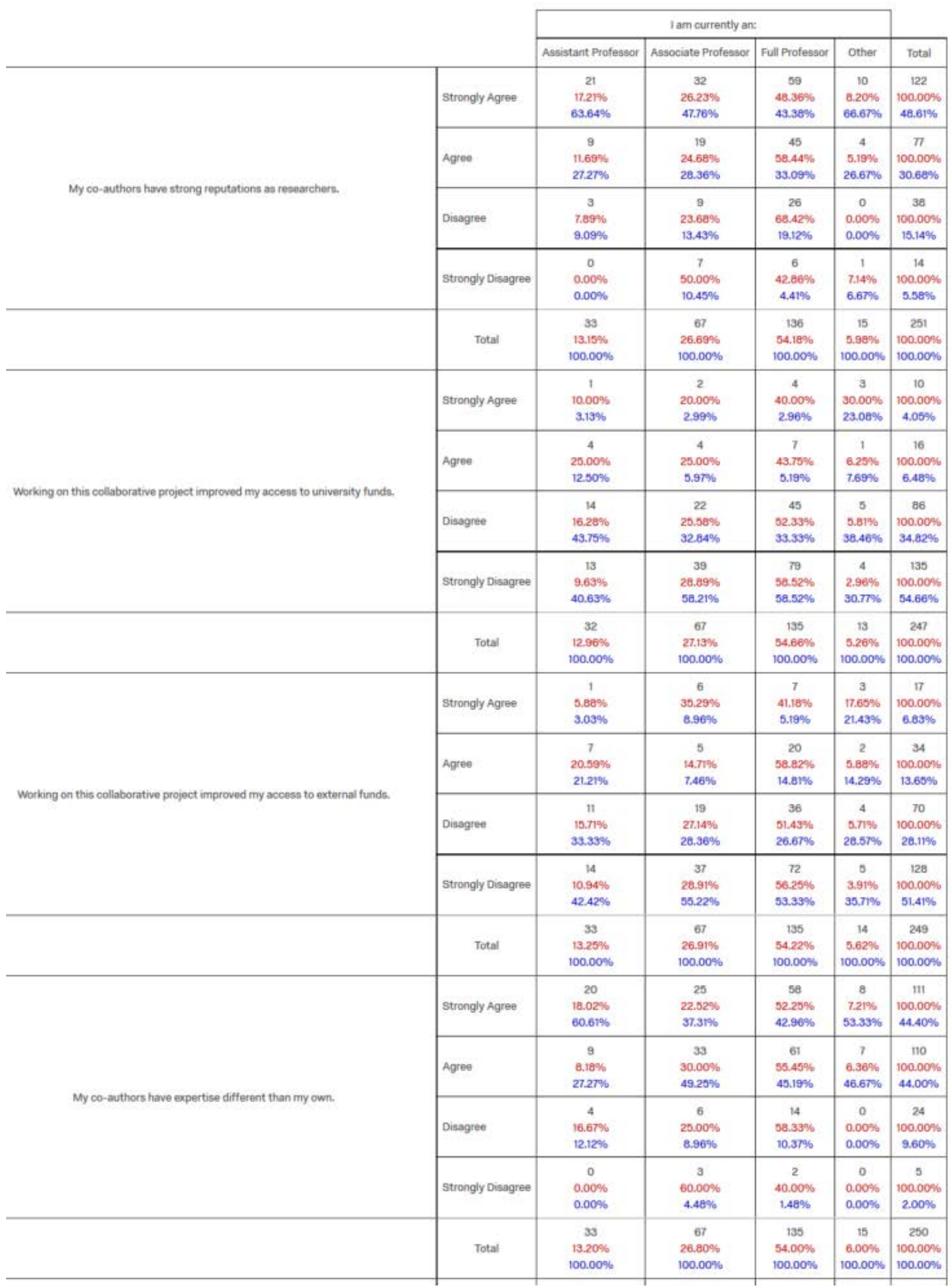


Cross Tabulation Table: 1-1(Continued)

\begin{tabular}{|c|c|c|c|c|c|c|}
\hline \multirow{4}{*}{ Participating improved my acoess to special data or research equipment. } & Strongly Agree & $\begin{array}{c}7 \\
17.50 \% \\
21.21 \%\end{array}$ & $\begin{array}{c}8 \\
20.00 \% \\
11.94 \%\end{array}$ & $\begin{array}{c}23 \\
57.50 \% \\
16.91 \%\end{array}$ & $\begin{array}{c}2 \\
5.00 \% \\
13.33 \%\end{array}$ & $\begin{array}{c}40 \\
100.00 \% \\
15.94 \%\end{array}$ \\
\hline & Agree & $\begin{array}{c}9 \\
21.43 \% \\
27.27 \%\end{array}$ & $\begin{array}{c}9 \\
21.43 \% \\
13.43 \%\end{array}$ & $\begin{array}{c}23 \\
54.76 \% \\
16.91 \%\end{array}$ & $\begin{array}{c}1 \\
2.38 \% \\
6.67 \%\end{array}$ & $\begin{array}{c}42 \\
100.00 \% \\
16.73 \%\end{array}$ \\
\hline & Disagree & $\begin{array}{c}9 \\
12.86 \% \\
27.27 \%\end{array}$ & $\begin{array}{c}21 \\
30.00 \% \\
31.34 \%\end{array}$ & $\begin{array}{c}34 \\
48.57 \% \\
25.00 \%\end{array}$ & $\begin{array}{c}6 \\
8.57 \% \\
40.00 \%\end{array}$ & $\begin{array}{c}70 \\
100.00 \% \\
27.89 \%\end{array}$ \\
\hline & Strongly Disagree & $\begin{array}{c}8 \\
8.08 \% \\
24.24 \%\end{array}$ & $\begin{array}{c}29 \\
29.29 \% \\
43.28 \%\end{array}$ & $\begin{array}{c}56 \\
56.57 \% \\
41.18 \%\end{array}$ & $\begin{array}{c}6 \\
6.06 \% \\
40.00 \%\end{array}$ & $\begin{array}{c}99 \\
100.00 \% \\
39.44 \%\end{array}$ \\
\hline & Total & $\begin{array}{c}33 \\
13.15 \% \\
100.00 \%\end{array}$ & $\begin{array}{c}67 \\
26.69 \% \\
100.00 \%\end{array}$ & $\begin{array}{c}136 \\
54.18 \% \\
100.00 \%\end{array}$ & $\begin{array}{c}15 \\
5.98 \% \\
100.00 \%\end{array}$ & $\begin{array}{c}251 \\
100.00 \% \\
100.00 \%\end{array}$ \\
\hline \multirow{5}{*}{ Working together allowed us to pool knowiedpe to accomplish complex research. } & Strongly Agree & $\begin{array}{c}26 \\
15.29 \% \\
78.79 \%\end{array}$ & $\begin{array}{c}43 \\
25.29 \% \\
64.18 \%\end{array}$ & $\begin{array}{c}89 \\
52.35 \% \\
65.44 \%\end{array}$ & $\begin{array}{c}12 \\
7.06 \% \\
80.00 \%\end{array}$ & $\begin{array}{c}170 \\
100.00 \% \\
67.73 \%\end{array}$ \\
\hline & Agree & $\begin{array}{c}7 \\
9.72 \% \\
21.21 \%\end{array}$ & $\begin{array}{c}21 \\
28.17 \% \\
31.34 \%\end{array}$ & $\begin{array}{c}43 \\
59.72 \% \\
31.62 \%\end{array}$ & $\begin{array}{c}1 \\
1.39 \% \\
6.67 \%\end{array}$ & $\begin{array}{c}72 \\
100.00 \% \\
28.69 \%\end{array}$ \\
\hline & Disagree & $\begin{array}{c}0 \\
0.00 \% \\
0.00 \%\end{array}$ & $\begin{array}{c}1 \\
25.00 \% \\
1.49 \%\end{array}$ & $\begin{array}{c}2 \\
50.00 \% \\
1.47 \%\end{array}$ & $\begin{array}{c}1 \\
25.00 \% \\
6.67 \%\end{array}$ & $\begin{array}{c}4 \\
100.00 \% \\
1.59 \%\end{array}$ \\
\hline & Strongly Disagree & $\begin{array}{c}0 \\
0.00 \% \\
0.00 \%\end{array}$ & $\begin{array}{c}2 \\
40.00 \% \\
2.99 \%\end{array}$ & $\begin{array}{c}2 \\
40.00 \% \\
1.47 \%\end{array}$ & $\begin{array}{c}1 \\
20.00 \% \\
6.67 \%\end{array}$ & $\begin{array}{c}5 \\
100.00 \% \\
1.99 \%\end{array}$ \\
\hline & Total & $\begin{array}{c}33 \\
13.15 \% \\
100.00 \%\end{array}$ & $\begin{array}{c}67 \\
26.69 \% \\
100.00 \%\end{array}$ & $\begin{array}{c}136 \\
54.18 \% \\
100.00 \%\end{array}$ & $\begin{array}{c}15 \\
5.98 \% \\
100.00 \%\end{array}$ & $\begin{array}{c}251 \\
100.00 \% \\
100.00 \%\end{array}$ \\
\hline \multirow{5}{*}{ Working with my co-authors allowed me to gain more peer recognition and visibility. } & Strongly Agree & $\begin{array}{c}20 \\
27.40 \% \\
60.61 \%\end{array}$ & $\begin{array}{c}22 \\
30.14 \% \\
32.84 \%\end{array}$ & $\begin{array}{c}23 \\
31.51 \% \\
16.91 \%\end{array}$ & $\begin{array}{c}8 \\
10.96 \% \\
53.33 \%\end{array}$ & $\begin{array}{c}73 \\
100.00 \% \\
29.08 \%\end{array}$ \\
\hline & Agree & $\begin{array}{c}9 \\
11.25 \% \\
27.27 \%\end{array}$ & $\begin{array}{c}27 \\
33.75 \% \\
40.30 \%\end{array}$ & $\begin{array}{c}40 \\
50.00 \% \\
29.41 \%\end{array}$ & $\begin{array}{c}4 \\
5.00 \% \\
26.67 \%\end{array}$ & $\begin{array}{c}80 \\
100.00 \% \\
31.87 \%\end{array}$ \\
\hline & Disagree & $\begin{array}{c}3 \\
4.41 \% \\
9.09 \%\end{array}$ & $\begin{array}{c}12 \\
17.65 \% \\
17.91 \%\end{array}$ & $\begin{array}{c}52 \\
76.47 \% \\
38.24 \%\end{array}$ & $\begin{array}{c}1 \\
1.47 \% \\
6.67 \%\end{array}$ & $\begin{array}{c}68 \\
100.00 \% \\
27.09 \%\end{array}$ \\
\hline & Strongly Disagree & $\begin{array}{c}1 \\
3.33 \% \\
3.03 \%\end{array}$ & $\begin{array}{c}6 \\
20.00 \% \\
8.96 \%\end{array}$ & $\begin{array}{c}21 \\
70.00 \% \\
15.44 \%\end{array}$ & $\begin{array}{c}2 \\
6.67 \% \\
13.33 \%\end{array}$ & $\begin{array}{c}30 \\
100.00 \% \\
11.95 \%\end{array}$ \\
\hline & Total & $\begin{array}{c}33 \\
13.15 \% \\
100.00 \%\end{array}$ & $\begin{array}{c}67 \\
26.69 \% \\
100.00 \%\end{array}$ & $\begin{array}{c}136 \\
54.18 \% \\
100.00 \%\end{array}$ & $\begin{array}{c}15 \\
5.98 \% \\
100.00 \%\end{array}$ & $\begin{array}{c}251 \\
100.00 \% \\
100.00 \%\end{array}$ \\
\hline
\end{tabular}


Cross Tabulation Table: 1-1 (Continued)

\begin{tabular}{|c|c|c|c|c|c|c|}
\hline & & \multicolumn{4}{|c|}{ I am currently ar: } & \multirow[b]{2}{*}{ Total } \\
\hline & & Aasiatant Professor & Associate Professor & Full Professor & Other & \\
\hline \multirow{5}{*}{ I had worked effectively with one of my co-authors before on a successful project. } & Strongly Agree & $\begin{array}{c}24 \\
17.02 \% \\
72.73 \%\end{array}$ & $\begin{array}{c}32 \\
22.70 \% \\
49.23 \%\end{array}$ & $\begin{array}{c}79 \\
56.03 \% \\
58.09 \%\end{array}$ & $\begin{array}{c}6 \\
4.26 \% \\
40.00 \%\end{array}$ & $\begin{array}{c}141 \\
100.00 \% \\
56.63 \%\end{array}$ \\
\hline & Agree & $\begin{array}{c}3 \\
7.14 \% \\
9.09 \%\end{array}$ & $\begin{array}{c}11 \\
26.19 \% \\
16.92 \%\end{array}$ & $\begin{array}{c}25 \\
59.52 \% \\
18.38 \%\end{array}$ & $\begin{array}{c}3 \\
7.14 \% \\
20.00 \%\end{array}$ & $\begin{array}{c}42 \\
100.00 \% \\
16.87 \%\end{array}$ \\
\hline & Disagree & $\begin{array}{c}5 \\
11.90 \% \\
15.15 \%\end{array}$ & $\begin{array}{c}12 \\
28.57 \% \\
18.46 \%\end{array}$ & $\begin{array}{c}21 \\
50.00 \% \\
15.44 \%\end{array}$ & $\begin{array}{c}4 \\
9.52 \% \\
26.67 \%\end{array}$ & $\begin{array}{c}42 \\
100.00 \% \\
16.87 \%\end{array}$ \\
\hline & Strongly Disagree & $\begin{array}{c}1 \\
4.17 \% \\
3.03 \%\end{array}$ & $\begin{array}{c}10 \\
41.67 \% \\
15.38 \%\end{array}$ & $\begin{array}{c}11 \\
45.83 \% \\
8.09 \%\end{array}$ & $\begin{array}{c}2 \\
8.33 \% \\
13.33 \%\end{array}$ & $\begin{array}{c}24 \\
100.00 \% \\
9.64 \%\end{array}$ \\
\hline & Total & $\begin{array}{c}33 \\
13.25 \% \\
100.00 \%\end{array}$ & $\begin{array}{c}65 \\
26.10 \% \\
100.00 \%\end{array}$ & $\begin{array}{c}136 \\
54.62 \% \\
100.00 \%\end{array}$ & $\begin{array}{c}15 \\
6.02 \% \\
100.00 \%\end{array}$ & $\begin{array}{c}249 \\
100.00 \% \\
100.00 \%\end{array}$ \\
\hline \multirow{5}{*}{ My co-authors are pleasant and fun to work with. } & Strongly Agree & $\begin{array}{c}22 \\
13.33 \% \\
66.67 \%\end{array}$ & $\begin{array}{c}41 \\
24.85 \% \\
61.19 \%\end{array}$ & $\begin{array}{c}93 \\
56.36 \% \\
68.38 \%\end{array}$ & $\begin{array}{c}9 \\
5.45 \% \\
60.00 \%\end{array}$ & $\begin{array}{c}165 \\
100.00 \% \\
65.74 \%\end{array}$ \\
\hline & Agree & $\begin{array}{c}10 \\
12.82 \% \\
30.30 \%\end{array}$ & $\begin{array}{c}23 \\
29.49 \% \\
34.33 \%\end{array}$ & $\begin{array}{c}40 \\
51.28 \% \\
29.41 \%\end{array}$ & $\begin{array}{c}5 \\
6.41 \% \\
33.33 \%\end{array}$ & $\begin{array}{c}78 \\
100.00 \% \\
31.08 \%\end{array}$ \\
\hline & Disagree & $\begin{array}{c}1 \\
14.29 \% \\
3.03 \%\end{array}$ & $\begin{array}{c}2 \\
28.57 \% \\
2.99 \%\end{array}$ & $\begin{array}{c}3 \\
42.86 \% \\
2.2196\end{array}$ & $\begin{array}{c}1 \\
14.29 \% \\
6.67 \%\end{array}$ & $\begin{array}{c}7 \\
100.00 \% \\
2.79 \%\end{array}$ \\
\hline & Strongly Disagree & $\begin{array}{c}0 \\
0.00 \% \\
0.00 \%\end{array}$ & $\begin{array}{c}1 \\
100.00 \% \\
1.49 \%\end{array}$ & $\begin{array}{c}0 \\
0.00 \% \\
0.00 \%\end{array}$ & $\begin{array}{c}0 \\
0.00 \% \\
0.00 \%\end{array}$ & $\begin{array}{c}1 \\
100.00 \% \\
0.40 \%\end{array}$ \\
\hline & Total & $\begin{array}{c}33 \\
13.15 \% \\
100.00 \%\end{array}$ & $\begin{array}{c}67 \\
26.69 \% \\
100.00 \%\end{array}$ & $\begin{array}{c}136 \\
54.18 \% \\
100.00 \%\end{array}$ & $\begin{array}{c}15 \\
5.98 \% \\
100.00 \%\end{array}$ & $\begin{array}{c}251 \\
100.00 \% \\
100.00 \%\end{array}$ \\
\hline \multirow{5}{*}{ Because of the opportunity to publish with my international colleagues. } & Strongly Agree & $\begin{array}{c}19 \\
20.65 \% \\
57.56 \%\end{array}$ & $\begin{array}{c}24 \\
26.09 \% \\
35.82 \%\end{array}$ & $\begin{array}{c}39 \\
42.39 \% \\
28.68 \%\end{array}$ & $\begin{array}{c}10 \\
10.87 \% \\
66.67 \%\end{array}$ & $\begin{array}{c}92 \\
100.00 \% \\
36.65 \%\end{array}$ \\
\hline & Apree & $\begin{array}{c}8 \\
9.419 \% \\
24.24 \%\end{array}$ & $\begin{array}{c}27 \\
31.76 \% \\
40.30 \%\end{array}$ & $\begin{array}{c}47 \\
55.29 \% \\
34.56 \%\end{array}$ & $\begin{array}{c}3 \\
3.53 \% \\
20.00 \%\end{array}$ & $\begin{array}{c}85 \\
100.00 \% \\
33.86 \%\end{array}$ \\
\hline & Disagree & $\begin{array}{c}3 \\
7.32 \% \\
9.09 \%\end{array}$ & $\begin{array}{c}7 \\
17.07 \% \\
10.45 \%\end{array}$ & $\begin{array}{c}30 \\
73.17 \% \\
22.06 \%\end{array}$ & $\begin{array}{c}1 \\
2.44 \% \\
6.67 \%\end{array}$ & $\begin{array}{c}41 \\
100.00 \% \\
16.33 \%\end{array}$ \\
\hline & Strongly Disagree & $\begin{array}{c}3 \\
9.09 \% \\
9.09 \%\end{array}$ & $\begin{array}{c}9 \\
27.27 \% \\
13.43 \%\end{array}$ & $\begin{array}{c}20 \\
60.61 \% \\
14.71 \%\end{array}$ & $\begin{array}{c}1 \\
3.03 \% \\
6.67 \%\end{array}$ & $\begin{array}{c}33 \\
100.00 \% \\
13.15 \%\end{array}$ \\
\hline & Total & $\begin{array}{c}33 \\
13.15 \% \\
100.00 \%\end{array}$ & $\begin{array}{c}67 \\
26.69 \% \\
100.00 \%\end{array}$ & $\begin{array}{c}136 \\
54.18 \% \\
100.00 \%\end{array}$ & $\begin{array}{c}15 \\
5.98 \% \\
100.00 \%\end{array}$ & $\begin{array}{c}251 \\
100.00 \% \\
100.00 \%\end{array}$ \\
\hline
\end{tabular}


International Collaboration Among Social Science Scholars

Cross Tabulation Table: 1-1 (Continued)

\begin{tabular}{|c|c|c|c|c|c|c|}
\hline \multirow{5}{*}{ My o0-authors and I are fluent in the same language. } & Strongly Agree & $\begin{array}{c}15 \\
19.48 \% \\
45.45 \%\end{array}$ & $\begin{array}{c}17 \\
22.08 \% \\
25.37 \%\end{array}$ & $\begin{array}{c}39 \\
50.65 \% \\
28.89 \%\end{array}$ & $\begin{array}{c}6 \\
7.79 \% \\
40.00 \%\end{array}$ & $\begin{array}{c}\pi \\
100.00 \% \\
30.80 \%\end{array}$ \\
\hline & Agree & $\begin{array}{c}12 \\
12.37 \% \\
36.36 \%\end{array}$ & $\begin{array}{c}27 \\
27.84 \% \\
40.30 \%\end{array}$ & $\begin{array}{c}54 \\
55.67 \% \\
40.00 \%\end{array}$ & $\begin{array}{c}4 \\
4.12 \% \\
26.67 \%\end{array}$ & $\begin{array}{c}97 \\
100.00 \% \\
38.80 \%\end{array}$ \\
\hline & Disagree & $\begin{array}{c}3 \\
6.52 \% \\
9.09 \% \\
\end{array}$ & $\begin{array}{c}14 \\
30.43 \% \\
20.90 \%\end{array}$ & $\begin{array}{c}24 \\
52.17 \% \\
17.70 \% \\
\end{array}$ & $\begin{array}{c}5 \\
10.87 \% \\
39.33 \%\end{array}$ & $\begin{array}{c}46 \\
100.00 \% \\
18.40 \%\end{array}$ \\
\hline & Strongly Disagree & $\begin{array}{c}3 \\
10.00 \% \\
9.09 \%\end{array}$ & $\begin{array}{c}9 \\
30.00 \% \\
13.43 \%\end{array}$ & $\begin{array}{c}18 \\
60.00 \% \\
13.33 \%\end{array}$ & $\begin{array}{c}0 \\
0.00 \% \\
0.00 \%\end{array}$ & $\begin{array}{c}30 \\
100.00 \% \\
12.00 \%\end{array}$ \\
\hline & Total & $\begin{array}{c}33 \\
13.20 \% \\
100.00 \%\end{array}$ & $\begin{array}{c}67 \\
26.80 \% \\
100.00 \%\end{array}$ & $\begin{array}{c}135 \\
54.00 \% \\
100.00 \%\end{array}$ & $\begin{array}{c}15 \\
6.00 \% \\
100.00 \%\end{array}$ & $\begin{array}{c}250 \\
100.00 \% \\
100.00 \%\end{array}$ \\
\hline \multirow{5}{*}{ I wanted to mentor and help a junior colleague or graduate student. } & Strongly Agree & $\begin{array}{c}0 \\
0.00 \% \\
0.00 \%\end{array}$ & $\begin{array}{c}10 \\
20.00 \% \\
14.93 \%\end{array}$ & $\begin{array}{c}39 \\
78.00 \% \\
28.68 \%\end{array}$ & $\begin{array}{c}1 \\
2.00 \% \\
6.67 \%\end{array}$ & $\begin{array}{c}50 \\
100.00 \% \\
20.00 \%\end{array}$ \\
\hline & Agree & $\begin{array}{c}1 \\
3.23 \% \\
3.13 \%\end{array}$ & $\begin{array}{c}5 \\
16.13 \% \\
7.46 \%\end{array}$ & $\begin{array}{c}24 \\
71.42 \% \\
17.65 \% \\
\end{array}$ & $\begin{array}{c}1 \\
3.23 \% \\
6.67 \%\end{array}$ & $\begin{array}{c}31 \\
100.00 \% \\
12.40 \%\end{array}$ \\
\hline & Disagree & $\begin{array}{c}9 \\
14.06 \% \\
28.13 \%\end{array}$ & $\begin{array}{c}16 \\
25.00 \% \\
23.88 \% \\
\end{array}$ & $\begin{array}{c}33 \\
51.56 \% \\
24.26 \%\end{array}$ & $\begin{array}{c}6 \\
9.38 \% \\
40.00 \%\end{array}$ & $\begin{array}{c}64 \\
100.00 \% \\
25.60 \%\end{array}$ \\
\hline & strongly Disagree & $\begin{array}{c}22 \\
20.95 \% \\
68.75 \%\end{array}$ & $\begin{array}{c}36 \\
34.29 \% \\
53.73 \%\end{array}$ & $\begin{array}{c}40 \\
38.10 \% \\
29.41 \%\end{array}$ & $\begin{array}{c}7 \\
6.67 \% \\
46.67 \%\end{array}$ & $\begin{array}{c}105 \\
100.00 \% \\
42.00 \%\end{array}$ \\
\hline & Total & $\begin{array}{c}32 \\
12.80 \% \\
100.00 \%\end{array}$ & $\begin{array}{c}67 \\
26.80 \% \\
100.00 \%\end{array}$ & $\begin{array}{c}136 \\
54.40 \% \\
100.00 \%\end{array}$ & $\begin{array}{c}15 \\
6.00 \% \\
100.00 \%\end{array}$ & $\begin{array}{c}250 \\
100.00 \% \\
100.00 \%\end{array}$ \\
\hline
\end{tabular}


International Collaboration Among Social Science Scholars

\section{Cross Tabulation Table: 1-2}

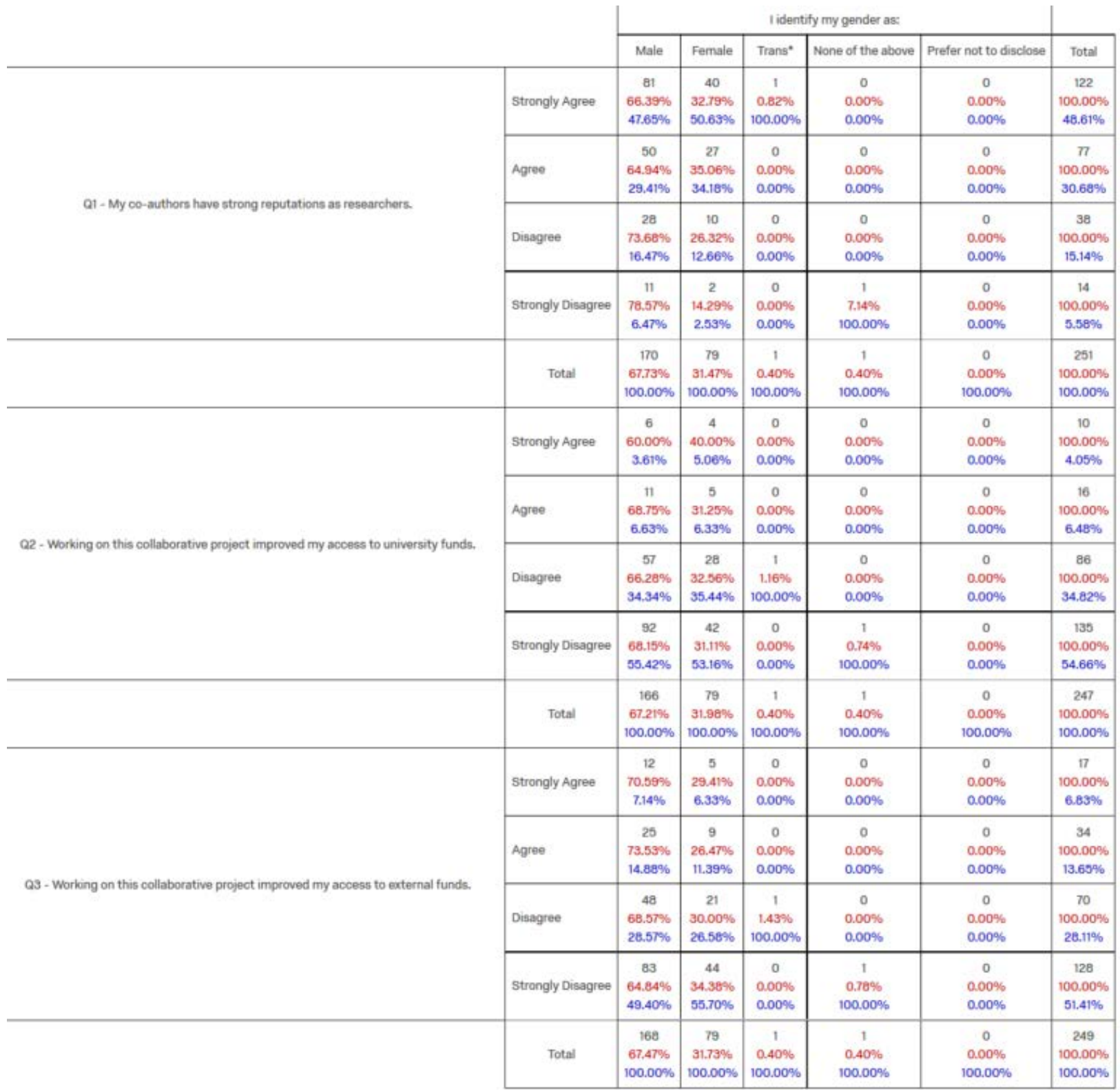




\section{Cross Tabulation Table: 1-2 (Continued)}

\begin{tabular}{|c|c|c|c|c|c|c|c|}
\hline & & \multicolumn{5}{|c|}{ Q 23 - I identify my gender as: } & \multirow[b]{2}{*}{ Total } \\
\hline & & Male & Female & Trans" & None of the above & Prefer not to disclose & \\
\hline \multirow{5}{*}{ Q4 - My co-authors have expertise different than my own. } & Strongly Agree & $\begin{array}{c}70 \\
63.06 \% \\
41.42 \%\end{array}$ & $\begin{array}{c}40 \\
36.04 \% \\
50.63 \%\end{array}$ & $\begin{array}{c}1 \\
0.90 \% \\
100.00 \%\end{array}$ & $\begin{array}{c}0 \\
0.00 \% \\
0.00 \%\end{array}$ & $\begin{array}{c}0 \\
0.00 \% \\
0.00 \%\end{array}$ & $\begin{array}{c}111 \\
100.00 \% \\
44.40 \%\end{array}$ \\
\hline & Agree & $\begin{array}{c}79 \\
71.82 \% \\
46.75 \%\end{array}$ & $\begin{array}{c}30 \\
27.27 \% \\
37.97 \%\end{array}$ & $\begin{array}{c}0 \\
0.00 \% \\
0.00 \%\end{array}$ & $\begin{array}{c}1 \\
0.91 \% \\
100.00 \%\end{array}$ & $\begin{array}{c}0 \\
0.00 \% \\
0.00 \%\end{array}$ & $\begin{array}{c}110 \\
100.00 \% \\
44.00 \%\end{array}$ \\
\hline & Disagree & $\begin{array}{c}17 \\
70.83 \% \\
10.06 \%\end{array}$ & $\begin{array}{c}7 \\
29.17 \% \\
8.86 \%\end{array}$ & $\begin{array}{c}0 \\
0.00 \% \\
0.00 \%\end{array}$ & $\begin{array}{c}0 \\
0.00 \% \\
0.00 \%\end{array}$ & $\begin{array}{c}0 \\
0.00 \% \\
0.00 \%\end{array}$ & $\begin{array}{c}24 \\
100.00 \% \\
9.60 \%\end{array}$ \\
\hline & Strongly Disagree & $\begin{array}{c}3 \\
60.00 \% \\
1.78 \%\end{array}$ & $\begin{array}{c}2 \\
40.00 \% \\
2.53 \%\end{array}$ & $\begin{array}{c}0 \\
0.00 \% \\
0.00 \%\end{array}$ & $\begin{array}{c}0 \\
0.00 \% \\
0.00 \%\end{array}$ & $\begin{array}{c}0 \\
0.00 \% \\
0.00 \%\end{array}$ & $\begin{array}{c}5 \\
100.00 \% \\
2.00 \%\end{array}$ \\
\hline & Total & $\begin{array}{c}169 \\
67.60 \% \\
100.00 \%\end{array}$ & $\begin{array}{c}79 \\
31.60 \% \\
100.00 \%\end{array}$ & $\begin{array}{c}1 \\
0.40 \% \\
100.00 \%\end{array}$ & $\begin{array}{c}1 \\
0.40 \% \\
100.00 \%\end{array}$ & $\begin{array}{c}0 \\
0.00 \% \\
100.00 \%\end{array}$ & $\begin{array}{c}250 \\
100.00 \% \\
100.00 \%\end{array}$ \\
\hline \multirow{5}{*}{ Q5 - Participating improved my access to special data or research equipment. } & Strongly Agree & $\begin{array}{c}91 \\
\pi 7.50 \% \\
18.24 \%\end{array}$ & $\begin{array}{c}9 \\
22.50 \% \\
11.39 \%\end{array}$ & $\begin{array}{c}0 \\
0.00 \% \\
0.00 \%\end{array}$ & $\begin{array}{c}0 \\
0.00 \% \\
0.00 \%\end{array}$ & $\begin{array}{c}0 \\
0.00 \% \\
0.00 \%\end{array}$ & $\begin{array}{c}40 \\
100.00 \% \\
15.94 \%\end{array}$ \\
\hline & Agree & $\begin{array}{c}26 \\
61.90 \% \\
15.29 \%\end{array}$ & $\begin{array}{c}16 \\
38.10 \% \\
20.25 \%\end{array}$ & $\begin{array}{c}0 \\
0.00 \% \\
0.00 \%\end{array}$ & $\begin{array}{c}0 \\
0.00 \% \\
0.00 \%\end{array}$ & $\begin{array}{c}0 \\
0.00 \% \\
0.00 \%\end{array}$ & $\begin{array}{c}42 \\
100.00 \% \\
16.73 \%\end{array}$ \\
\hline & Disagree & $\begin{array}{c}47 \\
67.14 \% \\
27.65 \%\end{array}$ & $\begin{array}{c}22 \\
31.43 \% \\
27.85 \%\end{array}$ & $\begin{array}{c}1 \\
1.43 \% \\
100.00 \%\end{array}$ & $\begin{array}{c}0 \\
0.00 \% \\
0.00 \%\end{array}$ & $\begin{array}{c}0 \\
0.00 \% \\
0.00 \%\end{array}$ & $\begin{array}{c}70 \\
100.00 \% \\
27.89 \%\end{array}$ \\
\hline & Strongly Disagree & $\begin{array}{c}66 \\
66.67 \% \\
38.82 \%\end{array}$ & $\begin{array}{c}32 \\
32.32 \% \\
40.51 \%\end{array}$ & $\begin{array}{c}0 \\
0.00 \% \\
0.00 \%\end{array}$ & $\begin{array}{c}1 \\
1.01 \% \\
100.00 \%\end{array}$ & $\begin{array}{c}0 \\
0.00 \% \\
0.00 \%\end{array}$ & $\begin{array}{c}99 \\
100.00 \% \\
39.44 \%\end{array}$ \\
\hline & Total & $\begin{array}{c}170 \\
67.73 \% \\
100.00 \%\end{array}$ & $\begin{array}{c}79 \\
31.47 \% \\
100.00 \%\end{array}$ & $\begin{array}{c}1 \\
0.40 \% \\
100.00 \%\end{array}$ & $\begin{array}{c}1 \\
0.40 \% \\
100.00 \%\end{array}$ & $\begin{array}{c}0 \\
0.00 \% \\
100.00 \%\end{array}$ & $\begin{array}{c}251 \\
100.00 \% \\
100.00 \% \\
\end{array}$ \\
\hline \multirow{5}{*}{ Q6 - Working together allowed us to pool knowledge to accomplish complex research. } & Strongly Agree & $\begin{array}{c}114 \\
67.06 \% \\
67.06 \%\end{array}$ & $\begin{array}{c}55 \\
32.35 \% \\
69.62 \%\end{array}$ & $\begin{array}{c}1 \\
0.59 \% \\
100.00 \%\end{array}$ & $\begin{array}{c}0 \\
0.00 \% \\
0.00 \%\end{array}$ & $\begin{array}{c}0 \\
0.00 \% \\
0.00 \%\end{array}$ & $\begin{array}{c}170 \\
100.00 \% \\
67.73 \%\end{array}$ \\
\hline & Agree & $\begin{array}{c}52 \\
72.22 \% \\
30.59 \%\end{array}$ & $\begin{array}{c}20 \\
27.78 \% \\
25.32 \%\end{array}$ & $\begin{array}{c}0 \\
0.00 \% \\
0.00 \%\end{array}$ & $\begin{array}{c}0 \\
0.00 \% \\
0.00 \%\end{array}$ & $\begin{array}{c}0 \\
0.00 \% \\
0.00 \%\end{array}$ & $\begin{array}{c}72 \\
100.00 \% \\
28.69 \%\end{array}$ \\
\hline & Disagree & $\begin{array}{c}1 \\
25.00 \% \\
0.59 \%\end{array}$ & $\begin{array}{c}2 \\
50.00 \% \\
2.53 \%\end{array}$ & $\begin{array}{c}0 \\
0.00 \% \\
0.00 \%\end{array}$ & $\begin{array}{c}1 \\
25.00 \% \\
100.00 \%\end{array}$ & $\begin{array}{c}0 \\
0.00 \% \\
0.00 \%\end{array}$ & $\begin{array}{c}4 \\
100.00 \% \\
1.59 \%\end{array}$ \\
\hline & Strongly Disagree & $\begin{array}{c}3 \\
60.00 \% \\
1.76 \%\end{array}$ & $\begin{array}{c}2 \\
40.00 \% \\
2.53 \%\end{array}$ & $\begin{array}{c}0 \\
0.00 \% \\
0.00 \%\end{array}$ & $\begin{array}{c}0 \\
0.00 \% \\
0.00 \%\end{array}$ & $\begin{array}{c}0 \\
0.00 \% \\
0.00 \%\end{array}$ & $\begin{array}{c}5 \\
100.00 \% \\
1.99 \%\end{array}$ \\
\hline & Total & $\begin{array}{c}170 \\
67.73 \% \\
100.00 \%\end{array}$ & $\begin{array}{c}79 \\
31.47 \% \\
100.00 \%\end{array}$ & $\begin{array}{c}1 \\
0.40 \% \\
100.00 \%\end{array}$ & $\begin{array}{c}1 \\
0.40 \% \\
100.00 \%\end{array}$ & $\begin{array}{c}0 \\
0.00 \% \\
100.00 \%\end{array}$ & $\begin{array}{c}251 \\
100.00 \% \\
100.00 \%\end{array}$ \\
\hline
\end{tabular}


International Collaboration Among Social Science Scholars

Cross Tabulation Table: 1-2 (Continued)

Q7 - Working with my co-authors allowed me to gain more peer recognition and visibility.

Q8 - I had worked effectively with one of my co-authors before on a successful project.

\begin{tabular}{|l|l|}
\hline Q23 - I identify my gender as: \\
\hline
\end{tabular}

\begin{tabular}{|c|c|c|c|c|c|c|c|}
\hline \multirow[t]{2}{*}{ 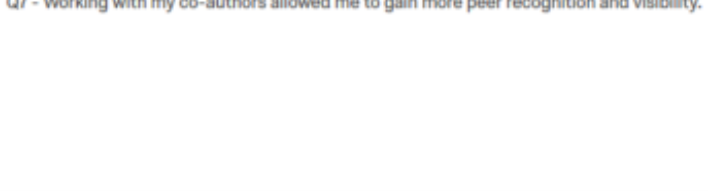 } & Disagree & $\begin{array}{c}48 \\
70.59 \% \\
28.24 \%\end{array}$ & $\begin{array}{c}19 \\
27.94 \% \\
24.05 \%\end{array}$ & $\begin{array}{c}0 \\
0.00 \% \\
0.00 \%\end{array}$ & $\begin{array}{c}1 \\
1.47 \% \\
100.00 \%\end{array}$ & $\begin{array}{c}0 \\
0.00 \% \\
0.00 \%\end{array}$ & $\begin{array}{c}68 \\
100.00 \% \\
27.09 \%\end{array}$ \\
\hline & Strongly Disagree & $\begin{array}{c}23 \\
76.67 \% \\
13.53 \%\end{array}$ & $\begin{array}{c}7 \\
23.33 \% \\
8.86 \%\end{array}$ & $\begin{array}{c}0 \\
0.00 \% \\
0.00 \%\end{array}$ & $\begin{array}{c}0 \\
0.00 \% \\
0.00 \%\end{array}$ & $\begin{array}{c}0 \\
0.00 \% \\
0.00 \%\end{array}$ & $\begin{array}{c}30 \\
100.00 \% \\
11.95 \%\end{array}$ \\
\hline & Total & $\begin{array}{c}170 \\
67.73 \% \\
100.00 \%\end{array}$ & $\begin{array}{c}79 \\
31.47 \% \\
100.00 \%\end{array}$ & $\begin{array}{c}1 \\
0.40 \% \\
100.00 \%\end{array}$ & $\begin{array}{c}1 \\
0.40 \% \\
100.00 \%\end{array}$ & $\begin{array}{c}0 \\
0.00 \% \\
100.00 \%\end{array}$ & $\begin{array}{c}251 \\
100.00 \% \\
100.00 \%\end{array}$ \\
\hline \multirow{5}{*}{ Q8 - I had worked effectively with one of my co-authors before on a successful project. } & Strongly Agree & $\begin{array}{c}101 \\
71.63 \% \\
59.76 \%\end{array}$ & $\begin{array}{c}40 \\
28.37 \% \\
51.28 \%\end{array}$ & $\begin{array}{c}0 \\
0.00 \% \\
0.00 \%\end{array}$ & $\begin{array}{c}0 \\
0.00 \% \\
0.00 \%\end{array}$ & $\begin{array}{c}0 \\
0.00 \% \\
0.00 \%\end{array}$ & $\begin{array}{c}141 \\
100.00 \% \\
56.63 \%\end{array}$ \\
\hline & Agree & $\begin{array}{c}29 \\
69.05 \% \\
17.16 \%\end{array}$ & $\begin{array}{c}12 \\
28.57 \% \\
15.38 \%\end{array}$ & $\begin{array}{c}1 \\
2.38 \% \\
100.00 \%\end{array}$ & $\begin{array}{c}0 \\
0.00 \% \\
0.00 \%\end{array}$ & $\begin{array}{c}0 \\
0.00 \% \\
0.00 \%\end{array}$ & $\begin{array}{c}42 \\
100.00 \% \\
16.87 \%\end{array}$ \\
\hline & Disagree & $\begin{array}{c}23 \\
54.76 \% \\
13.61 \%\end{array}$ & $\begin{array}{c}18 \\
42.86 \% \\
23.08 \%\end{array}$ & $\begin{array}{c}0 \\
0.00 \% \\
0.00 \%\end{array}$ & $\begin{array}{c}1 \\
2.38 \% \\
100.00 \%\end{array}$ & $\begin{array}{c}0 \\
0.00 \% \\
0.00 \%\end{array}$ & $\begin{array}{c}42 \\
100.00 \% \\
16.87 \%\end{array}$ \\
\hline & Strongly Disagree & $\begin{array}{c}16 \\
66.67 \% \\
9.47 \%\end{array}$ & $\begin{array}{c}8 \\
33.33 \% \\
10.26 \%\end{array}$ & $\begin{array}{c}0 \\
0.00 \% \\
0.00 \%\end{array}$ & $\begin{array}{c}0 \\
0.00 \% \\
0.00 \%\end{array}$ & $\begin{array}{c}0 \\
0.00 \% \\
0.00 \%\end{array}$ & $\begin{array}{c}24 \\
100.00 \% \\
9.64 \%\end{array}$ \\
\hline & Total & $\begin{array}{c}169 \\
67.87 \% \\
100.00 \%\end{array}$ & $\begin{array}{c}78 \\
31.33 \% \\
100.00 \%\end{array}$ & $\begin{array}{c}1 \\
0.40 \% \\
100.00 \%\end{array}$ & $\begin{array}{c}1 \\
0.40 \% \\
100.00 \%\end{array}$ & $\begin{array}{c}0 \\
0.00 \% \\
100.00 \%\end{array}$ & $\begin{array}{c}249 \\
100.00 \% \\
100.00 \%\end{array}$ \\
\hline \multirow{5}{*}{ Q9 - My co-authors are pleasant and fun to work with. } & Strongly Agree & $\begin{array}{c}115 \\
69.70 \% \\
67.65 \%\end{array}$ & $\begin{array}{c}50 \\
30.30 \% \\
63.29 \%\end{array}$ & $\begin{array}{c}0 \\
0.00 \% \\
0.00 \%\end{array}$ & $\begin{array}{c}0 \\
0.00 \% \\
0.00 \%\end{array}$ & $\begin{array}{c}0 \\
0.00 \% \\
0.00 \%\end{array}$ & $\begin{array}{c}165 \\
100.00 \% \\
65.74 \%\end{array}$ \\
\hline & Agree & \begin{tabular}{c|}
49 \\
$62.82 \%$ \\
$28.82 \%$
\end{tabular} & \begin{tabular}{c|}
27 \\
$34.62 \%$ \\
$34.18 \%$
\end{tabular} & $\begin{array}{c}1 \\
1.28 \% \\
100.00 \%\end{array}$ & $\begin{array}{c}1 \\
1.28 \% \\
100.00 \%\end{array}$ & $\begin{array}{c}0 \\
0.00 \% \\
0.00 \%\end{array}$ & $\begin{array}{c}78 \\
100.00 \% \\
31.08 \%\end{array}$ \\
\hline & Disagree & $\begin{array}{c}5 \\
71.43 \% \\
2.94 \%\end{array}$ & $\begin{array}{c}2 \\
28.57 \% \\
2.53 \%\end{array}$ & $\begin{array}{c}0 \\
0.00 \% \\
0.00 \%\end{array}$ & $\begin{array}{c}0 \\
0.00 \% \\
0.00 \%\end{array}$ & $\begin{array}{c}0 \\
0.00 \% \\
0.00 \%\end{array}$ & $\begin{array}{c}7 \\
100.00 \% \\
2.79 \%\end{array}$ \\
\hline & Strongly Disagree & $\begin{array}{c}1 \\
100.00 \% \\
0.59 \%\end{array}$ & $\begin{array}{c}0 \\
0.00 \% \\
0.00 \%\end{array}$ & $\begin{array}{c}0 \\
0.00 \% \\
0.00 \%\end{array}$ & $\begin{array}{c}0 \\
0.00 \% \\
0.00 \%\end{array}$ & $\begin{array}{c}0 \\
0.00 \% \\
0.00 \%\end{array}$ & $\begin{array}{c}1 \\
100.00 \% \\
0.40 \%\end{array}$ \\
\hline & Total & $\begin{array}{c}170 \\
67.73 \% \\
100.00 \%\end{array}$ & $\begin{array}{c}79 \\
31.47 \% \\
100.00 \%\end{array}$ & $\begin{array}{c}1 \\
0.40 \% \\
100.00 \%\end{array}$ & $\begin{array}{c}1 \\
0.40 \% \\
100.00 \%\end{array}$ & $\begin{array}{c}0 \\
0.00 \% \\
100.00 \%\end{array}$ & $\begin{array}{c}251 \\
100.00 \% \\
100.00 \%\end{array}$ \\
\hline
\end{tabular}


Cross Tabulation Table: 1-2 (Continued)

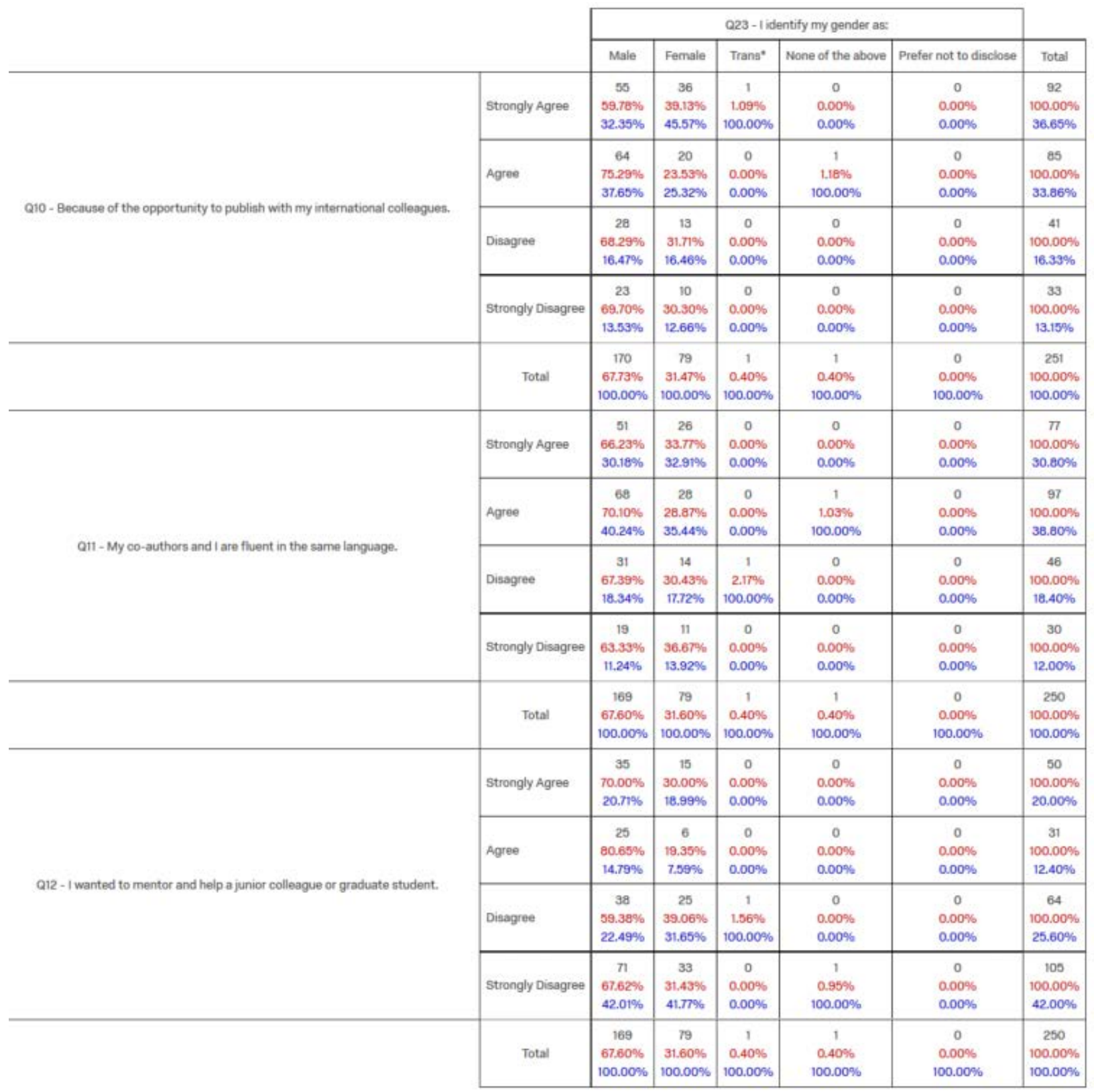




\section{Cross Tabulation Table 1-3}

\begin{tabular}{|c|c|c|c|c|c|c|}
\hline & & \multicolumn{4}{|c|}{ Q1 - My co-authors have strong reputations as researchers. } & \multirow{2}{*}{ Total } \\
\hline & & Strongly Agree & Agree & Disagree & Strongly Disagree & \\
\hline \multirow{3}{*}{ My native languege is: } & Language Other Than English & $\begin{array}{c}64 \\
50.00 \% \\
53.33 \%\end{array}$ & $\begin{array}{c}37 \\
28.91 \% \\
49.33 \%\end{array}$ & $\begin{array}{c}21 \\
16.41 \% \\
56.76 \%\end{array}$ & $\begin{array}{c}6 \\
4.69 \% \\
42.86 \%\end{array}$ & $\begin{array}{c}128 \\
100.00 \% \\
52.03 \%\end{array}$ \\
\hline & English & $\begin{array}{c}56 \\
47.46 \% \\
46.67 \%\end{array}$ & $\begin{array}{c}38 \\
32.20 \% \\
50.67 \%\end{array}$ & $\begin{array}{c}16 \\
13.56 \% \\
43.24 \%\end{array}$ & $\begin{array}{c}8 \\
6.78 \% \\
57.14 \%\end{array}$ & $\begin{array}{c}118 \\
100.00 \% \\
47.97 \%\end{array}$ \\
\hline & Total & $\begin{array}{c}120 \\
48.78 \% \\
100.00 \%\end{array}$ & $\begin{array}{c}75 \\
30.49 \% \\
100.00 \%\end{array}$ & $\begin{array}{c}37 \\
15.04 \% \\
100.00 \%\end{array}$ & $\begin{array}{c}14 \\
5.69 \% \\
100.00 \%\end{array}$ & $\begin{array}{c}246 \\
100.00 \% \\
100.00 \%\end{array}$ \\
\hline
\end{tabular}

\begin{tabular}{|c|c|c|c|c|c|c|}
\hline & \multicolumn{4}{|c|}{ Q2 - Working on this collaborative project improved my access to university funds. } & \multirow[b]{2}{*}{ Total } \\
\hline & & Strongly Agree & Agree & Disagree & Strongly Disagree & \\
\hline \multirow{3}{*}{ My native language is: } & Language Other Than English & $\begin{array}{c}8 \\
6.25 \% \\
80.00 \%\end{array}$ & $\begin{array}{c}9 \\
7.03 \% \\
60.00 \%\end{array}$ & $\begin{array}{c}49 \\
38.28 \% \\
58.33 \%\end{array}$ & $\begin{array}{c}62 \\
48.44 \% \\
46.62 \%\end{array}$ & $\begin{array}{c}128 \\
100.00 \% \\
52.89 \%\end{array}$ \\
\hline & English & $\begin{array}{c}2 \\
1.75 \% \\
20.00 \%\end{array}$ & $\begin{array}{c}6 \\
5.26 \% \\
40.00 \%\end{array}$ & $\begin{array}{c}35 \\
30.70 \% \\
41.67 \%\end{array}$ & $\begin{array}{c}71 \\
62.28 \% \\
53.38 \%\end{array}$ & $\begin{array}{c}114 \\
100.00 \% \\
47.11 \%\end{array}$ \\
\hline & Total & $\begin{array}{c}10 \\
4.13 \% \\
100.00 \%\end{array}$ & $\begin{array}{c}15 \\
6.20 \% \\
100.00 \%\end{array}$ & $\begin{array}{c}84 \\
34.77 \% \\
100.00 \%\end{array}$ & $\begin{array}{c}133 \\
54.96 \% \\
100.00 \%\end{array}$ & $\begin{array}{c}242 \\
100.00 \% \\
100.00 \%\end{array}$ \\
\hline
\end{tabular}

\begin{tabular}{|c|c|c|c|c|c|c|}
\hline & & \multicolumn{4}{|c|}{ Q3 - Working on this collaborative project improved my access to external funds. } & \multirow[b]{2}{*}{ Total } \\
\hline & & Strongly Agree & Agree & Disagree & Strongly Disagree & \\
\hline \multirow{3}{*}{ My native language is: } & Language Other Than English & $\begin{array}{c}11 \\
8.59 \% \\
64.71 \%\end{array}$ & $\begin{array}{c}18 \\
14.06 \% \\
54.55 \%\end{array}$ & $\begin{array}{c}38 \\
29.69 \% \\
55.88 \%\end{array}$ & $\begin{array}{c}61 \\
47.66 \% \\
48.41 \%\end{array}$ & $\begin{array}{c}128 \\
100.00 \% \\
52.46 \%\end{array}$ \\
\hline & English & $\begin{array}{c}6 \\
5.17 \% \\
35.29 \%\end{array}$ & $\begin{array}{c}15 \\
12.93 \% \\
45.45 \%\end{array}$ & $\begin{array}{c}30 \\
25.86 \% \\
44.12 \%\end{array}$ & $\begin{array}{c}65 \\
56.03 \% \\
51.59 \%\end{array}$ & $\begin{array}{c}116 \\
100.00 \% \\
47.54 \%\end{array}$ \\
\hline & Total & $\begin{array}{c}17 \\
6.97 \% \\
100.00 \%\end{array}$ & $\begin{array}{c}33 \\
13.52 \% \\
100.00 \%\end{array}$ & $\begin{array}{c}68 \\
27.87 \% \\
100.00 \%\end{array}$ & $\begin{array}{c}126 \\
51.64 \% \\
100.00 \%\end{array}$ & $\begin{array}{c}244 \\
100.00 \% \\
100.00 \%\end{array}$ \\
\hline
\end{tabular}

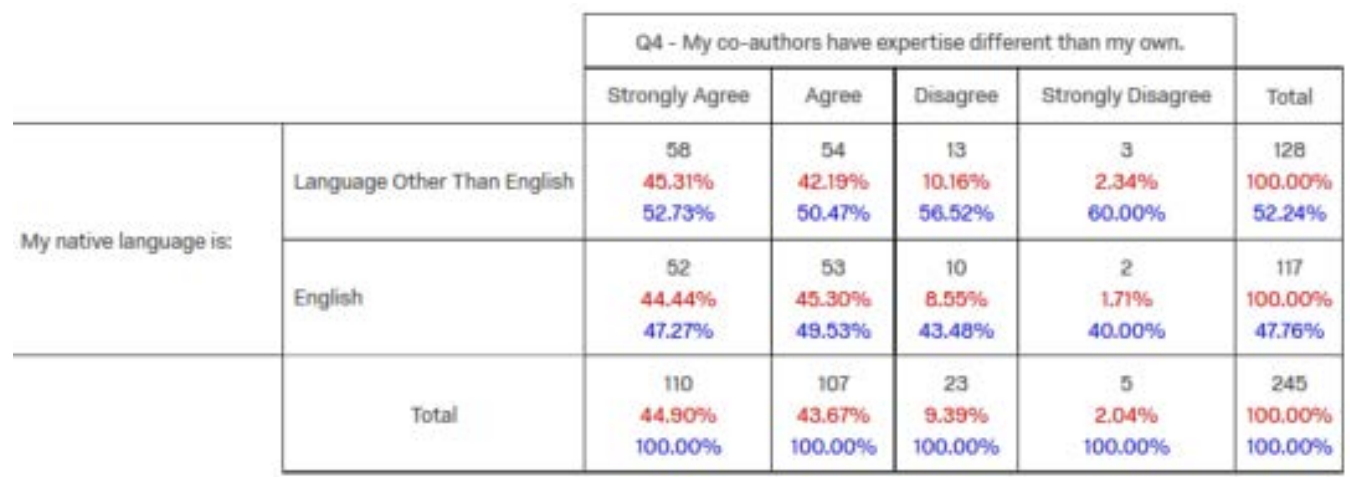


International Collaboration Among Social Science Scholars

\section{Cross Tabulation Table 1-3 (Continued)}

\begin{tabular}{|c|c|c|c|c|c|c|}
\hline & & \multicolumn{4}{|c|}{ QS - Participating improved my access to special data or research equipment. } & \multirow[b]{2}{*}{ Total } \\
\hline & & Strongly Agree & Agree & Disagree & Strongly Disagree & \\
\hline \multirow{3}{*}{ My native language is: } & Language Other Than English & $\begin{array}{c}17 \\
13.28 \% \\
44.74 \%\end{array}$ & $\begin{array}{c}18 \\
14.06 \% \\
43.90 \%\end{array}$ & $\begin{array}{c}36 \\
28.13 \% \\
52.94 \%\end{array}$ & $\begin{array}{c}57 \\
44.53 \% \\
57.58 \%\end{array}$ & $\begin{array}{c}128 \\
100.00 \% \\
52.03 \%\end{array}$ \\
\hline & English & $\begin{array}{c}21 \\
17.80 \% \\
50.26 \%\end{array}$ & $\begin{array}{c}23 \\
19.49 \% \\
56.10 \%\end{array}$ & $\begin{array}{c}32 \\
27.12 \% \\
47.06 \%\end{array}$ & $\begin{array}{c}42 \\
35.59 \% \\
42.42 \%\end{array}$ & $\begin{array}{c}118 \\
100.00 \% \\
47.97 \%\end{array}$ \\
\hline & Total & $\begin{array}{c}38 \\
15.45 \% \\
100.00 \%\end{array}$ & $\begin{array}{c}41 \\
16.67 \% \\
100.00 \%\end{array}$ & $\begin{array}{c}68 \\
27.64 \% \\
100.00 \%\end{array}$ & $\begin{array}{c}99 \\
40.24 \% \\
100.00 \%\end{array}$ & $\begin{array}{c}246 \\
100.00 \% \\
100.00 \%\end{array}$ \\
\hline
\end{tabular}

\begin{tabular}{|c|c|c|c|c|c|c|}
\hline & & \multicolumn{4}{|c|}{ Q6 -Working together allowed us to pool knowledge to accomplish complex research. } & \multirow[b]{2}{*}{ Total } \\
\hline & & Strongly Agree & Agree & Disagree & Strongly Disagree & \\
\hline \multirow{3}{*}{ My native language is: } & Language Other Than English & $\begin{array}{c}91 \\
71.09 \% \\
54.82 \%\end{array}$ & $\begin{array}{c}33 \\
25.78 \% \\
46.48 \%\end{array}$ & $\begin{array}{c}3 \\
2.34 \% \\
75.00 \%\end{array}$ & $\begin{array}{c}1 \\
0.78 \% \\
20.00 \%\end{array}$ & $\begin{array}{c}128 \\
100.00 \% \\
52.03 \%\end{array}$ \\
\hline & English & $\begin{array}{c}75 \\
63.56 \% \\
45.18 \%\end{array}$ & $\begin{array}{c}38 \\
32.20 \% \\
53.52 \%\end{array}$ & $\begin{array}{c}1 \\
0.85 \% \\
25.00 \%\end{array}$ & $\begin{array}{c}4 \\
3.39 \% \\
80.00 \%\end{array}$ & $\begin{array}{c}118 \\
100.00 \% \\
47.97 \%\end{array}$ \\
\hline & Total & $\begin{array}{c}166 \\
67.48 \% \\
100.00 \%\end{array}$ & $\begin{array}{c}71 \\
28.86 \% \\
100.00 \%\end{array}$ & $\begin{array}{c}4 \\
1.63 \% \\
100.00 \%\end{array}$ & $\begin{array}{c}5 \\
2.03 \% \\
100.00 \%\end{array}$ & $\begin{array}{c}246 \\
100.00 \% \\
100.00 \%\end{array}$ \\
\hline
\end{tabular}

\begin{tabular}{|c|c|c|c|c|c|c|}
\hline & & \multicolumn{4}{|c|}{ Q7 - Working with my co-authors allowed me to gain more peer recognition and visibility. } & \multirow[b]{2}{*}{ Total } \\
\hline & & Strongly Agree & Agree & Disagree & Strongly Disagree & \\
\hline \multirow{3}{*}{ My native language is: } & Language Other Than English & $\begin{array}{c}42 \\
32.81 \% \\
58.33 \%\end{array}$ & $\begin{array}{c}46 \\
35.94 \% \\
58.97 \%\end{array}$ & $\begin{array}{c}27 \\
21.09 \% \\
40.30 \%\end{array}$ & $\begin{array}{c}13 \\
10.16 \% \\
44.83 \%\end{array}$ & $\begin{array}{c}128 \\
100.00 \% \\
52.03 \%\end{array}$ \\
\hline & English & $\begin{array}{c}30 \\
25.42 \% \\
41.67 \%\end{array}$ & $\begin{array}{c}32 \\
27.12 \% \\
41.03 \%\end{array}$ & $\begin{array}{c}40 \\
33.90 \% \\
59.70 \%\end{array}$ & $\begin{array}{c}16 \\
13.56 \% \\
55.17 \%\end{array}$ & $\begin{array}{c}118 \\
100.00 \% \\
47.97 \%\end{array}$ \\
\hline & Total & $\begin{array}{c}72 \\
29.27 \% \\
100.00 \%\end{array}$ & $\begin{array}{c}78 \\
31.71 \% \\
100.00 \%\end{array}$ & $\begin{array}{c}67 \\
27.24 \% \\
100.00 \%\end{array}$ & $\begin{array}{c}29 \\
11.79 \% \\
100.00 \%\end{array}$ & $\begin{array}{c}246 \\
100.00 \% \\
100.00 \%\end{array}$ \\
\hline
\end{tabular}

\begin{tabular}{|c|c|c|c|c|c|c|}
\hline & & \multicolumn{4}{|c|}{ Q8 - I had worked effectively with one of my co-authors before on a successful project. } & \multirow[b]{2}{*}{ Total } \\
\hline & & Strongly Agree & Agree & Disagree & Strongly Disagree & \\
\hline \multirow{3}{*}{ My native language is: } & Language Other Than English & $\begin{array}{c}71 \\
56.35 \% \\
51.08 \%\end{array}$ & $\begin{array}{c}23 \\
18.25 \% \\
54.76 \%\end{array}$ & $\begin{array}{c}21 \\
16.67 \% \\
50.00 \%\end{array}$ & $\begin{array}{c}11 \\
8.73 \% \\
52.38 \%\end{array}$ & $\begin{array}{c}126 \\
100.00 \% \\
51.64 \%\end{array}$ \\
\hline & English & $\begin{array}{c}68 \\
57.63 \% \\
48.92 \%\end{array}$ & $\begin{array}{c}19 \\
16.10 \% \\
45.24 \%\end{array}$ & $\begin{array}{c}21 \\
17.80 \% \\
50.00 \%\end{array}$ & $\begin{array}{c}10 \\
8.47 \% \\
47.62 \%\end{array}$ & $\begin{array}{c}118 \\
100.00 \% \\
48.36 \%\end{array}$ \\
\hline & Total & $\begin{array}{c}139 \\
56.97 \% \\
100.00 \%\end{array}$ & $\begin{array}{c}42 \\
17.21 \% \\
100.00 \%\end{array}$ & $\begin{array}{c}42 \\
17.21 \% \\
100.00 \%\end{array}$ & $\begin{array}{c}21 \\
8.61 \% \\
100.00 \%\end{array}$ & $\begin{array}{c}244 \\
100.00 \% \\
100.00 \%\end{array}$ \\
\hline
\end{tabular}


International Collaboration Among Social Science Scholars

\section{Cross Tabulation Table 1-3 (Continued)}

\begin{tabular}{|c|c|c|c|c|c|c|}
\hline & & \multicolumn{4}{|c|}{ Q9-My co-authors are pleasant and fun to work with. } & \multirow{2}{*}{ Total } \\
\hline & & Strongly Agree & Agree & Disagree & Strongly Disagree & \\
\hline \multirow{3}{*}{ My native language is: } & Language Other Than English & $\begin{array}{c}86 \\
67.19 \% \\
52.76 \%\end{array}$ & $\begin{array}{c}39 \\
30.47 \% \\
52.00 \%\end{array}$ & $\begin{array}{c}3 \\
2.3 .4 \% \\
42.86 \%\end{array}$ & $\begin{array}{c}0 \\
0.00 \% \\
0.00 \%\end{array}$ & $\begin{array}{c}128 \\
100.00 \% \\
52.03 \%\end{array}$ \\
\hline & English & $\begin{array}{c}7 \\
65.25 \% \\
47.24 \%\end{array}$ & $\begin{array}{c}36 \\
30.51 \% \\
48.00 \%\end{array}$ & $\begin{array}{c}4 \\
3.39 \% \\
57.14 \%\end{array}$ & $\begin{array}{c}1 \\
0.85 \% \\
100.00 \%\end{array}$ & $\begin{array}{c}118 \\
100.00 \% \\
47.97 \%\end{array}$ \\
\hline & Total & $\begin{array}{c}163 \\
66.26 \% \\
100.00 \%\end{array}$ & $\begin{array}{c}75 \\
30.49 \% \\
100.00 \%\end{array}$ & $\begin{array}{c}7 \\
2.85 \% \\
100.00 \%\end{array}$ & $\begin{array}{c}1 \\
0.41 \% \\
100.00 \%\end{array}$ & $\begin{array}{c}246 \\
100.00 \% \\
100.00 \%\end{array}$ \\
\hline
\end{tabular}

\begin{tabular}{|c|c|c|c|c|c|c|}
\hline & & \multicolumn{4}{|c|}{ Q10 - Because of the opportunity to publish with my international colleagues. } & \multirow[b]{2}{*}{ Total } \\
\hline & & Strongly Agree & Agree & Disagree & Strongly Disagree & \\
\hline \multirow{3}{*}{ My native language is: } & Language Other Than English & $\begin{array}{c}54 \\
42.19 \% \\
59.34 \%\end{array}$ & $\begin{array}{c}45 \\
35.16 \% \\
54.22 \%\end{array}$ & $\begin{array}{c}14 \\
10.94 \% \\
35.00 \%\end{array}$ & $\begin{array}{c}15 \\
11.72 \% \\
46.88 \%\end{array}$ & $\begin{array}{c}128 \\
100.00 \% \\
52.03 \%\end{array}$ \\
\hline & English & $\begin{array}{c}37 \\
31.36 \% \\
40.66 \%\end{array}$ & $\begin{array}{c}38 \\
32.20 \% \\
45.78 \%\end{array}$ & $\begin{array}{c}26 \\
22.03 \% \\
65.00 \%\end{array}$ & $\begin{array}{c}17 \\
14.41 \% \\
53.13 \%\end{array}$ & $\begin{array}{c}118 \\
100.00 \% \\
47.97 \%\end{array}$ \\
\hline & Total & $\begin{array}{c}91 \\
36.99 \% \\
100.00 \%\end{array}$ & $\begin{array}{c}83 \\
33.74 \% \\
100.00 \%\end{array}$ & $\begin{array}{c}40 \\
16.26 \% \\
100.00 \%\end{array}$ & $\begin{array}{c}32 \\
13.01 \% \\
100.00 \%\end{array}$ & $\begin{array}{c}246 \\
100.00 \% \\
100.00 \%\end{array}$ \\
\hline
\end{tabular}

\begin{tabular}{|c|c|c|c|c|c|c|}
\hline & & \multicolumn{4}{|c|}{ Q11-My co-authors and 1 are fluent in the same language. } & \multirow[b]{2}{*}{ Total } \\
\hline & & Strongly Agree & Agree & Disagree & Strongly Disagree & \\
\hline \multirow{9}{*}{ My native language is: } & & 34 & 53 & 25 & 15 & 127 \\
\hline & Language Other Than English & $26.77 \%$ & $41.73 \%$ & $19.69 \%$ & $11.81 \%$ & $100.00 \%$ \\
\hline & & $44.74 \%$ & $55.79 \%$ & $55.56 \%$ & $51.72 \%$ & $51.84 \%$ \\
\hline & & 42 & 42 & 20 & 14 & 118 \\
\hline & English & $35.59 \%$ & $35.59 \%$ & $16.95 \%$ & $11.86 \%$ & $100.00 \%$ \\
\hline & & $50.26 \%$ & $44.21 \%$ & $44.44 \%$ & $48.28 \%$ & $48.16 \%$ \\
\hline & \multirow{3}{*}{ Total } & 76 & 95 & 45 & 29 & 245 \\
\hline & & $31.02 \%$ & $38.78 \%$ & $18.37 \%$ & $11.84 \%$ & $100.00 \%$ \\
\hline & & $100.00 \%$ & $100.00 \%$ & $100.00 \%$ & $100.00 \%$ & $100.00 \%$ \\
\hline
\end{tabular}

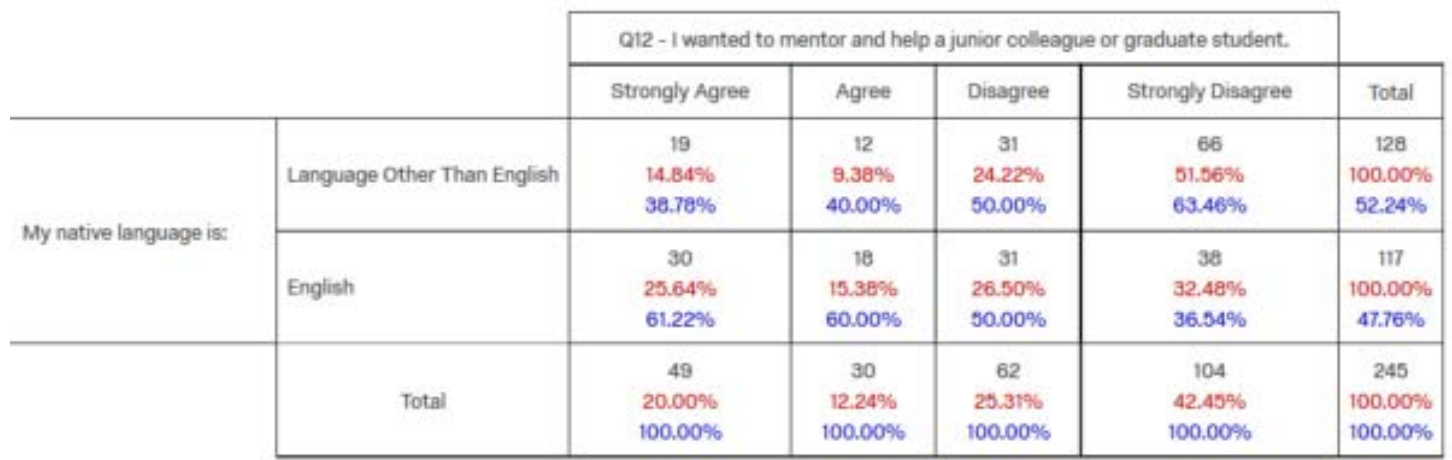


International Collaboration Among Social Science Scholars

\section{Cross Tabulation Table 1-4}

\begin{tabular}{|c|c|c|c|c|c|}
\hline & & \multicolumn{3}{|c|}{ Q26 - I was introduced to one of my 00 -authors during my PhD Program } & \multirow[b]{2}{*}{ Total } \\
\hline & & Yes & No & Unsure & \\
\hline \multirow{5}{*}{ Q1 - My oo-authors have strong reputations as researchers. } & Strongly Agree & $\begin{array}{c}52 \\
42.98 \% \\
57.14 \%\end{array}$ & $\begin{array}{c}68 \\
56.20 \% \\
43.31 \%\end{array}$ & $\begin{array}{c}1 \\
0.83 \% \\
100.00 \%\end{array}$ & $\begin{array}{c}121 \\
100.00 \% \\
48.59 \%\end{array}$ \\
\hline & Agree & $\begin{array}{c}24 \\
31.58 \% \\
26.37 \%\end{array}$ & $\begin{array}{c}52 \\
68.42 \% \\
33.12 \%\end{array}$ & $\begin{array}{c}0 \\
0.00 \% \\
0.00 \%\end{array}$ & $\begin{array}{c}76 \\
100.00 \% \\
30.52 \%\end{array}$ \\
\hline & Disagree & $\begin{array}{c}12 \\
31.58 \% \\
13.19 \%\end{array}$ & $\begin{array}{c}26 \\
68.42 \% \\
16.56 \%\end{array}$ & $\begin{array}{c}0 \\
0.00 \% \\
0.00 \%\end{array}$ & $\begin{array}{c}38 \\
100.00 \% \\
15.26 \%\end{array}$ \\
\hline & Strongly Disagree & $\begin{array}{c}3 \\
21.43 \% \\
3.30 \%\end{array}$ & $\begin{array}{c}11 \\
78.57 \% \\
7.01 \%\end{array}$ & $\begin{array}{c}0 \\
0.00 \% \\
0.00 \%\end{array}$ & $\begin{array}{c}14 \\
100.00 \% \\
5.62 \%\end{array}$ \\
\hline & Total & $\begin{array}{c}91 \\
36.55 \% \\
100.00 \%\end{array}$ & $\begin{array}{c}157 \\
63.05 \% \\
100.00 \%\end{array}$ & $\begin{array}{c}1 \\
0.40 \% \\
100.00 \%\end{array}$ & $\begin{array}{c}249 \\
100.00 \% \\
100.00 \%\end{array}$ \\
\hline \multirow{5}{*}{ Q2 - Working on this collaborative project improved my access to university funds. } & Strongly Agree & $\begin{array}{c}4 \\
40.00 \% \\
4.44 \%\end{array}$ & $\begin{array}{c}6 \\
60.00 \% \\
3.90 \%\end{array}$ & $\begin{array}{c}0 \\
0.00 \% \\
0.00 \%\end{array}$ & $\begin{array}{c}10 \\
100.00 \% \\
4.08 \%\end{array}$ \\
\hline & Agree & $\begin{array}{c}7 \\
43.75 \% \\
7.78 \%\end{array}$ & $\begin{array}{c}9 \\
56.25 \% \\
5.84 \%\end{array}$ & $\begin{array}{c}0 \\
0.00 \% \\
0.00 \%\end{array}$ & $\begin{array}{c}16 \\
100.00 \% \\
6.53 \%\end{array}$ \\
\hline & Disagree & $\begin{array}{c}35 \\
40.70 \% \\
38.89 \% \\
\end{array}$ & $\begin{array}{c}50 \\
58.14 \% \\
32.47 \% \\
\end{array}$ & $\begin{array}{c}1 \\
1.16 \% \\
100.00 \%\end{array}$ & $\begin{array}{c}86 \\
100.00 \% \\
35.10 \%\end{array}$ \\
\hline & Strongly Disagree & $\begin{array}{c}44 \\
33.08 \% \\
48.89 \%\end{array}$ & $\begin{array}{c}89 \\
66.92 \% \\
57.79 \%\end{array}$ & $\begin{array}{c}0 \\
0.00 \% \\
0.00 \%\end{array}$ & $\begin{array}{c}133 \\
100.00 \% \\
54.29 \%\end{array}$ \\
\hline & Total & $\begin{array}{c}90 \\
36.73 \% \\
100.00 \%\end{array}$ & $\begin{array}{c}15.4 \\
62.86 \% \\
100.00 \%\end{array}$ & $\begin{array}{c}1 \\
0.41 \% \\
100.00 \%\end{array}$ & $\begin{array}{c}245 \\
100.00 \% \\
100.00 \%\end{array}$ \\
\hline \multirow{5}{*}{ Q3 - Working on this collaborative project improved my access to external funds. } & Strongly Agree & $\begin{array}{c}7 \\
41.18 \% \\
7.78 \%\end{array}$ & $\begin{array}{c}10 \\
58.82 \% \\
6.41 \%\end{array}$ & $\begin{array}{c}0 \\
0.00 \% \\
0.00 \%\end{array}$ & $\begin{array}{c}17 \\
100.00 \% \\
6.88 \%\end{array}$ \\
\hline & Agree & $\begin{array}{c}14 \\
41.18 \% \\
15.56 \%\end{array}$ & $\begin{array}{c}19 \\
50.88 \% \\
12.18 \%\end{array}$ & $\begin{array}{c}1 \\
2.94 \% \\
100.00 \%\end{array}$ & $\begin{array}{c}34 \\
100.00 \% \\
13.77 \%\end{array}$ \\
\hline & Disagree & $\begin{array}{c}24 \\
34.29 \% \\
26.67 \%\end{array}$ & $\begin{array}{c}46 \\
65.71 \% \\
29.49 \%\end{array}$ & $\begin{array}{c}0 \\
0.00 \% \\
0.00 \%\end{array}$ & $\begin{array}{c}70 \\
100.00 \% \\
28.34 \%\end{array}$ \\
\hline & Strongly Disagree & $\begin{array}{c}45 \\
35.71 \% \\
50.00 \%\end{array}$ & $\begin{array}{c}81 \\
64.29 \% \\
51.92 \%\end{array}$ & $\begin{array}{c}0 \\
0.00 \% \\
0.00 \%\end{array}$ & $\begin{array}{c}126 \\
100.00 \% \\
51.01 \%\end{array}$ \\
\hline & Total & $\begin{array}{c}90 \\
36.44 \% \\
100.00 \%\end{array}$ & $\begin{array}{c}156 \\
63.16 \% \\
100.00 \%\end{array}$ & $\begin{array}{c}1 \\
0.40 \% \\
100.00 \%\end{array}$ & $\begin{array}{c}247 \\
100.00 \% \\
100.00 \%\end{array}$ \\
\hline
\end{tabular}


International Collaboration Among Social Science Scholars

Cross Tabulation Table 1-4 (Continued)

Q4 - My co-authors have expertise different than my own.

Q5 - Participating improved my access to special data or research equipment.

\begin{tabular}{|c|c|c|c|c|}
\hline & \multicolumn{3}{|c|}{ Q26 - I was introduced to one of my o0-authors during my PhD program. } & \multirow[b]{2}{*}{ Total } \\
\hline & Yes & No & Unsure & \\
\hline Strongly Agree & $\begin{array}{c}42 \\
38.18 \% \\
46.67 \%\end{array}$ & $\begin{array}{c}67 \\
60.91 \% \\
42.68 \%\end{array}$ & $\begin{array}{c}1 \\
0.91 \% \\
100.00 \%\end{array}$ & $\begin{array}{c}110 \\
100.00 \% \\
44.35 \%\end{array}$ \\
\hline Agree & $\begin{array}{c}42 \\
38.53 \% \\
46.67 \%\end{array}$ & $\begin{array}{c}67 \\
61.47 \% \\
42.68 \%\end{array}$ & $\begin{array}{c}0 \\
0.00 \% \\
0.00 \%\end{array}$ & $\begin{array}{c}109 \\
100.00 \% \\
43.95 \%\end{array}$ \\
\hline Disagree & $\begin{array}{c}5 \\
20.83 \% \\
5.56 \%\end{array}$ & $\begin{array}{c}19 \\
79.17 \% \\
12.10 \%\end{array}$ & $\begin{array}{c}0 \\
0.00 \% \\
0.00 \%\end{array}$ & $\begin{array}{c}24 \\
100.00 \% \\
9.68 \%\end{array}$ \\
\hline Strongly Disagree & $\begin{array}{c}1 \\
20.00 \% \\
1.11 \%\end{array}$ & $\begin{array}{c}4 \\
80.00 \% \\
2.50 \%\end{array}$ & $\begin{array}{c}0 \\
0.00 \% \\
0.00 \%\end{array}$ & $\begin{array}{c}5 \\
100.00 \% \\
2.02 \%\end{array}$ \\
\hline Total & $\begin{array}{c}90 \\
36.29 \% \\
100.00 \%\end{array}$ & $\begin{array}{c}157 \\
63.31 \% \\
100.00 \%\end{array}$ & $\begin{array}{c}1 \\
0.40 \% \\
100.00 \%\end{array}$ & $\begin{array}{c}248 \\
100.00 \% \\
100.00 \%\end{array}$ \\
\hline Strongly Agree & $\begin{array}{c}12 \\
30.00 \% \\
13.19 \%\end{array}$ & $\begin{array}{c}28 \\
70.00 \% \\
17.83 \%\end{array}$ & $\begin{array}{c}0 \\
0.00 \% \\
0.00 \%\end{array}$ & $\begin{array}{c}40 \\
100.00 \% \\
16.06 \%\end{array}$ \\
\hline Agree & $\begin{array}{c}18 \\
43.90 \% \\
19.78 \%\end{array}$ & $\begin{array}{c}22 \\
53.66 \% \\
14.01 \%\end{array}$ & $\begin{array}{c}1 \\
2.44 \% \\
100.00 \%\end{array}$ & $\begin{array}{c}41 \\
100.00 \% \\
16.47 \%\end{array}$ \\
\hline Disagree & $\begin{array}{c}23 \\
33.33 \% \\
25.27 \%\end{array}$ & $\begin{array}{c}46 \\
66.67 \% \\
29.30 \%\end{array}$ & $\begin{array}{c}0 \\
0.00 \% \\
0.00 \%\end{array}$ & $\begin{array}{c}69 \\
100.00 \% \\
27.71 \%\end{array}$ \\
\hline Strongly Disagree & $\begin{array}{c}38 \\
38.38 \% \\
41.76 \%\end{array}$ & $\begin{array}{c}61 \\
61.62 \% \\
38.85 \%\end{array}$ & $\begin{array}{c}0 \\
0.00 \% \\
0.00 \%\end{array}$ & $\begin{array}{c}99 \\
100.00 \% \\
39.76 \%\end{array}$ \\
\hline Total & $\begin{array}{c}91 \\
36.55 \% \\
100.00 \%\end{array}$ & $\begin{array}{c}157 \\
63.05 \% \\
100.00 \%\end{array}$ & $\begin{array}{c}1 \\
0.40 \% \\
100.00 \%\end{array}$ & $\begin{array}{c}249 \\
100.00 \% \\
100.00 \%\end{array}$ \\
\hline Strongly Agree & $\begin{array}{c}68 \\
40.48 \% \\
74.73 \%\end{array}$ & $\begin{array}{c}99 \\
58.93 \% \\
63.06 \%\end{array}$ & $\begin{array}{c}1 \\
0.60 \% \\
100.00 \%\end{array}$ & $\begin{array}{c}168 \\
100.00 \% \\
67.47 \%\end{array}$ \\
\hline Agree & $\begin{array}{c}20 \\
27.78 \% \\
21.98 \%\end{array}$ & $\begin{array}{c}52 \\
72.22 \% \\
33.12 \%\end{array}$ & $\begin{array}{c}0 \\
0.00 \% \\
0.00 \%\end{array}$ & $\begin{array}{c}72 \\
100.00 \% \\
28.92 \%\end{array}$ \\
\hline Disagree & $\begin{array}{c}1 \\
25.00 \% \\
1.10 \%\end{array}$ & $\begin{array}{c}3 \\
75.00 \% \\
1.91 \%\end{array}$ & $\begin{array}{c}0 \\
0.00 \% \\
0.00 \%\end{array}$ & $\begin{array}{c}4 \\
100.00 \% \\
1.61 \%\end{array}$ \\
\hline Strongly Disagree & $\begin{array}{c}2 \\
40.00 \% \\
2.20 \%\end{array}$ & $\begin{array}{c}3 \\
60.00 \% \\
1.91 \%\end{array}$ & $\begin{array}{c}0 \\
0.00 \% \\
0.00 \%\end{array}$ & $\begin{array}{c}5 \\
100.00 \% \\
2.01 \%\end{array}$ \\
\hline Total & $\begin{array}{c}91 \\
36.55 \% \\
100.00 \%\end{array}$ & $\begin{array}{c}157 \\
63.05 \% \\
100.00 \%\end{array}$ & $\begin{array}{c}1 \\
0.40 \% \\
100.00 \%\end{array}$ & $\begin{array}{c}249 \\
100.00 \% \\
100.00 \%\end{array}$ \\
\hline
\end{tabular}


International Collaboration Among Social Science Scholars

\section{Cross Tabulation Table 1-4 (Continued)}

Q7 - Working with my co-authors allowed me to gain more peer recognition and visibility.

Q8 - I had worked effectively with one of my co-authors before on a successful project.

Q9 - My co-authors are pleasant and fun to work with.

\begin{tabular}{|c|c|c|c|c|}
\hline & \multicolumn{3}{|c|}{ Q26 - I was introduced to one of my $\infty_{0}$-authors during my PhD program } & \multirow[b]{2}{*}{ Total } \\
\hline & Yes & No & Unsure & \\
\hline Strongly Agree & $\begin{array}{c}37 \\
51.39 \% \\
40.66 \%\end{array}$ & $\begin{array}{c}34 \\
47.22 \% \\
21.66 \%\end{array}$ & $\begin{array}{c}1 \\
1.39 \% \\
100.00 \%\end{array}$ & $\begin{array}{c}72 \\
100.00 \% \\
28.92 \%\end{array}$ \\
\hline Agree & $\begin{array}{c}30 \\
37.97 \% \\
32.97 \%\end{array}$ & $\begin{array}{c}49 \\
62.03 \% \\
31.21 \%\end{array}$ & $\begin{array}{c}0 \\
0.00 \% \\
0.00 \%\end{array}$ & $\begin{array}{c}79 \\
100.00 \% \\
31.73 \%\end{array}$ \\
\hline Disagree & $\begin{array}{c}14 \\
20.59 \% \\
15.38 \%\end{array}$ & $\begin{array}{c}54 \\
79.41 \% \\
34.39 \%\end{array}$ & $\begin{array}{c}0 \\
0.00 \% \\
0.00 \%\end{array}$ & $\begin{array}{c}68 \\
100.00 \% \\
27.31 \%\end{array}$ \\
\hline Strongly Disagree & $\begin{array}{c}10 \\
33.33 \% \\
10.99 \%\end{array}$ & $\begin{array}{c}20 \\
66.67 \% \\
12.74 \%\end{array}$ & $\begin{array}{c}0 \\
0.00 \% \\
0.00 \%\end{array}$ & $\begin{array}{c}30 \\
100.00 \% \\
12.05 \%\end{array}$ \\
\hline Total & $\begin{array}{c}91 \\
36.55 \% \\
100.00 \%\end{array}$ & $\begin{array}{c}157 \\
63.05 \% \\
100.00 \%\end{array}$ & $\begin{array}{c}1 \\
0.40 \% \\
100.00 \%\end{array}$ & $\begin{array}{c}249 \\
100.00 \% \\
100.00 \%\end{array}$ \\
\hline Strongly Agree & $\begin{array}{c}58 \\
41.43 \% \\
64.44 \%\end{array}$ & $\begin{array}{c}81 \\
57.86 \% \\
51.92 \%\end{array}$ & $\begin{array}{c}1 \\
0.71 \% \\
100.00 \%\end{array}$ & $\begin{array}{c}140 \\
100.00 \% \\
56.68 \%\end{array}$ \\
\hline Agree & $\begin{array}{c}13 \\
30.95 \% \\
14.44 \%\end{array}$ & $\begin{array}{c}29 \\
69.05 \% \\
18.59 \%\end{array}$ & $\begin{array}{c}0 \\
0.00 \% \\
0.00 \%\end{array}$ & $\begin{array}{c}42 \\
100.00 \% \\
17.00 \%\end{array}$ \\
\hline Disagree & $\begin{array}{c}16 \\
39.02 \% \\
17.78 \%\end{array}$ & $\begin{array}{c}25 \\
60.98 \% \\
16.03 \%\end{array}$ & $\begin{array}{c}0 \\
0.00 \% \\
0.00 \%\end{array}$ & $\begin{array}{c}41 \\
100.00 \% \\
16.60 \%\end{array}$ \\
\hline Strongly Disagree & $\begin{array}{c}3 \\
12.50 \% \\
3.33 \%\end{array}$ & $\begin{array}{c}21 \\
87.50 \% \\
13.46 \%\end{array}$ & $\begin{array}{c}0 \\
0.00 \% \\
0.00 \%\end{array}$ & $\begin{array}{c}24 \\
100.00 \% \\
9.72 \%\end{array}$ \\
\hline Total & $\begin{array}{c}90 \\
36.44 \% \\
100.00 \%\end{array}$ & $\begin{array}{c}156 \\
63.16 \% \\
100.00 \%\end{array}$ & $\begin{array}{c}1 \\
0.40 \% \\
100.00 \%\end{array}$ & $\begin{array}{c}247 \\
100.00 \% \\
100.00 \%\end{array}$ \\
\hline Strongly Agree & $\begin{array}{c}58 \\
35.37 \% \\
63.74 \%\end{array}$ & $\begin{array}{c}105 \\
64.02 \% \\
66.88 \%\end{array}$ & $\begin{array}{c}1 \\
0.61 \% \\
100.00 \%\end{array}$ & $\begin{array}{c}164 \\
100.00 \% \\
65.86 \%\end{array}$ \\
\hline Agree & $\begin{array}{c}30 \\
38.96 \% \\
32.97 \%\end{array}$ & $\begin{array}{c}47 \\
61.04 \% \\
29.94 \%\end{array}$ & $\begin{array}{c}0 \\
0.00 \% \\
0.00 \%\end{array}$ & $\begin{array}{c}77 \\
100.00 \% \\
30.92 \%\end{array}$ \\
\hline Disagree & $\begin{array}{c}3 \\
42.86 \% \\
3.30 \%\end{array}$ & $\begin{array}{c}4 \\
57.14 \% \\
2.55 \%\end{array}$ & $\begin{array}{c}0 \\
0.00 \% \\
0.00 \%\end{array}$ & $\begin{array}{c}7 \\
100.00 \% \\
2.81 \%\end{array}$ \\
\hline Strongly Disagree & $\begin{array}{c}0 \\
0.00 \% \\
0.00 \%\end{array}$ & $\begin{array}{c}1 \\
100.00 \% \\
0.64 \%\end{array}$ & $\begin{array}{c}0 \\
0.00 \% \\
0.00 \%\end{array}$ & $\begin{array}{c}1 \\
100.00 \% \\
0.40 \%\end{array}$ \\
\hline Total & $\begin{array}{c}91 \\
36.55 \% \\
100.00 \%\end{array}$ & $\begin{array}{c}157 \\
63.05 \% \\
100.00 \%\end{array}$ & $\begin{array}{c}1 \\
0.40 \% \\
100.00 \%\end{array}$ & $\begin{array}{c}249 \\
100.00 \% \\
100.00 \%\end{array}$ \\
\hline
\end{tabular}


Cross Tabulation Table 1-4 (Continued)

Q10 - Because of the opportunity to publish with my international colleagues,

Q11 - My co-authors and I are fluent in the same language.

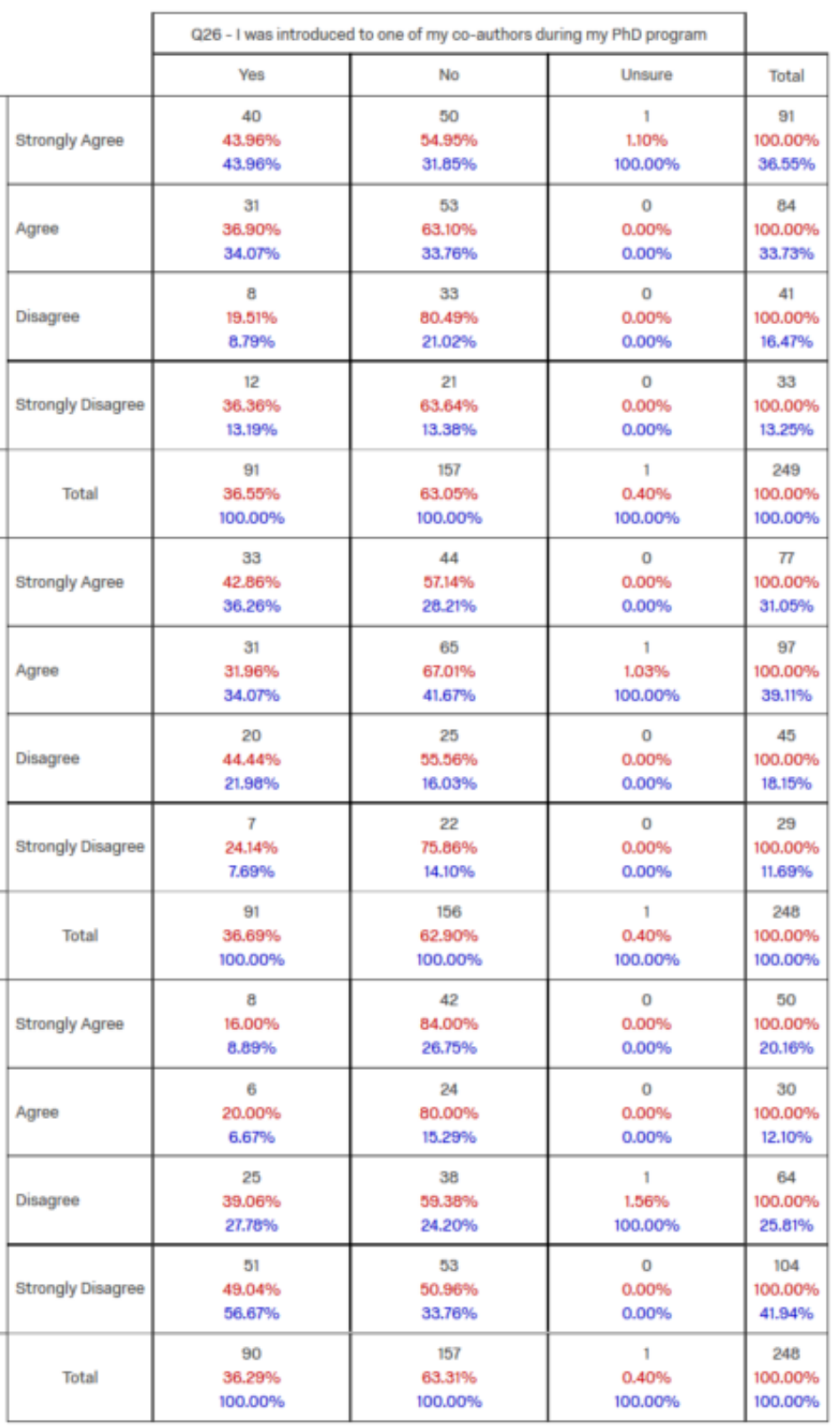


International Collaboration Among Social Science Scholars

\section{Cross Tabulation Table 1-5}

\begin{tabular}{|c|c|c|c|c|}
\hline & & \multicolumn{2}{|c|}{ Q27 - I have co-authored multiple times with at least one of my 00 -authors (more than one time). } & \multirow[b]{2}{*}{ Total } \\
\hline & & Yes & No & \\
\hline \multirow{5}{*}{ Q1 - My o0-authors have strong reputations as researchers. } & Strongly Agree & $\begin{array}{c}108 \\
88.52 \% \\
51.18 \%\end{array}$ & $\begin{array}{c}14 \\
11.48 \% \\
35.00 \%\end{array}$ & $\begin{array}{c}122 \\
100.00 \% \\
48.61 \%\end{array}$ \\
\hline & Agree & $\begin{array}{c}62 \\
80.52 \% \\
29.38 \%\end{array}$ & $\begin{array}{c}15 \\
19.48 \% \\
37.50 \%\end{array}$ & $\begin{array}{c}\pi \\
100.00 \% \\
30.68 \%\end{array}$ \\
\hline & Disagree & $\begin{array}{c}30 \\
78.95 \% \\
14.22 \%\end{array}$ & $\begin{array}{c}8 \\
21.05 \% \\
20.00 \%\end{array}$ & $\begin{array}{c}38 \\
100.00 \% \\
15.14 \%\end{array}$ \\
\hline & Strongly Disagree & $\begin{array}{c}11 \\
78.57 \% \\
5.21 \%\end{array}$ & $\begin{array}{c}3 \\
21.43 \% \\
7.50 \%\end{array}$ & $\begin{array}{c}14 \\
100.00 \% \\
5.58 \%\end{array}$ \\
\hline & Total & $\begin{array}{c}211 \\
84.06 \% \\
100.00 \%\end{array}$ & $\begin{array}{c}40 \\
15.94 \% \\
100.00 \%\end{array}$ & $\begin{array}{c}251 \\
100.00 \% \\
100.00 \%\end{array}$ \\
\hline \multirow{5}{*}{ Q2 - Working on this collaborative project improved my access to university funds. } & Strongly Agree & $\begin{array}{c}9 \\
90.00 \% \\
4.35 \%\end{array}$ & $\begin{array}{c}1 \\
10.00 \% \\
2.50 \%\end{array}$ & $\begin{array}{c}10 \\
100.00 \% \\
4.05 \%\end{array}$ \\
\hline & Agree & $\begin{array}{c}15 \\
93.75 \% \\
7.25 \%\end{array}$ & $\begin{array}{c}1 \\
6.25 \% \\
2.50 \%\end{array}$ & $\begin{array}{c}16 \\
100.00 \% \\
6.48 \%\end{array}$ \\
\hline & Disagree & $\begin{array}{c}73 \\
84.88 \% \\
35.27 \%\end{array}$ & $\begin{array}{c}13 \\
15.12 \% \\
32.50 \%\end{array}$ & $\begin{array}{c}86 \\
100.00 \% \\
34.82 \%\end{array}$ \\
\hline & Strongly Disagree & $\begin{array}{c}110 \\
81.48 \% \\
53.14 \%\end{array}$ & $\begin{array}{c}25 \\
18.52 \% \\
62.50 \%\end{array}$ & $\begin{array}{c}135 \\
100.00 \% \\
54.66 \%\end{array}$ \\
\hline & Total & $\begin{array}{c}207 \\
83.81 \% \\
100.00 \%\end{array}$ & $\begin{array}{c}40 \\
16.19 \% \\
100.00 \%\end{array}$ & $\begin{array}{c}247 \\
100.00 \% \\
100.00 \%\end{array}$ \\
\hline \multirow{5}{*}{ Q3 - Working on this collaborative project improved my access to external funds. } & Strongly Agree & $\begin{array}{c}16 \\
94.12 \% \\
7.66 \%\end{array}$ & $\begin{array}{c}1 \\
5.88 \% \\
2.50 \%\end{array}$ & $\begin{array}{c}17 \\
100.00 \% \\
6.83 \%\end{array}$ \\
\hline & Agree & $\begin{array}{c}30 \\
88.24 \% \\
14.35 \%\end{array}$ & $\begin{array}{c}4 \\
11.76 \% \\
10.00 \%\end{array}$ & $\begin{array}{c}34 \\
100.00 \% \\
13.65 \%\end{array}$ \\
\hline & Disagree & $\begin{array}{c}62 \\
82.57 \% \\
29.67 \%\end{array}$ & $\begin{array}{c}8 \\
11.43 \% \\
20.00 \%\end{array}$ & $\begin{array}{c}70 \\
100.00 \% \\
28.11 \%\end{array}$ \\
\hline & Strongly Disagree & $\begin{array}{c}101 \\
78.91 \% \\
48.33 \%\end{array}$ & $\begin{array}{c}27 \\
21.09 \% \\
67.50 \%\end{array}$ & $\begin{array}{c}128 \\
100.00 \% \\
51.41 \%\end{array}$ \\
\hline & Total & $\begin{array}{c}209 \\
83.94 \% \\
100.00 \%\end{array}$ & $\begin{array}{c}40 \\
16.06 \% \\
100.00 \%\end{array}$ & $\begin{array}{c}249 \\
100.00 \% \\
100.00 \%\end{array}$ \\
\hline
\end{tabular}


International Collaboration Among Social Science Scholars

\section{Cross Tabulation Table 1-5 (Continued)}

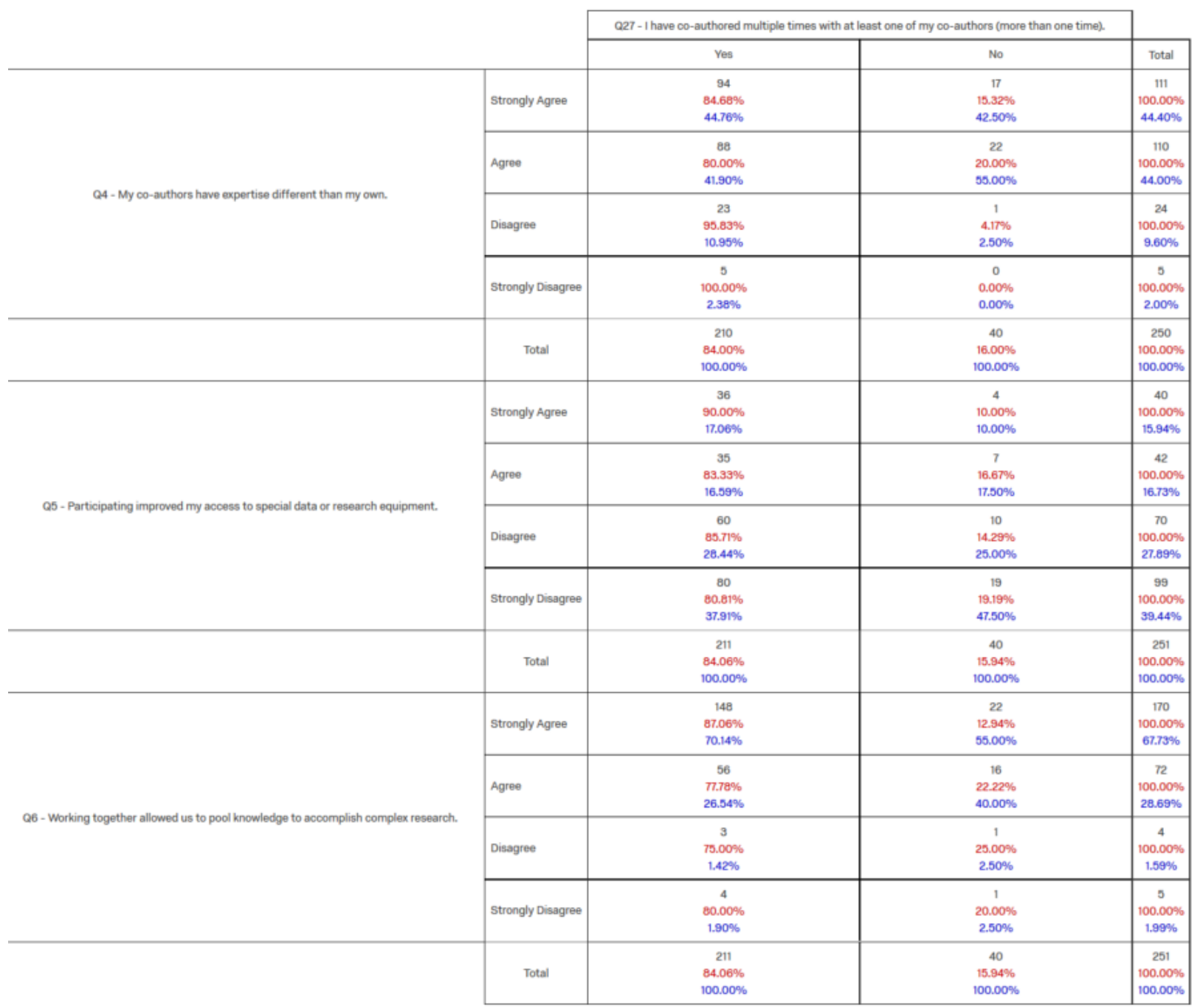


International Collaboration Among Social Science Scholars

\section{Cross Tabulation Table 1-5 (Continued)}

\begin{tabular}{|c|c|c|c|c|}
\hline & \multirow{2}{*}{\multicolumn{2}{|c|}{ Q27 - I have co-authored multiple times with at least one of my 00 -authors (more than one time). }} & \multirow{3}{*}{ Total } \\
\hline & & & & \\
\hline & & Yes & No & \\
\hline \multirow{5}{*}{ Q7 - Working with my co-authors allowed me to gain more peer recognition and visibility. } & Strongly Agree & $\begin{array}{c}60 \\
82.19 \% \\
28.44 \%\end{array}$ & $\begin{array}{c}13 \\
17.21 \% \\
32.50 \%\end{array}$ & \begin{tabular}{|c|}
73 \\
$100.00 \%$ \\
$29.08 \%$
\end{tabular} \\
\hline & Agree & $\begin{array}{c}71 \\
88.75 \% \\
33.65 \%\end{array}$ & $\begin{array}{c}9 \\
11.25 \% \\
22.50 \%\end{array}$ & \begin{tabular}{|c|}
80 \\
$100.00 \%$ \\
$31.87 \%$
\end{tabular} \\
\hline & Disagree & $\begin{array}{c}52 \\
76.47 \% \\
24.64 \%\end{array}$ & $\begin{array}{c}16 \\
23.59 \% \\
40.00 \%\end{array}$ & \begin{tabular}{|c|}
68 \\
$100.00 \%$ \\
$27.09 \%$
\end{tabular} \\
\hline & Strongly Disagree & $\begin{array}{c}28 \\
93.33 \% \\
13.27 \%\end{array}$ & $\begin{array}{c}2 \\
6.67 \% \\
5.00 \%\end{array}$ & $\begin{array}{c}30 \\
100.00 \% \\
11.95 \%\end{array}$ \\
\hline & Total & $\begin{array}{c}211 \\
84.06 \% \\
100.00 \%\end{array}$ & $\begin{array}{c}40 \\
15.94 \% \\
100.00 \%\end{array}$ & \begin{tabular}{|c}
251 \\
$100.00 \%$ \\
$100.00 \%$
\end{tabular} \\
\hline \multirow{5}{*}{ QQ - I had worked effectively with one of my co-authors before on a successfful project. } & Strongly Agree & $\begin{array}{c}135 \\
95.74 \% \\
64.59 \%\end{array}$ & $\begin{array}{c}6 \\
4.26 \% \\
15.00 \%\end{array}$ & $\begin{array}{c}141 \\
100.00 \% \\
56.63 \%\end{array}$ \\
\hline & Agree & $\begin{array}{c}38 \\
90.48 \% \\
18.18 \%\end{array}$ & $\begin{array}{c}4 \\
9.52 \% \\
10.00 \%\end{array}$ & $\begin{array}{c}42 \\
100.00 \% \\
16.87 \%\end{array}$ \\
\hline & Disagree & $\begin{array}{c}24 \\
57.14 \% \\
11.48 \%\end{array}$ & $\begin{array}{c}18 \\
42.86 \% \\
45.00 \%\end{array}$ & \begin{tabular}{|c|}
42 \\
$100.00 \%$ \\
$16.87 \%$
\end{tabular} \\
\hline & Strongly Disagree & $\begin{array}{c}12 \\
50.00 \% \\
5.74 \%\end{array}$ & $\begin{array}{c}12 \\
50.00 \% \\
30.00 \%\end{array}$ & $\begin{array}{c}24 \\
100.00 \% \\
9.64 \%\end{array}$ \\
\hline & Total & $\begin{array}{c}209 \\
83.94 \% \\
100.00 \%\end{array}$ & $\begin{array}{c}40 \\
16.06 \% \\
100.00 \%\end{array}$ & \begin{tabular}{|c|}
249 \\
$100.00 \%$ \\
$100.00 \%$
\end{tabular} \\
\hline \multirow{5}{*}{ Q9 - My co-authors are pleasant and fun to work with. } & Strongly Agree & $\begin{array}{c}151 \\
91.52 \% \\
7.56 \% \%\end{array}$ & $\begin{array}{c}14 \\
8.46 \% \\
35.00 \%\end{array}$ & $\begin{array}{c}165 \\
100.00 \% \\
65.74 \%\end{array}$ \\
\hline & Agree & $\begin{array}{c}54 \\
69.23 \% \\
25.59 \%\end{array}$ & $\begin{array}{c}24 \\
30.7 \% \% \\
60.00 \%\end{array}$ & \begin{tabular}{|c|}
78 \\
$100.00 \%$ \\
$31.00 \%$
\end{tabular} \\
\hline & Disagree & $\begin{array}{c}5 \\
71.43 \% \\
2.37 \%\end{array}$ & $\begin{array}{c}2 \\
28.57 \% \\
5.00 \%\end{array}$ & $\begin{array}{c}7 \\
100.00 \% \\
2.79 \%\end{array}$ \\
\hline & Strongly Disagree & $\begin{array}{c}1 \\
100.00 \% \\
0.47 \%\end{array}$ & $\begin{array}{c}0 \\
0.00 \% \\
0.00 \%\end{array}$ & $\begin{array}{c}1 \\
100.00 \% \\
0.40 \%\end{array}$ \\
\hline & Total & $\begin{array}{c}211 \\
84.06 \% \\
100.00 \%\end{array}$ & $\begin{array}{c}40 \\
15.94 \% \\
100.00 \%\end{array}$ & $\begin{array}{c}251 \\
100.00 \% \\
100.00 \%\end{array}$ \\
\hline
\end{tabular}


International Collaboration Among Social Science Scholars

\section{Cross Tabulation Table 1-5 (Continued)}

\begin{tabular}{|c|c|c|c|c|}
\hline & \multicolumn{2}{|c|}{ Q27 - I have c0-authored multiple times with at least one of my 00 -authors (more than one time). } & \multirow[b]{2}{*}{ Total } \\
\hline & & Yes & No & \\
\hline \multirow{4}{*}{ Q10 - Because of the opportunity to publish with my international colleagues. } & Strongly Agree & $\begin{array}{c}\pi \\
83.70 \% \\
36.49 \%\end{array}$ & $\begin{array}{c}15 \\
16.30 \% \\
37.50 \%\end{array}$ & $\begin{array}{c}92 \\
100.00 \% \\
36.65 \%\end{array}$ \\
\hline & Agree & $\begin{array}{c}74 \\
87.06 \% \\
35.07 \%\end{array}$ & $\begin{array}{c}11 \\
12.94 \% \\
27.50 \%\end{array}$ & $\begin{array}{c}85 \\
100.00 \% \\
33.86 \%\end{array}$ \\
\hline & Disagree & $\begin{array}{c}31 \\
75.61 \% \\
14.69 \%\end{array}$ & $\begin{array}{c}10 \\
24.39 \% \\
25.00 \%\end{array}$ & $\begin{array}{c}41 \\
100.00 \% \\
16.33 \%\end{array}$ \\
\hline & Strongly Disagree & $\begin{array}{c}29 \\
87.88 \% \\
13.74 \%\end{array}$ & $\begin{array}{c}4 \\
12.12 \% \\
10.00 \%\end{array}$ & $\begin{array}{c}33 \\
100.00 \% \\
13.15 \%\end{array}$ \\
\hline \multirow{6}{*}{ Q11 - My co-authors and I are fluent in the same language. } & Total & $\begin{array}{c}211 \\
84.06 \% \\
100.00 \%\end{array}$ & $\begin{array}{c}40 \\
15.94 \% \\
100.00 \%\end{array}$ & $\begin{array}{c}251 \\
100.00 \% \\
100.00 \%\end{array}$ \\
\hline & Strongly Agree & $\begin{array}{c}68 \\
88.21 \% \\
32.38 \%\end{array}$ & $\begin{array}{c}9 \\
11.69 \% \\
22.50 \%\end{array}$ & $\begin{array}{c}7 \\
100.00 \% \\
30.80 \%\end{array}$ \\
\hline & Agree & $\begin{array}{c}83 \\
85.57 \% \\
39.52 \%\end{array}$ & $\begin{array}{c}14 \\
14.43 \% \\
35.00 \%\end{array}$ & $\begin{array}{c}97 \\
100.00 \% \\
38.80 \%\end{array}$ \\
\hline & Disagree & $\begin{array}{c}36 \\
78.26 \% \\
77.14 \%\end{array}$ & $\begin{array}{c}10 \\
21.74 \% \\
25.00 \%\end{array}$ & $\begin{array}{c}46 \\
100.00 \% \\
18.40 \%\end{array}$ \\
\hline & Strongly Disagree & $\begin{array}{c}23 \\
76.67 \% \\
10.95 \%\end{array}$ & $\begin{array}{c}7 \\
23.33 \% \\
17.50 \%\end{array}$ & $\begin{array}{c}30 \\
100.00 \% \\
12.00 \%\end{array}$ \\
\hline & Total & $\begin{array}{c}210 \\
84.00 \% \\
100.00 \%\end{array}$ & $\begin{array}{c}40 \\
16.00 \% \\
100.00 \%\end{array}$ & $\begin{array}{c}250 \\
100.00 \% \\
100.00 \%\end{array}$ \\
\hline \multirow{5}{*}{ Q12 - I wanted to mentor and help a junior colleague or graduate student. } & Strongly Agree & $\begin{array}{c}42 \\
84.00 \% \\
20.00 \%\end{array}$ & $\begin{array}{c}8 \\
16.00 \% \\
20.00 \%\end{array}$ & $\begin{array}{c}50 \\
100.00 \% \\
20.00 \%\end{array}$ \\
\hline & Agree & $\begin{array}{c}26 \\
83.27 \% \\
12.38 \%\end{array}$ & $\begin{array}{c}5 \\
16.13 \% \\
12.50 \%\end{array}$ & $\begin{array}{c}31 \\
100.00 \% \\
12.40 \%\end{array}$ \\
\hline & Disagree & $\begin{array}{c}55 \\
85.94 \% \\
26.199 \%\end{array}$ & $\begin{array}{c}9 \\
14.06 \% \\
22.50 \%\end{array}$ & $\begin{array}{c}64 \\
100.00 \% \\
25.60 \%\end{array}$ \\
\hline & Strongly Disagree & $\begin{array}{c}87 \\
82.86 \% \\
41.4396\end{array}$ & $\begin{array}{c}18 \\
17.14 \% \\
45.00 \%\end{array}$ & $\begin{array}{c}105 \\
100.00 \% \\
42.00 \%\end{array}$ \\
\hline & Total & $\begin{array}{c}210 \\
84.00 \% \\
100.00 \%\end{array}$ & $\begin{array}{c}40 \\
16.00 \% \\
100.00 \%\end{array}$ & $\begin{array}{c}250 \\
100.00 \% \\
100.00 \%\end{array}$ \\
\hline
\end{tabular}


Table 27: Research Question Four - Cross Tabulation - Most Important Motivation

\begin{tabular}{|c|c|c|}
\hline $\begin{array}{l}\text { Cross } \\
\text { Tabulation } \\
\text { Results }\end{array}$ & Main Question - Q13 & $\begin{array}{l}\text { Cross Tabulation } \\
\text { Question }\end{array}$ \\
\hline $2-1$ & $\begin{array}{l}\text { The most important } \\
\text { motivation for participating } \\
\text { in this international } \\
\text { collaboration was ... }\end{array}$ & $\begin{array}{l}\text { Q22 - I am currently an: } \\
\text { Assistant Professor, } \\
\text { Associate Professor, } \\
\text { Full Professor, Other }\end{array}$ \\
\hline $2-2$ & $\begin{array}{l}\text { The most important } \\
\text { motivation for participating } \\
\text { in this international } \\
\text { collaboration was ... }\end{array}$ & $\begin{array}{l}\text { Q23 - I identify my } \\
\text { gender as: } \\
\text { Male, Female, Trans*, } \\
\text { None of the above, } \\
\text { Prefer not to disclose. }\end{array}$ \\
\hline $2-3$ & $\begin{array}{l}\text { The most important } \\
\text { motivation for participating } \\
\text { in this international } \\
\text { collaboration was ... }\end{array}$ & $\begin{array}{l}\text { Q24 - My native } \\
\text { language is: } \\
\text { Choice from list of } \\
\text { languages. Sub- } \\
\text { organized: languages } \\
\text { other than English and } \\
\text { English }\end{array}$ \\
\hline $2-4$ & $\begin{array}{l}\text { The most important } \\
\text { motivation for participating } \\
\text { in this international } \\
\text { collaboration was ... }\end{array}$ & $\begin{array}{l}\text { Q26 - I was introduced } \\
\text { to one of my co-authors } \\
\text { during my PhD } \\
\text { program. }\end{array}$ \\
\hline $2-5$ & $\begin{array}{l}\text { The most important } \\
\text { motivation for participating } \\
\text { in this international } \\
\text { collaboration was ... }\end{array}$ & $\begin{array}{l}\text { Q27 - I have co- } \\
\text { authored multiple times } \\
\text { with at least one of my } \\
\text { co-authors (more than } \\
\text { one time). }\end{array}$ \\
\hline
\end{tabular}


International Collaboration Among Social Science Scholars

Cross Tabulation Table 2-1:

Q13 - The Most Important Motivation for Participating in This International Collaboration Was and Q22 - Tenure Level

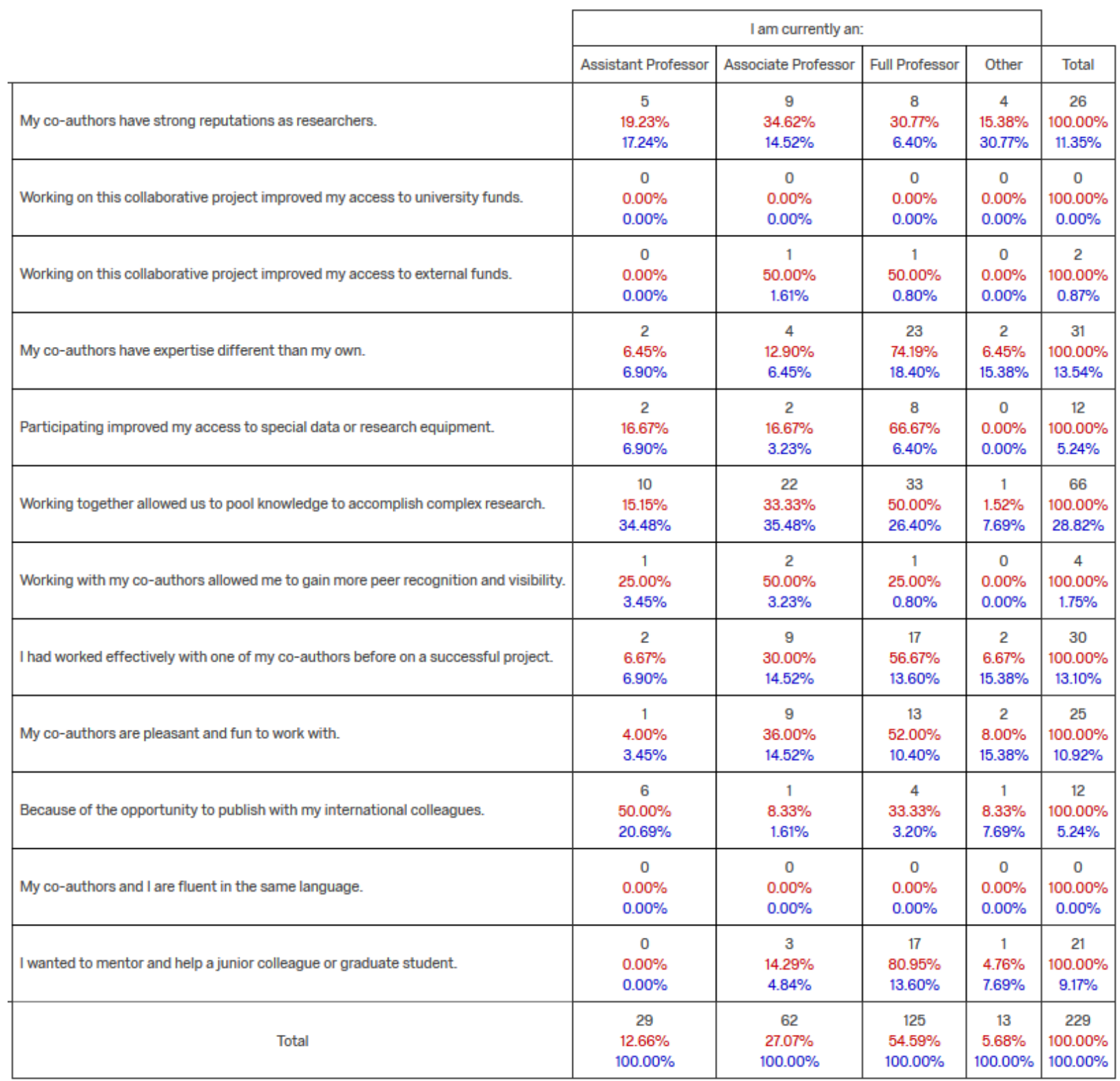


International Collaboration Among Social Science Scholars

Cross Tabulation Table 2-2:

Q13 - The Most Important Motivation for Participating in This International Collaboration Was and Q23 Gender Identification

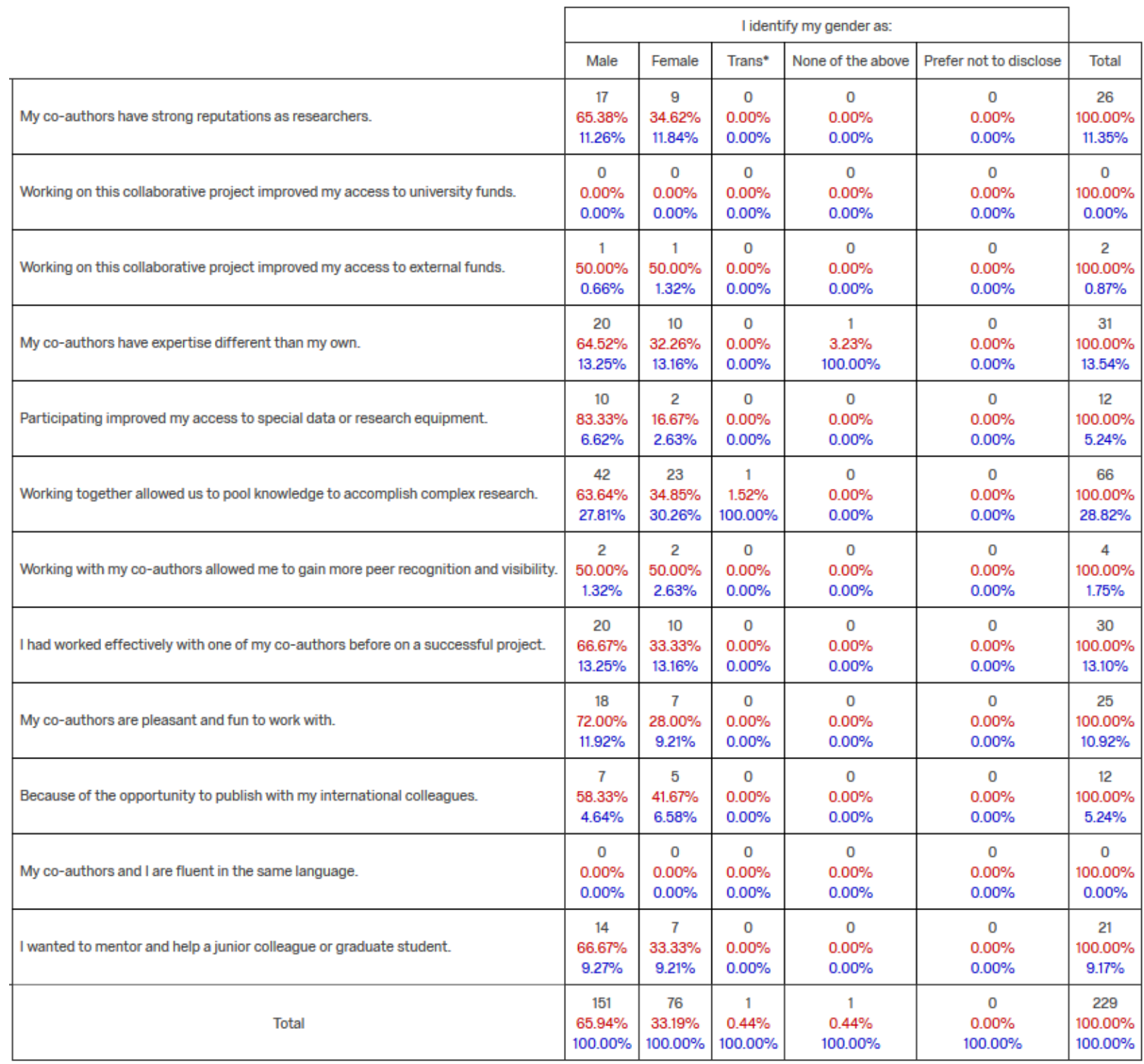


International Collaboration Among Social Science Scholars

Cross Tabulation Table 2-3:

\begin{tabular}{|c|c|c|c|c|c|c|c|c|c|c|c|c|c|c|}
\hline & \multicolumn{12}{|c|}{ 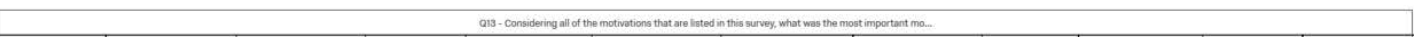 } & \\
\hline & & 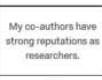 & 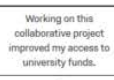 & 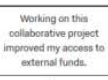 & 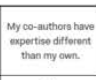 & 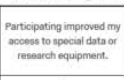 & 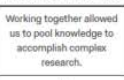 & 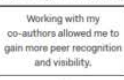 & 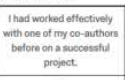 & 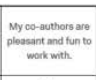 & 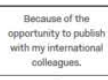 & 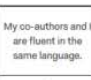 & 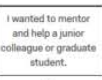 & rotal \\
\hline \multirow{3}{*}{ 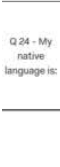 } & 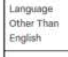 & 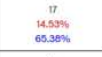 & $\begin{array}{c}0 \\
\substack{a \\
\text { a.oos } \\
0.000} \\
\end{array}$ & $\begin{array}{l}1 \\
\text { s.son } \\
\text { socoos } \\
\end{array}$ & 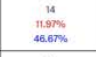 & 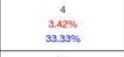 & 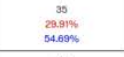 & $\begin{array}{c}2 \\
\text { ind } \\
\text { sonoos } \\
\end{array}$ & $\begin{array}{l}12 \\
10200 \\
400005 \\
4\end{array}$ & 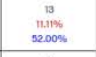 & $\begin{array}{c}\substack{7 \\
\text { rank } \\
750000} \\
\end{array}$ & 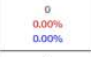 & 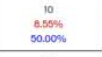 & 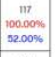 \\
\hline & Enowh & 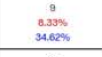 & $\begin{array}{l}\substack{0 \\
\text { and } \\
\text { a.cosos }} \\
\end{array}$ & 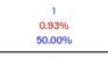 & 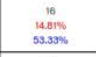 & 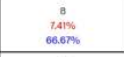 & 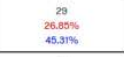 & 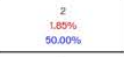 & 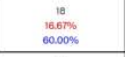 & 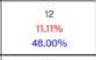 & 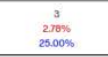 & 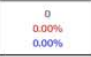 & 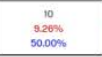 & 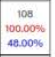 \\
\hline & Total & 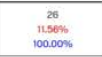 & $\begin{array}{c}0 \\
\text { o. } 0005 \\
1000000\end{array}$ & 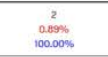 & 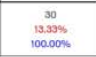 & 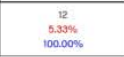 & 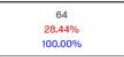 & 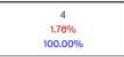 & 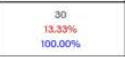 & $\begin{array}{c}20 \\
\text { nellos } \\
\text { 100.005 }\end{array}$ & 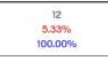 & $\begin{array}{c}0 \\
0.00 \% \\
100000 \%\end{array}$ & 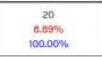 & 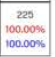 \\
\hline
\end{tabular}

Cross Tabulation Table 2-3: Data repeated in larger image

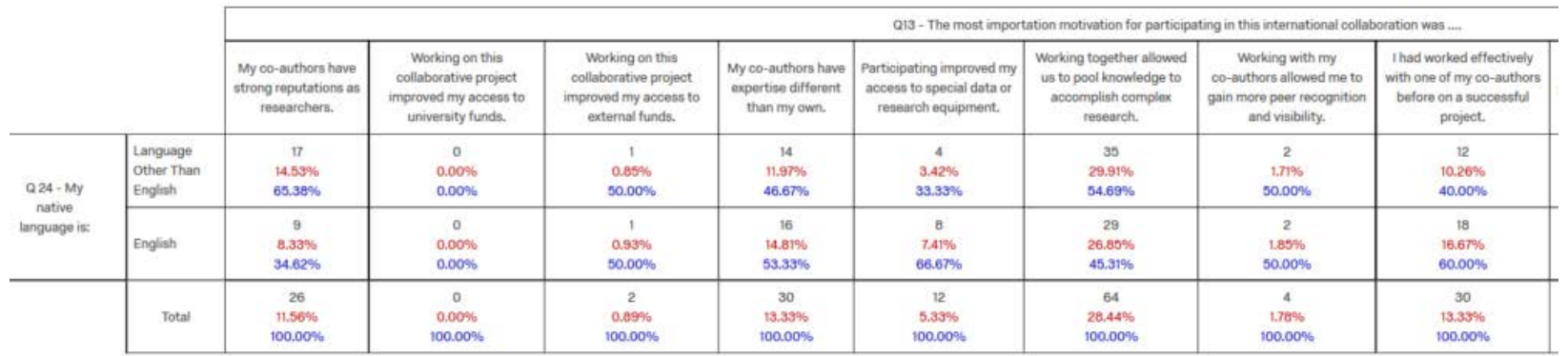

\begin{tabular}{|c|c|c|c|c|}
\hline \multicolumn{4}{|c|}{ Q13 - The most importation motivation for participating in this international collaboration was. } & \multirow[b]{2}{*}{ Total } \\
\hline $\begin{array}{l}\text { My co-authors are } \\
\text { pleasant and fun to } \\
\text { work with. }\end{array}$ & $\begin{array}{l}\text { Because of the } \\
\text { opportunity to publish } \\
\text { with my international } \\
\text { colleagues. }\end{array}$ & $\begin{array}{l}\text { My oo-authors and I } \\
\text { are fluent in the } \\
\text { same language. }\end{array}$ & $\begin{array}{l}\text { I wanted to mentor } \\
\text { and help a junior } \\
\text { colleague or graduate } \\
\text { student. }\end{array}$ & \\
\hline $\begin{array}{c}13 \\
11.11 \% \\
52.00 \%\end{array}$ & $\begin{array}{c}9 \\
7.69 \% \\
75.00 \%\end{array}$ & $\begin{array}{c}0 \\
0.00 \% \\
0.00 \%\end{array}$ & $\begin{array}{c}10 \\
8.55 \% \\
50.00 \%\end{array}$ & $\begin{array}{c}117 \\
100.00 \% \\
52.00 \%\end{array}$ \\
\hline $\begin{array}{c}12 \\
11.11 \% \\
48.00 \%\end{array}$ & $\begin{array}{c}3 \\
2.78 \% \\
25.00 \% \\
\end{array}$ & $\begin{array}{c}0 \\
0.00 \% \\
0.00 \%\end{array}$ & $\begin{array}{c}10 \\
9.26 \% \\
50.00 \%\end{array}$ & $\begin{array}{c}108 \\
100.00 \% \\
46.00 \% \\
\end{array}$ \\
\hline $\begin{array}{c}25 \\
11.11 \% \\
100.00 \%\end{array}$ & $\begin{array}{c}12 \\
5.33 \% \\
100.00 \%\end{array}$ & $\begin{array}{c}0 \\
0.00 \% \\
100.00 \%\end{array}$ & $\begin{array}{c}20 \\
2.69 \% \\
100.00 \%\end{array}$ & $\begin{array}{c}225 \\
100.00 \% \\
100.00 \%\end{array}$ \\
\hline
\end{tabular}


International Collaboration Among Social Science Scholars

Cross Tabulation Table 2-4:

Q13 - The Most Important Motivation for Participating in This International Collaboration Was and Q26 - I Was Introduced to One of My Co-Authors During My PhD Program

\begin{tabular}{|c|c|c|c|c|}
\hline & \multicolumn{3}{|c|}{ Q26 - I was introduced to one of my co-authors during my $\mathrm{PhD}$ program. } & \multirow[b]{2}{*}{ Total } \\
\hline & Yes & No & Unsure & \\
\hline My co-authors have strong reputations as researchers. & $\begin{array}{c}11 \\
44.00 \% \\
13.41 \%\end{array}$ & $\begin{array}{c}14 \\
56.00 \% \\
9.72 \%\end{array}$ & $\begin{array}{c}0 \\
0.00 \% \\
0.00 \%\end{array}$ & $\begin{array}{c}25 \\
100.00 \% \\
11.01 \%\end{array}$ \\
\hline Working on this collaborative project improved my access to university funds. & $\begin{array}{c}0 \\
0.00 \% \\
0.00 \%\end{array}$ & $\begin{array}{c}0 \\
0.00 \% \\
0.00 \%\end{array}$ & $\begin{array}{c}0 \\
0.00 \% \\
0.00 \%\end{array}$ & $\begin{array}{c}0 \\
100.00 \% \\
0.00 \%\end{array}$ \\
\hline Working on this collaborative project improved my access to external funds. & $\begin{array}{c}1 \\
50.00 \% \\
1.22 \%\end{array}$ & $\begin{array}{c}1 \\
50.00 \% \\
0.69 \%\end{array}$ & $\begin{array}{c}0 \\
0.00 \% \\
0.00 \%\end{array}$ & $\begin{array}{c}2 \\
100.00 \% \\
0.88 \%\end{array}$ \\
\hline My co-authors have expertise different than my own. & $\begin{array}{c}7 \\
22.58 \% \\
8.54 \%\end{array}$ & $\begin{array}{c}24 \\
77.42 \% \\
16.67 \%\end{array}$ & $\begin{array}{c}0 \\
0.00 \% \\
0.00 \%\end{array}$ & $\begin{array}{c}31 \\
100.00 \% \\
13.66 \%\end{array}$ \\
\hline Participating improved my access to special data or research equipment. & $\begin{array}{c}3 \\
25.00 \% \\
3.66 \%\end{array}$ & $\begin{array}{c}9 \\
75.00 \% \\
6.25 \%\end{array}$ & $\begin{array}{c}0 \\
0.00 \% \\
0.00 \%\end{array}$ & $\begin{array}{c}12 \\
100.00 \% \\
5.29 \%\end{array}$ \\
\hline Working together allowed us to pool knowledge to accomplish complex research. & $\begin{array}{c}30 \\
46.15 \% \\
36.59 \%\end{array}$ & $\begin{array}{c}35 \\
53.85 \% \\
24.31 \%\end{array}$ & $\begin{array}{c}0 \\
0.00 \% \\
0.00 \%\end{array}$ & $\begin{array}{c}65 \\
100.00 \% \\
28.63 \%\end{array}$ \\
\hline Working with my co-authors allowed me to gain more peer recognition and visibility. & $\begin{array}{c}3 \\
75.00 \% \\
3.66 \%\end{array}$ & $\begin{array}{c}1 \\
25.00 \% \\
0.69 \%\end{array}$ & $\begin{array}{c}0 \\
0.00 \% \\
0.00 \%\end{array}$ & $\begin{array}{c}4 \\
100.00 \% \\
1.76 \%\end{array}$ \\
\hline I had worked effectively with one of my co-authors before on a successful project. & $\begin{array}{c}12 \\
40.00 \% \\
14.63 \%\end{array}$ & $\begin{array}{c}18 \\
60.00 \% \\
12.50 \%\end{array}$ & $\begin{array}{c}0 \\
0.00 \% \\
0.00 \%\end{array}$ & $\begin{array}{c}30 \\
100.00 \% \\
13.22 \%\end{array}$ \\
\hline My co-authors are pleasant and fun to work with. & $\begin{array}{c}8 \\
32.00 \% \\
9.76 \%\end{array}$ & $\begin{array}{c}16 \\
64.00 \% \\
11.11 \%\end{array}$ & $\begin{array}{c}1 \\
4.00 \% \\
100.00 \%\end{array}$ & $\begin{array}{c}25 \\
100.00 \% \\
11.01 \%\end{array}$ \\
\hline Because of the opportunity to publish with my international colleagues. & $\begin{array}{c}5 \\
41.67 \% \\
6.10 \%\end{array}$ & $\begin{array}{c}7 \\
58.33 \% \\
4.86 \%\end{array}$ & $\begin{array}{c}0 \\
0.00 \% \\
0.00 \%\end{array}$ & $\begin{array}{c}12 \\
100.00 \% \\
5.29 \%\end{array}$ \\
\hline My co-authors and $I$ are fluent in the same language. & $\begin{array}{c}0 \\
0.00 \% \\
0.00 \%\end{array}$ & $\begin{array}{c}0 \\
0.00 \% \\
0.00 \%\end{array}$ & $\begin{array}{c}0 \\
0.00 \% \\
0.00 \%\end{array}$ & $\begin{array}{c}0 \\
100.00 \% \\
0.00 \%\end{array}$ \\
\hline I wanted to mentor and help a junior colleague or graduate student. & $\begin{array}{c}2 \\
9.52 \% \\
2.44 \%\end{array}$ & $\begin{array}{c}19 \\
90.48 \% \\
13.19 \%\end{array}$ & $\begin{array}{c}0 \\
0.00 \% \\
0.00 \%\end{array}$ & $\begin{array}{c}21 \\
100.00 \% \\
9.25 \%\end{array}$ \\
\hline Total & $\begin{array}{c}82 \\
36.12 \% \\
100.00 \%\end{array}$ & $\begin{array}{c}144 \\
63.44 \% \\
100.00 \%\end{array}$ & $\begin{array}{c}1 \\
0.44 \% \\
100.00 \%\end{array}$ & $\begin{array}{c}227 \\
100.00 \% \\
100.00 \%\end{array}$ \\
\hline
\end{tabular}


International Collaboration Among Social Science Scholars

Cross Tabulation Table 2-5:

Q13 - The Most Important Motivation for Participating in This International

Collaboration Was and Q27 - I have co-authored multiple times with at least one of my coauthors (more than one time)

\begin{tabular}{|c|c|c|c|}
\hline & \multicolumn{2}{|c|}{ I have co-authored multiple times with at least one of my co-authors (more than one time). } & \multirow[b]{2}{*}{ Total } \\
\hline & Yes & No & \\
\hline My co-authors have strong reputations as researchers. & $\begin{array}{c}20 \\
76.92 \% \\
10.47 \%\end{array}$ & $\begin{array}{c}6 \\
23.08 \% \\
15.79 \%\end{array}$ & $\begin{array}{c}26 \\
100.00 \% \\
11.35 \%\end{array}$ \\
\hline Working on this collaborative project improved my access to university funds. & $\begin{array}{c}0 \\
0.00 \% \\
0.00 \%\end{array}$ & $\begin{array}{c}0 \\
0.00 \% \\
0.00 \%\end{array}$ & $\begin{array}{c}0 \\
100.00 \% \\
0.00 \%\end{array}$ \\
\hline Working on this collaborative project improved my access to external funds. & $\begin{array}{c}2 \\
100.00 \% \\
1.05 \%\end{array}$ & $\begin{array}{c}0 \\
0.00 \% \\
0.00 \%\end{array}$ & $\begin{array}{c}2 \\
100.00 \% \\
0.87 \%\end{array}$ \\
\hline My co-authors have expertise different than my own. & $\begin{array}{c}25 \\
80.65 \% \\
13.09 \%\end{array}$ & $\begin{array}{c}6 \\
19.35 \% \\
15.79 \%\end{array}$ & $\begin{array}{c}31 \\
100.00 \% \\
13.54 \%\end{array}$ \\
\hline Participating improved my access to special data or research equipment. & $\begin{array}{c}11 \\
91.67 \% \\
5.76 \%\end{array}$ & $\begin{array}{c}1 \\
8.33 \% \\
2.63 \% \\
\end{array}$ & $\begin{array}{c}12 \\
100.00 \% \\
5.24 \%\end{array}$ \\
\hline Working together allowed us to pool knowledge to accomplish complex research. & $\begin{array}{c}51 \\
77.27 \% \\
26.70 \%\end{array}$ & $\begin{array}{c}15 \\
22.73 \% \\
39.47 \%\end{array}$ & $\begin{array}{c}66 \\
100.00 \% \\
28.82 \%\end{array}$ \\
\hline Working with my co-authors allowed me to gain more peer recognition and visibility. & $\begin{array}{c}4 \\
100.00 \% \\
2.09 \%\end{array}$ & $\begin{array}{c}0 \\
0.00 \% \\
0.00 \%\end{array}$ & $\begin{array}{c}4 \\
100.00 \% \\
1.75 \% \\
\end{array}$ \\
\hline I had worked effectively with one of my co-authors before on a successful project. & $\begin{array}{c}30 \\
100.00 \% \\
15.71 \%\end{array}$ & $\begin{array}{c}0 \\
0.00 \% \\
0.00 \%\end{array}$ & $\begin{array}{c}30 \\
100.00 \% \\
13.10 \%\end{array}$ \\
\hline My co-authors are pleasant and fun to work with. & $\begin{array}{c}23 \\
92.00 \% \\
12.04 \%\end{array}$ & $\begin{array}{c}2 \\
8.00 \% \\
5.26 \% \\
\end{array}$ & $\begin{array}{c}25 \\
100.00 \% \\
10.92 \%\end{array}$ \\
\hline Because of the opportunity to publish with my international colleagues. & $\begin{array}{c}8 \\
66.67 \% \\
4.19 \%\end{array}$ & $\begin{array}{c}4 \\
33.33 \% \\
10.53 \%\end{array}$ & $\begin{array}{c}12 \\
100.00 \% \\
5.24 \%\end{array}$ \\
\hline My co-authors and I are fluent in the same language. & $\begin{array}{c}0 \\
0.00 \% \\
0.00 \%\end{array}$ & $\begin{array}{c}0 \\
0.00 \% \\
0.00 \% \\
\end{array}$ & $\begin{array}{c}0 \\
100.00 \% \\
0.00 \%\end{array}$ \\
\hline I wanted to mentor and help a junior colleague or graduate student. & $\begin{array}{c}17 \\
80.95 \% \\
8.90 \%\end{array}$ & $\begin{array}{c}4 \\
19.05 \% \\
10.53 \%\end{array}$ & $\begin{array}{c}21 \\
100.00 \% \\
9.17 \%\end{array}$ \\
\hline Total & $\begin{array}{c}191 \\
83.41 \% \\
100.00 \%\end{array}$ & $\begin{array}{c}38 \\
16.59 \% \\
100.00 \%\end{array}$ & $\begin{array}{c}229 \\
100.00 \% \\
100.00 \%\end{array}$ \\
\hline
\end{tabular}


Table 28: Research Question 4-Cross Tabulation - University Resources Travel Funding

\begin{tabular}{|c|c|c|}
\hline $\begin{array}{l}\text { Cross } \\
\text { Tabulation } \\
\text { Results }\end{array}$ & Main Question - Q14-Q17 & $\begin{array}{l}\text { Cross Tabulation } \\
\text { Question }\end{array}$ \\
\hline \multirow[t]{4}{*}{$3-1$} & $\begin{array}{l}\text { Q14 - University offers } \\
\text { funding for travel related to } \\
\text { international collaboration }\end{array}$ & \multirow{4}{*}{$\begin{array}{l}\text { Q22 - I am currently an: } \\
\text { Assistant Professor, } \\
\text { Associate Professor, Full } \\
\text { Professor, Other }\end{array}$} \\
\hline & $\begin{array}{l}\text { Q15 - University offers } \\
\text { funding/grants for } \\
\text { international collaboration } \\
\text { (other than funding for } \\
\text { travel) }\end{array}$ & \\
\hline & $\begin{array}{l}\text { Q16 - University offers } \\
\text { sabbatical or release time } \\
\text { to support participation in } \\
\text { international collaborations }\end{array}$ & \\
\hline & $\begin{array}{l}\text { Q17 - University offers } \\
\text { seminars or networking } \\
\text { sessions about international } \\
\text { collaboration }\end{array}$ & \\
\hline $3-2$ & As Above & $\begin{array}{l}\text { Q23-I identify my gender } \\
\text { as: Male, Female, Trans*, } \\
\text { None of the above, Prefer } \\
\text { not to disclose. }\end{array}$ \\
\hline $3-3$ & As Above & $\begin{array}{l}\text { Q24-My native language is: } \\
\text { Choice from list of } \\
\text { languages. Sub-organized: } \\
\text { languages other than } \\
\text { English and English }\end{array}$ \\
\hline $3-4$ & As Above & $\begin{array}{l}\text { Q26 - I was introduced to } \\
\text { one of my co-authors } \\
\text { during my PhD program. }\end{array}$ \\
\hline $3-5$ & As Above & $\begin{array}{l}\text { Q27 - I have co-authored } \\
\text { multiple times with at least } \\
\text { one of my co-authors (more } \\
\text { than one time). }\end{array}$ \\
\hline
\end{tabular}




\section{Cross Tabulation Table 3-1:}

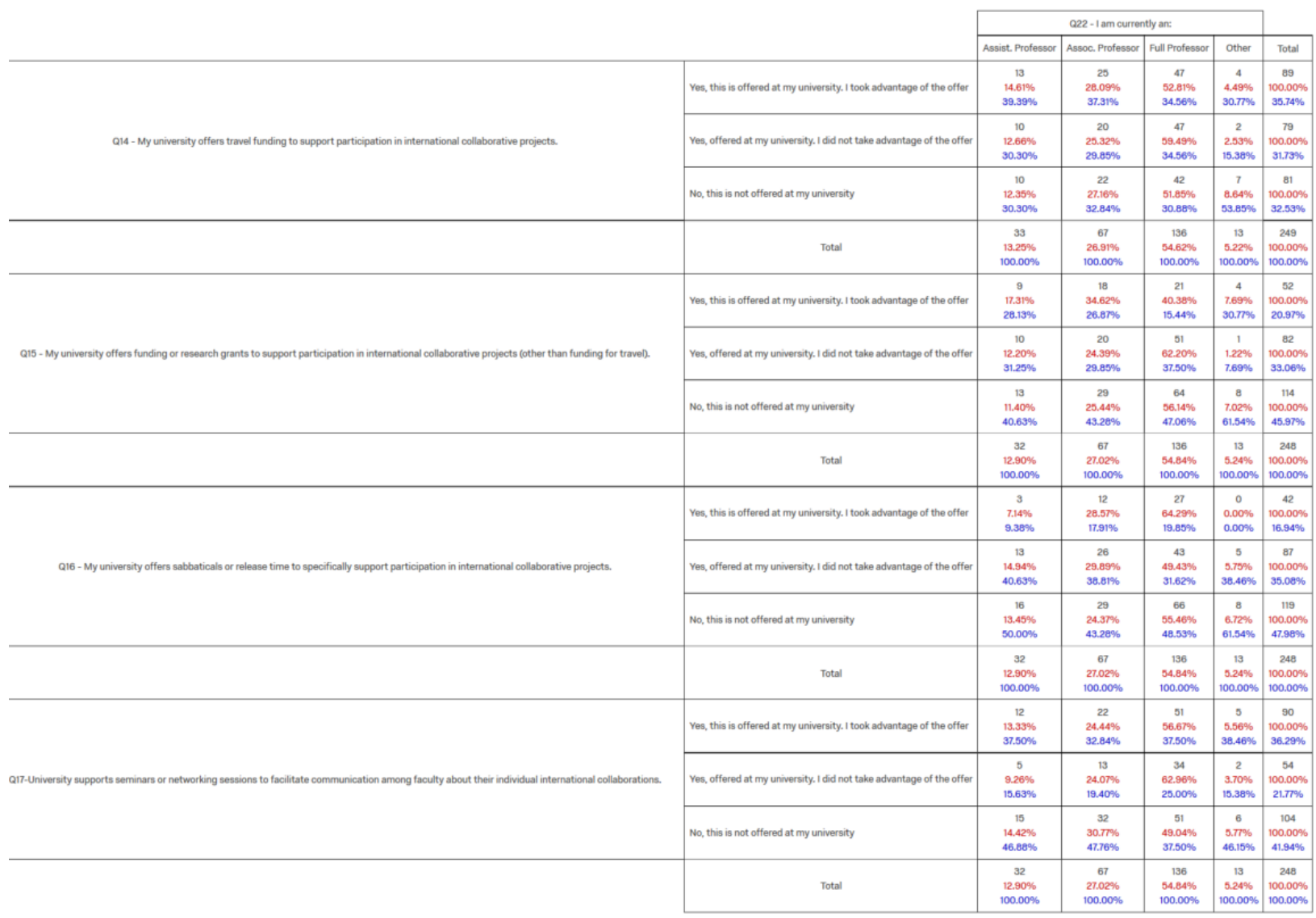


International Collaboration Among Social Science Scholars

\section{Cross Tabulation Table 3-2:}

\begin{tabular}{|c|c|c|c|c|c|c|c|}
\hline & \multirow{2}{*}{\multicolumn{5}{|c|}{ Q23- - iddentify my gender as: }} & \multirow{3}{*}{ Total } \\
\hline & & & & & & & \\
\hline & & Male & Female & Trans" $^{*}$ & None listed & Prefer not to disclose & \\
\hline \multirow{4}{*}{ Q14 - My universisty offers travel funding to support participation in international collaborative projects. } & Vea, this is offered at my univeratity, 1 took achantage of the ofter & $\begin{array}{c}66 \\
74.16 \% \\
39.29 \%\end{array}$ & \begin{tabular}{|c|}
22 \\
$24.72 \%$ \\
$27.85 \%$ \\
\end{tabular} & $\begin{array}{c}0 \\
0.00 \% \\
0.00 \%\end{array}$ & $\begin{array}{c}1 \\
1.12 \% \\
100.00 \%\end{array}$ & $\begin{array}{c}0 \\
0.00 \% \% \\
0.00 \% \%\end{array}$ & \begin{tabular}{|c|}
89 \\
$100.00 \% \%$ \\
$30.74 \%$
\end{tabular} \\
\hline & Veas, offered at my unversity. idid not take advantage of the offer & $\begin{array}{c}57 \\
72.15 \% \\
33.93 \% \\
\end{array}$ & $\begin{array}{c}22 \\
27.75 \% \% \\
27.85 \%\end{array}$ & $\begin{array}{c}0 \\
0.00 \% \\
0.00 \%\end{array}$ & $\begin{array}{c}0 \\
0.00 \% \\
0.00 \%\end{array}$ & $\begin{array}{c}0 \\
0.00 \% \% \\
0.00 \%\end{array}$ & $\begin{array}{c}79 \\
100.00 \% \\
31.73 \% \\
\end{array}$ \\
\hline & No, this is not offered at my university & $\begin{array}{c}45 \\
55.56 \% \\
26.79 \% \\
\end{array}$ & \begin{tabular}{|c|}
35 \\
$49.21 \%$ \\
$44.30 \%$ \\
\end{tabular} & \begin{tabular}{|c|}
1 \\
$1.23 \%$ \\
$10.000 \%$ \\
\end{tabular} & $\begin{array}{c}0 \\
0.00 \% \\
0.00 \%\end{array}$ & $\begin{array}{c}0 \\
0.00 \% \\
0.00 \%\end{array}$ & $\begin{array}{c}81 \\
100.00 \% \\
32.53 \% \\
\end{array}$ \\
\hline & Total & $\begin{array}{c}168 \\
67,47 \% \\
100.00 \%\end{array}$ & $\begin{array}{c}79 \\
31,73 \% \\
100.00 \%\end{array}$ & $\begin{array}{c}1 \\
0.40 \% \\
100.00 \% \\
\end{array}$ & $\begin{array}{c}1 \\
0.40 \% \% \\
100.00 \%\end{array}$ & $\begin{array}{c}0 \\
0.00 \% \\
100.00 \%\end{array}$ & \begin{tabular}{|c|}
249 \\
100.0004 \\
100.0096
\end{tabular} \\
\hline \multirow{4}{*}{ Q15 - My universily offers finding or research grants to support partcipation in international collaborative projects (other than funding for travel.). } & Yes, this is offered at my univeraity. It took achantage of the offer & $\begin{array}{c}39 \\
72.00 \% 5 \\
23.21 \%\end{array}$ & \begin{tabular}{|c|}
13 \\
$20.00 \%$ \\
$16.87 \%$
\end{tabular} & $\begin{array}{c}0 \\
0.00 \% \\
0.00 \%\end{array}$ & $\begin{array}{c}0 \\
0.00 \% \\
0.00 \%\end{array}$ & $\begin{array}{c}0 \\
0.00 \% \\
0.00 \%\end{array}$ & \begin{tabular}{|c|}
52 \\
$100.00 \%$ \\
$20.97 \%$
\end{tabular} \\
\hline & Yos, offered at my university, I id not take advantage of the offer & \begin{tabular}{|c|}
57 \\
$69.51 \%$ \\
$33.99 \%$
\end{tabular} & \begin{tabular}{|c|}
25 \\
$30.49 \%$ \\
$32.05 \%$
\end{tabular} & \begin{tabular}{|c|}
0 \\
$0.00 \%$ \\
$0.00 \%$ \\
\end{tabular} & $\begin{array}{c}0 \\
0.00 \% \\
0.00 \%\end{array}$ & $\begin{array}{c}0 \\
0.00 \% \\
0.00 \%\end{array}$ & \begin{tabular}{|c|}
82 \\
$100.00 \% 4$ \\
$33.06 \%$
\end{tabular} \\
\hline & No, this is not offered at my university & $\begin{array}{c}72 \\
63216 \% \\
42.86 \%\end{array}$ & $\begin{array}{l}40 \\
35.09 \% \\
51.28 \%\end{array}$ & $\begin{array}{c}1 \\
0.0896 \\
100000 \%\end{array}$ & $\begin{array}{c}1 \\
0.88 \% \\
100.00 \%\end{array}$ & $\begin{array}{c}0 \\
0.00 \% \\
0.00 \%\end{array}$ & $\begin{array}{c}114 \\
100.00 \% \\
455.97 \% \\
\end{array}$ \\
\hline & Total & $\begin{array}{c}168 \\
67.74 \% \\
10.00 \%\end{array}$ & $\begin{array}{c}78 \\
7.45 \% \\
31.450 \% \\
\end{array}$ & $\begin{array}{c}1 \\
0.40 \% \\
100.00 \% 6 \\
\end{array}$ & $\begin{array}{c}1 \\
0.40 \% \\
10.00 \% \\
\end{array}$ & $\begin{array}{c}0 \\
0.00 \% \\
100.00 \%\end{array}$ & $\begin{array}{c}248 \\
100.00 \% \\
100.00 \%\end{array}$ \\
\hline \multirow{4}{*}{ Q16- My university offers sabbaticals or release time to specifically support participation in international collaborative projects. } & Yea, tha is offered at my universaty, it took advantage of the offer & $\begin{array}{c}31 \\
73.91 \% \\
18.45 \% \\
\end{array}$ & \begin{tabular}{|c|}
11 \\
$28.19 \%$ \\
$14.10 \% \%$ \\
\end{tabular} & $\begin{array}{c}0 \\
0.00 \% \\
0.00 \%\end{array}$ & $\begin{array}{c}0 \\
0.00 \% \\
0.00 \%\end{array}$ & $\begin{array}{c}0 \\
0.00 \% \\
0.00 \%\end{array}$ & \begin{tabular}{|c|}
42 \\
100.0094 \\
$16.94 \% 5$
\end{tabular} \\
\hline & Ves, offered at my university. Idid not take advantage of the offer & \begin{tabular}{|c|}
65 \\
$74.71 \%$ \\
$38.69 \%$ \\
\end{tabular} & \begin{tabular}{|c|}
22 \\
$20.29 \%$ \\
$28.21 \%$ \\
\end{tabular} & \begin{tabular}{|c|} 
\\
$0.00 \%$ \\
$0.00 \%$ \\
\end{tabular} & $\begin{array}{c}0 \\
0.00 \% \\
0.00 \%\end{array}$ & $\begin{array}{c}0 \\
0.00 \% \\
0.00 \%\end{array}$ & \begin{tabular}{|c|}
87 \\
$100.00 \%$ \\
$35.08 \%$ \\
\end{tabular} \\
\hline & No, this is not offered at my university & $\begin{array}{c}72 \\
60.50 \% \\
42.26 \%\end{array}$ & \begin{tabular}{|l|}
40 \\
$37.72 \%$ \\
$57.69 \%$
\end{tabular} & $\begin{array}{c}1 \\
0.04 \% \\
100.00 \%\end{array}$ & $\begin{array}{c}1 \\
0.04 \% \\
100.00 \%\end{array}$ & $\begin{array}{c}0 \\
0.00 \% \\
0.00 \%\end{array}$ & $\begin{array}{c}119 \\
100.00 \% \\
47.98 \%\end{array}$ \\
\hline & Total & $\begin{array}{c}168 \\
677.74 \% \\
100.00 \% \\
\end{array}$ & $\begin{array}{c}78 \\
31.45 \% \\
100.00 \% \\
\end{array}$ & $\begin{array}{c}1 \\
0.40 \% \\
100.00 \% 6\end{array}$ & $\begin{array}{c}1 \\
0.40 \% \\
100.00 \% \\
\end{array}$ & $\begin{array}{c}0 \\
0.00 \% \\
100.00 \%\end{array}$ & $\begin{array}{c}248 \\
100.000 \% \\
100.00 \% 6 \\
\end{array}$ \\
\hline \multirow{4}{*}{ 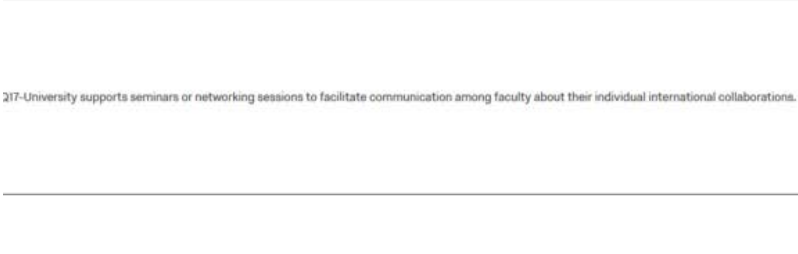 } & Yes, this is offered at my university, it took ablantage of the offer & \begin{tabular}{|c|c|}
68 \\
$75.56 \%$ \\
$40.48 \%$ \\
\end{tabular} & $\begin{array}{c}22 \\
24.44 \% \\
28.21 \% \\
\end{array}$ & $\begin{array}{c}0 \\
0.000 \% \\
0.00 \% \\
\end{array}$ & $\begin{array}{c}0 \\
0.00 \% \% \\
0.00 \%\end{array}$ & $\begin{array}{c}0 \\
0.00 \% \\
0.00 \% \\
\end{array}$ & \begin{tabular}{|c|}
90 \\
$100.00 \% 4$ \\
$36.29 \%$ \\
\end{tabular} \\
\hline & Yes, offered at my university. Idid not take advantage of the offer & $\begin{array}{c}40 \\
74.07 \% \\
23.81 \% \\
\end{array}$ & \begin{tabular}{|c|}
13 \\
$24.407 \%$ \\
$16.67 \%$ \\
\end{tabular} & $\begin{array}{c}1 \\
1.05 \% \\
100.00 \%\end{array}$ & $\begin{array}{c}0 \\
0.00 \% \\
0.00 \%\end{array}$ & $\begin{array}{c}0 \\
0.00 \% \% \\
0.00 \%\end{array}$ & \begin{tabular}{|c|}
54 \\
$100.00 \%$ \\
$21.77 \%$
\end{tabular} \\
\hline & No, this is not offered at my university & $\begin{array}{c}60 \\
57.69 \% \\
35.71 \%\end{array}$ & \begin{tabular}{|c|}
49 \\
$41.35 \%$ \\
$55.13 \%$ \\
\end{tabular} & $\begin{array}{c}0 \\
0.00 \% \\
0.00 \%\end{array}$ & $\begin{array}{c}1 \\
0.96 \% \\
100.00 \%\end{array}$ & $\begin{array}{c}0 \\
0.00 \% \\
0.00 \%\end{array}$ & \begin{tabular}{|c|}
104 \\
$100.00 \%$ \\
$41.94 \%$
\end{tabular} \\
\hline & Total & $\begin{array}{c}168 \\
67.74 \% \\
100.00 \%\end{array}$ & $\begin{array}{c}78 \\
71.45 \% \\
100.00 \%\end{array}$ & \begin{tabular}{c|}
1 \\
$0.40 \%$ \\
$10.00 \%$
\end{tabular} & $\begin{array}{c}1 \\
0.40 \% \% \\
100.00 \%\end{array}$ & $\begin{array}{c}0 \\
0.00 \% \\
100.00 \%\end{array}$ & \begin{tabular}{|c|}
248 \\
100.0006 \\
100.0096
\end{tabular} \\
\hline
\end{tabular}


International Collaboration Among Social Science Scholars

Cross Tabulation Table 3-3:

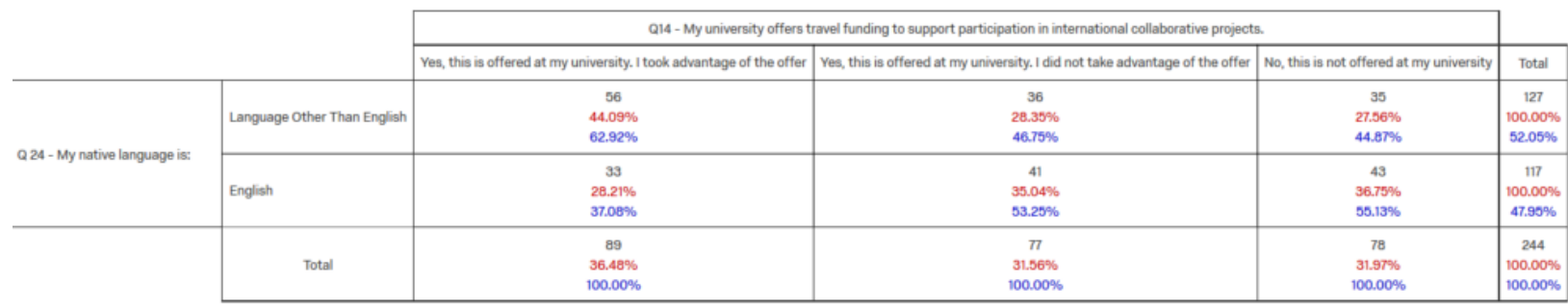

\begin{tabular}{|c|c|c|c|c|c|}
\hline & & \multicolumn{3}{|c|}{ Q15 - My university offers funding or research grants to support participation in international collaborative projects (other than funding for travel). } & \multirow[b]{2}{*}{ Total } \\
\hline & & Yes, this is offered at my university. I took advantage of the offer & Yes, this is offered at my university. I did not take advantage of the offer & No, this is not offered at my university & \\
\hline \multirow{3}{*}{ Q 24 - My native language is: } & Language Other Than English & $\begin{array}{c}34 \\
26.98 \% \\
65.38 \%\end{array}$ & $\begin{array}{c}37 \\
29.37 \% \\
46.25 \%\end{array}$ & $\begin{array}{c}55 \\
43.65 \% \\
49.55 \%\end{array}$ & $\begin{array}{c}126 \\
100.00 \% \\
51.85 \%\end{array}$ \\
\hline & English & $\begin{array}{c}18 \\
15.38 \% \\
34.62 \%\end{array}$ & $\begin{array}{c}43 \\
36.75 \% \\
53.75 \%\end{array}$ & $\begin{array}{c}56 \\
47.86 \% \\
50.45 \%\end{array}$ & $\begin{array}{c}117 \\
100.00 \% \\
48.15 \%\end{array}$ \\
\hline & Total & $\begin{array}{c}52 \\
21.40 \% \\
100.00 \%\end{array}$ & $\begin{array}{c}80 \\
32.92 \% \\
100.00 \%\end{array}$ & $\begin{array}{c}I_{45} 11.68 \% \\
100.00 \%\end{array}$ & $\begin{array}{c}243 \\
100.00 \% \\
100.00 \%\end{array}$ \\
\hline
\end{tabular}

\begin{tabular}{|c|c|c|c|c|c|}
\hline & & \multicolumn{3}{|c|}{ Q16 - My university offers sabbaticals or release time to specifically support participation in international oollaborative projects. } & \multirow[b]{2}{*}{ Total } \\
\hline & & Yes, this is offered at my university. I took advantage of the offer & Yes, this is offered at my university. I did not take advantage of the offer & No, this is not offered at my university & \\
\hline \multirow{3}{*}{ Q 24 - My native language is: } & Language Other Than English & $\begin{array}{c}25 \\
19.84 \% \\
59.52 \%\end{array}$ & $\begin{array}{c}54 \\
42.86 \% \\
62.79 \%\end{array}$ & $\begin{array}{c}47 \\
37.30 \% \\
40.87 \%\end{array}$ & $\begin{array}{c}126 \\
100.00 \% \\
51.85 \%\end{array}$ \\
\hline & English & $\begin{array}{c}17 \\
14.53 \% \\
40.48 \%\end{array}$ & $\begin{array}{c}32 \\
27.35 \% \\
37.21 \%\end{array}$ & $\begin{array}{c}68 \\
58.12 \% \\
59.13 \%\end{array}$ & $\begin{array}{c}117 \\
100.00 \% \\
48.15 \%\end{array}$ \\
\hline & Total & $\begin{array}{c}42 \\
17.28 \% \\
100.00 \%\end{array}$ & $\begin{array}{c}86 \\
35.39 \% \\
100.00 \%\end{array}$ & $\begin{array}{c}115 \\
47.33 \% \\
100.00 \%\end{array}$ & $\begin{array}{c}243 \\
100.00 \% \\
100.00 \%\end{array}$ \\
\hline
\end{tabular}

\begin{tabular}{|c|c|c|c|c|c|}
\hline & & \multicolumn{3}{|c|}{ Q17 - My university supports seminars or networking sessions to facilitate communication among faculty about their individual international collaborations. } & \multirow[b]{2}{*}{ Total } \\
\hline & & Yes, this is offered at my university. I took advantage of the offer & Yes, this is offered at my university. I did not take advantage of the offer & No, this is not offered at my university & \\
\hline \multirow{3}{*}{ Q.24 - My native language is: } & Language Other Than English & $\begin{array}{c}56 \\
44.44 \% \\
62.22 \%\end{array}$ & $\begin{array}{c}28 \\
22.22 \% \\
51.85 \%\end{array}$ & $\begin{array}{c}42 \\
33.33 \% \\
42.42 \%\end{array}$ & $\begin{array}{c}126 \\
100.00 \% \\
51.85 \%\end{array}$ \\
\hline & English & $\begin{array}{c}34 \\
29.06 \% \\
37.78 \%\end{array}$ & $\begin{array}{c}26 \\
22.22 \% \\
48.15 \%\end{array}$ & $\begin{array}{c}57 \\
48.72 \% \\
57.58 \%\end{array}$ & $\begin{array}{c}117 \\
100.00 \% \\
48.15 \%\end{array}$ \\
\hline & Total & $\begin{array}{c}90 \\
37.04 \% \\
100.00 \%\end{array}$ & $\begin{array}{c}54 \\
22.22 \% \\
100.00 \%\end{array}$ & $\begin{array}{c}99 \\
40.74 \% \\
100.00 \%\end{array}$ & $\begin{array}{c}243 \\
100.00 \% \\
100.00 \%\end{array}$ \\
\hline
\end{tabular}


International Collaboration Among Social Science Scholars

\section{Cross Tabulation Table 3-4:}

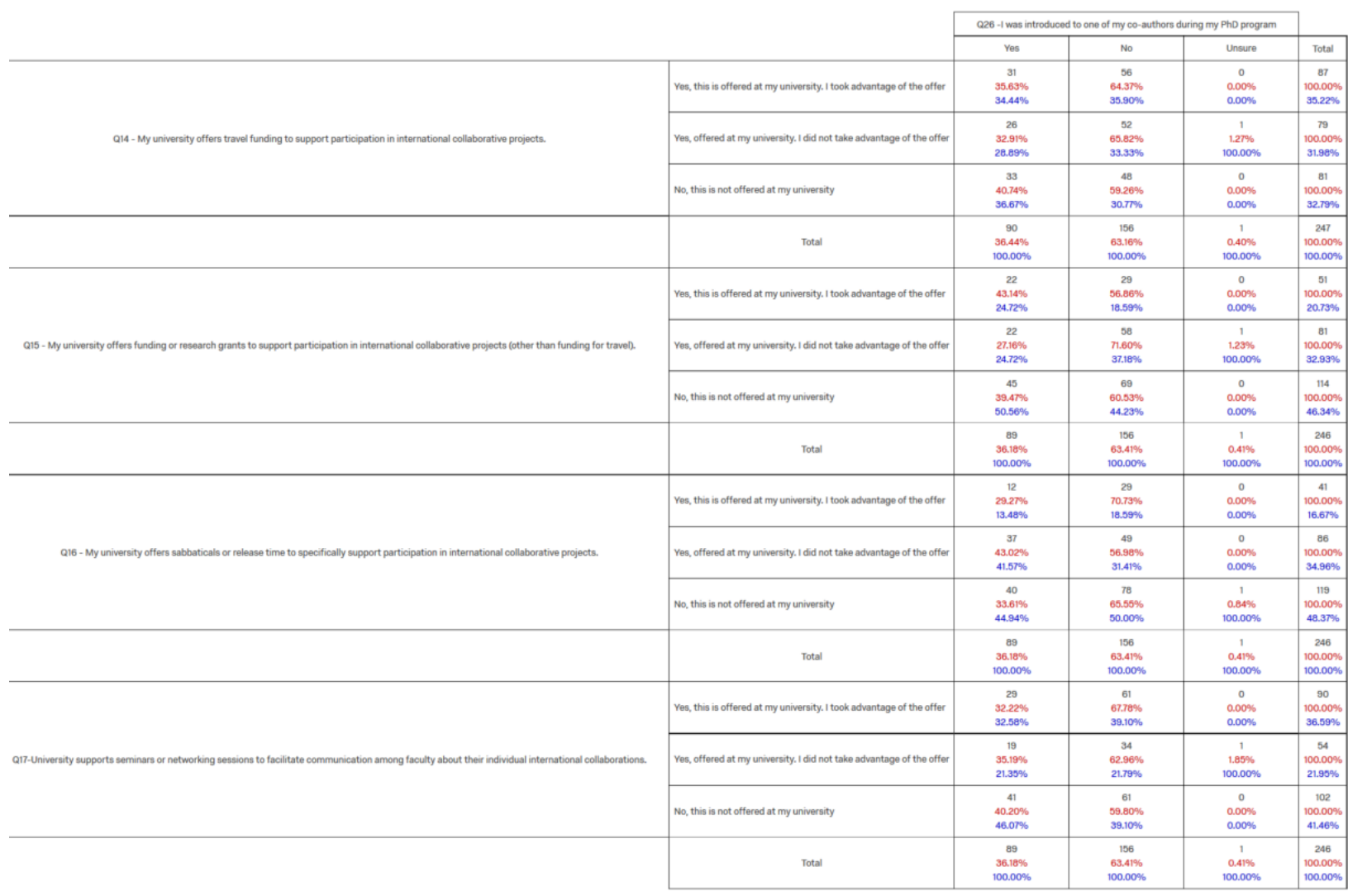


International Collaboration Among Social Science Scholars

\section{Cross Tabulation Table 3-5:}

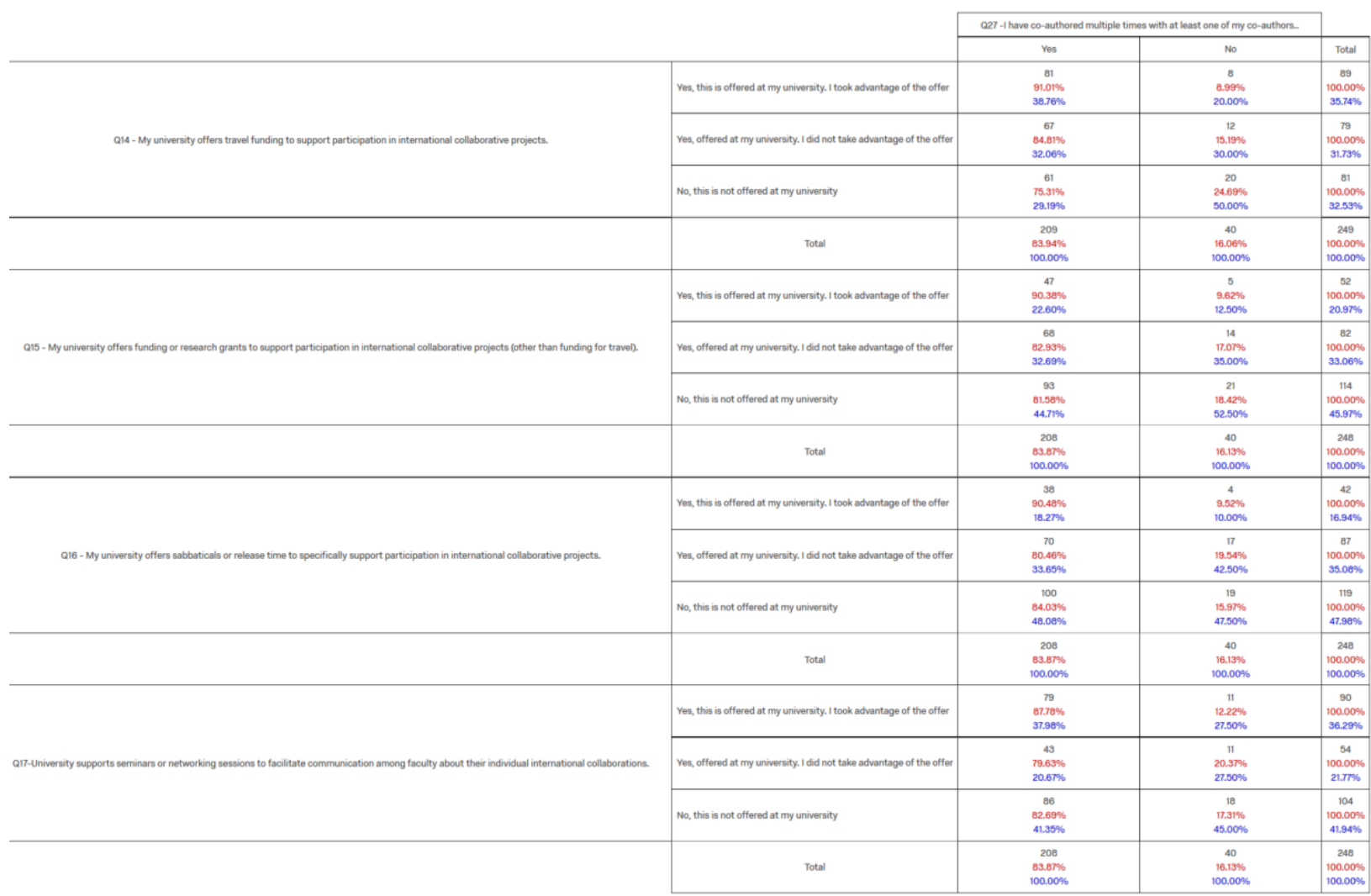


Table 29: Research Question Four-Cross Tabulation-University Stipulates For Tenure and Promotion-University Encourage-Article Co-Authored with International Colleagues Count for More

\begin{tabular}{|c|c|c|}
\hline $\begin{array}{l}\text { Cross } \\
\text { Tabulation } \\
\text { Results }\end{array}$ & Main Questions Q18-Q20 & $\begin{array}{l}\text { Cross Tabulation } \\
\text { Question }\end{array}$ \\
\hline $4-1$ & \begin{tabular}{|l|}
$\begin{array}{l}\text { Q18 - University } \\
\text { stipulates participation in } \\
\text { international collaborative } \\
\text { projects for tenure and } \\
\text { promotion }\end{array}$ \\
$\begin{array}{l}\text { Q19 - University } \\
\text { encourages international } \\
\text { collaboration but does not } \\
\text { require }\end{array}$ \\
$\begin{array}{l}\text { Q20 - Internationally co- } \\
\text { authored articles count } \\
\text { more towards tenure and } \\
\text { promotion }\end{array}$
\end{tabular} & $\begin{array}{l}\text { Q22 - I am currently an: } \\
\text { Assistant Professor, } \\
\text { Associate Professor, Full } \\
\text { Professor, Other }\end{array}$ \\
\hline 4-2 & As Above & $\begin{array}{l}\text { Q23 - I identify my } \\
\text { gender as: } \\
\text { Male, Female, Trans*, } \\
\text { None of the above, Prefer } \\
\text { not to disclose. }\end{array}$ \\
\hline 4-3 & As Above & $\begin{array}{l}\text { Q24 - My native language } \\
\text { is: } \\
\text { Choice from list of } \\
\text { languages. Sub-organized: } \\
\text { languages other than } \\
\text { English and English }\end{array}$ \\
\hline $4-4$ & As Above & $\begin{array}{l}\text { Q26 - I was introduced to } \\
\text { one of my co-authors } \\
\text { during my PhD program. }\end{array}$ \\
\hline 4-5 & As Above & $\begin{array}{l}\text { Q27 - I have co-authored } \\
\text { multiple times with at } \\
\text { least one of my co-authors } \\
\text { (more than one time). }\end{array}$ \\
\hline
\end{tabular}


International Collaboration Among Social Science Scholars

\section{Cross Tabulation Table 4-1:}

\begin{tabular}{|c|c|c|c|c|c|c|}
\hline & & \multicolumn{4}{|c|}{ Q22-Iam ourrently an: } & \multirow[b]{2}{*}{ Total } \\
\hline & & Assistant Professor & Associate Professor & Full Professor & other & \\
\hline \multirow{3}{*}{ Q18 - My university stipulates that international collaboration and co-authorship is required for tenure and promotion. } & Yes & $\begin{array}{c}4 \\
28.57 \% \\
12.12 \%\end{array}$ & $\begin{array}{c}1 \\
7.14 \% \\
1.49 \%\end{array}$ & $\begin{array}{c}{ }^{7} \\
50.00 \% \\
5.22 \%\end{array}$ & $\begin{array}{c}2 \\
14.29 \% \\
16.67 \%\end{array}$ & $\begin{array}{c}14 \\
100.00 \% \\
5.69 \%\end{array}$ \\
\hline & No & $\begin{array}{c}29 \\
12.50 \% \\
87.88 \%\end{array}$ & $\begin{array}{c}66 \\
28.45 \% \\
98.51 \%\end{array}$ & $\begin{array}{c}127 \\
54.74 \% \\
94.76 \%\end{array}$ & $\begin{array}{c}10 \\
4.31 \% \\
83.33 \%\end{array}$ & $\begin{array}{c}232 \\
100.00 \% 6 \\
94.31 \%\end{array}$ \\
\hline & Total & $\begin{array}{c}33 \\
13.41 \% \\
100.00 \% \\
\end{array}$ & $\begin{array}{c}67 \\
27.24 \% \\
100.00 \%\end{array}$ & $\begin{array}{c}134 \\
34.47 \% \\
100.00 \%\end{array}$ & $\begin{array}{c}12 \\
4.88 \% \\
100.00 \%\end{array}$ & $\begin{array}{c}246 \\
100.00 \% \\
100.00 \%\end{array}$ \\
\hline \multirow{3}{*}{ Q19 - My university encourages international collaboration and co-authorship but does not require it for tenure and promotion. } & Yes & $\begin{array}{c}16 \\
9.76 \% \\
48.48 \% \\
\end{array}$ & $\begin{array}{c}48 \\
29.27 \% \\
71.64 \%\end{array}$ & $\begin{array}{c}69 \\
54.27 \% \\
66.92 \%\end{array}$ & $\begin{array}{c}11 \\
6.71 \% \\
91.67 \%\end{array}$ & $\begin{array}{c}164 \\
100.00 \% \\
66.94 \%\end{array}$ \\
\hline & No & $\begin{array}{c}17 \\
20.99 \% \\
51.52 \%\end{array}$ & $\begin{array}{c}19 \\
23.46 \% \\
28.36 \%\end{array}$ & $\begin{array}{c}44 \\
54.32 \% \\
33.08 \%\end{array}$ & $\begin{array}{c}1 \\
1.29 \% \\
8.33 \%\end{array}$ & $\begin{array}{c}81 \\
100.00 \% \\
33.06 \%\end{array}$ \\
\hline & Total & $\begin{array}{c}39 \\
13.47 \% \\
1300.00 \%\end{array}$ & $\begin{array}{c}67 \\
27.35 \% \\
100.00 \%\end{array}$ & $\begin{array}{c}133 \\
54.29 \% \\
100.00 \%\end{array}$ & $\begin{array}{c}12 \\
4.90 \% \\
100.00 \%\end{array}$ & $\begin{array}{c}245 \\
100.00 \% \\
100.00 \%\end{array}$ \\
\hline \multirow{3}{*}{ 120-At my university, when considering articles published in journals with a similar impact foctor, internationally co-nuthored articles count more towards tonure/promotion } & Yes & $\begin{array}{c}3 \\
18.75 \% \\
9.0996\end{array}$ & $\begin{array}{c}3 \\
18.75 \% \\
4.48 \%\end{array}$ & $\begin{array}{c}9 \\
56.25 \% \\
6.6 \% \%\end{array}$ & $\begin{array}{r}1 \\
6.25 \% \\
8.33 \% \\
\end{array}$ & $\begin{array}{c}16 \\
100.00 \% \\
6.48 \%\end{array}$ \\
\hline & No & $\begin{array}{c}30 \\
12.99 \% \\
90.91 \%\end{array}$ & $\begin{array}{c}64 \\
21.71 \% \\
95.52 \%\end{array}$ & $\begin{array}{c}126 \\
54.50 \% \\
93.33 \%\end{array}$ & $\begin{array}{c}11 \\
4.76 \% \\
91.67 \%\end{array}$ & $\begin{array}{c}231 \\
100.00 \% \\
93.52 \%\end{array}$ \\
\hline & Total & $\begin{array}{c}33 \\
13.36 \% \\
100.00 \%\end{array}$ & $\begin{array}{c}67 \\
27.13 \% \\
100.00 \%\end{array}$ & $\begin{array}{c}135 \\
54.66 \% \\
100.00 \%\end{array}$ & $\begin{array}{c}12 \\
4.86 \% \\
100.00 \%\end{array}$ & $\begin{array}{c}247 \\
100.00 \% \\
100.00 \%\end{array}$ \\
\hline
\end{tabular}


International Collaboration Among Social Science Scholars

\section{Cross Tabulation Table 4-2:}

\begin{tabular}{|c|c|c|c|c|c|c|c|}
\hline & & \multicolumn{5}{|c|}{ Q23-1identify my gender as: } & \multirow[b]{2}{*}{ Total } \\
\hline & & Male & Female & Trans" & None of the above & Prefer not to discliose & \\
\hline \multirow{3}{*}{ Q18 - My university stipulates that international collaboration and oc-authorship is required for tenure and promotion. } & Yes & $\begin{array}{c}9 \\
64.29 \% \\
5.42 \%\end{array}$ & $\begin{array}{c}5 \\
35.7196 \\
6.4196\end{array}$ & $\begin{array}{c}0 \\
0.00 \% \\
0.00 \%\end{array}$ & $\begin{array}{c}0 \\
0.00 \% \\
0.00 \%\end{array}$ & $\begin{array}{c}0.0 \\
0.00 \% \\
0.00 \%\end{array}$ & $\begin{array}{c}14 \\
100.00 \% \\
5.69 \%\end{array}$ \\
\hline & No & $\begin{array}{c}157 \\
67.67 \% \\
94.58 \% \\
\end{array}$ & \begin{tabular}{c|}
73 \\
$31.47 \%$ \\
$93.59 \%$
\end{tabular} & $\begin{array}{c}1 \\
0.43 \% \\
100.00 \%\end{array}$ & $\begin{array}{c}1 \\
0.43 \% \\
100.00 \%\end{array}$ & $\begin{array}{c}0 \\
0.00 \% \\
0.00 \%\end{array}$ & $\begin{array}{c}292 \\
100.00 \% \\
94.31 \%\end{array}$ \\
\hline & Total & $\begin{array}{c}166 \\
67.48 \% \\
1700.00 \% \\
\end{array}$ & \begin{tabular}{|c|}
78 \\
$31.71 \%$ \\
$100.00 \%$
\end{tabular} & $\begin{array}{c}1 \\
0.41 \% \\
100.00 \%\end{array}$ & $\begin{array}{c}1 \\
0.41 \% \\
100.00 \%\end{array}$ & $\begin{array}{c}0 \\
0.00 \% \\
100.00 \%\end{array}$ & $\begin{array}{c}246 \\
100.00 \% \\
10000 \%\end{array}$ \\
\hline \multirow{3}{*}{ Q19 - My university encourages international collaboration and co-authorship but does not require it for tenure and promotion. } & Yes & $\begin{array}{c}109 \\
66.46 \% \\
66.06 \% \\
\end{array}$ & \begin{tabular}{|c|}
54 \\
$32.93 \%$ \\
$69.23 \%$ \\
\end{tabular} & $\begin{array}{c}1 \\
0.61 \% \\
100.00 \%\end{array}$ & $\begin{array}{c}0 \\
0.00 \% \\
0.00 \%\end{array}$ & $\begin{array}{c}0 \\
0.00 \% \\
0.00 \%\end{array}$ & $\begin{array}{c}164 \\
100.00 \% \\
66.94 \%\end{array}$ \\
\hline & No & $\begin{array}{c}56 \\
69.14 \% \\
33.94 \% \\
\end{array}$ & \begin{tabular}{c|}
24 \\
$29.63 \%$ \\
$30.77 \%$ \\
\end{tabular} & $\begin{array}{c}0 \\
0.00 \% \\
0.00 \%\end{array}$ & $\begin{array}{c}1 \\
1.23 \% \\
100.00 \%\end{array}$ & $\begin{array}{c}\stackrel{0}{0} \\
0.00 \% \\
0.00 \%\end{array}$ & $\begin{array}{c}81 \\
100.00 \% \\
33.06 \%\end{array}$ \\
\hline & Total & $\begin{array}{c}165 \\
67.35 \% \\
100.00 \% \\
\end{array}$ & \begin{tabular}{|c|}
78 \\
$31.84 \%$ \\
$100.00 \%$ \\
\end{tabular} & $\begin{array}{c}1 \\
0.41 \% \\
100.00 \%\end{array}$ & $\begin{array}{c}1 \\
0.41 \% \\
100.00 \%\end{array}$ & $\begin{array}{c}0 \\
0.00 \% \\
100.00 \%\end{array}$ & $\begin{array}{c}245 \\
100.00 \% \\
100.00 \%\end{array}$ \\
\hline \multirow{3}{*}{ Q20-At my university, when considering articles publiahed in journals with a similar impact tactor, intermationally 00 -authored articles count more towards tenure/promotion } & Ves & $\begin{array}{c}8 \\
50.00 \% \\
4.79 \%\end{array}$ & \begin{tabular}{|c|}
8 \\
$50.00 \%$ \\
$10.26 \%$
\end{tabular} & $\begin{array}{c}0 \\
0.00 \% \\
0.00 \%\end{array}$ & $\begin{array}{c}0 \\
0.00 \% \\
0.00 \%\end{array}$ & $\begin{array}{c}0 \\
0.00 \% \\
0.00 \%\end{array}$ & $\begin{array}{c}16 \\
100.00 \% \\
6.48 \%\end{array}$ \\
\hline & No & $\begin{array}{c}159 \\
68.83 \% \\
95.21 \% \\
\end{array}$ & \begin{tabular}{|c|}
70 \\
$30.30 \%$ \\
$89.74 \%$ \\
\end{tabular} & $\begin{array}{c}1 \\
0.43 \% \\
100.00 \%\end{array}$ & $\begin{array}{c}1 \\
0.43 \% \\
100.00 \%\end{array}$ & $\begin{array}{c}0 \\
0.00 \% \\
0.00 \%\end{array}$ & $\begin{array}{c}231 \\
100.00 \% \\
93.52 \%\end{array}$ \\
\hline & Total & $\begin{array}{c}167 \\
67.61 \% \\
100.00 \%\end{array}$ & $\begin{array}{c}78 \\
31.58 \% \\
1100.00 \% \\
\end{array}$ & $\begin{array}{c}1 \\
0.40 \% \\
100.00 \%\end{array}$ & $\begin{array}{c}1 \\
0.40 \% \\
100.00 \%\end{array}$ & $\begin{array}{c}0 \\
0.00 \% \\
100.00 \%\end{array}$ & $\begin{array}{c}247 \\
100.00 \% \\
100.00 \%\end{array}$ \\
\hline
\end{tabular}


International Collaboration Among Social Science Scholars

Cross Tabulation Table 4-3:

\begin{tabular}{|c|c|c|c|c|}
\hline & & \multicolumn{2}{|c|}{ Q18 - My university stipulates that international collaboration and c0-authorship is required for tenure and promotion. } & \multirow[b]{2}{*}{ Total } \\
\hline & & Yes & No & \\
\hline \multirow{3}{*}{ Q24 - My native language is: } & Language Other Than English & $\begin{array}{c}13 \\
10.32 \% \\
92.86 \%\end{array}$ & $\begin{array}{c}113 \\
89.68 \% \\
49.78 \%\end{array}$ & $\begin{array}{c}126 \\
100.00 \% \\
52.28 \%\end{array}$ \\
\hline & English & $\begin{array}{c}1 \\
0.87 \% \\
7.14 \%\end{array}$ & $\begin{array}{c}114 \\
99.13 \% \\
50.22 \%\end{array}$ & $\begin{array}{c}115 \\
100.00 \% \\
47.72 \%\end{array}$ \\
\hline & Total & $\begin{array}{c}14 \\
5.81 \% \\
100.00 \%\end{array}$ & $\begin{array}{c}227 \\
94.19 \% \\
100.00 \%\end{array}$ & $\begin{array}{c}241 \\
100.00 \% \\
100.00 \%\end{array}$ \\
\hline
\end{tabular}

\begin{tabular}{|c|c|c|c|c|}
\hline & \multicolumn{2}{|c|}{ Q19 - My university encourages international collaboration and c0-authorship but does not require it for tenure and promotion. } & \multirow{2}{*}{\begin{tabular}{|l} 
Total \\
\end{tabular}} \\
\hline & & Yes & No & \\
\hline \multirow{3}{*}{ Q 24 - My native language is: } & Language Other Than English & $\begin{array}{c}91 \\
72.80 \% \\
56.88 \%\end{array}$ & $\begin{array}{c}34 \\
27.20 \% \\
42.50 \%\end{array}$ & $\begin{array}{c}125 \\
100.00 \% \\
52.08 \%\end{array}$ \\
\hline & English & $\begin{array}{c}69 \\
60.00 \% \\
43.13 \%\end{array}$ & $\begin{array}{c}46 \\
40.00 \% \\
57.50 \%\end{array}$ & $\begin{array}{c}115 \\
100.00 \% \\
47.92 \%\end{array}$ \\
\hline & Total & $\begin{array}{c}160 \\
66.67 \% \\
100.00 \%\end{array}$ & $\begin{array}{c}80 \\
33.33 \% \\
100.00 \%\end{array}$ & $\begin{array}{c}240 \\
100.00 \% \\
100.00 \%\end{array}$ \\
\hline
\end{tabular}

\begin{tabular}{|c|c|c|c|c|}
\hline & \multicolumn{2}{|c|}{ Q20-At my university, when considering articles published in journals with a simiar impact factor, internationally co-authored artioles count more towards tenure/promotion than articiles $c 0$-authored with scholars in this country. } & \multirow[b]{2}{*}{ Total } \\
\hline & & $\begin{array}{ll}\text { Yes } \\
\end{array}$ & No & \\
\hline \multirow{3}{*}{ Q24-My native language is: } & Language Other Than English & $\begin{array}{c}10 \\
7.94 \% \\
62.50 \% \\
\end{array}$ & $\begin{array}{c}116 \\
92.06 \% \\
51.33 \% \\
\end{array}$ & $\begin{array}{c}126 \\
10.00 \% \\
52.07 \%\end{array}$ \\
\hline & English & $\begin{array}{c}6 \\
5.17 \% \\
37.50 \%\end{array}$ & $\begin{array}{c}110 \\
94.83 \% \\
48.67 \%\end{array}$ & $\begin{array}{c}116 \\
100.00 \% \\
47.93 \%\end{array}$ \\
\hline & Total & $\begin{array}{c}16 \\
6.61 \% \\
100.00 \%\end{array}$ & $\begin{array}{c}226 \\
93.39 \% \\
100.00 \%\end{array}$ & $\begin{array}{c}242 \\
100.00 \% \\
100.00 \%\end{array}$ \\
\hline
\end{tabular}


International Collaboration Among Social Science Scholars

\section{Cross Tabulation Table 4-4:}

\begin{tabular}{|c|c|c|c|c|c|}
\hline & & \multicolumn{3}{|c|}{ Q26 - I was introduced to one of my co-authors during my PhD program. } & \multirow[b]{2}{*}{ Total } \\
\hline & & Yes & No & Unsure & \\
\hline \multirow{3}{*}{ Q18 - My uniwersity stipulates that international collaboration and c0-authorship is required for tenure and promotion. } & Yes & $\begin{array}{c}4 \\
28.57 \% \\
4.49 \%\end{array}$ & $\begin{array}{c}10 \\
71.43 \% \\
6.49 \%\end{array}$ & $\begin{array}{c}0 \\
0.00 \% \\
0.00 \%\end{array}$ & \begin{tabular}{|c|}
14 \\
$100.00 \%$ \\
$5.74 \%$
\end{tabular} \\
\hline & No & $\begin{array}{c}85 \\
36.96 \% \\
95.51 \%\end{array}$ & $\begin{array}{c}144 \\
62.61 \% \\
93.51 \% \\
\end{array}$ & $\begin{array}{c}1 \\
0.43 \% \\
100.00 \%\end{array}$ & $\begin{array}{c}230 \\
100.00 \% \\
94.26 \% \\
\end{array}$ \\
\hline & Total & $\begin{array}{c}89 \\
36.48 \% \\
100.00 \%\end{array}$ & $\begin{array}{c}154 \\
63.11 \% \\
100.00 \%\end{array}$ & $\begin{array}{c}1 \\
0.41 \% \\
100.00 \%\end{array}$ & $\begin{array}{c}244 \\
100.00 \% \\
100.00 \%\end{array}$ \\
\hline \multirow{3}{*}{ Q19 - My university encourrages international collaboration and co-authorship but does not require it for tenure and promotion. } & Yes & $\begin{array}{c}58 \\
3580 \% \\
65.17 \%\end{array}$ & $\begin{array}{c}103 \\
6958 \% \\
67.32 \%\end{array}$ & $\begin{array}{c}1 \\
0.62 \% \\
100.00 \%\end{array}$ & $\begin{array}{c}162 \\
100.00 \% \\
66.67 \%\end{array}$ \\
\hline & No & $\begin{array}{c}31 \\
38.27 \% \\
34.83 \%\end{array}$ & $\begin{array}{c}50 \\
61.73 \% \\
32.68 \%\end{array}$ & $\begin{array}{c}0 \\
0.00 \% \% \\
0.00 \%\end{array}$ & $\begin{array}{c}81 \\
100.00 \% \\
33.33 \%\end{array}$ \\
\hline & Total & $\begin{array}{c}89 \\
36.63 \% \\
100.00 \%\end{array}$ & $\begin{array}{c}153 \\
62.96 \% \\
100.00 \%\end{array}$ & $\begin{array}{c}1 \\
0.41 \% \\
100.00 \%\end{array}$ & $\begin{array}{c}243 \\
100.00 \% \\
100.00 \%\end{array}$ \\
\hline \multirow{3}{*}{ Q20-At my university, when considering articles published in journals with a similar impact factor, internationally co-authored articles count more towards tenure/promotion } & Yes & $\begin{array}{c}10 \\
62.50 \% \\
11.11 \%\end{array}$ & $\begin{array}{c}6 \\
37.50 \% \\
3.90 \%\end{array}$ & $\begin{array}{c}0 \\
0.00 \% \\
0.00 \%\end{array}$ & $\begin{array}{c}16 \\
100.00 \% \\
6.53 \%\end{array}$ \\
\hline & No & $\begin{array}{c}80 \\
34.93 \% \\
88.89 \% \\
\end{array}$ & $\begin{array}{c}148 \\
64.63 \% \\
96.10 \% \\
\end{array}$ & $\begin{array}{c}1 \\
0.44 \% \\
100.00 \%\end{array}$ & $\begin{array}{c}229 \\
100.00 \% \\
93.47 \% \\
\end{array}$ \\
\hline & Total & $\begin{array}{c}90 \\
36,73 \% \\
100.00 \%\end{array}$ & $\begin{array}{c}154 \\
62.86 \% \\
100.00 \%\end{array}$ & $\begin{array}{c}1 \\
0.41 \% \\
100.00 \%\end{array}$ & \begin{tabular}{|c|}
245 \\
$100.00 \%$ \\
$100.00 \%$
\end{tabular} \\
\hline
\end{tabular}


International Collaboration Among Social Science Scholars

\section{Cross Tabulation Table 4-5:}

\begin{tabular}{|c|c|c|c|c|}
\hline & & \multicolumn{2}{|c|}{ Q27 - I have co-authored multiple times with at least one of my co-authors. } & \multirow[b]{2}{*}{ Total } \\
\hline & & Yes & No & \\
\hline \multirow{3}{*}{ Q18 - My university stipulates that international collaboration and 00 -authorship is required for tenure and promotion. } & Yes & $\begin{array}{c}12 \\
88.517 \% \\
5.83 \%\end{array}$ & $\begin{array}{c}2 \\
14.29 \% \\
5.00 \% \\
\end{array}$ & $\begin{array}{c}14 \\
100.00 \% \\
5.69 \% \\
\end{array}$ \\
\hline & No & $\begin{array}{c}194 \\
83.62 \% \\
94.17 \%\end{array}$ & $\begin{array}{c}38 \\
16.38 \% \\
95.00 \%\end{array}$ & $\begin{array}{c}232 \\
100.00 \% \\
94.31 \%\end{array}$ \\
\hline & Total & $\begin{array}{c}206 \\
83.74 \% \\
100.00 \% \\
\end{array}$ & $\begin{array}{c}40 \\
16.26 \% \\
100.00 \% \\
\end{array}$ & $\begin{array}{c}246 \\
10.00 \% \\
100.00 \% \\
\end{array}$ \\
\hline \multirow{3}{*}{ Q19- My university encourages international collaboration and co-authorship but does not require it for tenure and promotion. } & Yes & $\begin{array}{c}136 \\
82.93 \% \\
66.34 \% \\
\end{array}$ & $\begin{array}{c}28 \\
17.07 \% \\
70.00 \% \\
\end{array}$ & $\begin{array}{c}164 \\
10.00 \% \\
66.94 \%\end{array}$ \\
\hline & No & $\begin{array}{c}69 \\
83.19 \% \\
\text { s3.66\% }\end{array}$ & $\begin{array}{c}12 \\
14.81 \% \\
30.00 \%\end{array}$ & $\begin{array}{c}81 \\
100.00 \% \\
33.06 \%\end{array}$ \\
\hline & Total & $\begin{array}{c}205 \\
83.67 \% \\
100.00 \% \\
\end{array}$ & $\begin{array}{c}40 \\
16.33 \% \\
100.00 \%\end{array}$ & $\begin{array}{c}245 \\
100.00 \% \\
100.00 \%\end{array}$ \\
\hline \multirow{3}{*}{ Q20-At my university, when considering articles published in journals with a similar impact factor, internationally co-authored articles count more towards tenure/promotion } & Yes & $\begin{array}{c}14 \\
87.50 \% \\
6.76 \%\end{array}$ & $\begin{array}{c}2 \\
12.50 \% \\
5.00 \%\end{array}$ & $\begin{array}{c}16 \\
100.00 \% \\
6.48 \% \\
\end{array}$ \\
\hline & No & $\begin{array}{c}193 \\
83.55 \% \\
93.24 \% \\
\end{array}$ & $\begin{array}{c}38 \\
16.45 \% \\
95.00 \%\end{array}$ & $\begin{array}{c}231 \\
100.00 \% \\
93.52 \% \\
\end{array}$ \\
\hline & Total & $\begin{array}{c}207 \\
83.81 \% \\
100.00 \%\end{array}$ & $\begin{array}{c}40 \\
16.19 \% \\
100.00 \%\end{array}$ & $\begin{array}{c}247 \\
100.00 \% \\
100.00 \%\end{array}$ \\
\hline
\end{tabular}


Table 30: Research Question Four - Cross Tabulation - Tenure Level

\begin{tabular}{|c|l|c|}
\hline $\begin{array}{c}\text { Cross } \\
\text { Tabulation } \\
\text { Results }\end{array}$ & \multicolumn{1}{|c|}{ Main Question - Q22 } & $\begin{array}{c}\text { Cross Tabulation } \\
\text { Question }\end{array}$ \\
\hline 5 -1 & $\begin{array}{l}\text { I am currently an: } \\
\text { Assistant Professor, } \\
\text { Associate Professor, Full } \\
\text { Professor, Other }\end{array}$ & $\begin{array}{c}\text { Q24 - My native } \\
\text { language is: } \\
\text { Choice from list of } \\
\text { languages. Sub- } \\
\text { organized: languages } \\
\text { other than English and } \\
\text { English }\end{array}$ \\
\hline 5 5-2 & $\begin{array}{l}\text { I am currently an: } \\
\text { Assistant Professor, } \\
\text { Associate Professor, Full } \\
\text { Professor, Other }\end{array}$ & $\begin{array}{c}\text { Q26 - I was introduced } \\
\text { to one of my co-authors } \\
\text { during my PhD } \\
\text { program. }\end{array}$ \\
\hline $5-3$ & $\begin{array}{l}\text { I am currently an: } \\
\text { Assistant Professor, } \\
\text { Associate Professor, Full } \\
\text { Professor, Other }\end{array}$ & $\begin{array}{c}\text { Q27 - I have co- } \\
\text { authored multiple times } \\
\text { with at least one of my } \\
\text { co-authors (more than } \\
\text { one time) }\end{array}$ \\
\hline
\end{tabular}

\section{Cross Tabulation Table 5-1:}

\begin{tabular}{|c|c|c|c|c|c|c|}
\hline & & \multicolumn{4}{|c|}{ I am currently an: } & \multirow[b]{2}{*}{ Total } \\
\hline & & Assistant Professor & Associate Professor & Full Professor & other & \\
\hline \multirow{3}{*}{ My native language is: } & Language Other Than English & $\begin{array}{c}24 \\
18.75 \% \\
75.00 \%\end{array}$ & $\begin{array}{c}36 \\
28.13 \% \\
54.55 \%\end{array}$ & $\begin{array}{c}61 \\
47.66 \% \\
45.86 \%\end{array}$ & $\begin{array}{c}7 \\
5.47 \% \\
46.67 \%\end{array}$ & $\begin{array}{c}128 \\
100.00 \% \\
52.03 \%\end{array}$ \\
\hline & English & $\begin{array}{c}8 \\
6.78 \% \\
20.00 \%\end{array}$ & $\begin{array}{c}30 \\
25.42 \% \\
45.45 \%\end{array}$ & $\begin{array}{c}72 \\
61.02 \% \\
54.14 \%\end{array}$ & $\begin{array}{c}8 \\
6.78 \% \\
53.33 \%\end{array}$ & $\begin{array}{c}118 \\
100.00 \% \\
47.97 \%\end{array}$ \\
\hline & Total & $\begin{array}{c}32 \\
13.01 \% \\
100.00 \%\end{array}$ & $\begin{array}{c}66 \\
26.83 \% \\
100.00 \%\end{array}$ & $\begin{array}{c}133 \\
54.07 \% \\
100.00 \%\end{array}$ & $\begin{array}{c}15 \\
6.10 \% \\
100.00 \%\end{array}$ & $\begin{array}{c}246 \\
100.00 \% \\
100.00 \%\end{array}$ \\
\hline
\end{tabular}


International Collaboration Among Social Science Scholars

Cross Tabulation Table 5-2:

\begin{tabular}{|c|c|c|c|c|c|}
\hline & & \multicolumn{3}{|c|}{ I was introduced to one of my co-authors during my PhO program. } & \multirow[b]{2}{*}{ Total } \\
\hline & & Yes & No & Unsure & \\
\hline \multirow{5}{*}{ I am currently an: } & Assistant Professor & $\begin{array}{c}27 \\
81.82 \% \\
29.67 \%\end{array}$ & $\begin{array}{c}6 \\
18.18 \% \\
3.82 \%\end{array}$ & $\begin{array}{c}0 \\
0.00 \% \\
0.00 \%\end{array}$ & $\begin{array}{c}33 \\
100.00 \% \\
13.25 \%\end{array}$ \\
\hline & Associate Professor & $\begin{array}{c}27 \\
41.54 \% \\
29.67 \%\end{array}$ & $\begin{array}{c}38 \\
58.46 \% \\
24.20 \%\end{array}$ & $\begin{array}{c}0 \\
0.00 \% \\
0.00 \%\end{array}$ & $\begin{array}{c}65 \\
100.00 \% \\
26.10 \%\end{array}$ \\
\hline & Full Professor & $\begin{array}{c}30 \\
22.06 \% \\
32.97 \%\end{array}$ & $\begin{array}{c}105 \\
77.21 \% \\
66.88 \%\end{array}$ & $\begin{array}{c}1 \\
0.74 \% \\
100.00 \%\end{array}$ & $\begin{array}{c}136 \\
100.00 \% \\
54.62 \%\end{array}$ \\
\hline & Other & $\begin{array}{c}7 \\
46.67 \% \\
7.69 \%\end{array}$ & $\begin{array}{c}8 \\
53.33 \% \\
5.10 \%\end{array}$ & $\begin{array}{c}0 \\
0.00 \% \\
0.00 \%\end{array}$ & $\begin{array}{c}15 \\
100.00 \% \\
6.02 \%\end{array}$ \\
\hline & Total & $\begin{array}{c}91 \\
36.50 \% \\
100.00 \%\end{array}$ & $\begin{array}{c}157 \\
63.05 \% \\
100.00 \%\end{array}$ & $\begin{array}{c}1 \\
0.40 \% \\
100.00 \%\end{array}$ & $\begin{array}{c}249 \\
100.00 \% \\
100.00 \%\end{array}$ \\
\hline
\end{tabular}

\section{Cross Tabulation Table 5-3:}

\begin{tabular}{|c|c|c|c|c|}
\hline & & \multicolumn{2}{|c|}{ I have co-authored multiple times with at least one of my co-authors (more than one time). } & \multirow[b]{2}{*}{ Total } \\
\hline & & Yes & No & \\
\hline \multirow{5}{*}{ I am currently an: } & Assistant Professor & $\begin{array}{c}30 \\
90.91 \% \\
14.22 \%\end{array}$ & $\begin{array}{c}3 \\
9.09 \% \\
7.50 \%\end{array}$ & $\begin{array}{c}33 \\
100.00 \% \\
13.15 \%\end{array}$ \\
\hline & Associate Professor & $\begin{array}{c}52 \\
7.61 \% \\
24.64 \%\end{array}$ & $\begin{array}{c}15 \\
22.39 \% \\
37.50 \%\end{array}$ & $\begin{array}{c}67 \\
100.00 \% \\
26.69 \%\end{array}$ \\
\hline & Full Professor & $\begin{array}{c}116 \\
85.29 \% \\
54.98 \%\end{array}$ & $\begin{array}{c}20 \\
14.71 \% \\
50.00 \%\end{array}$ & $\begin{array}{c}136 \\
100.00 \% \\
54.18 \%\end{array}$ \\
\hline & Other & $\begin{array}{c}13 \\
86.67 \% \\
6.16 \%\end{array}$ & $\begin{array}{c}2 \\
13.33 \% \\
5.00 \%\end{array}$ & $\begin{array}{c}15 \\
100.00 \% \\
5.98 \%\end{array}$ \\
\hline & Total & $\begin{array}{c}211 \\
84.06 \% \\
100.00 \%\end{array}$ & $\begin{array}{c}40 \\
15.94 \% \\
100.00 \%\end{array}$ & $\begin{array}{c}251 \\
100.00 \% \\
100.00 \%\end{array}$ \\
\hline
\end{tabular}


Table 31: Research Question Four - Cross Tabulation - Gender Identification

\begin{tabular}{|c|l|c|}
\hline $\begin{array}{c}\text { Cross } \\
\text { Tabulation } \\
\text { Results }\end{array}$ & \multicolumn{1}{|c|}{ Main Question - Q23 } & \multicolumn{1}{c|}{$\begin{array}{c}\text { Cross Tabulation } \\
\text { Question }\end{array}$} \\
\hline $\mathbf{6 - 1}$ & $\begin{array}{l}\text { I identify my gender as: } \\
\text { Male, Female, Trans*, None } \\
\text { of the above, Prefer not to } \\
\text { disclose. }\end{array}$ & $\begin{array}{c}\text { Q24 - My native } \\
\text { language is: } \\
\text { Choice from list of } \\
\text { languages. Sub- } \\
\text { organized: languages } \\
\text { other than English and } \\
\text { English }\end{array}$ \\
\hline $\mathbf{6 - 2}$ & $\begin{array}{l}\text { I identify my gender as: } \\
\text { Male, Female, Trans*, None } \\
\text { of the above, Prefer not to } \\
\text { disclose. }\end{array}$ & $\begin{array}{l}\text { Q26 - I was introduced } \\
\text { to one of my co-authors } \\
\text { during my PhD } \\
\text { program. }\end{array}$ \\
\hline $\mathbf{6 - 3}$ & $\begin{array}{l}\text { I identify my gender as: } \\
\text { Male, Female, Trans*, None } \\
\text { of the above, Prefer not to } \\
\text { disclose. }\end{array}$ & $\begin{array}{l}\text { Q27 - I have co- } \\
\text { authored multiple times } \\
\text { with at least one of my } \\
\text { co-authors (more than } \\
\text { one time) }\end{array}$ \\
\hline
\end{tabular}

\section{Cross Tabulation Table 6-1:}

\begin{tabular}{|c|c|c|c|c|c|c|c|}
\hline & & \multicolumn{5}{|c|}{ I identify my gender as: } & \multirow[b]{2}{*}{ Total } \\
\hline & & Male & Female & Trans* & None of the above & Prefer not to disclose & \\
\hline \multirow{3}{*}{ My native language is: } & Language Other Than English & $\begin{array}{c}90 \\
70.31 \% \\
54.22 \%\end{array}$ & $\begin{array}{c}36 \\
28.13 \% \\
46.15 \%\end{array}$ & $\begin{array}{c}1 \\
0.78 \% \\
100.00 \%\end{array}$ & $\begin{array}{c}1 \\
0.78 \% \\
100.00 \%\end{array}$ & $\begin{array}{c}0 \\
0.00 \% \\
0.00 \%\end{array}$ & $\begin{array}{c}128 \\
100.00 \% \\
52.03 \%\end{array}$ \\
\hline & English & $\begin{array}{c}76 \\
64.41 \% \\
45.78 \%\end{array}$ & $\begin{array}{c}42 \\
35.59 \% \\
53.85 \%\end{array}$ & $\begin{array}{c}0 \\
0.00 \% \\
0.00 \%\end{array}$ & $\begin{array}{c}0 \\
0.00 \% \\
0.00 \%\end{array}$ & $\begin{array}{c}0 \\
0.00 \% \\
0.00 \%\end{array}$ & $\begin{array}{c}118 \\
100.00 \% \\
47.97 \%\end{array}$ \\
\hline & Total & $\begin{array}{c}166 \\
67.48 \% \\
100.00 \%\end{array}$ & $\begin{array}{c}78 \\
31.71 \% \\
100.00 \%\end{array}$ & $\begin{array}{c}1 \\
0.41 \% \\
100.00 \%\end{array}$ & $\begin{array}{c}1 \\
0.41 \% \\
100.00 \%\end{array}$ & $\begin{array}{c}0 \\
0.00 \% \\
100.00 \%\end{array}$ & $\begin{array}{c}246 \\
100.00 \% \\
100.00 \%\end{array}$ \\
\hline
\end{tabular}


International Collaboration Among Social Science Scholars

Cross Tabulation Table 6-2:

\begin{tabular}{|c|c|c|c|c|c|}
\hline & & \multicolumn{3}{|c|}{ I was introduced to one of my oo-authors during my PhD program } & \multirow[b]{2}{*}{ Total } \\
\hline & & Yes & No & Unsure & \\
\hline \multirow{6}{*}{ I identify my gender as: } & Male & $\begin{array}{c}61 \\
36.09 \% \\
67.03 \%\end{array}$ & $\begin{array}{c}107 \\
63.31 \% \\
68.15 \%\end{array}$ & $\begin{array}{c}1 \\
0.59 \% \\
100.00 \%\end{array}$ & $\begin{array}{c}169 \\
100.00 \% \\
67.87 \%\end{array}$ \\
\hline & Female & $\begin{array}{c}30 \\
38.46 \% \\
32.97 \%\end{array}$ & $\begin{array}{c}48 \\
61.54 \% \\
30.57 \%\end{array}$ & $\begin{array}{c}0 \\
0.00 \% \\
0.00 \%\end{array}$ & $\begin{array}{c}78 \\
100.00 \% \\
31.33 \%\end{array}$ \\
\hline & Trans* & $\begin{array}{c}0 \\
0.00 \% \\
0.00 \%\end{array}$ & $\begin{array}{c}1 \\
100.00 \% \\
0.64 \%\end{array}$ & $\begin{array}{c}0 \\
0.00 \% \\
0.00 \%\end{array}$ & $\begin{array}{c}1 \\
100.00 \% \\
0.40 \%\end{array}$ \\
\hline & None of the above & $\begin{array}{c}0 \\
0.00 \% \\
0.00 \%\end{array}$ & $\begin{array}{c}1 \\
100.00 \% \\
0.64 \%\end{array}$ & $\begin{array}{c}0 \\
0.00 \% \\
0.00 \%\end{array}$ & $\begin{array}{c}1 \\
100.00 \% \\
0.40 \%\end{array}$ \\
\hline & Prefer not to disclose & $\begin{array}{c}0 \\
0.00 \% \\
0.00 \%\end{array}$ & $\begin{array}{c}0 \\
0.00 \% \\
0.00 \%\end{array}$ & $\begin{array}{c}0 \\
0.00 \% \\
0.00 \%\end{array}$ & $\begin{array}{c}0 \\
100.00 \% \\
0.00 \%\end{array}$ \\
\hline & Total & $\begin{array}{c}91 \\
36.55 \% \\
100.00 \%\end{array}$ & $\begin{array}{c}157 \\
62.05 \% \\
100.00 \%\end{array}$ & $\begin{array}{c}1 \\
0.40 \% \\
100.00 \%\end{array}$ & $\begin{array}{c}249 \\
100.00 \% \\
100.00 \%\end{array}$ \\
\hline
\end{tabular}

Cross Tabulation Table 6-3:

\begin{tabular}{|c|c|c|c|c|}
\hline & \multicolumn{2}{|c|}{ I have o0-authored multiple times with at least one of my oo-authors (more than one time). } & \multirow[b]{2}{*}{ Total } \\
\hline & & Yes & No & \\
\hline \multirow{6}{*}{ I identify my gender as: } & Male & $\begin{array}{c}150 \\
88.24 \% \\
71.09 \%\end{array}$ & $\begin{array}{c}20 \\
11.76 \% \\
50.00 \%\end{array}$ & $\begin{array}{c}170 \\
100.00 \% \\
67.73 \%\end{array}$ \\
\hline & Female & $\begin{array}{c}61 \\
77.22 \% \\
28.91 \%\end{array}$ & $\begin{array}{c}18 \\
22.78 \% \\
45.00 \%\end{array}$ & $\begin{array}{c}79 \\
100.00 \% \\
31.47 \%\end{array}$ \\
\hline & Trans* & $\begin{array}{c}0 \\
0.00 \% \\
0.00 \%\end{array}$ & $\begin{array}{c}1 \\
100.00 \% \\
2.50 \%\end{array}$ & $\begin{array}{c}1 \\
100.00 \% \\
0.40 \%\end{array}$ \\
\hline & None of the above & $\begin{array}{c}0 \\
0.00 \% \\
0.00 \%\end{array}$ & $\begin{array}{c}1 \\
100.00 \% \\
2.50 \%\end{array}$ & $\begin{array}{c}1 \\
100.00 \% \\
0.40 \%\end{array}$ \\
\hline & Prefer not to disclose & $\begin{array}{c}0 \\
0.00 \% \\
0.00 \%\end{array}$ & $\begin{array}{c}0 \\
0.00 \% \\
0.00 \%\end{array}$ & $\begin{array}{c}0 \\
100.00 \% \\
0.00 \%\end{array}$ \\
\hline & Total & $\begin{array}{c}211 \\
84.06 \% \\
100.00 \%\end{array}$ & $\begin{array}{c}40 \\
15.94 \% \\
100.00 \%\end{array}$ & $\begin{array}{c}251 \\
100.00 \% \\
100.00 \%\end{array}$ \\
\hline
\end{tabular}


International Collaboration Among Social Science Scholars

Table 32: Research Question Four - Cross Tabulation - Native Language

\begin{tabular}{|c|l|c|}
\hline $\begin{array}{c}\text { Cross } \\
\text { Tabulation } \\
\text { Results }\end{array}$ & \multicolumn{1}{|c|}{ Main Question - Q24 } & $\begin{array}{c}\text { Cross Tabulation } \\
\text { Question }\end{array}$ \\
\hline $\mathbf{7 - 1}$ & $\begin{array}{l}\text { My native language is: } \\
\text { Choice from list of } \\
\text { languages. Sub-organized: } \\
\text { languages other than English } \\
\text { and English }\end{array}$ & $\begin{array}{c}\text { Q26 - I was introduced } \\
\text { to one of my co-authors } \\
\text { during my PhD } \\
\text { program. }\end{array}$ \\
\hline $\mathbf{7 - 2}$ & $\begin{array}{l}\text { My native language is: } \\
\text { Choice from list of } \\
\text { languages. Sub-organized: } \\
\text { languages other than English } \\
\text { and English }\end{array}$ & $\begin{array}{l}\text { Q27 - I have co- } \\
\text { authored multiple times } \\
\text { with at least one of my } \\
\text { co-authors (more than } \\
\text { one time) }\end{array}$ \\
\hline
\end{tabular}

Cross Tabulation Table 7-1:

\begin{tabular}{|c|c|c|c|c|c|}
\hline & & \multicolumn{3}{|c|}{ I was introduced to one of my co-authors during my PhO program } & \multirow[b]{2}{*}{ Total } \\
\hline & & Yes & No & Unsure & \\
\hline \multirow{3}{*}{ My native language is: } & Language Other Than English & $\begin{array}{c}59 \\
46.09 \% \\
65.56 \%\end{array}$ & $\begin{array}{c}69 \\
53.91 \% \\
45.10 \%\end{array}$ & $\begin{array}{c}0 \\
0.00 \% \\
0.00 \%\end{array}$ & $\begin{array}{c}128 \\
100.00 \% \\
52.46 \%\end{array}$ \\
\hline & English & $\begin{array}{c}31 \\
26.72 \% \\
34.44 \%\end{array}$ & $\begin{array}{c}84 \\
72.41 \% \\
54.90 \%\end{array}$ & $\begin{array}{c}1 \\
0.86 \% \\
100.00 \%\end{array}$ & $\begin{array}{c}116 \\
100.00 \% \\
47.54 \%\end{array}$ \\
\hline & Total & $\begin{array}{c}90 \\
36.89 \% \\
100.00 \%\end{array}$ & $\begin{array}{c}153 \\
62.70 \% \\
100.00 \%\end{array}$ & $\begin{array}{c}1 \\
0.41 \% \\
100.00 \%\end{array}$ & $\begin{array}{c}244 \\
100.00 \% \\
100.00 \%\end{array}$ \\
\hline
\end{tabular}

Cross Tabulation Table 7-2:

\begin{tabular}{|c|c|c|c|c|}
\hline & \multicolumn{2}{|c|}{ I have co-authored multiple times with at least one of my co-authors (more than one time). } & \multirow[b]{2}{*}{ Total } \\
\hline & & Yes & No & \\
\hline \multirow{3}{*}{ My native language is: } & Language Other Than English & $\begin{array}{c}107 \\
83.59 \% \\
51.94 \%\end{array}$ & $\begin{array}{c}21 \\
16.41 \% \\
52.50 \%\end{array}$ & $\begin{array}{c}128 \\
100.00 \% \\
52.03 \%\end{array}$ \\
\hline & English & $\begin{array}{c}99 \\
83.90 \% \\
48.06 \%\end{array}$ & $\begin{array}{c}19 \\
16.10 \% \\
47.50 \%\end{array}$ & $\begin{array}{c}118 \\
100.00 \% \\
47.97 \%\end{array}$ \\
\hline & Total & $\begin{array}{c}206 \\
83.74 \% \\
100.00 \%\end{array}$ & $\begin{array}{c}40 \\
16.26 \% \\
100.00 \%\end{array}$ & $\begin{array}{c}246 \\
100.00 \% \\
100.00 \%\end{array}$ \\
\hline
\end{tabular}

